UNIVERSIDADE DE SÃO PAULO

INSTITUTO DE ASTRONOMIA, GEOFÍSICA E CIÊNCIAS ATMOSFÉRICAS DEPARTAMENTO DE CIÊNCIAS ATMOSFÉRICAS

Estudo do efeito das partículas de aerossol emitidas por queimadas sobre a radiação solar incidente em superfície a partir de medições efetuadas na Reserva Biológica do Jaru

\author{
BIANCA LOBO SILVA
}




\title{
Estudo do efeito das partículas de aerossol emitidas por queimadas sobre a radiação solar incidente em superfície a partir de medições efetuadas na Reserva Biológica do Jaru
}

\author{
BIANCA LOBO SILVA
}

Dissertação apresentada ao Instituto de Astronomia, Geofísica e Ciências Atmosféricas da Universidade de São Paulo para a obtenção do título de Mestre em Ciências.

Área de concentração: Meteorologia

Orientador: Prof. Dra. Márcia Akemi Yamasoe

São Paulo 


\section{AGRADECIMENTOS}

Agradecimento especial à Prof. Dra Márcia Akemi Yamasoe pela orientação, apoio, confiança e compreensão nos momentos difíceis.

Ao Dr. Nilton Manuel Évora do Rosário, pelo acompanhamento e sugestões ao longo do trabalho.

A todos os meus colegas do grupo de radiação do IAG/USP, pelo apoio e troca de idéias.

Aos amigos da USP Ivan, Elisabeth, César, Gláuber, Lívia e todos os que estiveram ao meu lado ao longo dos últimos anos. Ciências

Agradeço a todo o corpo docente e administrativo do Departamento de Atmosféricas, em particular aos funcionários da secretaria e do suporte.

A universidade de São Paulo (USP) pela disposição dos meios materiais e corpo docente, peças fundamentais a minha elevação científica e formação.

A CAPES e ao CNPq pelo apoio financeiro.

À minha família pelo suporte emocional e incentivador. Sem vocês o cominho seria muito mais tortuoso. 
"Somos feitos para superar obstáculos, resolver problemas, atingir metas. Sem obstáculos a superar ou metas a atingir, não existe satisfação nem felicidade."

Maxwell Maltz 


\section{RESUMO}

Durante a estação seca, é comum se observar um grande número de queimadas ocorrendo no Brasil. A fumaça proveniente da queima intensa é facilmente vista em imagens de satélite, principalmente na região de Cerrado e na Bacia Amazônica, e é responsável pela injeção de uma grande quantidade de partículas na atmosfera. Essas partículas de aerossol irão interagir diretamente com a radiação solar incidente, pelos processos de absorção e espalhamento, o que afetará a irradiância solar global incidente em superfície, a fração entre componente direto e difuso e a distribuição espectral. A modelagem precisa dessa interação ainda requer investigação científica. Nesse contexto, os resultados apresentados neste trabalho buscaram avaliar o desempenho de modelos ópticos para o aerossol de queimadas propostos por Rosário (2011) para a região da Reserva Biológica do Jaru (ou Rebio Jaru), Rondônia, durante a estação seca de 2007. Os modelos ópticos foram separados em intervalos de albedo simples, resultando em três grupos ou regimes: um mais absorvedor, um moderadamente absorvedor e um mais espalhador.

Os dados simulados utilizando o código de transferência radiativa SBDART foram comparados com medidas feitas in situ na Rebio Jaru. Os dados foram obtidos entre os dias 24 de agosto e 31 de outubro de 2007. Foram analisados dados medidos por um Multifilter Rotating Shadowband Radiometer (MFRSR - canais de 670, 870 e $1036 \mathrm{~nm}$ e da irradiância solar total), por um sensor PAR (irradiância fotossinteticamente ativa) e dados de um pirânometro (irradiância solar total).

A irradiância fotossinteticamente ativa compreende o intervalo entre 400 e 700 nm e corresponde à energia solar utilizada na fotossíntese realizada pelas plantas. Ela foi utilizada para avaliar o desempenho dos modelos propostos por Rosário (2011). Para esse intervalo espectral, o modelo óptico mais espalhador é o que melhor representou o período analisado. Estudos de caso foram feitos para avaliar o comportamento dos demais dados para dias com valores distintos da profundidade óptica do aerossol em 550nm. Os resultados obtidos pela análise das medidas feitas pelo MFRSR divergiram com relação ao do sensor PAR e do Piranômetro. As divergências observadas podem estar associadas à degradação instrumental. 
Sugere-se que sejam realizados estudos mais detalhados levando em consideração o conteúdo integrado de vapor d'água, entre outras variáveis meteorológicas, com a finalidade de definir um método eficiente para determinar o melhor modelo óptico para o aerossol de queimadas e para diferentes regiões da Bacia Amazônica, como efetuado por Rosário (2011) na região de Alta Floresta.

Palavras chave: Propriedades ópticas do aerossol, Irradiância, Aerossol, Queimadas, Bacia Amazônia 


\begin{abstract}
During the dry season biomass burning activities are frequent in Brazil. The smoke from these intense fires can easily be seen with satellite imaging, mostly in the centermost region of Brazil and the Amazon, and it is responsible for the input of large amounts of particles to the atmosphere. These aerosol particles interact directly with the incoming solar radiation, through absorption and scattering processes, which will affect the incoming global solar irradiation reaching the surface, the fraction between the direct and diffuse components and the spectral distribution. The accurate modeling of these interactions requires further scientific investigation. In this context, the present work evaluated the performance of biomass burning aerosol optical models proposed by Rosario (2011) for the southern Amazon, in the Jaru Biological Reserve, Rondônia, during the dry season of 2007. The proposed models were classified according to single scattering albedo intervals, and three distinct groups or regimes were identified: one for more absorbing particles, one for moderately absorbing particles and one for more scattering particles.

Simulated data using the Radiative Transfer code SBDART were compared with in situ measurements performed at Rebio Jaru. The data were collected between August 24th and October 31st 2007. Data measured by a Multifilter Shadowband Rotating Radiometer (MFRSR - channels 670, 870 and $1036 \mathrm{~nm}$ and the total solar irradiance) from a PAR sensor (photosynthetically active radiation) and from a pyranometer (total solar irradiance) were included in the analysis.

Photosynthetically active irradiance spectral interval spans between 400 and 700 $\mathrm{nm}$, and corresponds to the solar energy used on the vegetation photosynthesis. This spectral region was chosen to evaluate the performance of the optical models. For this spectral interval, the more scattering optical model better represented the measured values. Case studies were conducted to evaluate the performance of the radiative transfer code and the optical models on days with distinct values of the aerosol optical depth at 550nm. The results showed that simulations for MFRSR channels diverged from the PAR sensor and the pyranometer. These divergences could be associated to instrumental degradation.
\end{abstract}


It is suggested that further studies be conducted taking into account water vapor content variability, and other meteorological variables, in order to define an efficient method to determine the best optical model for the smoke aerosol and for different regions in the Amazon Basin, as performed by Rosario (2011) for Alta Floresta.

Keywords: Aerosol optical model, Irradiance, Aerosol, Biomass burning, Amazon Basin 


\section{INDICE}

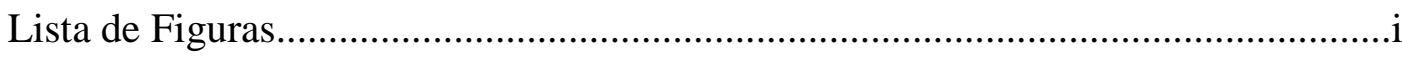

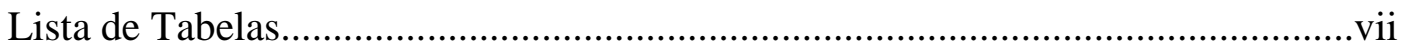

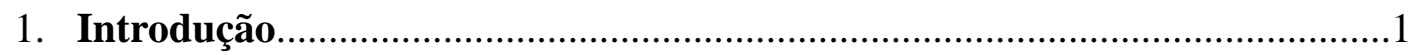

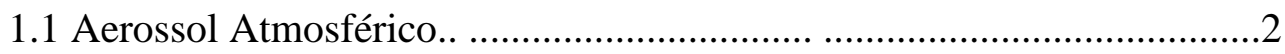

$1.2 \mathrm{O}$ papel do aerossol no Balanço de Energia..........................................5

1.3 Propriedades das Partículas de Aerossol na Amazônia... ........................6

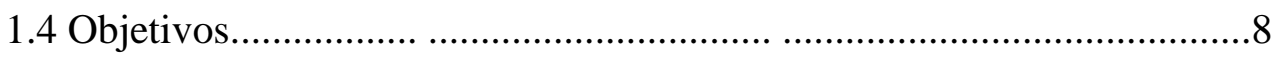

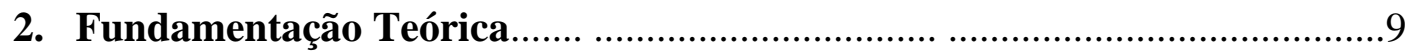

2.1 Radiação Solar..............................................................................10

2.2 Atmosfera Terrestre.. ...................................................................11

2.3 Interação da Radiação Solar com a Atmosfera Terrestre......................12

2.3.1 O Espalhamento Rayleigh.... ......................................14

2.3.2 Atenuação pelas Partículas de Aerossóis.......................15

2.3.3 Lei de Beer-Bouguer-Lambert.................................. 18

2.3.4 Coeficiente de Ångström...........................................19

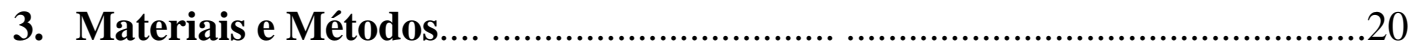

3.1 Reserva Biológica do Jaru... ..............................................................21

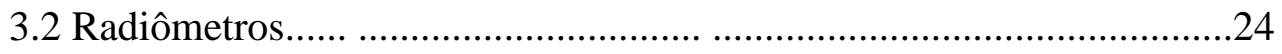

3.2.1 Multifilter Rotating Shadowband Radiometer (MFRSR).. 24

3.2.2 Sensor PAR SKE 510-SKYE..................................25

3.2.3 Pirânometro CM 21/31.............................................26

3.3 Calibração do MFRSR - Determinação da Constante Solar................26

3.3.1 Calibração do MFRSR pelo Método de Langley.........26

3.4 Cálculo da Profundidade Óptica Espectral do Aerossol com as medidas

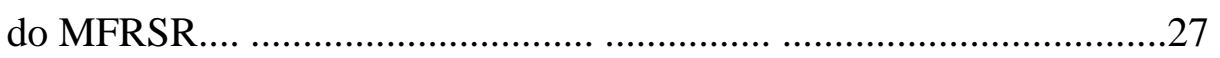

3.5 Modelos Ópticos para o Aerossol de Queimadas na Amazônia............29

3.6 Santa Barbara Disort Radiative Transfer - SBDART.... .....................32

3.7 Estimativa da Profundidade Óptica do Aerossol para o canal de 550nm...

4. Resultados 
4.2 Profunidade Óptica do Aerossol em 550nm..........................................38

4.3 Testes de Sensibilidade - SBDART......................................................39

4.4 Irradiância Modelada versus Observada.... .............................................46

4.4.1 Estudos de Caso para a Avaliação dos Modelos

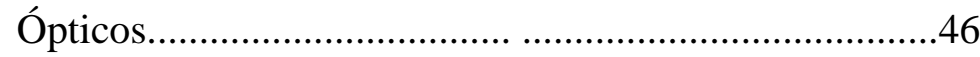

4.4.1.1 Sensor PAR e Canis do MFRSR...................46

4.4.1.2 Irradiância Solar Total Global......................87

4.4.2 Avaliação do Melhor Modelo Óptico para todo o Período Analisado....................................................................90

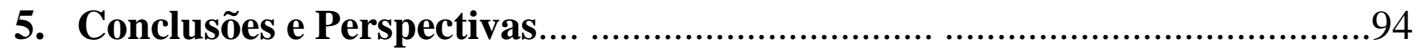

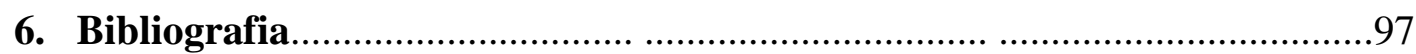




\section{LISTA DE FIGURAS}

Figura 1.1: Classificação das partículas de aerossol em função do seu diâmetro e os principais processos de formação e remoção (adaptado de Whitby, 1978)...... 4

Figura 1.2: Distribuição de massa por diâmetro das partículas quando condições naturais prevalecem (figura do topo) e durante períodos fortemente influenciados pela queima de biomassa. (Adaptado de Martin et al., 2010). .7

Figura 2.1: Distribuição espectral da densidade de energia emitida por um corpo negro à temperatura de $6000 \mathrm{~K}$ (representativo do sol). A região colorida corresponde à região do visível. (Fonte: disponível em http://cref.if.ufrgs.br/ leila/cor.htm. Acesso em abril de 2012) 10

Figura 2.2: Distribuição de irradiância espectral solar no TOA, ao nível médio do mar e a irradiância espectral emitida por um corpo negro à temperatura de $5900 \mathrm{~K}$. As áreas em destaque correspondem às regiões espectrais de significativa absorção por alguns gases presentes na atmosfera. Adaptado de Seinfeld e Pandis (1998).

Figura 2.3: Espectro de absorção de radiação do oxigênio molecular e ozônio (i), do vapor d'água (ii) e da atmosfera (iii). (Fonte: Seinfeld e Pandis, 1998).

Figura 2.4: Esquema representativo das interações entre um feixe de radiação incidente e uma partícula em suspensão na atmosfera. Adaptado de Seinfeld e Pandis, (1998)....15

Figura 2.5: Espalhamento da radiação eletromagnética por uma partícula. (Fonte: disponível em http://hyperphysics.phy-astr.gsu.edu/hbase/atmos/blusky.html. Acesso em abril de 2012)........

Figura 2.6: Geometria da atenuação da radiação solar pela atmosfera. O ângulo formado entre a posição do sol e o zênite é denominado de ângulo zenital solar. Considerando uma aproximação plano-paralela da atmosfera, a massa de ar óptica atravessada pelo feixe de radiação é dada por $m=\frac{1}{\cos \theta} \ldots . .$.

Figura 3.1: Imagem de satélite do estado de Rondônia, região de interesse onde estão demarcados a capital, Porto Velho, (A) e a Reserva Biológica do Jaru (B).

Figura 3.2: Concentração de massa do aerossol na Rebio Jaru durante a temporada úmida (i) e a temporada seca (ii) de 1999 medida em três níveis diferentes da torre localizada no sítio experimental. (Adaptado de Artaxo et al. 2002)... .23

Figura 3.3: Configurações do MFRSR. (a) Principais componentes, (b) Geometria de sombreamento. (Adaptado de Harrison et al., 1994).. 24

Figura 3.4: Foto ilustrativa do Sensor PAR (foto: Eduardo Fernandes Gomes, Técnico do Laboratório de Radiação e Aerossóis Atmosféricos do Departamento de Ciências Atmosféricas do Instituto de Astronomia, Geofísica e Ciências Atmosféricas da Universidade de São Paulo).... 
Figura 3.5: Profundidades ópticas típicas dos constituintes atmosféricos que afetam os canais espectrais do MFRSR padrão: Rayleigh (pressão de 1013,25 mb); aerossóis com raio efetivo (reff, é o raio médio dos aerossóis ponderado pela área analisada) igual a 0,2 e $0,5 \mu \mathrm{m}$ e $\mathrm{AOD}=0,1$ em $550 \mathrm{~nm}$; conteúdo de NO2 = 2 D.U. e O3 = 300 D.U. (Fonte Alexandrov et al., 2002)... .27

Figura 3.6: Localização das estações da AERONET utilizadas por Rosário (2011) para o desenvolvimento dos modelos ópticos do aerossol de queimadas para o sul da Bacia Amazônica.

Figura 3.7: Comparação entre o fator de eficiência de extinção (qext), o albedo simples ( $\omega)$ e o parâmetro de assimetria (g) dos modelos ópticos propostos por Rosário (2011) para o aerossol de queimadas na Amazônia. .31

Figura 4.1: (a) Irradiância solar global espectral para os canais de 415, 670, 870 e 1036 nm do MFRSR para o dia 05 de agosto de 2010 no OPS - LNA. (b) Método de Langley aplicado para o canal de $415 \mathrm{~nm}$ no período da tarde do mesmo dia. .35

Figura 4.2: Irradiância espectral no topo da atmosfera obtida a partir do Método de Langley para as campanhas de calibração ocorridas entre 2005 e 2010 no OPD LNA.

Figura 4.3: Variabilidade diária da profundidade óptica do aerossol em 550nm (a) e do coeficiente de Ångström (b) sobre a Rebio Jaru durante o experimento.. 38

Figura 4.4: Imagens obtidas pelo sensor MODIS a bordo do satélite Terra para os $263 \mathrm{e}$ 265 de 2007. Em vermelho a localização da Rebio Jaru.....

Figura 4.5: Irradiância na região PAR descendente à superfície para diferentes valores de AOD para cada um dos modelos ópticos de Rosário utilizados neste trabalho. (a) Para o disco solar localizado no zênite. (b) Para a distância zenital solar igual a $60^{\circ} . . . .40$

Figura 4.6: Irradiância solar total global descendente à superfície para diferentes valores de AOD para cada um dos modelos ópticos de Rosário utilizados neste trabalho. (a) Para o disco solar localizado no zênite. (b) Para a distância zenital solar igual a $60^{\circ}$

Figura 4.7: Irradiância no canal de 670nm descendente à superfície para diferentes valores de AOD para cada um dos modelos ópticos de Rosário utilizados neste trabalho. (a) Para o disco solar localizado no zênite. (b) Para a distância zenital solar igual a $60^{\circ}$.

Figura 4.8: Irradiância no canal de 870nm descendente à superfície para diferentes valores de AOD para cada um dos modelos ópticos de Rosário utilizados neste trabalho. (a) Para o disco solar localizado no zênite. (b) Para a distância zenital solar igual a $60^{\circ}$. 
Figura 4.9: Irradiância no canal de 1036nm descendente à superfície para diferentes valores de AOD para cada um dos modelos ópticos de Rosário utilizados neste trabalho. (a) Para o disco solar localizado no zênite. (b) Para a distância zenital solar igual a $60^{\circ}$.

Figura 4.10: Irradiância PAR e solar total global (BL) à superfície para diferentes valores de conteúdo de vapor d'água (cva, em g. $\mathrm{cm}^{-2}$ ). (a) Para o disco solar localizado no zênite. (b) Para a distância zenital solar igual a $60^{\circ}$ .44

Figura 4.11: Razão entre irradiância global e difusa dos canais de 670, 870 e 1036nm à superfície para diferentes valores de conteúdo de vapor d'água (cva, em g.cm ${ }^{-2}$ ). (a) Para o disco solar localizado no zênite. (b) Para a distância zenital solar igual a $60^{\circ}$ .44

Figura 4.12- Irradiância PAR e solar total global à superfície para diferentes valores de concentração de ozônio ([ $\left.\mathrm{O}_{3}\right]$, D.U.). (a) Para o disco solar localizado no zênite. (b) Para a distância zenital solar igual a $60^{\circ}$. 45

Figura 4.13- Razão entre irradiância global e difusa dos canais de 670, 870 e 1036nm à superfície para diferentes valores de concentração de ozônio ( $\left[\mathrm{O}_{3}\right]$, D.U.). (a) Para o disco solar localizado no zênite. (b) Para a distância zenital solar igual a $60^{\circ}$..... .45

Figura 4.14: Valores da profundidade óptica em 550nm (a) e do coeficiente de Ångström (b) para o dia do ano 269. . 47

Figura 4.15: Irradiância PAR observada e simulada à superfície para o dia 269. A linha vermelha representa o valor observado menos $5 \%$ e a linha vermelha tracejada representa o observado mais $5 \%$ .48

Figura 4.16: Razão entre a irradiância difusa e global observada e simulada à superfície para os canais de 670,870 e $1036 \mathrm{~nm}$ para o dia 269. A linha vermelha representa a razão dos valores observados menos $5 \%$ e a linha vermelha tracejada representa o observado mais $5 \%$ 50

4.17: (a) Diferença relativa entre a profundidade óptica de 670nm calculada e observada e (b) coeficiente de Ångström calculado com a profundidade óptica de 670nm obtida pelo MFRSR (em preto) e com o fator de eficiência de extinção dos três modelos ópticos para o dia 269 .... 51

Figura 4.18 - (a) Diferença relativa entre a profundidade óptica de 870nm calculada e observada e (b) coeficiente de Ångström calculado com a profundidade óptica de 870nm obtida pelo MFRSR (em preto) e com o fator de eficiência de extinção dos três modelos ópticos para o dia 269. .52

Figura 4.19 - (a) Diferença relativa entre a profundidade óptica de 1036nm calculada e observada e (b) coeficiente de Ångström calculado com a profundidade óptica de 1036nm obtida pelo MFRSR (em preto) e com o fator de eficiência de extinção dos três modelos ópticos para o dia 269 .53 
Figura 4.20 - Valores da profundidade óptica em 550nm (a) e do coeficiente de

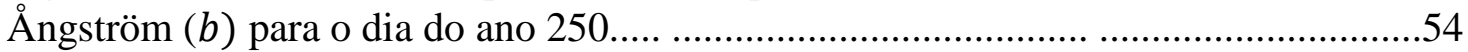

Figura 4.21 - Irradiância PAR observada e simulada à superfície para o dia 250. A linha vermelha representa o valor observado menos $5 \%$ e a linha vermelha tracejada representa o observado mais $5 \%$ 55

Figura 4.22 - Razão entre a irradiância difusa e global observada e simulada à superfície para os canais de $670 \mathrm{~nm}$ (a), $870 \mathrm{~nm}$ (b) e $1036 \mathrm{~nm}$ (c) para o dia 250. A linha vermelha representa a razão dos valores observados menos $5 \%$ e a linha vermelha tracejada representa o observado mais $5 \%$

Figura 4.23 - (a) Diferença relativa entre a profundidade óptica de 670nm calculada e observada e (b) coeficiente de Ångström calculado com a profundidade óptica de 670nm obtida pelo MFRSR (em preto) e com o fator de eficiência de extinção dos três modelos ópticos para o dia 250. .58

Figura 4.24 - (a) Diferença relativa entre a profundidade óptica de 870nm calculada e observada e (b) coeficiente de Ångström calculado com a profundidade óptica de 870nm obtida pelo MFRSR (em preto) e com o fator de eficiência de extinção dos três modelos ópticos para o dia 250 ..... 59

Figura 4.25 - (a) Diferença relativa entre a profundidade óptica de 1036nm calculada e observada e (b) coeficiente de Ångström calculado com a profundidade óptica de 1036nm obtida pelo MFRSR (em preto) e com o fator de eficiência de extinção dos três modelos ópticos para o dia 250 .

Figura 4.26 - Valores da profundidade óptica em 550nm (a) e do coeficiente de Ångström (b) para o dia do ano 236...

Figura 4.27 - Irradiância PAR observada e simulada à superfície para o dia 236. A linha vermelha representa o valor observado menos $5 \%$ e a linha vermelha tracejada representa o observado mais $5 \%$.

Figura 4.28 - Razão entre a irradiância difusa e global observada e simulada à superfície para os canais de $670 \mathrm{~nm}$ (a), $870 \mathrm{~nm}$ (b) e $1036 \mathrm{~nm}$ (c) para o dia 236. A linha vermelha representa a razão dos valores observados menos $5 \%$ e a linha vermelha tracejada representa o observado mais $5 \%$.

Figura 4.29 - (a) Diferença relativa entre a profundidade óptica de $670 \mathrm{~nm}$ calculada e observada e (b) coeficiente de Ångström calculado com a profundidade óptica de 670nm obtida pelo MFRSR (em preto) e com o fator de eficiência de extinção dos três modelos ópticos para o dia 236. 65

Figura 4.30 - (a) Diferença relativa entre a profundidade óptica de 870nm calculada e observada e (b) coeficiente de Ångström calculado com a profundidade óptica de 
870nm obtida pelo MFRSR (em preto) e com o fator de eficiência de extinção dos três modelos ópticos para o dia $236 . .$.

Figura 4.31 - (a) Diferença relativa entre a profundidade óptica de $1036 \mathrm{~nm}$ calculada e observada e (b) coeficiente de Ångström calculado com a profundidade óptica de 1036nm obtida pelo MFRSR (em preto) e com o fator de eficiência de extinção dos três modelos ópticos para o dia 236.

Figura 4.32 - Valores da profundidade óptica em 550nm (a) e do coeficiente de Ångström (b) para o dia do ano $237 \ldots$ .68

Figura 4.33 - Irradiância PAR observada e simulada à superfície para o dia 237. A linha vermelha representa o valor observado menos $5 \%$ e a linha vermelha tracejada representa o observado mais $5 \%$.

Figura 4.34 - Razão entre a irradiância difusa e global observada e simulada à superfície para os canais de $670 \mathrm{~nm}$ (a), $870 \mathrm{~nm}$ (b) e $1036 \mathrm{~nm}$ (c) para o dia 237. A linha vermelha representa a razão dos valores observados menos $5 \%$ e a linha vermelha tracejada representa o observado mais $5 \%$ .70

Figura 4.35 - (a) Diferença relativa entre a profundidade óptica de $670 \mathrm{~nm}$ calculada e observada e (b) coeficiente de Ångström calculado com a profundidade óptica de 670nm obtida pelo MFRSR (em preto) e com o fator de eficiência de extinção dos três modelos ópticos para o dia 237.

Figura 4.36 - (a) Diferença relativa entre a profundidade óptica de 870nm calculada e observada e (b) coeficiente de Ångström calculado com a profundidade óptica de 870nm obtida pelo MFRSR (em preto) e com o fator de eficiência de extinção dos três modelos ópticos para o dia 237. 72

Figura 4.37 - (a) Diferença relativa entre a profundidade óptica de 1036nm calculada e observada e (b) coeficiente de Ångström calculado com a profundidade óptica de 1036nm obtida pelo MFRSR (em preto) e com o fator de eficiência de extinção dos três modelos ópticos para o dia $237 \ldots$. .73

Figura 4.38 - Valores da profundidade óptica em 550nm (a) e do coeficiente de Ångström (b) para o dia do ano 253. .74

Figura 4.39 - Irradiância PAR observada e simulada à superfície para o dia 253. A linha vermelha representa o valor observado menos $5 \%$ e a linha vermelha tracejada representa o observado mais $5 \%$. .75

Figura 4.40 - Razão entre a irradiância difusa e global observada e simulada à superfície para os canais de $670 \mathrm{~nm}$ (a), $870 \mathrm{~nm}$ (b) e $1036 \mathrm{~nm}$ (c) para o dia 253. A linha vermelha representa a razão dos valores observados menos $5 \%$ e a linha vermelha tracejada representa o observado mais $5 \%$. .76 
Figura 4.41 - (a) Diferença relativa entre a profundidade óptica de 670nm calculada e observada e (b) coeficiente de Ångström calculado com a profundidade óptica de 670nm obtida pelo MFRSR (em preto) e com o fator de eficiência de extinção dos três modelos ópticos para o dia 253.

Figura 4.42 - (a) Diferença relativa entre a profundidade óptica de 870nm calculada e observada e (b) coeficiente de Ångström calculado com a profundidade óptica de 870nm obtida pelo MFRSR (em preto) e com o fator de eficiência de extinção dos três modelos ópticos para o dia 253 . .78

Figura 4.43 - (a) Diferença relativa entre a profundidade óptica de 1036nm calculada e observada e (b) coeficiente de Ångström calculado com a profundidade óptica de 1036nm obtida pelo MFRSR (em preto) e com o fator de eficiência de extinção dos três modelos ópticos para o dia 253. 79

Figura 4.44 - Valores da profundidade óptica em 550nm (a) e do coeficiente de Ångström (b) para o dia do ano 254 .. .80

Figura 4.45 - Irradiância PAR observada e simulada à superfície para o dia 254. A linha vermelha representa o valor observado menos $5 \%$ e a linha vermelha tracejada representa o observado mais $5 \%$.

Figura 4.46 - Razão entre a irradiância difusa e global observada e simulada à superfície para os canais de $670 \mathrm{~nm}$ (a), $870 \mathrm{~nm}$ (b) e $1036 \mathrm{~nm}$ (c) para o dia 254. A linha vermelha representa a razão dos valores observados menos $5 \%$ e a linha vermelha tracejada representa o observado mais $5 \%$ .83

Figura 4.47 - (a) Diferença relativa entre a profundidade óptica de 670nm calculada e observada e (b) coeficiente de Ångström calculado com a profundidade óptica de 670nm obtida pelo MFRSR (em preto) e com o fator de eficiência de extinção dos três modelos ópticos para o dia 254. .84

Figura 4.48 - (a) Diferença relativa entre a profundidade óptica de 870nm calculada e observada e (b) coeficiente de Ångström calculado com a profundidade óptica de 870nm obtida pelo MFRSR (em preto) e com o fator de eficiência de extinção dos três modelos ópticos para o dia 254 . .85

Figura 4.49 - (a) Diferença relativa entre a profundidade óptica de $1036 \mathrm{~nm}$ calculada e observada e (b) coeficiente de Ångström calculado com a profundidade óptica de 1036nm obtida pelo MFRSR (em preto) e com o fator de eficiência de extinção dos três modelos ópticos para o dia 254 .86

Figura 4.50 - Irradiância solar total global observada pelo MFRSR (a) e pelo Piranômetro (b) e simulada à superfície para o dia 236. A linha vermelha representa o valor observado menos $5 \%$ e a linha vermelha tracejada representa o observado mais $5 \%$ 88 
Figura 4.51 - Irradiância solar total global observada pelo MFRSR (a) e pelo Piranômetro (b) e simulada à superfície para o dia 269. A linha vermelha representa o valor observado menos $5 \%$ e a linha vermelha tracejada representa o observado mais $5 \%$ .89

Figura 4.52 - Frequência de ocorrência da diferença relativa entre os dados de irradiância PAR observados e os calculados com os três modelos ópticos para o aerossol de queimadas: (a) modelo médio, (b) modelo espalhador e (c) modelo absorvedor.......91

Figura 4.53 - Diferença relativa entre a irradiância PAR observada e a simulada, utilizando os três modelos ópticos propostos para o aerossol de queimadas da Amazônia, em função do dia e da profundidade óptica em $550 \mathrm{~nm}$ (AOD550). Modelo médio (a), modelo espalhador (b) e modelo absrovedor (c). 


\section{LISTA DE TABELAS}

Tabela 1.1: Estimativas da contribuição anual global de material particulado para atmosfera em função da natureza da fonte. (Fonte: Horvath, 2000) .............................2

Tabela 2.1: Composição média da atmosfera (Adaptado de Liou 2002) ......................12

Tabela 4.1: Estimativa das constantes de calibração E0, $\lambda$ (Wm-2nm-1) para os canais do MFRSR a partir do Método de Langley para as medições realizadas no OPD-LNA nos meses de julho e agosto de 2010 . 36 
Capítulo 1: Introducão 


\subsection{Aerossol Atmosférico}

O aerossol é definido como partículas sólidas ou líquidas suspensas em um gás com tamanho que varia de alguns nanômetros a dezenas de micrômetros (Seinfeld e Pandis, 1998). Neste trabalho chamaremos de aerossol o material particulado, e não o conjunto gás-partícula. Eles são provenientes de fontes e processos naturais, como a ressuspensão de poeira do solo, spray marinho e atividade vulcânica, ou de atividades antrópicas, como a queima de combustíveis fósseis (ver tabela 1.1). As partículas que são emitidas diretamente recebem o nome de aerossol primário, já as que são formadas através de processos de conversão gás-partícula na atmosfera são denominadas de aerossol secundário.

Tabela 1.1 - Estimativas da contribuição anual global de material particulado para atmosfera em função da natureza da fonte. (Fonte: Horvath, 2000)

\section{Quantidade de}

Fontes partículas produzidas

em Tg/ano

\begin{tabular}{|c|c|}
\hline$\rightarrow$ Natural & \\
\hline Solo & $100-500$ \\
\hline Queimadas de florestas & $3-150$ \\
\hline Sal marinho & 300 \\
\hline Emissões vulcânicas & $25-130$ \\
\hline \multicolumn{2}{|l|}{ Partículas de conversão gás-partícula } \\
\hline - Sulfato a partir de $\mathrm{H}_{2} \mathrm{~S}$ & $130-200$ \\
\hline - Nitrato a partir de $\mathrm{NO}_{\mathrm{x}}$ & $60-430$ \\
\hline - Hidrocarbonetos provenientes de plantas & $75-200$ \\
\hline Subtotal natural & $773-2200$ \\
\hline \multicolumn{2}{|l|}{$\rightarrow$ Origem antrópica } \\
\hline Partículas emitidas diretamente & $10-90$ \\
\hline \multicolumn{2}{|l|}{ Partículas de conversão gás-partícula } \\
\hline - Sulfato a partir de $\mathrm{SO}_{2}$ & $130-200$ \\
\hline - Nitrato a partir de $\mathrm{NO}_{\mathrm{x}}$ & $30-35$ \\
\hline - Hidrocarbonetos & $15-90$ \\
\hline Subtotal antrópico & $185-415$ \\
\hline
\end{tabular}


A atividade antrópica exerce um papel importante na concentração de aerossóis em uma escala global, provocando sérios problemas de saúde em áreas industriais densamente povoadas e também sendo a principal fonte de incertezas no contexto de mudança climática (Kokhanovsky, 2008).

Existem vários processos de remoção do aerossol atmosférico, que podem ser divididos em dois grupos: deposição seca e deposição úmida. Entre os processos de deposição seca destacam-se: sedimentação gravitacional (partícula cai devido à gravidade), interceptação (quando o escoamento das partículas ocorre muito próximo a um obstáculo pode ocorrer a colisão), por impacto (partículas com uma grande inércia, incapazes de seguir o fluxo colidem com o obstáculo), difusão (as partículas se movem randomicamente, colidem umas com as outras, o que pode levar a uma colisão com outros obstáculos ou a superfície) e turbulência (Seinfeld e Pandis, 1998; Horvath, 2000).

O aerossol atmosférico pode ser classificado a partir de seu tamanho, geralmente expresso pelo diâmetro aerodinâmico ${ }^{1}$ (da). Em relação a essa propriedade, as partículas menores do que 2,0 $\mu$ m são definidas como partículas finas enquanto que as partículas com diâmetro superior a este valor são chamadas de partículas grossas. Recentemente as partículas com diâmetro aerodinâmico menor do que 10,0 $\mu \mathrm{m}$ (PM10) passaram a ser chamadas de partículas inaláveis (Seinfeld e Pandis, 1998).

Existem vários modelos para determinar a distribuição de tamanho dos aerossóis na atmosfera. O mais utilizado é a distribuição lognormal. Segundo Whitby (1978), o aerossol atmosférico pode ser caracterizado de forma adequada a partir de três distribuições lognormais, definidas como modas:

(i) moda de nucleação ou partículas de Aitken - tem origem na condensação de vapores supersaturados, que leva à coagulação das partículas;

(ii) moda de acumulação - as partículas há mais tempo na atmosfera (de dias a semanas) interagem com as partículas da moda de nucleação.

(iii) moda grossa - partículas originadas por processos mecânicos, como a ressuspensão de poeira do solo e o spray marinho.

\footnotetext{
${ }^{1}$ Geralmente por apresentarem formas irregulares, o tamanho das partículas é difícil de ser determinado. Sendo assim é definido o diâmetro aerodinâmico, que corresponde ao diâmetro de uma esfera de densidade unitária com a mesma velocidade de sedimentação da partícula.
} 
Na figura 1.1 é apresentado um esquema idealizado da distribuição de tamanho do aerossol atmosférico e os principais processos responsáveis pela origem e remoção destes.
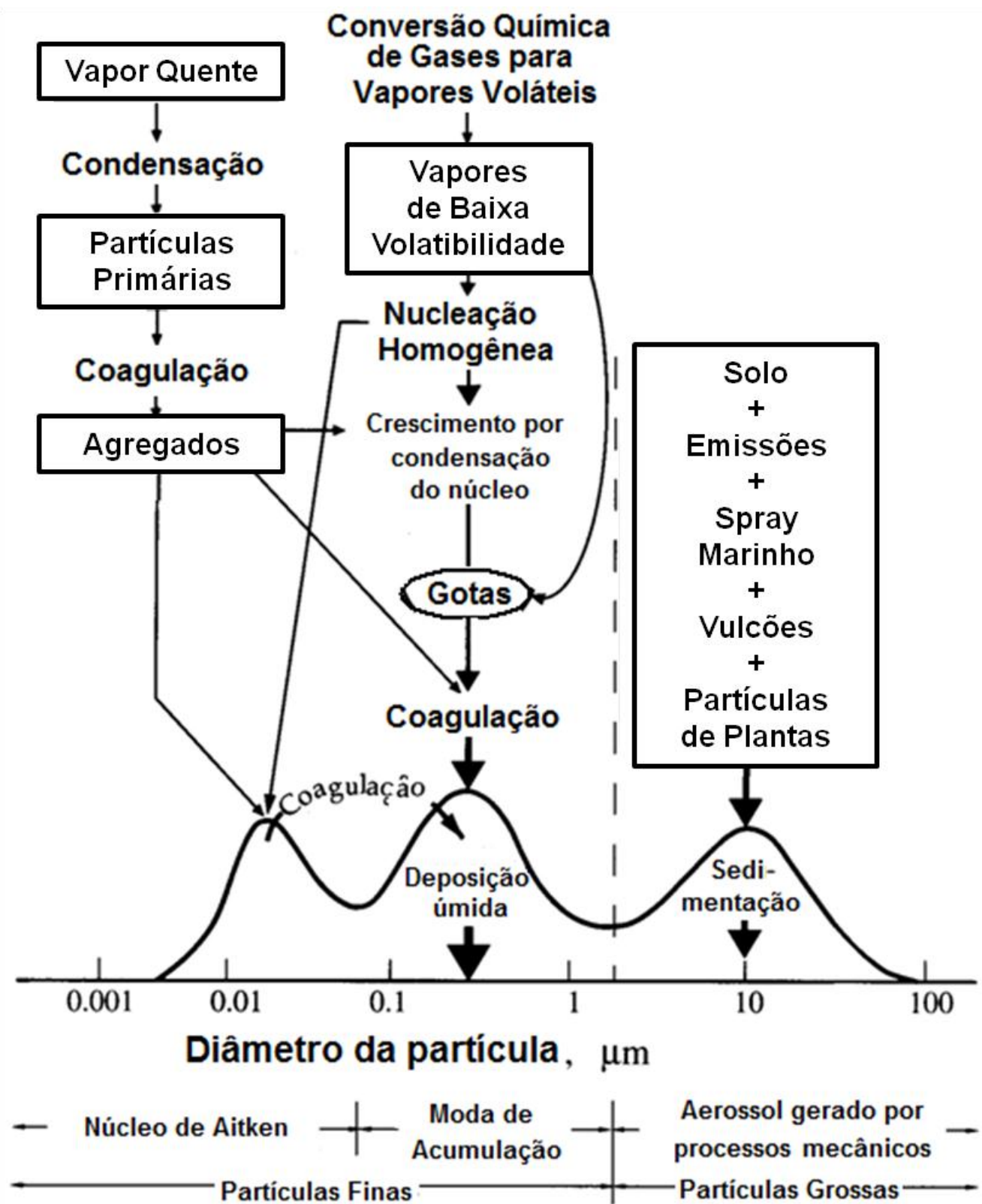

Figura 1.1 - Classificação das partículas de aerossol em função do seu diâmetro e os principais processos de formação e remoção (adaptado de Whitby, 1978). 


\subsection{O Papel do Aerossol no Balanço de Energia}

As partículas de aerossol alteram o balanço de energia terra-atmosfera por interagir direta e indiretamente com a radiação solar. $\mathrm{O}$ efeito direto envolve a absorção e o espalhamento da radiação solar, ou radiação de onda curta. O espalhamento da radiação de onda curta na atmosfera (e, portanto, o aumento do albedo terrestre) e a absorção da mesma pelas partículas de aerossol presentes na atmosfera (levando a um aquecimento da atmosfera), reduzem a quantidade de energia que chega à superfície (Charlson et al., 1992, Ramanathan et al., 2001). Vários estudos já foram realizados com o objetivo de estimar como a radiação solar incidente é afetada. Yamasoe (1999) sugeriu que em regiões de queimadas a forçante radiativa (medida de influência que um fator tem de alterar o balanço de energia que entra ou sai no sistema terra-atmosfera) pode chegar a $-45 \mathrm{Wm}^{-2}$. Procópio e Artaxo (2003) em um experimento feito entre agosto e outubro de 2003 no sul da Bacia Amazônica observaram que cerca de 20\% da radiação solar é absorvida ou refletida para o espaço pelos aerossóis de queimadas, levando a uma redução de $1 / 3$ na radiação direta que atinge a superfície e aumentando em 7 vezes a radiação difusa. Outro estudo indicou que a pluma de poluição associada à queima de biomassa absorve até $400 \mathrm{Wm}^{-2}$ de radiação, subtraindo $30 \%$ da radiação no comprimento de onda do visível (Artaxo et al., 2003), podendo, dessa forma, interferir nas taxas de fotossíntese. O decréscimo de energia chegando à superfície leva à redução da evaporação e a instauração de uma atmosfera mais seca e estável (Koren et al., 2004), alterando dessa forma a estrutura vertical da temperatura na atmosfera e sua termodinâmica. Esse efeito é definido como efeito semi-direto do aerossol (Hansen et al., 1997) .

O efeito indireto está acoplado ao papel dos aerossóis atuarem como núcleos de condensação de nuvens (NCN). O aumento na concentração de NCN leva ao aumento do número de gotículas, tornando a nuvem opticamente mais densa e, portanto, levando ao aumento de seu albedo (Twomey e Wolfe, 1984). O tamanho médio das gotas será menor, inibindo a precipitação levando consequentemente ao acréscimo no tempo de vida da nuvem (Braham, 1974). Haywoode e Boucher (2000) estimaram que a forçante radiativa global do efeito indireto é estimada entre $-0,3$ e $-1,8 \mathrm{Wm}^{-2}$. 


\subsection{Propriedades das Partículas de Aerossol na Amazônia}

Durante a temporada chuvosa (entre dezembro e março), a concentração de partículas medidas na Bacia Amazônica está entre as mais baixas encontradas sobre o continente e podem ser comparadas àquelas encontradas sobre oceanos remotos (Andreae, 2009). Já durante a temporada seca (entre junho e setembro), quando ocorrem os eventos de queima de biomassa, seja para manutenção de pastos ou para desflorestamento, grande parte da Bacia se torna um dos lugares mais poluídos do planeta (Artaxo et al., 2002). Estima-se que a taxa de emissão de material particulado com diâmetro menor ou igual a 2,5 $\mu \mathrm{m}$ chega a $8 \mathrm{Tg}$ /ano e do material particulado com até $10 \mu \mathrm{m}$ de diâmetro chega a 10 Tg/ano (Yokelson et al., 2008).

Através de dados obtidos durante o experimento AMAZE-08 (Amazonian Aerosol Characterization Experiment 2008) com um impactador em cascata durante março a abril de 2008 na Amazônia central (nessa ápoca considera-se que a influência de fontes externas à Bacia é pequena) e durante o LBA-SMOCC (Large-Scale Biosphere-Atmosphere Experiment in Amazonia: Smoke, Aerosols, Clouds, Rainfall, and Climate Field Campaign) em Rondônia, Martin et al. (2010) elaboraram gráficos (figura 1.2) apresentando a distribuição de massa em função do diâmetro nesses dois experimentos.

A figura 1.2 (topo) mostra que, para condições naturais (AMAZE-08), a distribuição é dominada por partículas da moda grossa (correspondendo a partículas primárias biológicas). Na figura 1.2 (inferior), durante a temporada em que ocorre a queima de biomassa (LBA-SMOCC), a distribuição é dominada pela fração fina e a concentração total em massa das partículas também apresenta uma grande elevação. 


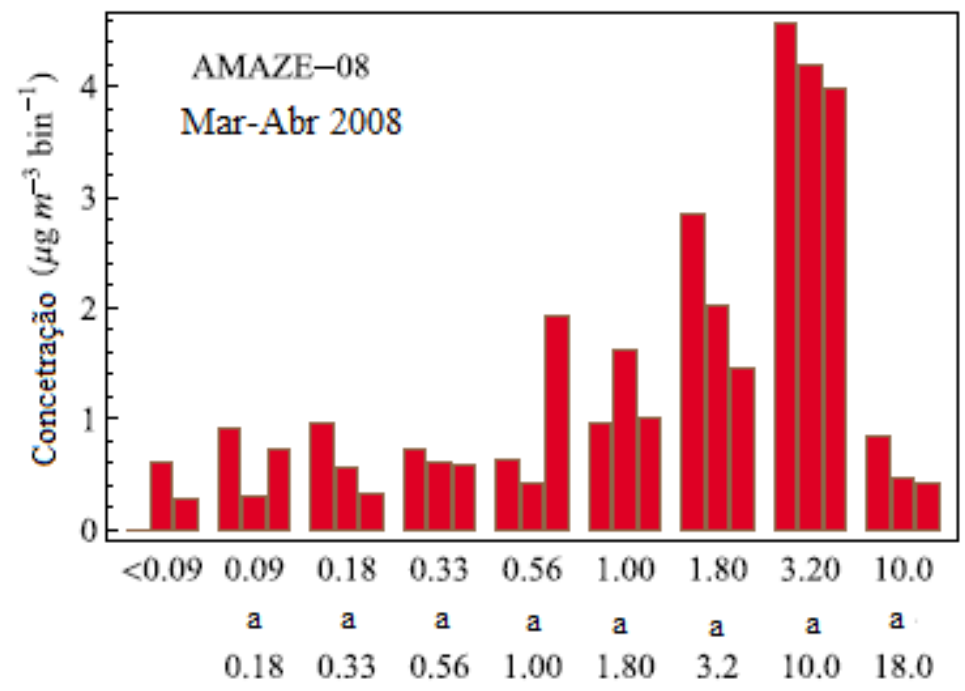

Diâmetro aerodinâmico $(\mu \mathrm{m})$

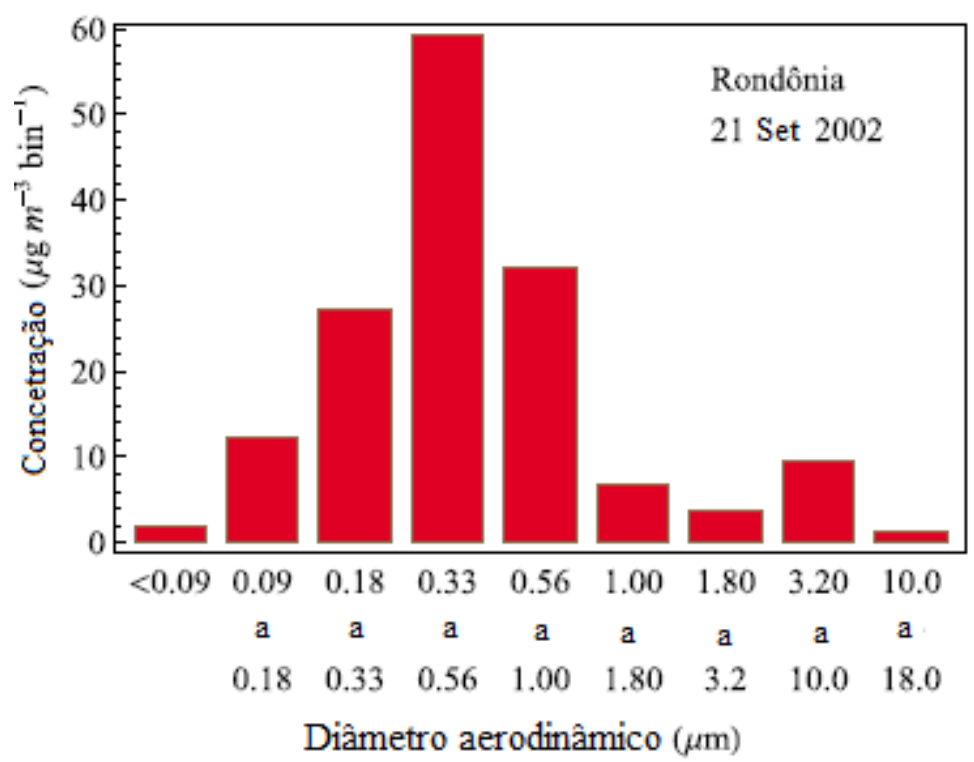

Figura 1.2 - Distribuição de massa por diâmetro das partículas quando condições naturais prevalecem (figura do topo) e durante períodos fortemente influenciados pela queima de biomassa. (Adaptado de Martin et al., 2010)

Além dessas variações sazonais, as variações geográficas também são facilmente observadas na Bacia Amazônica. Em Alta Floresta, na região sul da Amazônia, é possível observar dois regimes bem distintos na concentração em massa ao longo do ano: durante a temporada chuvosa, as concentrações de PM10 ficam aproximadamente entre 9 e $12 \mu \mathrm{g} \mathrm{m}^{-3}$ sendo a fração fina responsável por entre 2 e $3 \mu \mathrm{g} \mathrm{m}$; já na temporada seca, quando ocorrem os eventos de queima de biomassa na Bacia, a

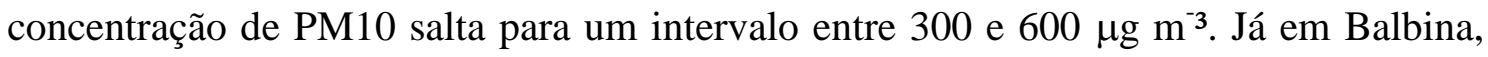


na região central da Amazônia, a variação ao longo do ano da concentração em massa é pequena, com uma média de PM10 em torno de $11 \mu \mathrm{g} \mathrm{m}^{-3}$ (Martin et al., 2010).

A grande variabilidade apresentada sazonalmente e geograficamente pelas partículas apresenta um desafio para aqueles que pretendem estudar e simular processos atmosféricos nessa região. Como tais estudos dependem do balanço de radiação tanto na atmosfera quanto em superfície, para estimar o efeito dos aerossóis nesse balanço, modelos ópticos desses aerossóis precisam ser elaborados e validados para superar esse desafio.

\subsection{Objetivos}

O objetivo principal deste trabalho é avaliar o desempenho dos modelos ópticos do aerossol de queimadas na região amazônica propostos por Rosário (2011) na recuperação de irradiância solar global, fotossinteticamente ativa e em bandas estreitas à superfície na Reserva Biológica do Jaru, Rondônia, com o uso de um código de transferência radiativa e posterior comparação com medições efetuadas em situações de céu claro, com diferentes cargas de aerossol. 
Capítulo 2: Fundamentacão Teórica 


\subsection{Radiação Solar}

A principal fonte de energia externa para a Terra é o sol. Tal energia chega ao nosso planeta na forma de radiação eletromagnética. $\mathrm{O}$ espectro solar compreende comprimentos de onda de raios gama até ondas de rádio (Liou, 2002). A curva de distribuição espectral é próxima à de um corpo negro à temperatura de $6000 \mathrm{~K}$, apresentada na figura 2.1.

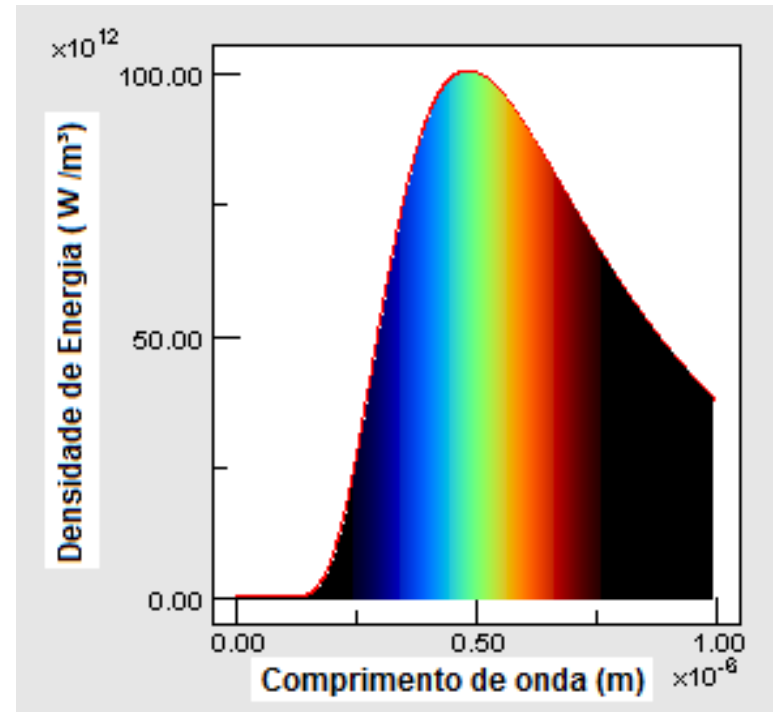

Figura 2.1 - Distribuição espectral da densidade de energia emitida por um corpo negro à temperatura de $6000 \mathrm{~K}$ (representativo do sol). A região colorida corresponde à região do visível. (Fonte: disponível em http://cref.if.ufrgs.br/ leila/cor.htm. Acesso em abril de 2012).

Cerca de 50\% da energia solar que atinge o topo da atmosfera (TOA, do inglês Top Of Atmosphere) concentram-se no espectro do visível (definido entre 400 e 760 $\mathrm{nm}), 10 \%$ em comprimentos de ondas menores do que o visível e $40 \%$ em comprimentos de ondas maiores do que o visível (Liou, 2002). O conhecimento de tal distribuição é fundamental para o sensoriamento remoto do sistema Terra-atmosfera e no monitoramento do aerossol atmosférico. 


\subsection{Atmosfera Terrestre}

A atmosfera terrestre usualmente é dividida em cinco camadas diferentes, caracterizadas pelas variações dos perfis verticais de temperatura e pressão. São elas:

- troposfera: que se estende da superfície a até cerca de 10 a $15 \mathrm{~km}$ de altura, caracterizada pela rápida diminuição da temperatura com a altitude. A maior parte dos fenômenos meteorológicos ocorre nesta camada. Seu topo recebe o nome de tropopausa.

- estratosfera: localizada entre a tropopausa e aproximadamente 45 a $55 \mathrm{~km}$. Contém a camada de ozônio e sua principal característica é o aumento de temperatura com a altitude. $\mathrm{O}$ limite superior da estratosfera recebe o nome de estratopausa.

- mesosfera: fica entre a estratopausa e a mesopausa, a aproximadamente 80 a 90 $\mathrm{km}$. A temperatura decresce com a altitude, atingindo o menor valor observado na atmosfera.

- termosfera: que se estende da mesopausa a centenas de quilômetros de altura. Nesta camada a temperatura aumenta com a altitude (podendo atingir 2000K, dependendo da atividade solar), devido à absorção da radiação pelas moléculas de nitrogênio e oxigênio.

- exosfera: camada acima de $500 \mathrm{~km}$ de altitude. As moléculas de gases com energia suficiente podem escapar da ação gravitacional da terra.

Acredita-se que a atmosfera atual tenha sido formada principalmente como resultado de substâncias voláteis presentes no interior do planeta, emitidas por atividades vulcânicas (Wallace e Hobbs, 1977). Ela é composta por dois grupos de gases, um com concentrações aproximadamente permanentes e outro com concentrações variáveis. Aproximadamente $78 \%$ da atmosfera é composta pelo gás nitrogênio e $21 \%$ pelo gás oxigênio. Em uma atmosfera seca, cerca de $1 \%$ corresponde a gases traço (tabela 2.1). Os gases permanentes têm volume virtualmente constante até aproximadamente $60 \mathrm{~km}$ de altitude.

Mesmo sendo minoritários, os constituintes variáveis apresentam um papel fundamental no balanço de radiação da atmosfera. Embora o dióxido de carbono apareça como constituinte permanente, sua concentração vem aumentando cerca de 0,4\% ao ano como resultado da queima de combustíveis fósseis, absorção e emissão pelos oceanos e fotossíntese (Liou, 2002). A concentração de metano também tem aumentado cerca de 1-2\% ao ano, associado principalmente à emissão biogênica devida ao crescimento da população humana. O desflorestamento, a queima de biomassa e a 
modificação das fontes de $\mathrm{CH}_{4}$ podem levar a mudanças na concentração do $\mathrm{CO}$. Existem também evidências do aumento da concentração do óxido nitroso, associado à combustão de combustíveis fósseis e desnitrificação de fertilizantes (Liou, 2002).

Tabela 2.1 - Composição média da atmosfera (Adaptado de Liou 2002)

\begin{tabular}{|c|c|c|c|}
\hline \multicolumn{4}{|c|}{ Composição da Atmosfera } \\
\hline \multicolumn{2}{|c|}{ Constituintes permanentes } & \multicolumn{2}{|c|}{ Constituintes variáveis } \\
\hline Constituinte & $\%$ por volume & Constituinte & $\%$ por volume \\
\hline Nitrogênio $\left(\mathrm{N}_{2}\right)$ & 78 & Vapor d'água $\left(\mathrm{H}_{2} \mathrm{O}\right)$ & $0-0.4$ \\
\hline Oxigênio $\left(\mathrm{O}_{2}\right)$ & 21 & Ozônio $\left(\mathrm{O}_{3}\right)$ & $0-12 \times 10^{-4}$ \\
\hline Argônio (Ar) & 0,934 & Dióxido de Enxofre $\left(\mathrm{SO}_{2}\right)$ & $0,001 \times 10^{-4}$ \\
\hline Dióxido de Carbono $\left(\mathrm{CO}_{2}\right)$ & 0,036 & Dióxido de Nitrogênio $\left(\mathrm{NO}_{2}\right)$ & $0,001 \times 10^{-4}$ \\
\hline Neon (Ne) & $18,18 \times 10^{-4}$ & Amônia $\left(\mathrm{NH}_{3}\right)$ & $0,004 \times 10^{-4}$ \\
\hline Hélio (He) & $5,24 \times 10^{-4}$ & Óxido Nítrico (NO) & $0,0005 \times 10^{-4}$ \\
\hline Criptônio (Kr) & $1,14 \times 10^{-4}$ & Vapor de ácido nítrico $\left(\mathrm{HNO}_{3}\right)$ & Traço \\
\hline Xenônio (Xe) & $0,089 \times 10^{-4}$ & Clorofluorcarbonetos & Traço \\
\hline Hidrogênio $(H)$ & $0,5 \times 10^{-4}$ & $\left(\mathrm{CFCCl}_{3}, \mathrm{CF}_{2} \mathrm{Cl}_{2}\right.$, etc. $)$ & Traço \\
\hline Metano $\left(\mathrm{CH}_{4}\right)$ & $1,7 \times 10^{-4}$ & & \\
\hline Óxido Nitroso $\left(\mathrm{N}_{2} \mathrm{O}\right)$ & $0,3 \times 10^{-4}$ & & \\
\hline Monóxido de Carbono (CO) & $0,08 \times 10^{-4}$ & & \\
\hline
\end{tabular}

\subsection{Interação da Radiação Solar com a Atmosfera Terrestre}

Ao penetrar na atmosfera, a radiação solar sofre um processo denominado de atenuação. A quantidade de energia atenuada depende dos tipos e da quantidade de gases e partículas presentes na atmosfera. Existem dois mecanismos responsáveis por esse processo: o espalhamento e a absorção (Horvarth, 1993). O espalhamento redireciona a energia do campo de radiação, provocado principalmente pela presença das partículas de aerossol e moléculas de ar (a influência de gases traço pode ser negligenciada neste caso). A absorção remove a energia do campo de radiação e a transforma em outro tipo de energia. Na figura 2.2 são apresentadas as curvas de irradiância solar espectral incidente no topo da atmosfera (TOA), da que incide em superfície ao nível médio do mar após sofrer atenuação (representada pelas áreas destacadas na figura) em uma atmosfera sem nuvens ou aerossóis e da emissão de um corpo negro à temperatura de $5900 \mathrm{~K}$. 


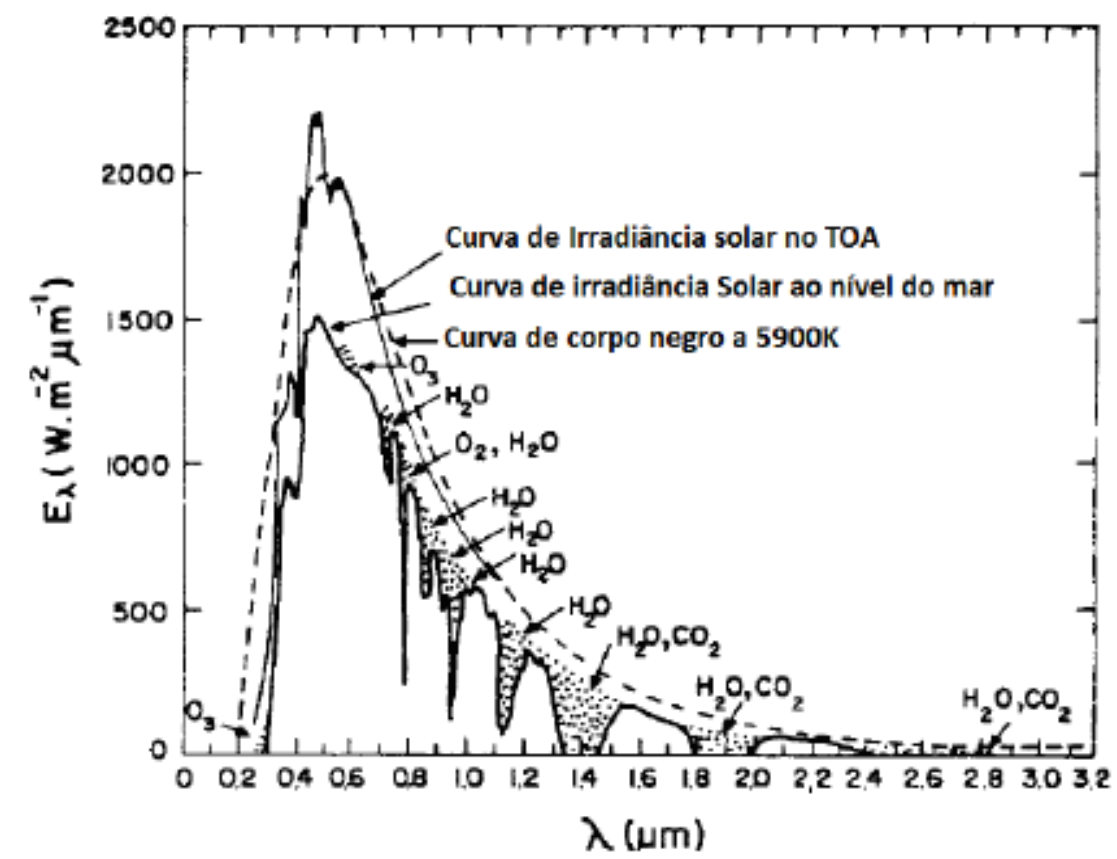

Figura 2.2- Distribuição de irradiância espectral solar no TOA, ao nível médio do mar e a irradiância espectral emitida por um corpo negro à temperatura de $5900 \mathrm{~K}$. As áreas em destaque correspondem às regiões espectrais de significativa absorção por alguns gases presentes na atmosfera. Adaptado de Seinfeld e Pandis (1998).

Observa-se que os principais gases responsáveis pela absorção da radiação solar são o ozônio $\left(\mathrm{O}_{3}\right)$, o oxigênio $\left(\mathrm{O}_{2}\right)$ e o vapor d'água $\left(\mathrm{H}_{2} \mathrm{O}\right)$. Na figura 2.3 são apresentados os espectros de absorção do $\mathrm{O}_{3}$, do $\mathrm{O}_{2}$ e do $\mathrm{H}_{2} \mathrm{O}$ e da atmosfera.

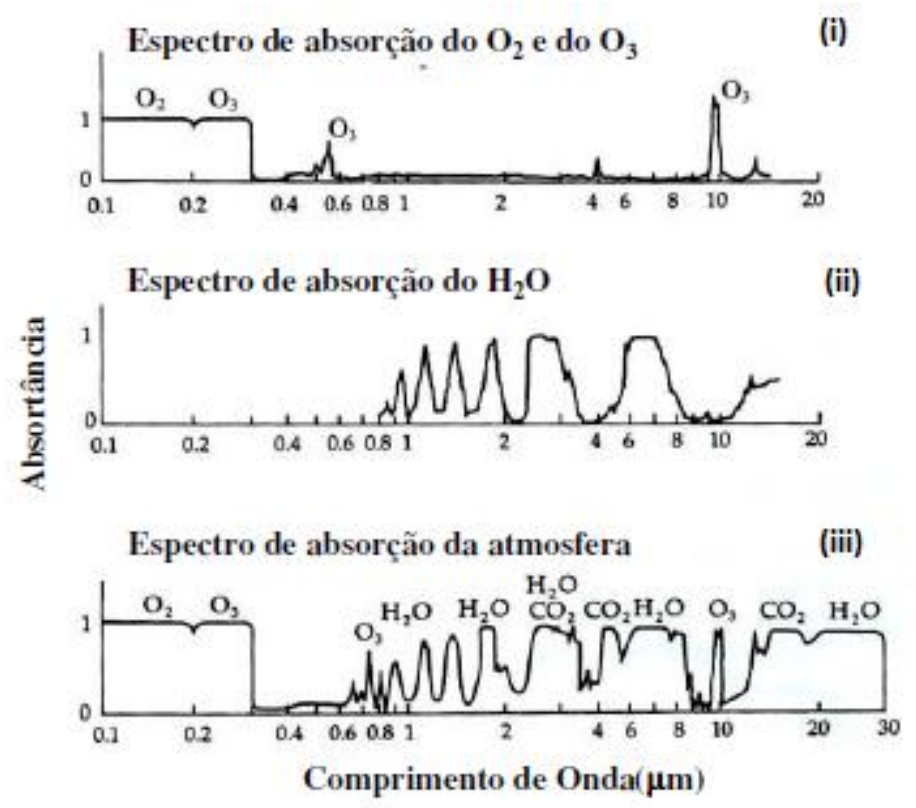

Figura 2.3 - Espectro de absortância do oxigênio molecular e ozônio (i), do vapor d'água (ii) e da atmosfera (iii). (Fonte: Seinfeld e Pandis, 1998). 
A absorção na região espectral do ultravioleta (entre 0,12 e 0,40 $\mu \mathrm{m}$ ) é dominada pelo $\mathrm{O}_{2}$ e pelo $\mathrm{O}_{3}$. No espectro do visível, o $\mathrm{O}_{3}$ é o principal absorvedor, em função da banda de Chappuis. No infravermelho próximo (entre 0,76 e 4,0 $\mu \mathrm{m}$ ) o principal absorvedor é o vapor d'água, mas também há a absorção associada ao $\mathrm{CO}_{2}$ e ao $\mathrm{O}_{3}$.

\subsubsection{O Espalhamento Rayleigh}

Em 1871, John Rayleigh quantificou o espalhamento da radiação eletromagnética para o caso em que o comprimento de onda da radiação incidente é muito maior que o tamanho da partícula espalhadora. Esta teoria é utilizada para o estudo do espalhamento da radiação pelas moléculas de ar, assim como alguns tipos de aerossóis, presentes na atmosfera.

Baseada na teoria Rayleigh, a seção de choque de espalhamento $\sigma_{\text {esp }}$ de uma única molécula é dada por (Liou, 2002):

$$
\sigma_{e s p}=\alpha_{p}{ }^{2} \frac{128 \pi^{5}}{3 \lambda^{4}}
$$

Onde $\alpha_{p}$ é a polarização da partícula, definida como a razão entre o dipolo elétrico induzido e o campo elétrico incidente na partícula. $\mathrm{O}$ parâmetro $\sigma_{e s p}$ representa a quantidade de energia retirada da direção original devido a um único evento de espalhamento tal que a energia é redistribuída pela área de uma esfera com centro dispersor e raio $\mathrm{r}$ (Liou, 2002).

A profundidade óptica devida ao espalhamento molecular $\tau_{\mathrm{m}}$ é obtida através da seção de choque de espalhamento:

$$
\tau_{m}(\lambda)=\sigma_{e s p}(\lambda) \int_{0}^{z_{\infty}} N(z) d z
$$

Onde N(z) é a densidade numérica de partículas por volume de moléculas de ar. Vários trabalhos propõem fórmulas empíricas para a profundidade óptica espectral de Rayleigh (Hansen e Travis, 1974; Fröhlich e Shaw, 1980; Bucholtz, 1995). A equação 2.3 representa uma dessas soluções, proposta por Hansen e Travis (1974):

$$
\tau_{m}(\lambda)=0.0088 \lambda^{-4}\left(1+0.0113 \lambda^{-2}+0.00013 \lambda^{-4}\right) \frac{P}{P_{0}}
$$

Onde $\lambda$ é o comprimento de onda em micrômetro, $\mathrm{P}$ é a pressão atmosférica local e $\mathrm{P}_{0}$ é a pressão ao nível médio do mar $(\approx 1013,25 h P a)$. 


\subsubsection{Atenuação pelas Partículas de Aerossóis}

Quando um feixe de radiação espectral incide em uma partícula, ocorre simultaneamente uma série de fenômenos distintos (figura 2.4). Para o presente estudo da interação da radiação solar com os aerossóis, serão levados em conta apenas a absorção e o espalhamento elástico (reflexão, difração e refração), no qual não há alteração do comprimento de onda da radiação incidente.

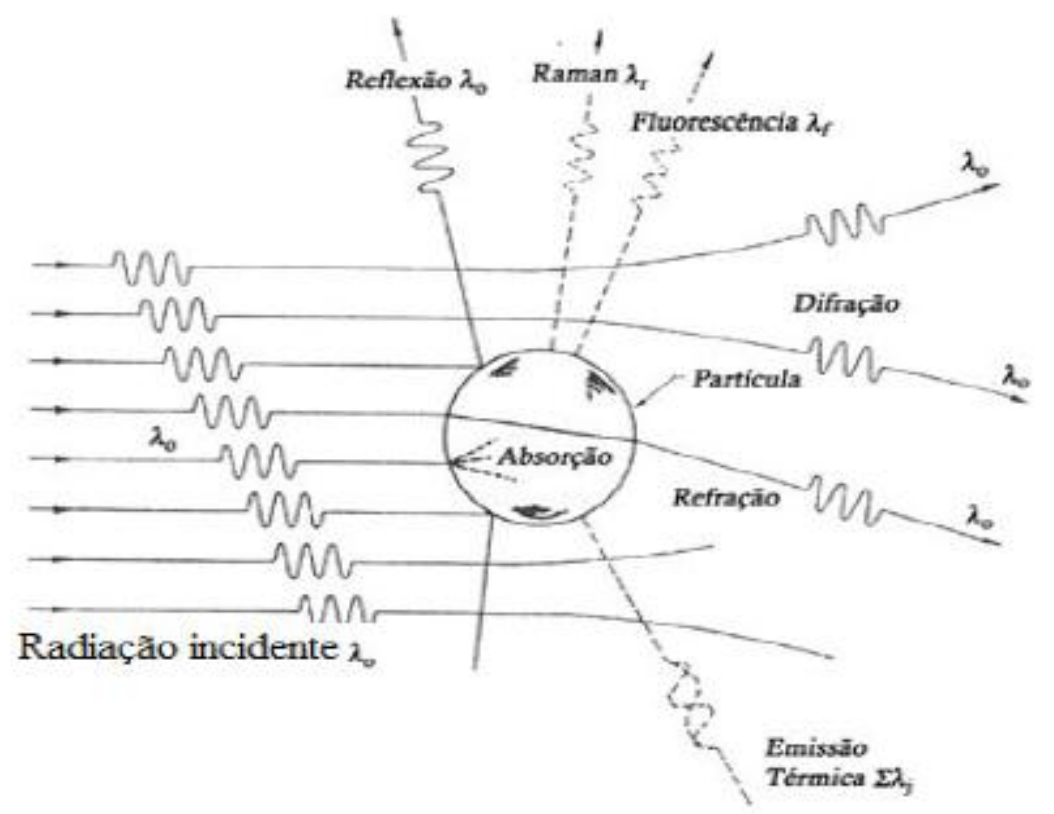

Figura 2.4 - Esquema representativo das interações entre um feixe de radiação incidente sobre uma partícula em suspensão na atmosfera. Adaptado de Seinfeld e Pandis, (1998).

A absorção e o espalhamento de radiação por uma partícula geralmente são quantificados pelas seções de choque de absorção $\left(\sigma_{a b s}\right)$ e de espalhamento $\left(\sigma_{e s p}\right)$. A seção de choque de extinção $\left(\sigma_{\text {ext }}\right)$ é definida como:

$$
\sigma_{e x t}=\sigma_{a b s}+\sigma_{e s p}
$$

A eficiência de extinção será dada pela razão da seção de choque de extinção e a área geométrica (A) da partícula (analogamente, obtêm-se a eficiência de absorção, $Q_{a b s}$, e de espalhamento, $\left.Q_{e s p}\right)$

$$
Q_{\text {ext }}=\frac{\sigma_{\text {ext }}}{A}
$$

Uma propriedade radiativa muito utilizada para quantificar quanto da radiação atenuada sofreu espalhamento é o albedo simples $(\omega)$. Ele pode ser expresso a partir da eficiência de extinção: 


$$
\omega=\frac{Q_{e s p}}{Q_{e x t}}=\frac{\sigma_{e s p}}{\sigma_{e x t}}
$$

Logo a fração da radiação extinta que é espalhada será $\omega$ e a fração absorvida será $1-\omega$.

O tamanho e a forma da partícula, junto com o comprimento de onda da radiação incidente e o índice de refração complexo, são os principais parâmetros que regem o espalhamento e a absorção da radiação por partículas. O tamanho da partícula geralmente é expresso pelo parâmetro de tamanho, que, para partículas esféricas é dada por

$$
\chi=\frac{2 \pi r}{\lambda}
$$

Onde r é o raio da partícula. Baseado no valor de $\chi$, o espalhamento pode ser dividido em diferentes regimes: para valores de $\chi \ll 1$, espalhamento Rayleigh; para $\chi \approx 1$, espalhamento Mie e para $\chi \gg 1$, espalhamento geométrico.

No espalhamento Rayleigh (partículas muito menores que o comprimento de onda da radiação incidente), a radiação monocromática será espalhada de forma proporcional nas direções frontal e traseira. Já no espalhamento Mie, a maior parte da radiação é espalhada no sentido de propagação do feixe (figura 2.5).

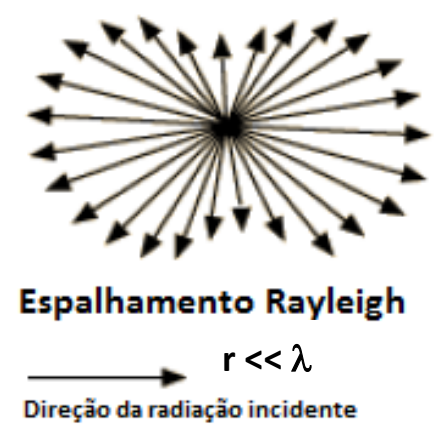

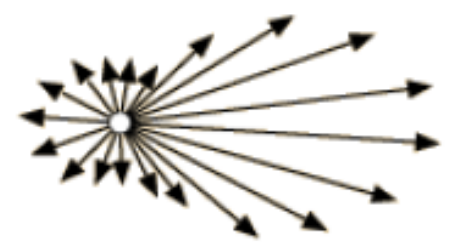

Espalhamento Mie $r \sim \lambda$

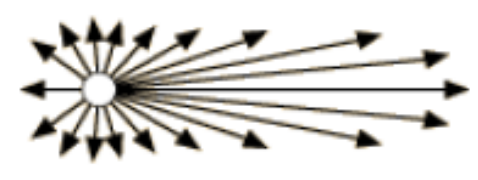

Espalhamento Mie para partículas muito grandes $r>\lambda$

Figura 2.5 - Espalhamento da radiação eletromagnética por uma partícula. (Fonte: disponível em http://hyperphysics.phy-astr.gsu.edu/hbase/atmos/blusky.html. Acesso em abril de 2012)

O índice de refração complexo $(\mathrm{N})$ reflete a composição química da partícula. A parte real $\left(n_{r e}\right)$ representa os processos de espalhamento e a parte imaginária $\left(n_{i m}\right)$ a absorção.

$$
N=n_{r e}+i n_{i m}
$$

Uma partícula com um índice de refração puramente real espalha a luz, mas não a absorve (Moosmüller et al., 2009). 
Conforme ilustrado na Figura 2.5, a direção para a qual a radiação será espalhada também apresenta uma dependência em relação ao tamanho da partícula. Para descrever a dependência angular da radiação espalhada pela partícula é utilizada a função de fase, $\mathrm{P}(\cos \Theta)$, onde $\Theta$ corresponde ao ângulo formado entre o feixe incidente e o emergente. Valores de $\Theta=0^{\circ}$ correspondem ao espalhamento frontal (feixe espalhado no mesmo sentido de incidência) e valores de $\Theta=180^{\circ}$ correspondem ao retroespalhamento (ou seja, o feixe é espalhado no sentido oposto ao de incidência). A função de fase é normalizada para que a probabilidade do espalhamento seja 1, e é dada por (Liou, 2002):

$$
\int_{0}^{2 \pi} \int_{0}^{\pi} \frac{P(\cos \Theta)}{4 \pi} \operatorname{sen} \Theta d \Theta d \varphi=1
$$

O parâmetro de assimetria $\left(g_{\lambda}\right)$ é uma grandeza derivada diretamente da função de fase, e é um importante parâmetro na avaliação da radiação espalhada por uma partícula. Ele representa o cosseno médio do ângulo de espalhamento, ponderado pela função de fase:

$$
g_{\lambda}=\frac{1}{2} \int_{-1}^{1} P(\cos \Theta) \cos \Theta d(\cos \Theta)
$$

O parâmetro de assimetria varia entre -1 e 1, sendo negativo nos casos em que predomina o retro-espalhamento e positivo quando predomina o pro - espalhamento. Quando $g_{\lambda}=0$, o espalhamento é simétrico.

\section{$\underline{\text { Teoria Mie }}$}

A teoria Mie é utilizada para descrever matematicamente a absorção e o espalhamento da radiação eletromagnética por partículas esféricas homogêneas. Os valores da eficiência de extinção e de espalhamento neste caso são dados por (Liou, 2002):

$$
\begin{gathered}
Q_{\text {ext }}=\frac{2}{\chi^{2}} \sum_{i=1}^{\infty}(2 i+1) \operatorname{Re}\left(a_{i}+b_{i}\right) \\
Q_{e s p}=\frac{2}{\chi^{2}} \sum_{i=1}^{\infty}(2 i+1)\left(\left|a_{i}\right|^{2}+\left|b_{i}\right|^{2}\right)
\end{gathered}
$$

Onde $a_{i} e b_{i}$ são parâmetros obtidos pela teoria Mie e $\chi$ é o parâmetro de tamanho. 


\subsubsection{Lei de Beer - Bouguer - Lambert}

Um feixe direto de radiação será atenuado ao interagir com um volume de matéria opticamente ativo. Admitindo que a irradiância monocromática que ingressa é $\mathrm{E}_{\mathrm{DN} \lambda} \mathrm{e}$ após atravessar um meio com espessura ds, a irradiância que sai é $\mathrm{E}_{\mathrm{DN} \lambda}+\mathrm{d} \mathrm{E}_{\mathrm{DN} \lambda}$, a atenuação da radiação será dada por:

$$
\mathrm{dE}_{\mathrm{DN} \lambda}=-k_{\lambda} \mathrm{E}_{\mathrm{DN} \lambda} d s
$$

onde $k_{\lambda}$ é o coeficiente de extinção.

Se o feixe incidente é $E_{0, \lambda}$, a radiação emergente a uma distância s pode ser obtida através da integração da equação (2.13) e será dada por

$$
\mathrm{E}_{\mathrm{DN} \lambda}=\mathrm{E}_{0, \lambda} \cdot \exp \left(-\int_{0}^{s} k_{\lambda} d s\right)
$$

Considerando a geometria da atmosfera terrestre, ds pode ser definido em termos do comprimento vertical dz e do ângulo zenital solar $\theta$ (figura 2.6).

$$
d s=\frac{d z}{\cos \theta}=d z \cdot m
$$

Logo a equação (2.16) pode ser reescrita na forma

$$
\mathrm{E}_{\mathrm{DN} \lambda}=\mathrm{E}_{0, \lambda} \cdot \exp \left(-m \int_{0}^{z} k_{\lambda} d z\right)
$$

A profundidade óptica $\tau$ é definida como a integral do coeficiente de extinção ao longo do caminho perpendicular ao plano horizontal, logo

$$
\tau=-\int_{0}^{z} k_{\lambda} d z
$$

Portanto

$$
\mathrm{E}_{\mathrm{DN} \lambda}=\mathrm{E}_{0, \lambda} \cdot \exp (-\tau \cdot m)
$$

A equação (2.18) é conhecida como a Lei de Beer - Bouguer - Lambert, ou simplesmente a Lei de Beer. 


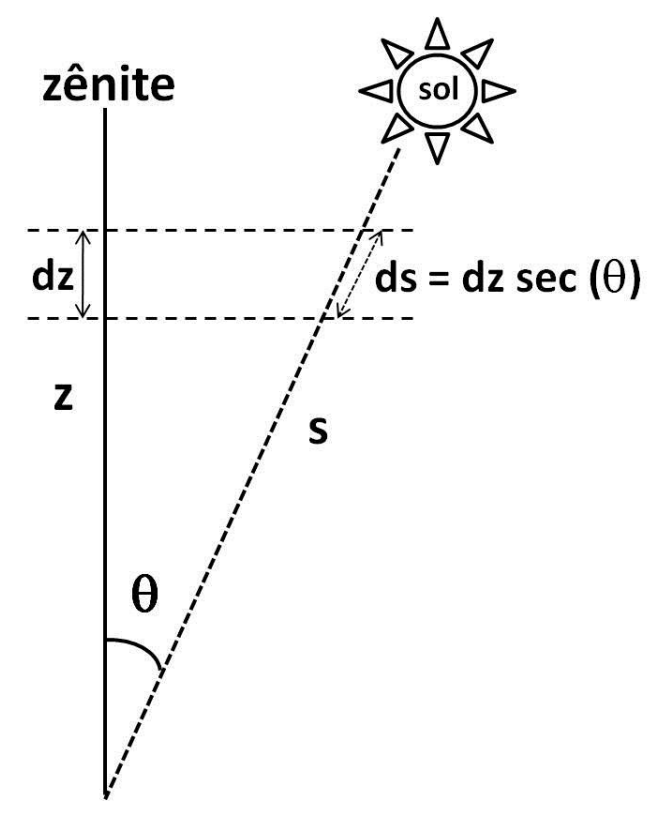

Figura 2.6 - Geometria da atenuação da radiação solar pela atmosfera. O ângulo formado entre a posição do sol e o zênite é denominado de ângulo zenital solar. Considerando uma aproximação plano-paralela da atmosfera, a massa de ar óptica atravessada pelo feixe de radiação é dada por $m=\frac{1}{\cos \theta}$.

\subsubsection{Coeficiente de Ångström}

A fórmula de turbidez de Ångström para o coeficiente de atenuação espectral devido à presença de aerossóis é dada por (Ångström, 1929 e 1930):

$$
\tau_{\lambda}=\frac{\beta}{\lambda^{\alpha}}
$$

onde $\tau_{\lambda}$ é o coeficiente de atenuação monocromática do aerossol, também chamada de profundidade óptica do aerossol (AOD), $\beta$ é o coeficiente de turbidez e $\alpha$ é o coeficiente de Ångström. Para $\lambda$ igual a $1 \mu \mathrm{m}, \beta$ é equivalente à AOD neste comprimento de onda.

O coeficiente de Ångström está relacionado com a distribuição do tamanho das partículas: altos valores de $\alpha$ indicam a presença majoritária de partículas de moda fina; valores de $\alpha$ próximos de zero indicam o predomínio de partículas grandes. A partir da AOD obtida em dois comprimentos de onda diferentes é possível obter $\alpha$ através da seguinte expressão:

$$
\alpha\left(\lambda_{1}, \lambda_{2}\right)=-\frac{\ln \left({ }^{\tau_{\lambda_{1}}} / \tau_{\lambda_{2}}\right)}{\ln \left({ }^{\lambda_{1}} / \lambda_{2}\right)}
$$


Capítulo 3: Materiais e Métodos 


\subsection{Reserva Biológica do Jaru}

O sítio experimental está localizado dentro da unidade de preservação biológica da Reserva Biológica do Jaru (Figura 3.1), doravante denominada Rebio Jaru ao longo deste trabalho $\left(-10,145^{\circ},-61,908^{\circ}\right)$, na parte sudoeste da Amazônia (Andreae et al., 2002). O clima da região é marcado por duas estações distintas, uma estação chuvosa de outubro a abril e uma estação seca de maio a setembro. Durante a estação chuvosa, as condições atmosféricas são favoráveis à rápida remoção dos aerossóis, porém na estação seca grande parte da Bacia Amazônia se torna um dos lugares mais poluídos do planeta (Artaxo et al., 2002).

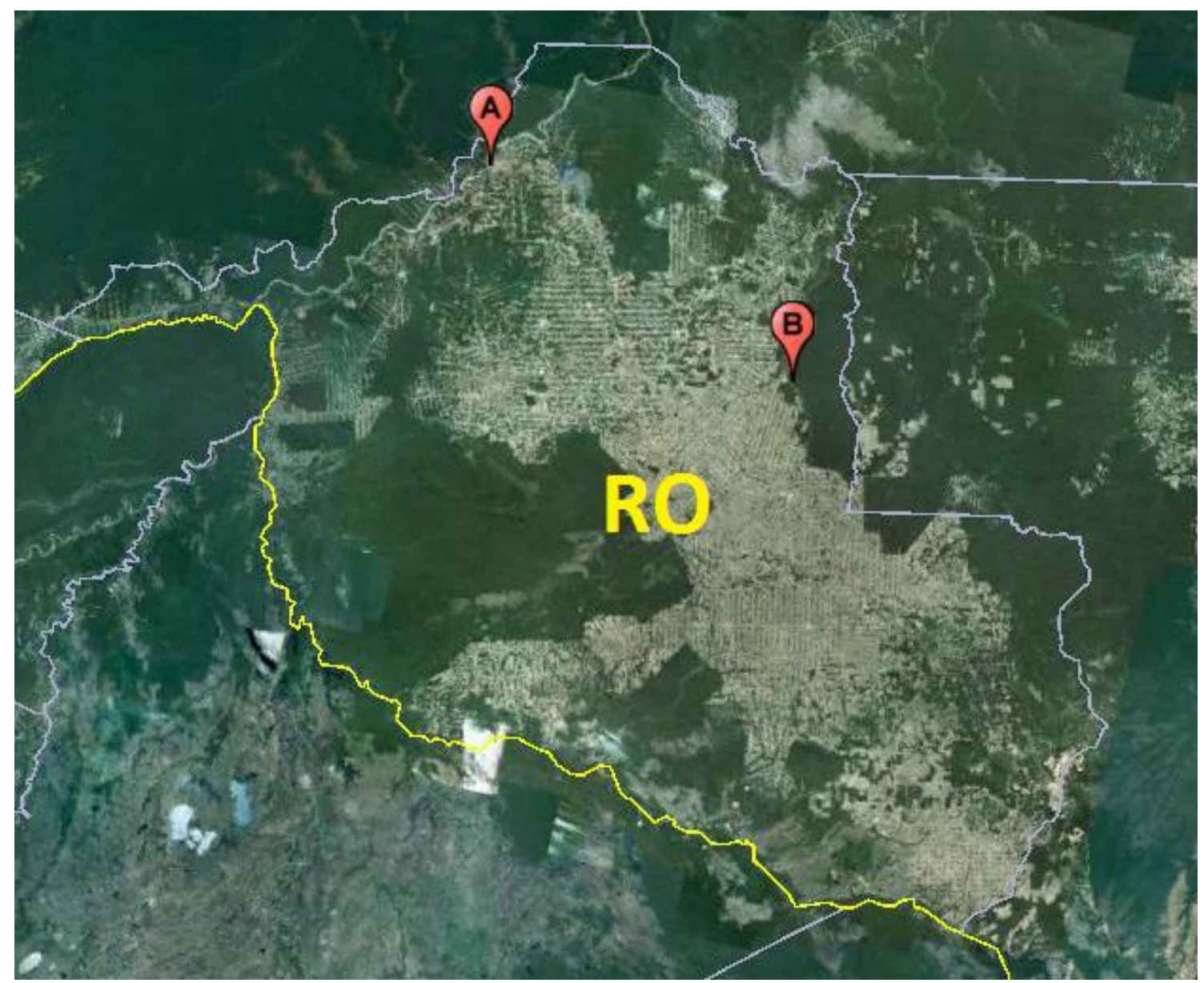

Figura 3.1 - Imagem de satélite do estado de Rondônia, região de interesse onde estão demarcados a capital, Porto Velho (A) e a Reserva Biológica do Jaru (B). 
Artaxo et al. (2002) compararam as propriedades físicas e químicas dos aerossóis coletados durante dois programas de medições intensivas do experimento de Larga Escala da Biosfera-Atmosfera na Amazônia (Large_Scale Biosphere-Atmosphere Experiment in Amazonia - LBA) ocorridos em 1999, um durante a estação seca e o outro na estação chuvosa na Rebio Jaru. As medidas foram feitas em três níveis diferentes da torre localizada no sítio experimental, com o intuito de analisar a deposição e gradientes dentro do dossel. Pelos gráficos da figura 3.2, podemos observar que durante a temporada úmida o aerossol de moda grossa é o que predomina na região, com os picos de concentração de massa inferiores a $14 \mu \mathrm{g} \mathrm{m}^{-3}$. Já a concentração de aerossóis de moda fina não ultrapassa o valor de $7 \mu \mathrm{g} \mathrm{m}^{-3}$. Comparado a essas condições, existe um grande contraste na estação seca, quando ocorre um grande número de eventos de queima de biomassa. Os valores de concentração são aproximadamente 10 vezes maiores, com picos de concentração próximos a $100 \mu \mathrm{g} \mathrm{m}^{-3}$, sendo que os valores observados da concentração de aerossóis de ambas as modas são bem próximos. Como um dos efeitos associados a essa diferença observada entre as estações úmida e seca, o balanço de energia regional é alterado por causa da alta concentração de partículas (Martin et al., 2010). 
(i)

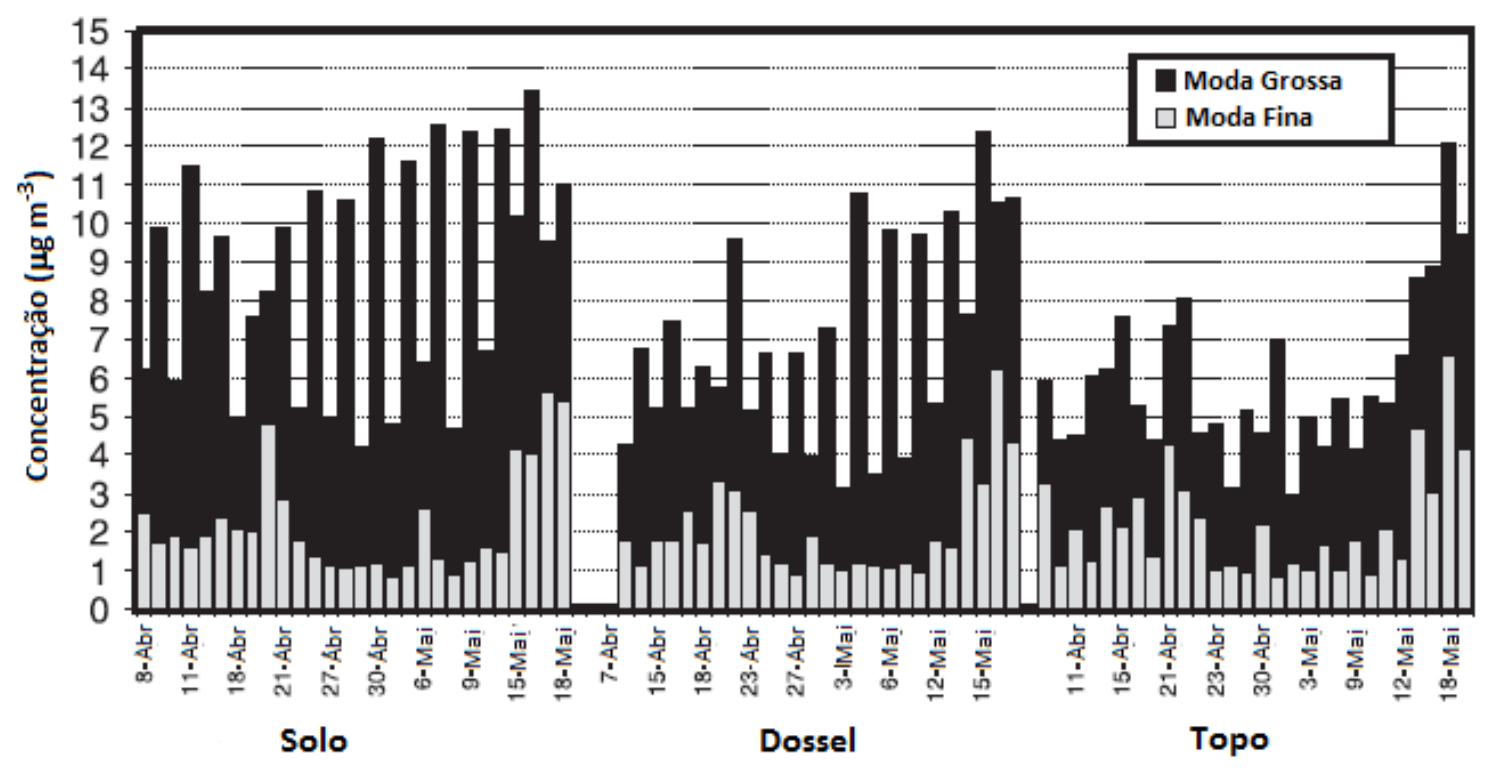

(ii)

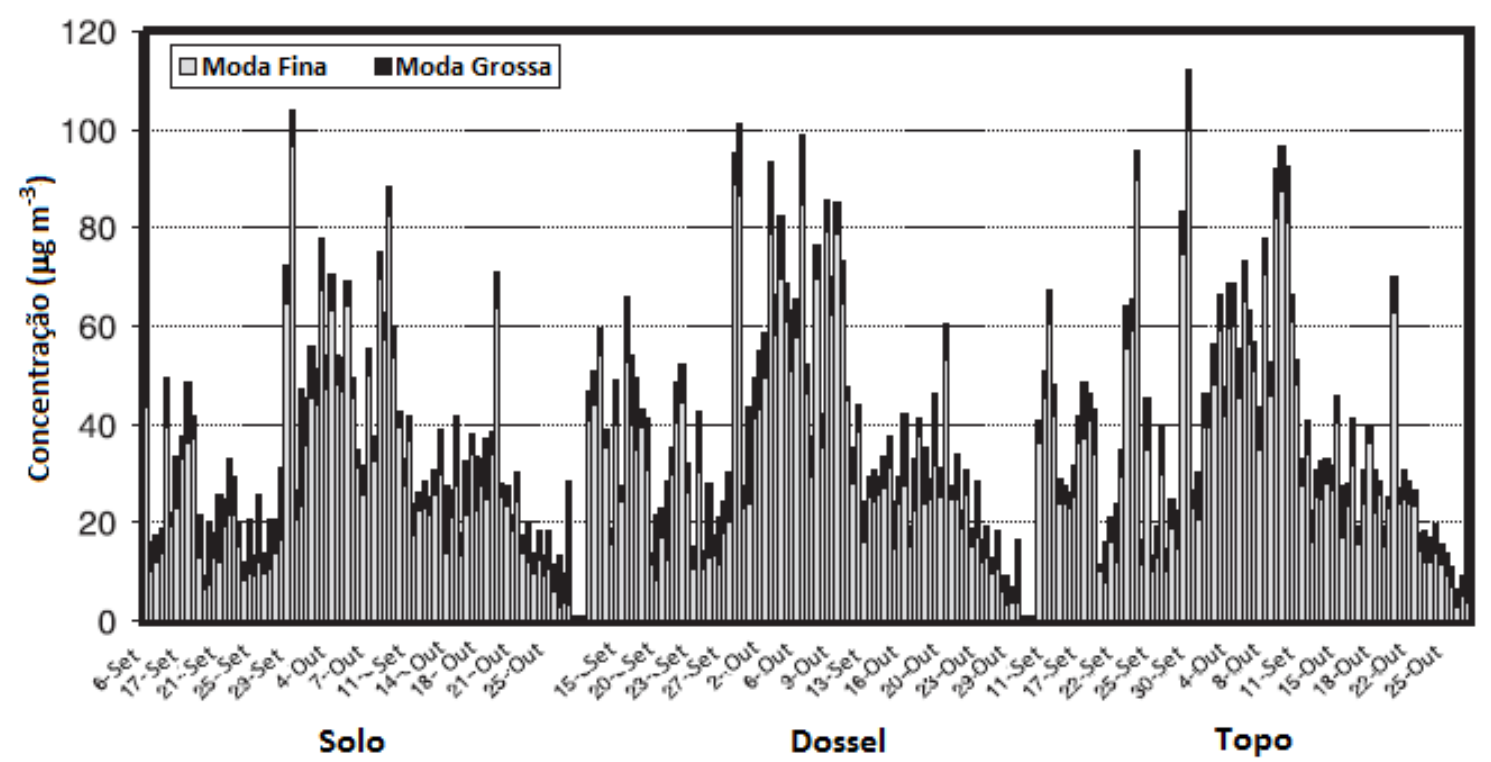

Figura 3.2 - Concentração de massa do aerossol na Rebio Jaru durante a temporada úmida (i) e a temporada seca (ii) de 1999 medida em três níveis diferentes da torre localizada no sítio experimental. (Adaptado de Artaxo et al. 2002) 


\subsection{Radiômetros}

\subsubsection{Multifilter Rotating Shadowband Radiometer (MFRSR)}

O MFRSR é um radiômetro multi-espectral que usa detectores independentes para fazer medidas nos canais espectrais de 415, 670, 870 e $1036 \mathrm{~nm}$ (com largura de 10nm), utilizados para estimar a AOD nesses comprimentos de onda e dois canais de $940 \mathrm{~nm}$ (um com largura de 10nm e outro com largura de $35 \mathrm{~nm}$, utilizados em estimativas de conteúdo de vapor d'água integrado na coluna atmosférica, Plana-Fattori et al, 2004) (Harrison et al., 1994). Além dessas bandas estreitas, o instrumento também possui um canal de banda larga de 350 a $1100 \mathrm{~nm}$. A geometria básica do MFRSR é apresentada na figura 3.3. O mecanismo permite um simples ajuste mecânico para a latitude. O detector fica localizado na parte superior do instrumento.

(a)

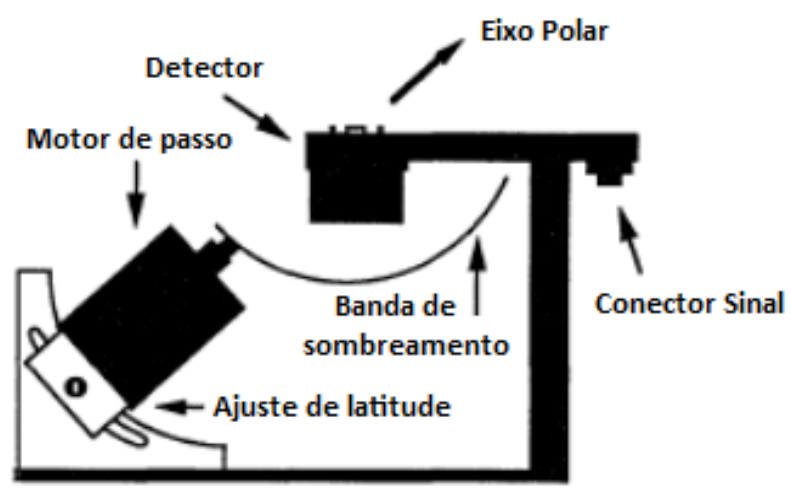

(b)

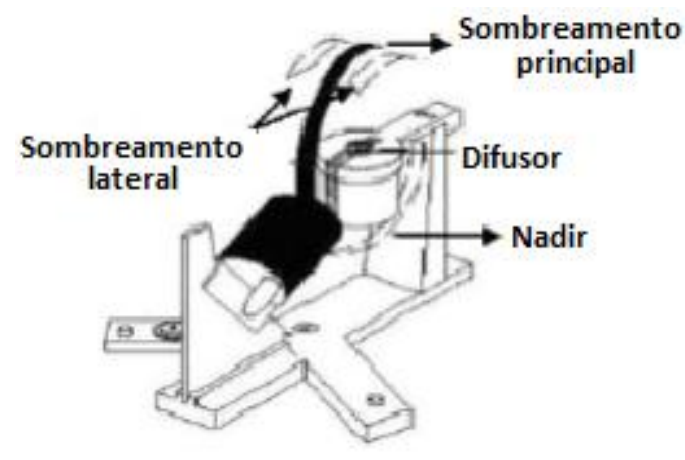

Figura 3.3 - Configurações do MFRSR. (a) Principais componentes, (b) Geometria de sombreamento. (Adaptado de Harrison et al., 1994)

É usada uma técnica de banda de sombreamento para se obter as irradiâncias direta-normal, solar global e solar difusa a cada minuto. A irradiância solar global é medida enquanto a banda está no nadir. A irradiância solar difusa é obtida a partir de três medidas em sequência. A banda é girada tal que a posição central bloqueia o Sol (a posição da banda de sombreamento é controlada por um microprocessador, com uma acurácia de $0,4^{\circ}$ ) e as outras duas medições são realizadas em cada um dos lados da posição central, respeitando um deslocamento de $9^{\circ}$. Essas medidas laterais são necessárias para corrigir o excesso de céu bloqueado pela posição central (Harrison et al., 1994). O valor médio das duas medições laterais é subtraído da irradiância solar global e o resultado é então adicionado à medição feita com a banda na posição central 
para fornecer a irradiância solar difusa. A irradiância direta-normal ( $\left.E_{\text {Dir-Nor }}\right)$ é calculada através da subtração entre a irradiância solar global e a irradiância solar difusa $\left(E_{D i f}\right)$. Essa técnica é baseada no fato de que a irradiância global ( $E_{\text {Global }}$ ) é a combinação dos componentes direto e difuso:

$$
E_{\text {Global }}=E_{\text {Dif }}+\cos (\theta) E_{\text {Dir-Nor }}
$$

lembrando que $\theta$ é o ângulo zenital solar.

\subsubsection{Sensor PAR SKE 510 - SKYE}

O sensor deste instrumento mede a Radiação Fotossinteticamente Ativa (PAR) compreendida no intervalo espectral entre 400 e 700nm. O modelo SKE 510, fabricado pelo SKYE, foi utilizado para as medições da PAR. Segundo as especificações do fabricante, o erro absoluto de calibração do sensor é tipicamente menor do que $3 \%$ da leitura, mas pode alcançar um erro máximo de $5 \%$ da leitura.

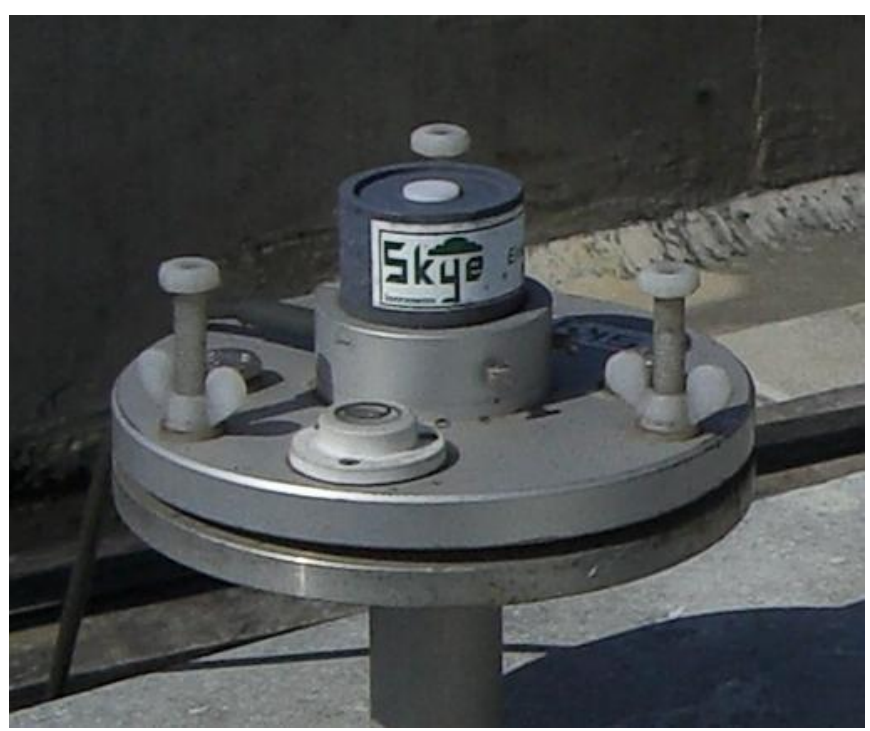

Figura 3.4 - Foto ilustrativa do Sensor PAR (foto: Eduardo Fernandes Gomes, Técnico do Laboratório de Radiação e Aerossóis Atmosféricos do Departamento de Ciências Atmosféricas do Instituto de Astronomia, Geofísica e Ciências Atmosféricas da Universidade de São Paulo). 


\subsubsection{Piranômetro CM 21/31}

Utilizado para medir a irradiância solar global total descendente em superfície $\left(\mathrm{Wm}^{-2}\right)$. O modelo utilizado é fabricado pela Kipp \& Zonen CM21. O instrumento é constituído de um detector termal, que responde à energia total absorvida. Teoricamente este detector demonstra uma não-seletividade à distribuição espectral da radiação solar total, mas é sensível quando exposto ao ambiente externo à radiação infravermelha de onda longa. Por isso o sensor fica protegido por uma cúpula de quartzo, que limita o intervalo espectral a $50 \%$ dos pontos entre 305 e $2.800 \mathrm{~nm}$ e $95 \%$ dos pontos entre 335 e $2.200 \mathrm{~nm}$.

\subsection{Calibração do MFRSR - Determinação da Constante Solar}

Com o objetivo de se familiarizar com o instrumento, foi realizada no período de julho e agosto de 2010 uma campanha experimental para a aferição da calibração do MFRSR no Observatório do Pico dos Dias do Laboratório Nacional de Astronomia (OPD-LNA), localizado entre os munícipios mineiros de Brazópolis e Piranguçu, a $1864 \mathrm{~m}$ de altitude, $900 \mathrm{~m}$ acima do nível médio da região.

A calibração deve ser feita constantemente, como para qualquer outro equipamento científico. Existem algumas formas para a calibração do instrumento como, por exemplo, comparar os dados obtidos com o MFRSR com dados de um instrumento de referência. Outra forma seria enviá-lo ao laboratório de origem (neste caso, localizado nos Estados Unidos), porém este procedimento envolve problemas de ordem burocrática e de tempo. Neste trabalho, o método de Langley foi escolhido para a aferição da calibração dos canais de banda estreita, já que dessa forma não é necessário o envio ao fabricante ou a presença de um instrumento de referência.

\subsubsection{Calibração do MFRSR pelo Método de Langley}

O método de Langley foi criado por Samuel P. Langley do Smithsonian Institution com o intuito de determinar a constante solar no início do século XX (Johnson, 1954). Em seu trabalho, Langley observou que é possível aplicar uma linearização a partir da Lei de Beer para obter uma estimativa da irradiância no topo da atmosfera e da profundidade óptica total. Linearizando a equação (2.18) aplicando-se o logaritmo natural, obtemos

$$
\ln \left(\mathrm{E}_{\lambda}\right)=\ln \left(\mathrm{E}_{\lambda 0}\right)-\tau_{\lambda} m
$$


Desta forma, dispondo-se de um conjunto de medidas de irradiância monocromática para um intervalo de valores de massa de ar óptica, podemos extrapolar as medidas para encontrarmos a irradiância espectral incidente no topo da atmosfera.

Para que este método possa ser aplicado algumas hipóteses devem ser levadas em consideração e também existem certas restrições às condições em que ele deve ser aplicado. O método requer que durante as medições a atmosfera seja estável e horizontalmente homogênea para diferentes ângulos de elevação, condição difícil de ser alcançada em centros urbanos. Dessa forma, Shaw (1983) sugeriu que a calibração seja feita em regiões com altitude mais elevada e longe de fontes de poluição, como é o caso do OPD-LNA.

\subsection{Cálculo da Profundidade Óptica Espectral do Aerossol com as medidas do MFRSR}

Neste trabalho os valores de profundidade óptica do aerossol foram estimados por Rosário et al. (2009). Basicamente, a partir da Lei de Beer é possível obter a profundidade óptica do aerossol para os canais de 415, 670, 870 e $1036 \mathrm{~nm}$ do MFRSR na ausência de nuvens. Os canais espectrais do MFRSR sofrem atenuação basicamente devido ao espalhamento molecular, pela absorção gasosa $\left(\mathrm{O}_{3}\right.$ no canal de $670 \mathrm{~nm}$ e $\mathrm{NO}_{2}$ em $415 \mathrm{~nm}$ ) e pela atenuação devido a presença de aerossóis na atmosfera (Alexandrov et al., 2002).

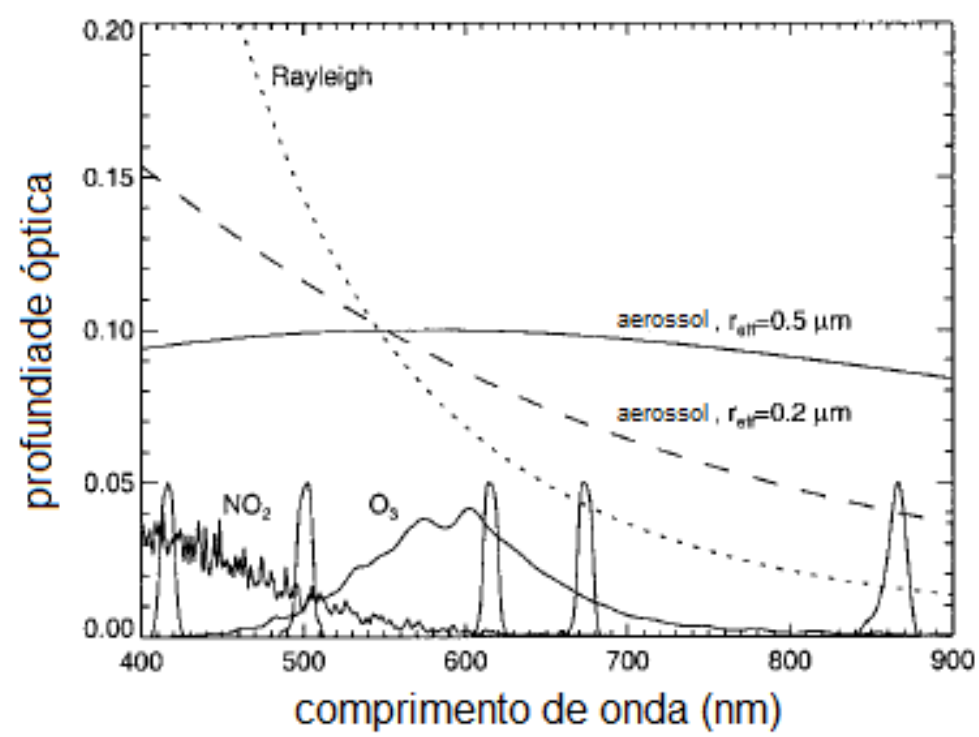

Figura 3.5 - Profundidades ópticas típicas dos constituintes atmosféricos que afetam os canais espectrais do MFRSR padrão: Rayleigh (pressão de 1013,25 mb); aerossóis com raio efetivo ( $\mathrm{r}_{\text {eff }}$, é o raio médio dos aerossóis ponderado pela área analisada) igual a 0,2 e 0,5 $\mu \mathrm{m}$ e $\mathrm{AOD}=$ 0,1 em $550 \mathrm{~nm}$; conteúdo de $\mathrm{NO}_{2}=2$ D.U. e $\mathrm{O}_{3}=300$ D.U. (Fonte Alexandrov et al., 2002) 
Logo, a profundidade óptica do aerossol utilizando a lei de Beer será expressa por:

$$
\tau_{a, \lambda}=\left[\ln \left(\frac{E_{0, \lambda}}{R^{2} E_{D N, \lambda}}\right)\right] / m_{a}-\frac{m_{m}}{m_{a}} \tau_{m, \lambda}-\frac{m_{O_{3}}}{m_{a}} \tau_{O_{3}, \lambda}-\frac{m_{N O_{2}}}{m_{a}} \tau_{N O_{2}, \lambda}
$$

Onde R é a correção devido à variação da distância Terra-Sol e é dada pela razão entre a distância média e a distância no dia de interesse.

A correção da atenuação molecular $\left(\tau_{m, \lambda}\right)$ foi realizada utilizando a fórmula da profundidade óptica molecular proposta por Hansen e Travis (1974) (equação 2.3). A correção para o efeito do ozônio foi feita utilizando a profundidade óptica do ozônio $\left(\tau_{O_{3}, \lambda}\right)$ estimada por Rosário et al. (2009) a partir do conteúdo médio de ozônio integrado na coluna de 257 D.U. (do inglês Dobson Unit) no sul da Bacia Amazônica. Essa correção é feita apenas para o canal de $670 \mathrm{~nm}$, que se localiza na banda de Chappuis e, portanto, sofre atenuação mensurável pelo ozônio.

Pelo gráfico da figura 3.3 pode-se observar que o canal de $415 \mathrm{~nm}$ sofre influência do $\mathrm{NO}_{2}$, porém a contribuição deste $\left(\tau_{\mathrm{NO}_{2}, \lambda}\right)$ tem sido negligenciada (Hansell et al., 2003); além do que a ausência de medições do seu conteúdo integrado dificulta estabelecer um valor confiável para a região de interesse.

As massas ópticas relativas molecular $\left(\mathrm{m}_{\mathrm{m}}\right)$ e do ozônio $\left(\mathrm{m}_{\mathrm{O} 3}\right)$ foram obtidas a partir das equações propostas por Kasten e Young (1989) e Staehelin et al. (1995). Como a distribuição vertical do aerossol não é conhecida previamente, a massa óptica relativa do aerossol $\left(\mathrm{m}_{\mathrm{a}}\right)$ foi aproximada pela massa óptica molecular. Quando é considerada esta aproximação, o erro médio cometido é de 0,3\%, segundo Schmid e Werhli (1995). A equação que corrige a irradiância solar extraterrestre devido ao ciclo anual da distância Terra-Sol foi obtida de Iqbal (1983).

Pela teoria de propagação de erros, a incerteza no valor da AOD considerando a equação 3.3 será dada por:

$$
\begin{gathered}
\sigma\left(\tau_{a, \lambda}\right)=\left\{\left[\frac{1}{m_{a}} \frac{\sigma\left(I_{0, \lambda}\right)}{I_{0, \lambda}}\right]^{2}+\left[\frac{1}{m_{a}} \frac{\sigma\left(I_{D N, \lambda}\right)}{I_{D N, \lambda}}\right]^{2}+\left[\frac{m_{m}}{m_{a}} \sigma\left(\tau_{m, \lambda}\right)\right]^{2}+\left[\frac{m_{O_{3}}}{m_{a}} \sigma\left(\tau_{O_{3}, \lambda}\right)\right]^{2}+\right. \\
\left.\left[\tau_{a, \lambda} \frac{\sigma\left(m_{a}\right)}{m_{a}}\right]^{2}+\left[\tau_{m, \lambda} \frac{\sigma\left(m_{m}\right)}{m_{a}}\right]^{2}+\left[\tau_{O_{3}} \frac{\sigma\left(m_{O_{3}}\right)}{m_{a}}\right]^{2}\right\}^{1 / 2}
\end{gathered}
$$




\subsection{Modelos Ópticos para o Aerossol de Queimadas na Amazônia}

Os modelos ópticos utilizados neste trabalho propostos por Rosário (2011), foram obtidos a partir da base de dados da AERONET para três sítios experimentais localizados na região sul da Bacia Amazônica: Alta Floresta, Abracos Hill e Rio Branco (figura 3.6). Essas estações estão localizadas dentro da região definida como arco de desflorestamento da floresta Amazônica, que sofre grande influência das queimadas utilizadas para o manejo do solo associado à pecuária e a agricultura.

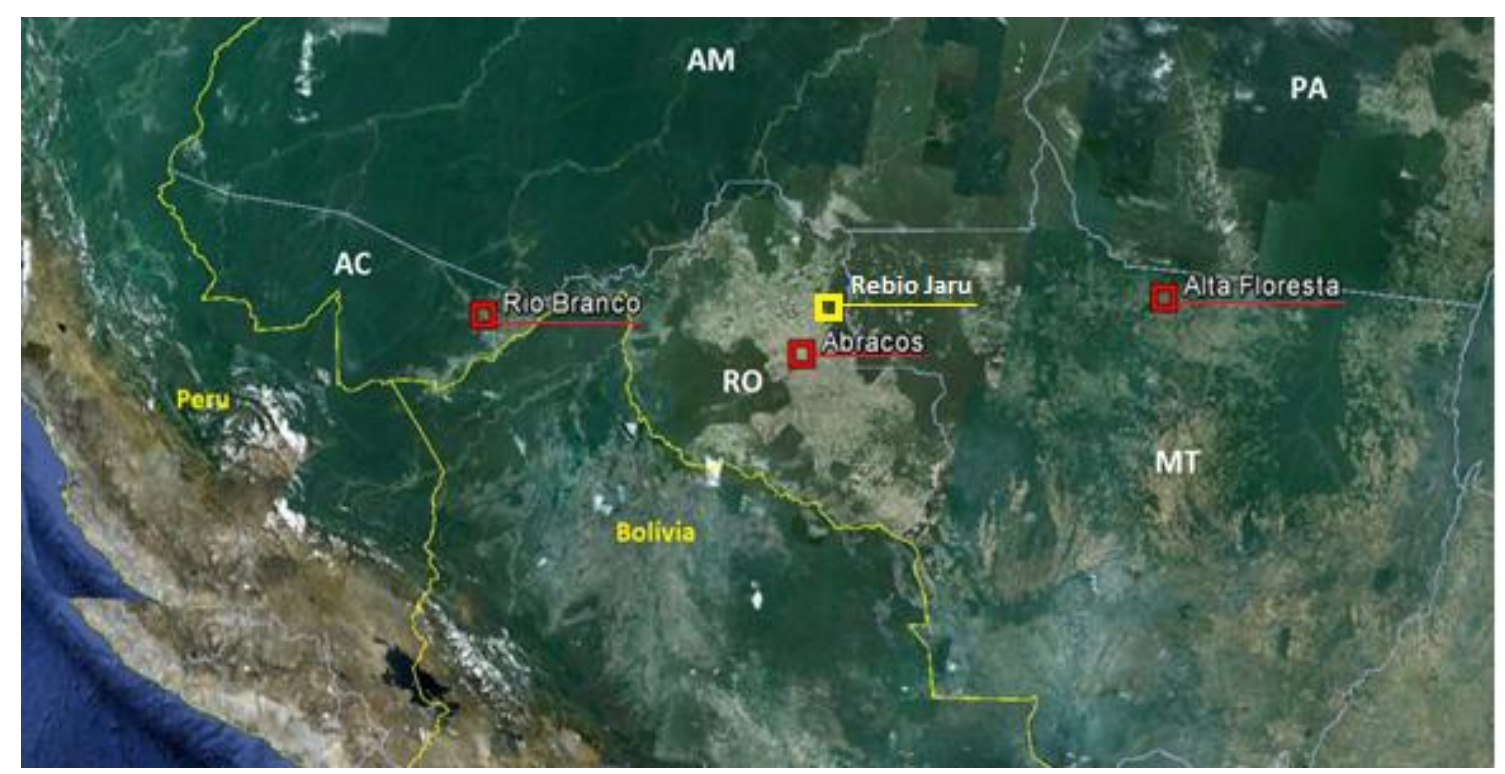

Figura 3.6 - Localização das estações da AERONET utilizadas por Rosário (2011) para o desenvolvimento dos modelos ópticos do aerossol de queimadas para o sul da Bacia Amazônica.

A partir de métodos de agrupamento, também chamados de clustering, é possível classificar, com base em um conjunto finito multidimensional de informações, seus elementos em grupos restritos e homogêneos internamente. A metodologia de clustering escolhida por Rosário (2011) foi a Partion Around Medoid (PAM, Kaufman e Rousseeuw, 1990), que tem como objetivo encontrar um número de objetos representativos que irá minimizar a soma das dissimilaridades das observações com relação ao objeto representativo mais próximo. Os dados de entrada utilizados no algoritmo de clustering foram o albedo simples $(\omega)$ e parâmetro de assimetria nas regiões espectrais do visível $(\lambda=440,670 \mathrm{~nm})$ e infravermelho próximo $(\lambda=870,1020$ $\mathrm{nm}$ ), e a dependência espectral desses parâmetros, através da razão das diferenças dos valores das propriedades ópticas e a diferença dos comprimentos de onda. A partir de sucessivas aplicações do algoritmo de clustering, 3 foi o número ótimo de clusters encontrados para as estações localizadas no Sul da Bacia Amazônica (Rosário, 2011). 
Utilizando a distribuição de tamanho e o índice de refração complexo médio de cada cluster como dados de entrada no código Mie, calcularam-se também o albedo simples, o parâmetro de assimetria e o fator de eficiência de extinção com maior resolução espectral.

O albedo simples é a propriedade radiativa que melhor evidencia as diferenças entre os regimes de aerossóis, por isso foi escolhido para distinguir os regimes obtidos. Eles são identificados conforme os valores de $\omega$ : o primeiro regime representa o cenário com o aerossol mais espalhador, o segundo por aerossóis moderadamente absorvedores e o último por aerossóis mais absorvedores de radiação.

Neste trabalho foram utilizados os regimes espalhador (R1) e absorvedor de Abracos Hill (R2), devido à proximidade da Rebio Jaru, e também um regime de referência (RR), definido como a média dos valores das propriedades ópticas das três estações.

(a)

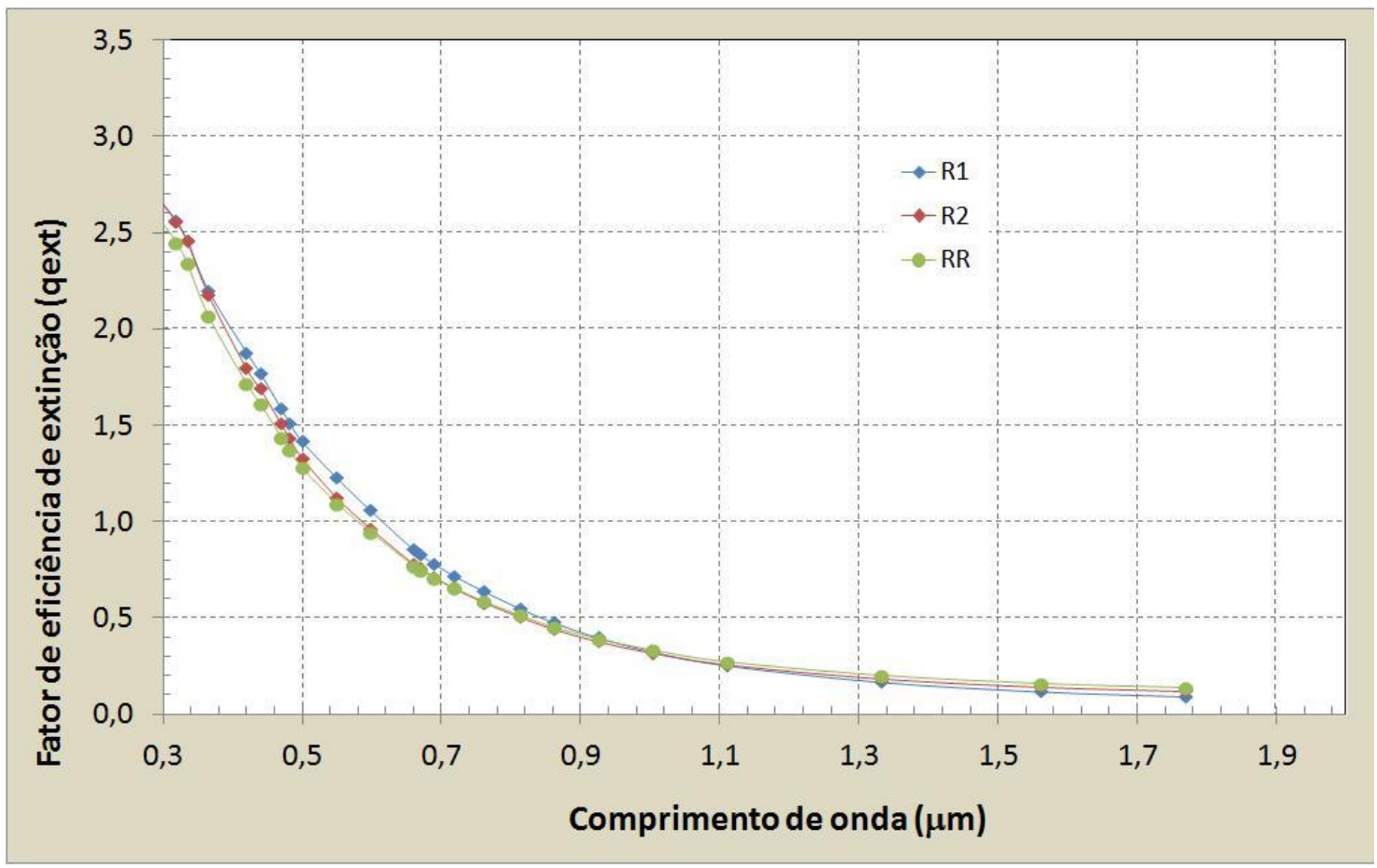


(b)

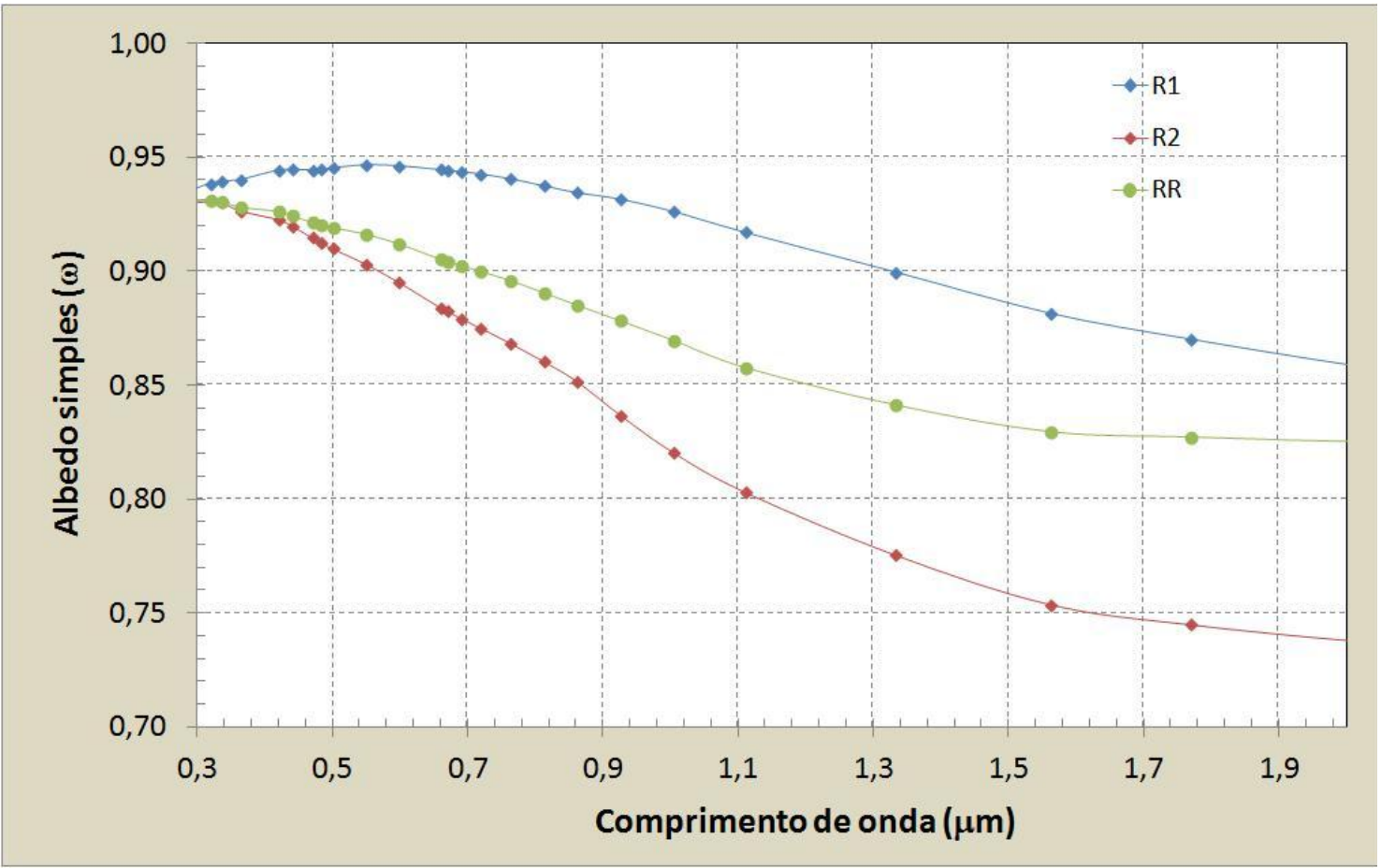

(c)

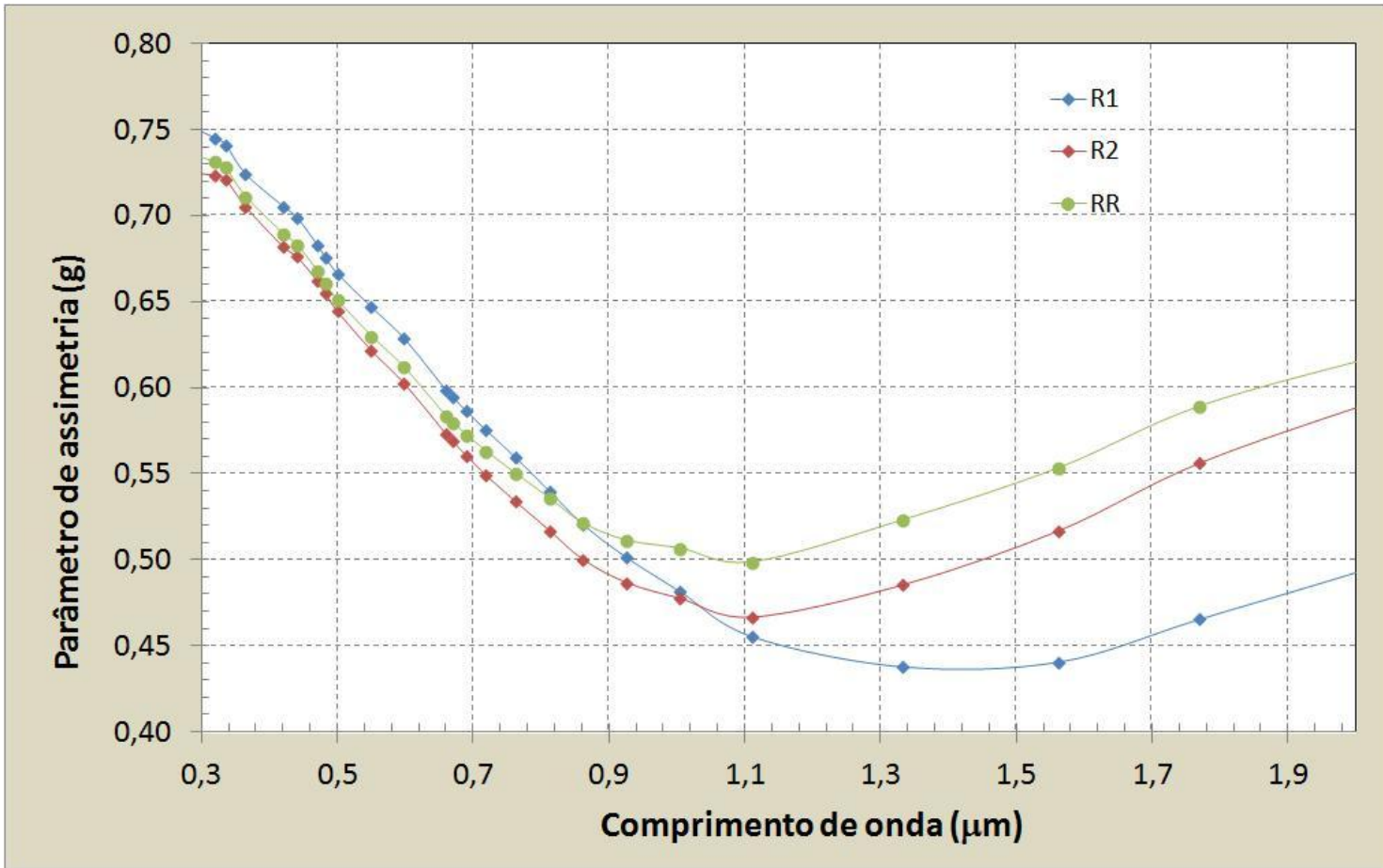

Figura 3.7 - Comparação entre o fator de eficiência de extinção (a), o albedo simples (b) e o parâmetro de assimetria (c) dos modelos ópticos propostos por Rosário (2011) para o aerossol de queimadas na Amazônia. 


\subsection{Santa Barbara Disort Radiative Transfer - SBDART}

O SBDART (Santa Barbara DISORT Atmospheric Radiative Transfer) é um código computacional de transferência radiativa plano-paralela, desenvolvido pelos pesquisadores do Institute for Computational Earth System Science da Universidade da Califórnia, Santa Barbara, Estados Unidos. Ele foi elaborado para a análise de uma grande variedade de problemas de transferência radiativa encontrados em sensoriamento remoto por satélite e estudos de balanço de radiação atmosférica (Ricchiazzi, 1998).

O método DISORT (cálculo de transferência radiativa por ordenadas discretas, Stamnes et al., 1988) é utilizado para se integrar numericamente a equação de transferência radiativa (ETR), fornecendo dessa maneira um algoritmo estável capaz de solucionar a ETR em uma atmosfera plano-paralela não homogênea. Chandrasekhar (1950) desenvolveu com sucesso o método em questão para aplicações relacionadas a transferência de radiação eletromagnética em atmosferas planetárias. O método é eficiente e robusto para os cálculos computacionais envolvendo o campo de radiação eletromagnética, mesmo levando em consideração a presença de nuvens e aerossóis (Liou,1973). A discretização da equação de transferência radiativa em sua forma mais simples e a solução de uma série de equações diferenciais de primeira ordem são a base desta metodologia. Segundo Liou (2002), o advento de técnicas computacionais para a resolução dessas equações diferenciais permitiu que o método das ordenadas discretas se demonstrasse eficiente e acurado nos cálculos relacionados ao espalhamento de radiação. 


\subsection{Estimativa da Profundidade Óptica do Aerossol para o Canal de}

\section{$550 \mathrm{~nm}$}

Além das propriedades ópticas definidas pelos modelos para o aerossol de queimadas, o valor instantâneo da profundidade óptica do aerossol no comprimento de onda de $550 \mathrm{~nm}$ (AOD550) também deve ser fornecido como parâmetro de entrada ao código de transferência radiativa. Como visto no capítulo 3.1.1, o MFRSR não efetua medidas para este comprimento de onda, logo o valor da AOD550 teve que ser estimado. Aplicando o logaritmo natural na função 2.19, teremos que:

$$
\ln \left(\tau_{\lambda}\right)=\ln (\beta)-\alpha \ln (\lambda)
$$

Com os valores de AOD dos canais de 670, 870 e $1036 \mathrm{~nm}$ obtidos a partir de medições instantâneas efetuadas com o MFRSR, podemos calcular o coeficiente de Ångström a partir da regressão linear entre o $\ln \left(\tau_{\lambda}\right)$ e $\ln (\lambda)$. O valor de $\alpha$ será igual ao valor do coeficiente angular obtido. Sendo assim, a AOD550 foi calculada para cada instante de medição através da equação:

$$
A O D 550=A O D 670 \cdot\left(\frac{670}{550}\right)^{\alpha}
$$


Capítulo 4: Resultados 


\subsection{Calibração do MFRSR}

O Observatório Pico dos Dias apresenta condições favoráveis à aplicação do Método de Langley, já que é uma região distante de importantes fontes de poluição e devido à sua altitude. Durante a campanha de calibração de 2010, realizada entre julho e agosto, foram escolhidos 18 períodos na parte da manhã e 11 na parte da tarde que apresentaram as condições apropriadas para a aplicação do método de Langley. A figura 4.1 ilustra a aplicação do método para um caso específico.

(a)

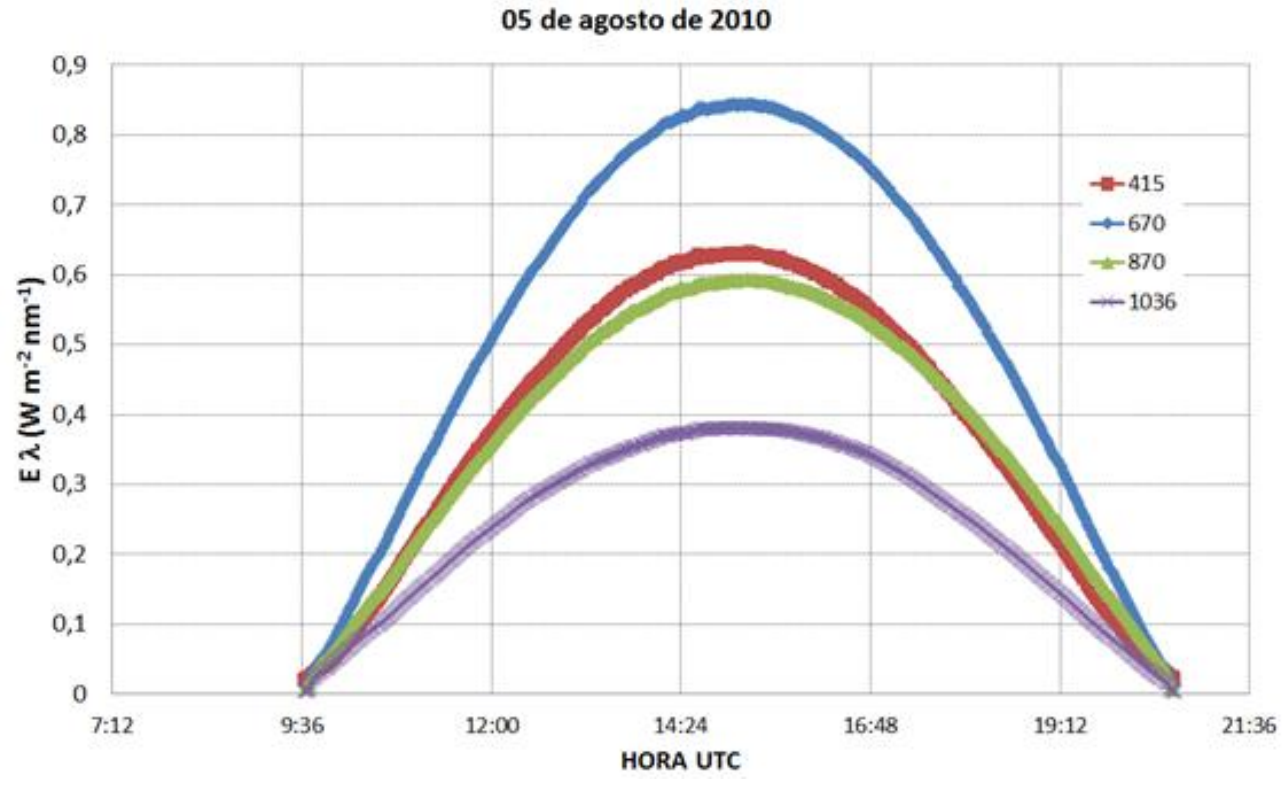

(b)

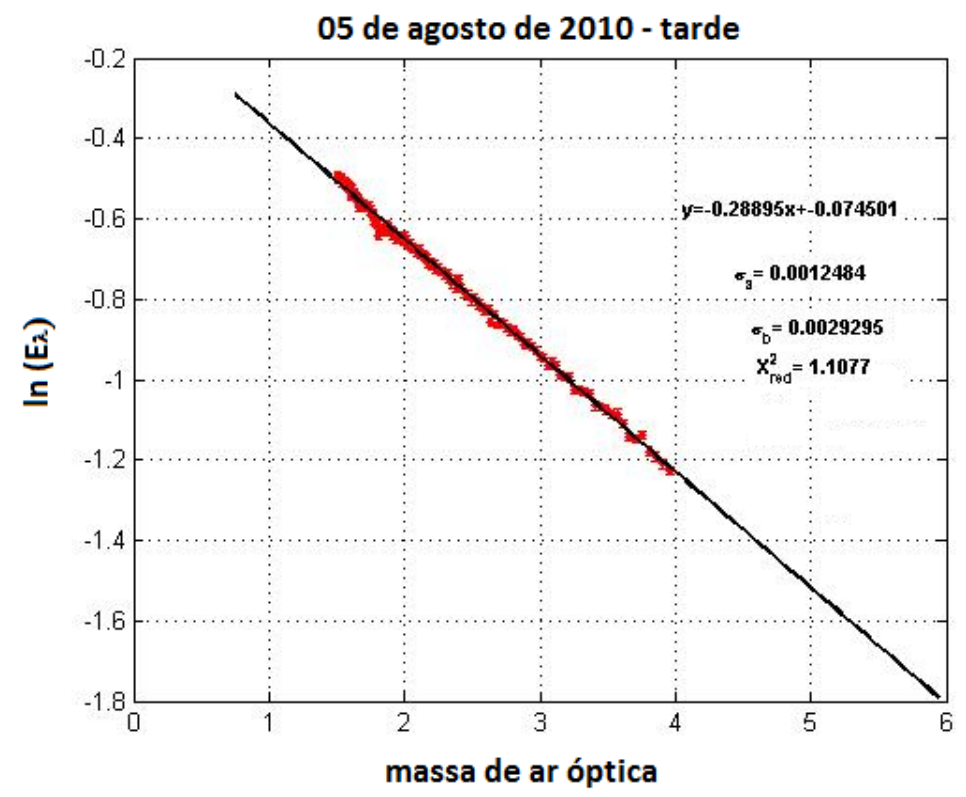

Figura 4.1 - (a) Irradiância solar global espectral para os canais de 415, 670, 870 e 1036 nm do MFRSR para o dia 05 de agosto de 2010 no OPD - LNA. (b) Método de Langley aplicado para o canal de $415 \mathrm{~nm}$ no período da tarde do mesmo dia. 
Os resultados para os casos analisados e as estimativas finais com respectivas incertezas estatísticas são apresentados na tabela 4.1.

Tabela 4.1 - Estimativa das constantes de calibração $\mathrm{E}_{0, \lambda}\left(\mathrm{Wm}^{-2} \mathrm{~nm}^{-1}\right)$ para os canais do MFRSR a partir do Método de Langley para as medições realizadas no OPD-LNA nos meses de julho e agosto de 2010.

\begin{tabular}{|c|c|c|c|}
\hline $415 \mathrm{~nm}$ & $670 \mathrm{~nm}$ & $870 \mathrm{~nm}$ & $1036 \mathrm{~nm}$ \\
\hline 0,942 & 1,152 & 0,778 & 0,503 \\
\hline 0,939 & 1,154 & 0,784 & 0,506 \\
\hline 0,979 & 1,180 & 0,797 & 0,511 \\
\hline 0,967 & 1,178 & 0,796 & 0,509 \\
\hline 0,954 & 1,169 & 0,793 & 0,514 \\
\hline 0,917 & 1,141 & 0,781 & 0,494 \\
\hline 0,988 & 1,200 & 0,814 & 0,502 \\
\hline 0,939 & 1,162 & 0,790 & 0,516 \\
\hline 0,956 & 1,169 & 0,792 & 0,518 \\
\hline 0,970 & 1,177 & 0,796 & 0,505 \\
\hline 0,915 & 1,144 & 0,782 & 0,508 \\
\hline 1,025 & 1,204 & 0,806 & 0,521 \\
\hline 0,959 & 1,175 & 0,798 & 0,517 \\
\hline 1,007 & 1,205 & 0,814 & 0,517 \\
\hline 0,971 & 1,180 & 0,799 & 0,514 \\
\hline 0,980 & 1,185 & 0,801 & 0,534 \\
\hline 0,960 & 1,176 & 0,798 & 0,519 \\
\hline 0,954 & 1,168 & 0,793 & 0,513 \\
\hline 0,956 & 1,157 & 0,779 & 0,526 \\
\hline 0,995 & 1,170 & 0,781 & 0,519 \\
\hline 1,005 & 1,174 & 0,779 & 0,523 \\
\hline 0,962 & 1,160 & 0,778 & 0,530 \\
\hline 0,973 & 1,167 & 0,782 & 0,529 \\
\hline 0,994 & 1,186 & 0,792 & 0,532 \\
\hline 0,928 & 1,146 & 0,774 & 0,522 \\
\hline 1,002 & 1,186 & 0,792 & 0,528 \\
\hline 0,955 & 1,160 & 0,779 & 0,516 \\
\hline 0,993 & 1,187 & 0,796 & 0,536 \\
\hline 1,004 & 1,203 & 0,808 & 0,542 \\
\hline \multicolumn{4}{|c|}{$E_{0, \lambda}(W m-2)$} \\
\hline 0,969 & 1,173 & 0,791 & 0,518 \\
\hline \multicolumn{4}{|c|}{ desvio padrão $\left(E_{0, \lambda}\right)$} \\
\hline 0,028 & 0,018 & 0,011 & 0,011 \\
\hline
\end{tabular}


A figura 4.2 mostra o gráfico das constantes de calibração do mesmo instrumento obtidas nas últimas campanhas de calibração, todas realizadas no OPDLNA. Não são esperados que os valores ao longo dos anos fossem iguais, já que é de conhecimento que o sensor do instrumento sofre uma deterioração com o tempo. O que se espera é que os valores sigam um comportamento parecido. Dito isto o canal de 415 nm apresenta um comportamento anômalo para o ano de 2008, quando ocorre o aumento do valor da constante de calibração, contrariando a tendência de redução observada ao longo dos anos anteriores. O canal de $1036 \mathrm{~nm}$ também apresenta disparidade, já que no ano de 2010 ocorreu uma queda acentuada quando comparada às anteriores (fato possivelmente explicado pela ocorrência de maior deterioração deste canal). Estes resultados demonstram a importância da calibração para que se obtenham cálculos acurados de profundidade óptica do aerossol a partir da Lei de Beer.

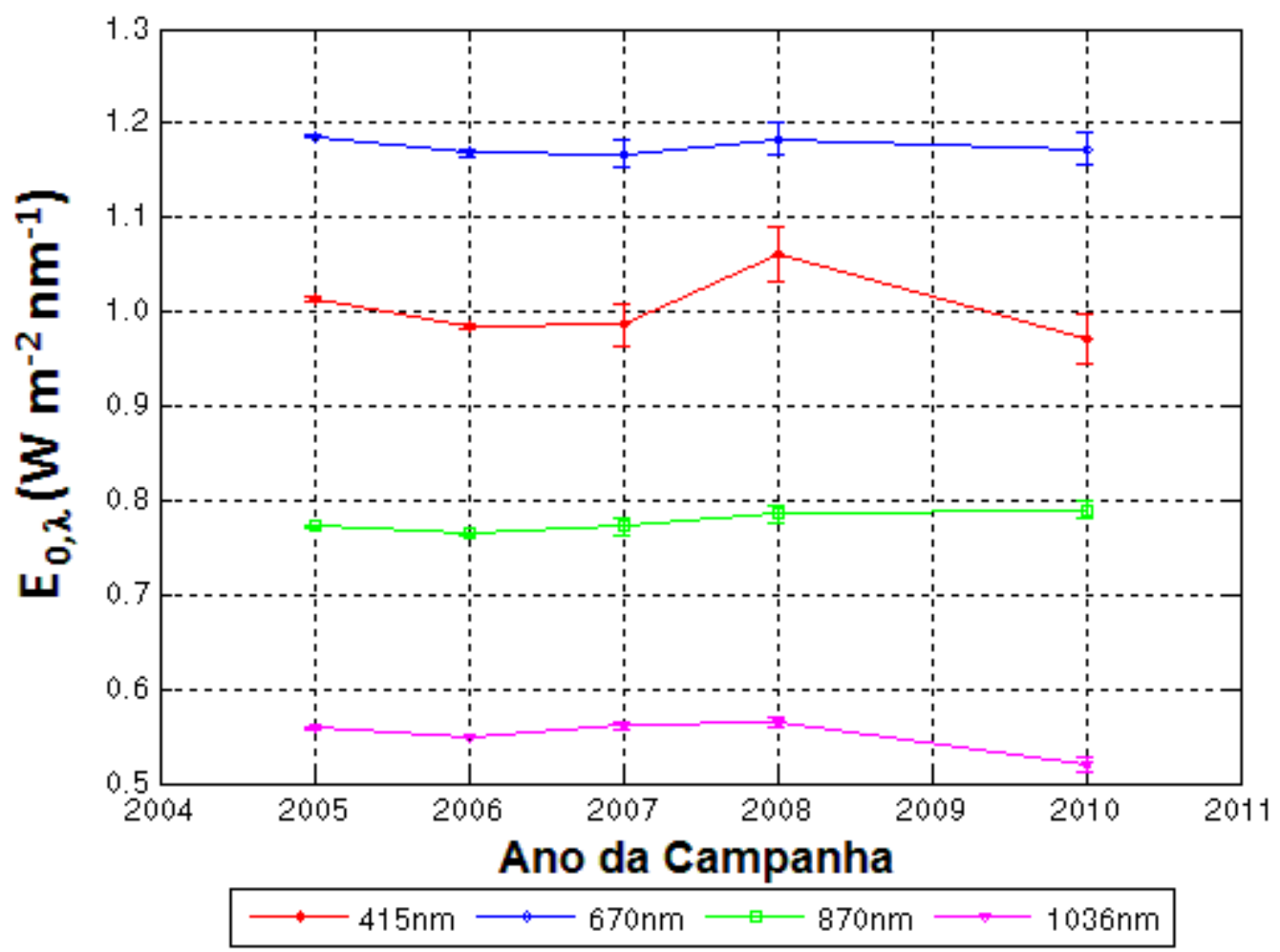

Figura 4.2 - Irradiância espectral no topo da atmosfera obtida a partir do Método de Langley para as campanhas de calibração ocorridas entre 2005 e 2010 no OPD - LNA. 


\subsection{Profundidade Óptica do Aerossol em 550nm}

A variabilidade diária da AOD550 ao longo do experimento (figura 4.3a) foi caracterizada por um período de crescimento (entre os dias 236 e 250) até alcançar o maior valor observado durante o experimento $(\sim 3,2)$. No dia 263 a AOD550 foi reduzida drasticamente e manteve um valor baixo também para o dia 265, fato explicado pela mudança para uma massa de ar mais limpo, verificado por inspeção visual a partir de imagens de satélite (figura 4.4). Os valores de AOD voltaram a ficar com valores moderados (entre 1,5 e 3,0) logo após este evento. No final do período o valor de AOD voltou a cair com o início da temporada chuvosa na região.

(a)

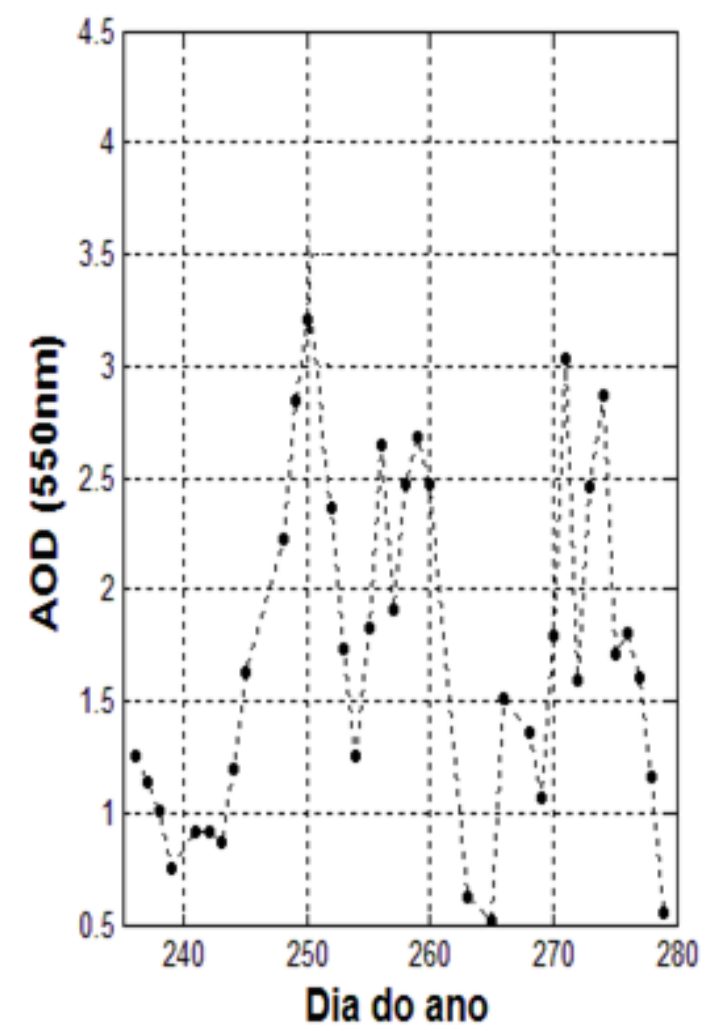

(b)

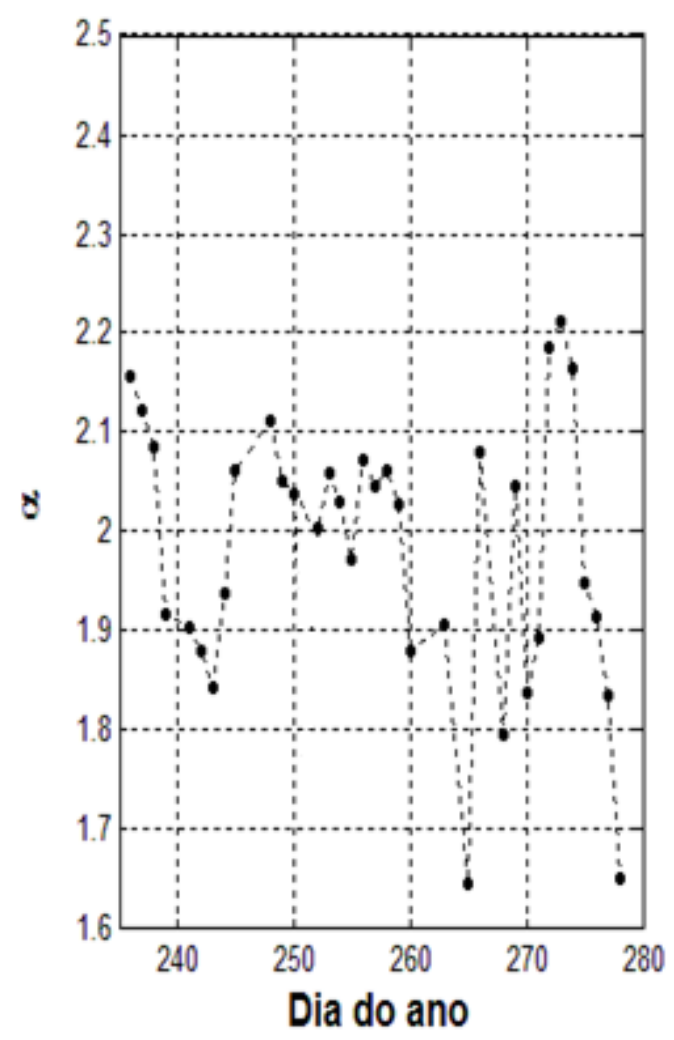

Figura 4.3 - Variabilidade diária da profundidade óptica do aerossol em 550nm (a) e do coeficiente de Ångström (b) sobre a Rebio Jaru durante o experimento. 

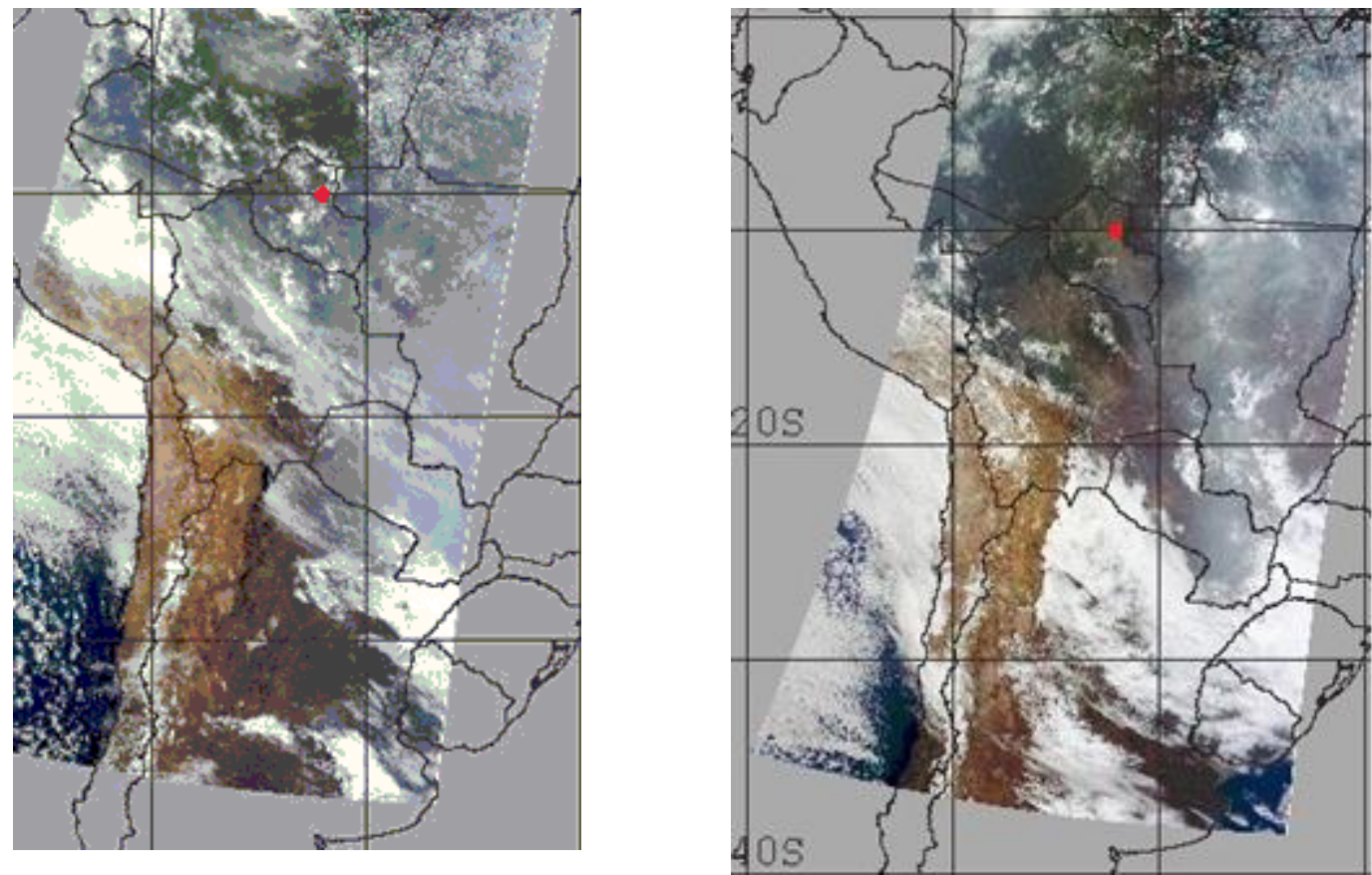

Figura 4.4 - Imagens obtidas pelo sensor MODIS a bordo do satélite Terra para os dias 263 e 265 de 2007. Em vermelho a localização da Rebio Jaru.

\subsection{Testes de Sensibilidade - SBDART}

Alguns testes de sensibilidade relativos às irradiâncias fotossinteticamente ativa, solar total global e dos canais de 670, 870 e $1036 \mathrm{~nm}$ à superfície foram realizados para avaliar os efeitos dos modelos ópticos para o aerossol de queimadas propostos sob diferentes condições de profundidade óptica do aerossol. Foram considerados o albedo de vegetação e o perfil vertical de atmosfera tropical da biblioteca do SBDART.

Como visto no item 3.1.2, o sensor PAR geralmente apresenta acurácia da ordem de 3\% e de acordo com Michalsky et al. (1999), a maioria dos piranômetros utilizados para medir a irradiância total descendente na superfície também é de aproximadamente 3\%. Logo esse valor pode ser considerado como referência para a avaliação da relevância do impacto de se levar em consideração diferentes regimes de aerossóis.

A figura 4.5 apresenta os resultados da irradiância solar na região PAR obtida à superfície considerando os 3 modelos ópticos utilizados neste trabalho, propostos por Rosário (2011) para diferentes profundidades ópticas do aerossol, e para dois ângulos de iluminação: para o disco solar no zênite e para a distância zenital solar igual a $60^{\circ}$. Os 
resultados são normalizados para a irradiância PAR em superfície para a AOD igual a zero. Pela análise dos gráficos é possível notar que a escolha do modelo correto torna-se mais importante com o aumento da AOD, como esperado. Para AOD menor do que 0,5, a divergência entre os modelos na PAR em superfície é menor do que 3\% seja para o disco solar no zênite ou para o ângulo zenital solar igual a $60^{\circ}$. Para AOD maior que 1,0 , as diferenças podem alcançar $10 \%$. O mesmo ocorre nos testes de sensibilidade feitos para a irradiância solar total global (figura 4.6), irradiância no canal de $670 \mathrm{~nm}$ (figura 4.7), irradiância no canal de $870 \mathrm{~nm}$ (figura 4.8) e para a irradiância no canal de 1036nm (figura 4.9). Portanto, o limite de AOD em $550 \mathrm{~nm}$ para a escolha dos regimes é de aproximadamente 0,5. Pelo gráfico da figura 4.3a, os valores de AOD em 550nm durante o período analisado ficou sempre acima deste limite, logo se faz importante a escolha de um modelo óptico adequado para a modelagem da irradiância à superfície, na presença de partículas de aerossol.

(a)

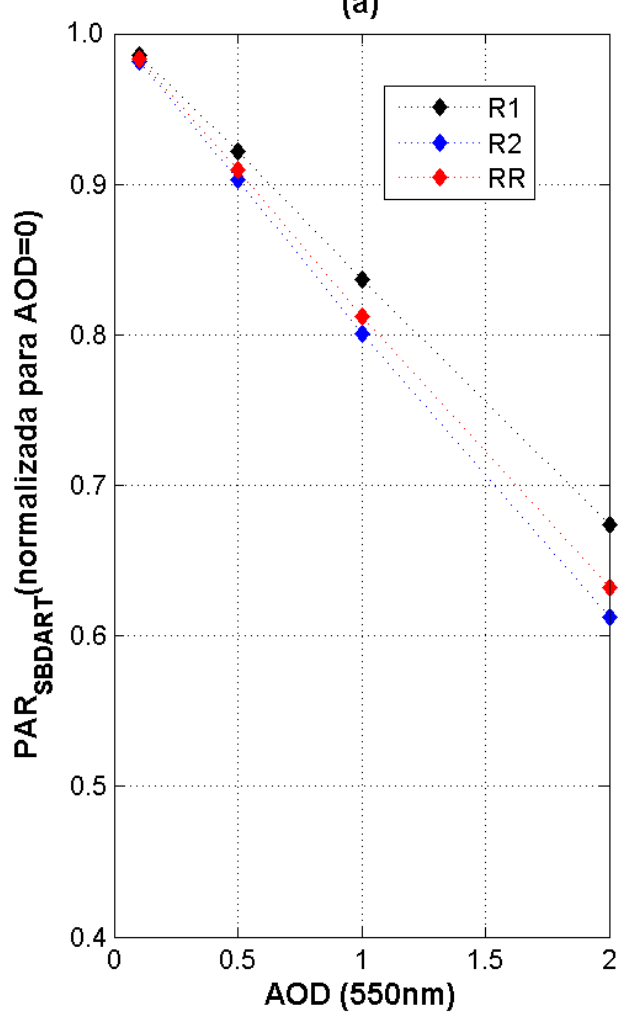

(b)

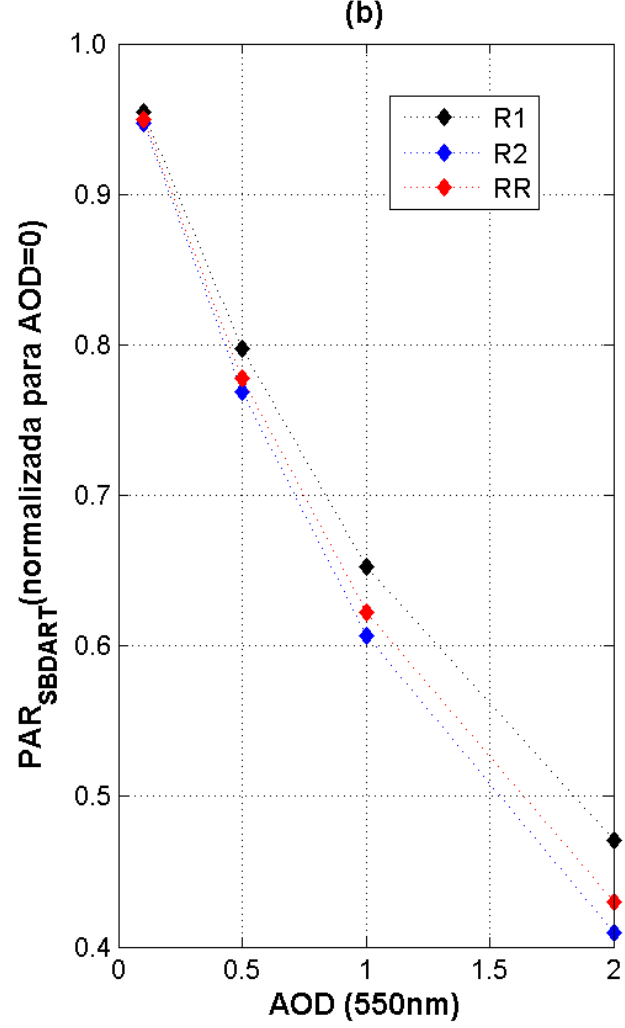

Figura 4.5 - Irradiância na região PAR descendente à superfície para diferentes valores de AOD para cada um dos modelos ópticos de Rosário utilizados neste trabalho. (a) Para o disco solar localizado no zênite. (b) Para a distância zenital solar igual a $60^{\circ}$. 
(a)

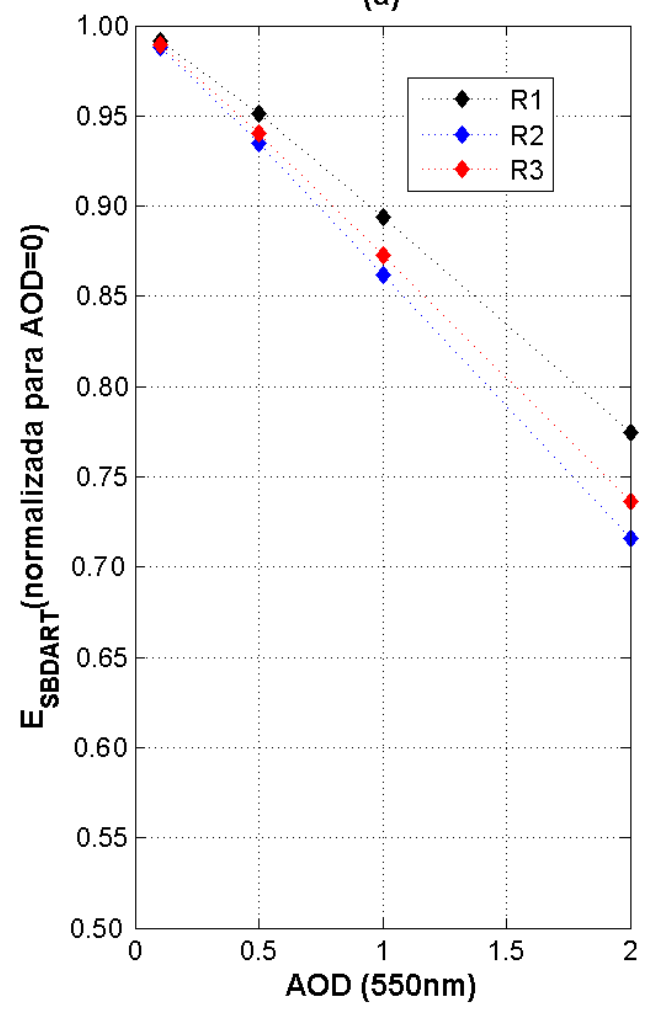

(b)

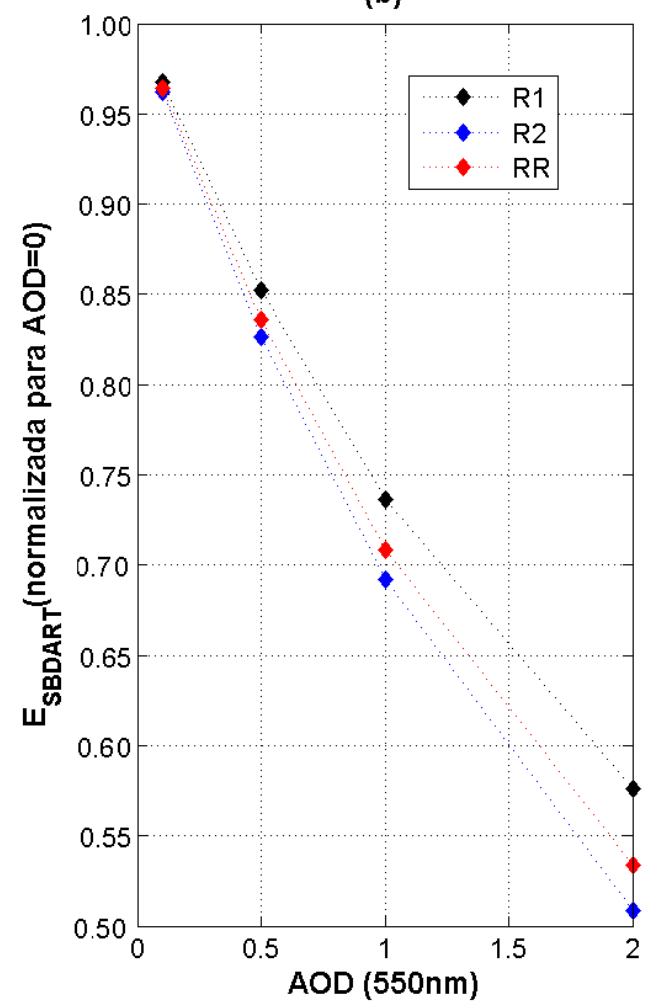

Figura 4.6 - Irradiância solar total global descendente à superfície para diferentes valores de AOD para cada um dos modelos ópticos de Rosário utilizados neste trabalho. (a) Para o disco solar localizado no zênite. (b) Para a distância zenital solar igual a $60^{\circ}$.

(a)

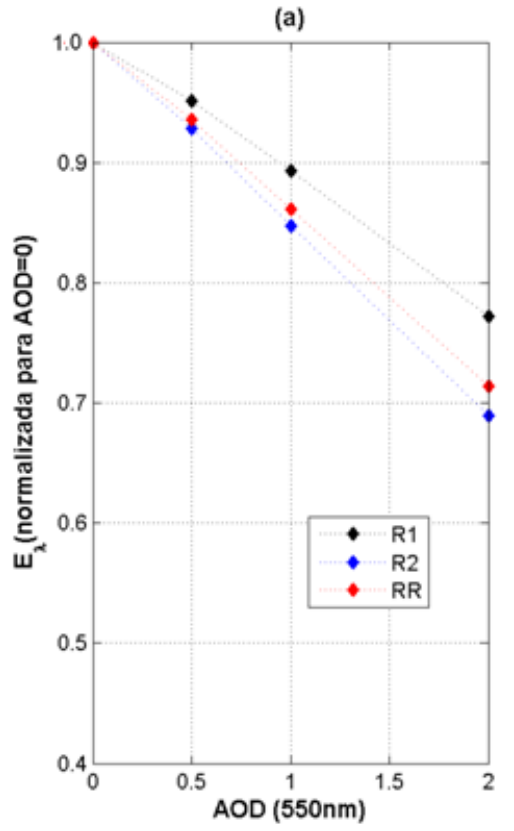

(b)

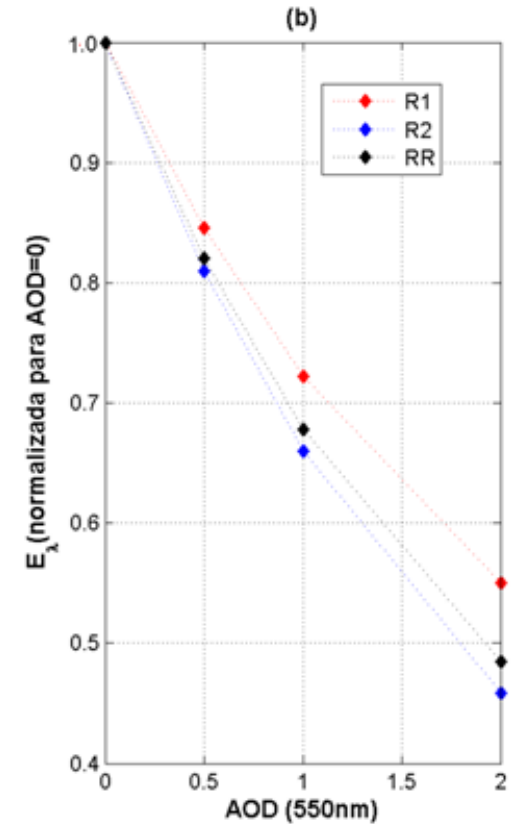

Figura 4.7 - Irradiância no canal de 670nm descendente à superfície para diferentes valores de AOD para cada um dos modelos ópticos de Rosário utilizados neste trabalho. (a) Para o disco solar localizado no zênite. (b) Para a distância zenital solar igual a $60^{\circ}$. 
(a)

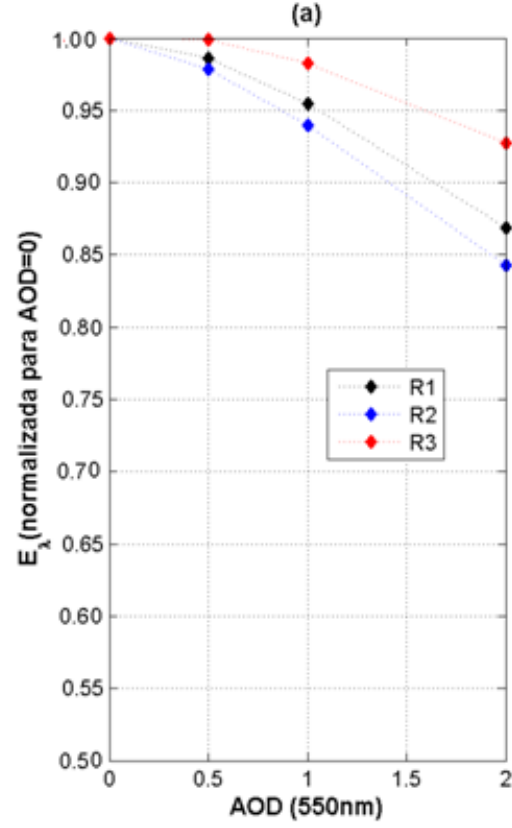

(b)

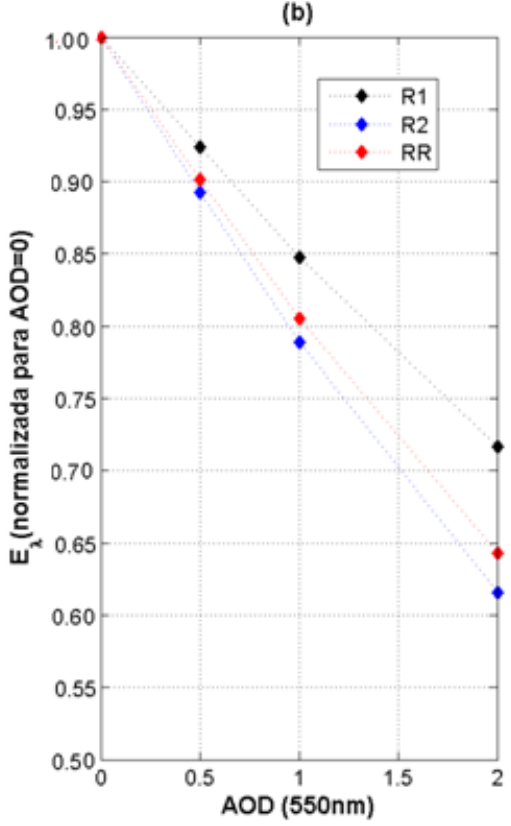

Figura 4.8 - Irradiância no canal de 870nm descendente à superfície para diferentes valores de AOD para cada um dos modelos ópticos de Rosário utilizados neste trabalho. (a) Para o disco solar localizado no zênite. (b) Para a distância zenital solar igual a $60^{\circ}$.
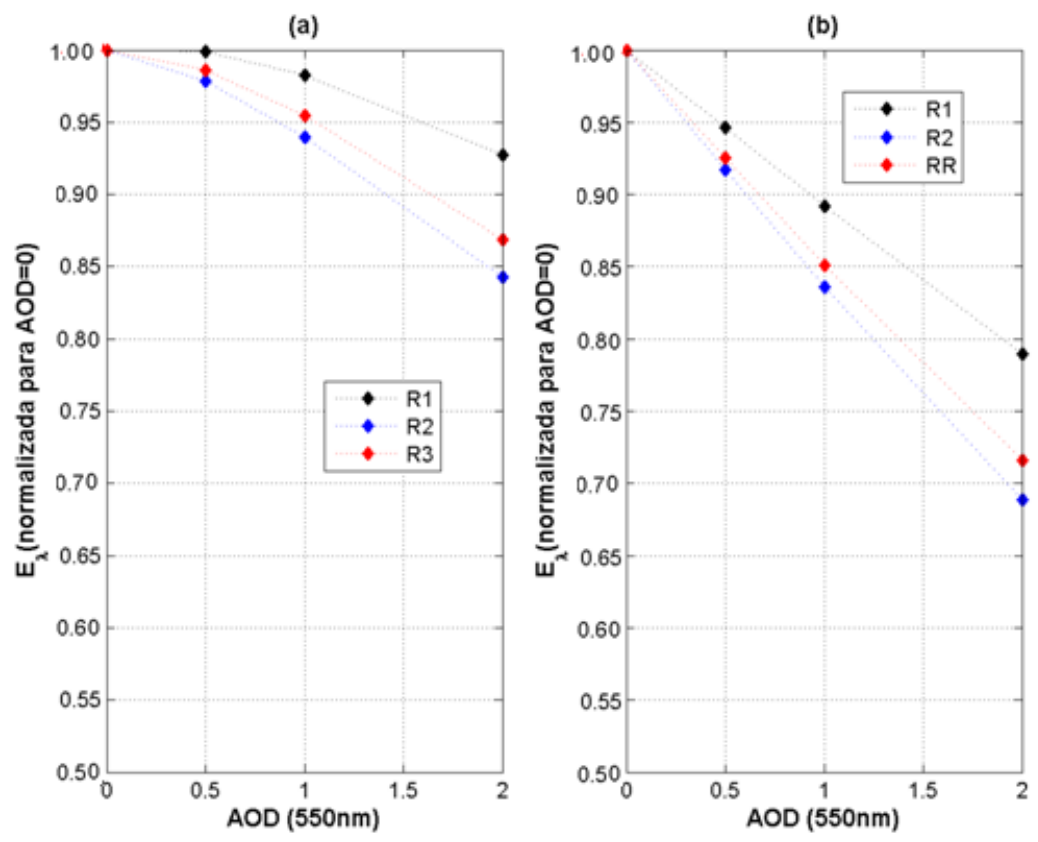

Figura 4.9 - Irradiância no canal de 1036nm descendente à superfície para diferentes valores de AOD para cada um dos modelos ópticos de Rosário utilizados neste trabalho. (a) Para o disco solar localizado no zênite. (b) Para a distância zenital solar igual a $60^{\circ}$. 
Testes de sensibilidade na estimativa de irradiância PAR, solar total global e da razão entre as irradiâncias difusa e global para os canais de 670, 870 e 1036nm à superfície foram realizados com a finalidade de determinar o impacto da variabilidade do conteúdo de vapor d'água (cva) e da concentração de ozônio ( $\left[\mathrm{O}_{3}\right]$ ) na coluna atmosférica (figuras 4.10 e 4.11, respectivamente). O canal de $415 \mathrm{~nm}$ foi descartado da análise, pois as condições observadas durante a estação de queimadas tendem a saturar o sensor do instrumento. A AOD foi mantida igual a zero e os resultados foram normalizados para os valores de irradiância calculados com o cva e $\left[\mathrm{O}_{3}\right]$ definidos pelo perfil de atmosfera tropical do SBDART $\left(4,117 \mathrm{~g} / \mathrm{cm}^{2}\right.$ e 216 D.U., respectivamente).

Os valores de cva utilizados nos testes são os valores mínimo $\left(1,94 \mathrm{~g} / \mathrm{cm}^{2}\right)$, máximo $\left(4,91 \mathrm{~g} / \mathrm{cm}^{2}\right)$ e médio $\left(3,47 \mathrm{~g} / \mathrm{cm}^{2}\right)$ detectados pelo fotômetro solar da AERONET localizado em Ji-Paraná, a cerca de 90 quilômetros ao sul da Rebio Jaru, entre os dias 24 de agosto e 31 de outubro de 2007. A irradiância solar total global é a que apresentou as maiores diferenças em relação à irradiância modelada para o caso em que é utilizado o perfil de atmosfera tropical do SBDART, porém a diferença ainda é menor do que $3 \%$ para o sol no zênite e menor que $2 \%$ para o ângulo zenital solar a $60^{\circ}$. Para os demais intervalos espectrais analisados apresentou uma diferença inferior a 0,5\%. Os valores de $\left[\mathrm{O}_{3}\right]$ foram obtidos do Total Ozone Mapping Spectrometer (TOMS) para o período entre 1996 e 2005 sobre o sul da Bacia Amazônica, onde $\left[\mathrm{O}_{3}\right] \_$mínimo $=250$ D.U. e $\left[\mathrm{O}_{3}\right] \_$máximo $=278$ D.U. Neste caso, as diferenças entre as irradiâncias modeladas com o valor da $\left[\mathrm{O}_{3}\right]$ do perfil de uma atmosfera tropical do SBDART e o valor máximo e mínimo encontrados na região foi menor do que $1 \%$. Dessa forma, a utilização do valor médio do conteúdo de vapor d'água e da concentração de ozônio integrada verticalmente na atmosfera, estipulados para um perfil de atmosfera tropical, não irá provocar incertezas significativas nos cálculos de irradiância em superfície para os casos analisados. 
(a)

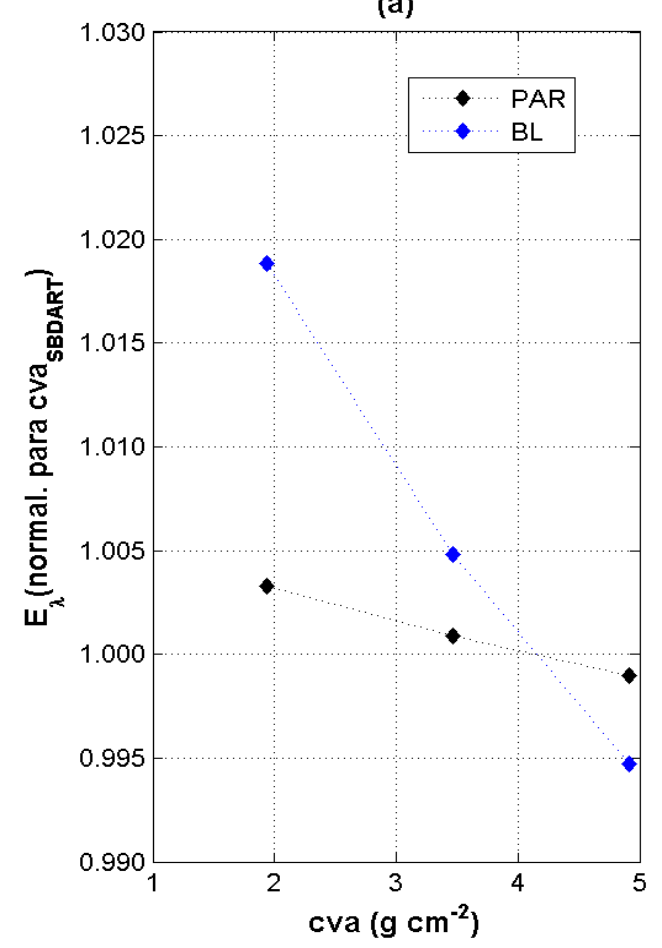

(b)

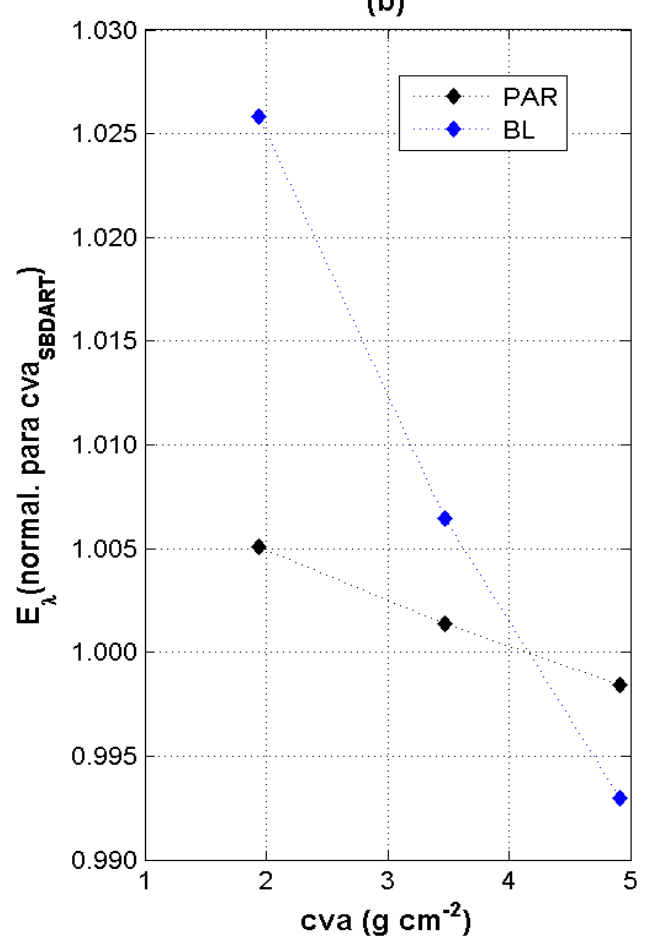

Figura 4.10 - Irradiância PAR e solar total global (BL) à superfície para diferentes valores de conteúdo de vapor d'água (cva, em g. $\mathrm{cm}^{-2}$ ). (a) Para o disco solar localizado no zênite. (b) Para a distância zenital solar igual a $60^{\circ}$.

(a)

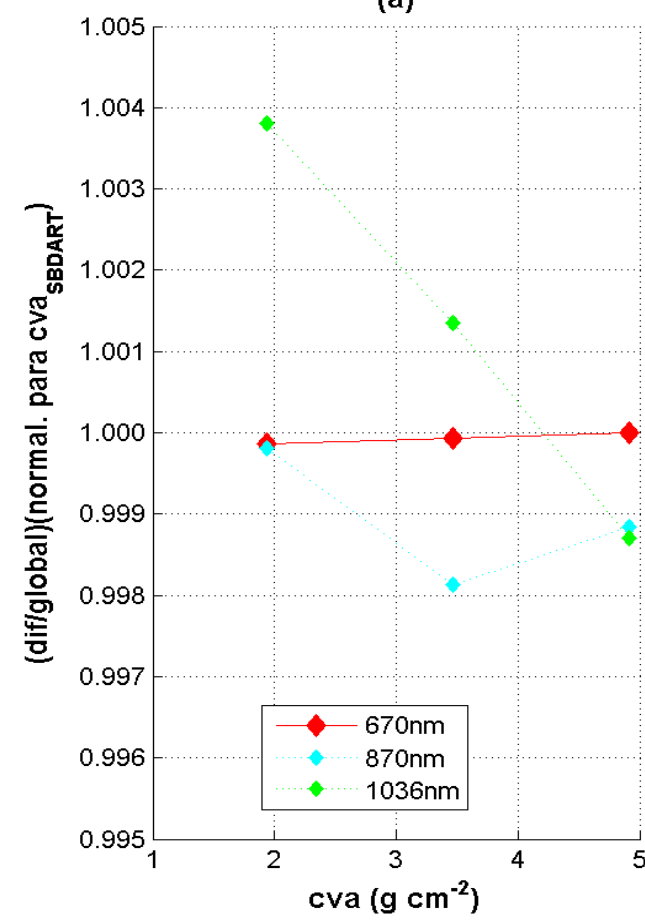

(b)

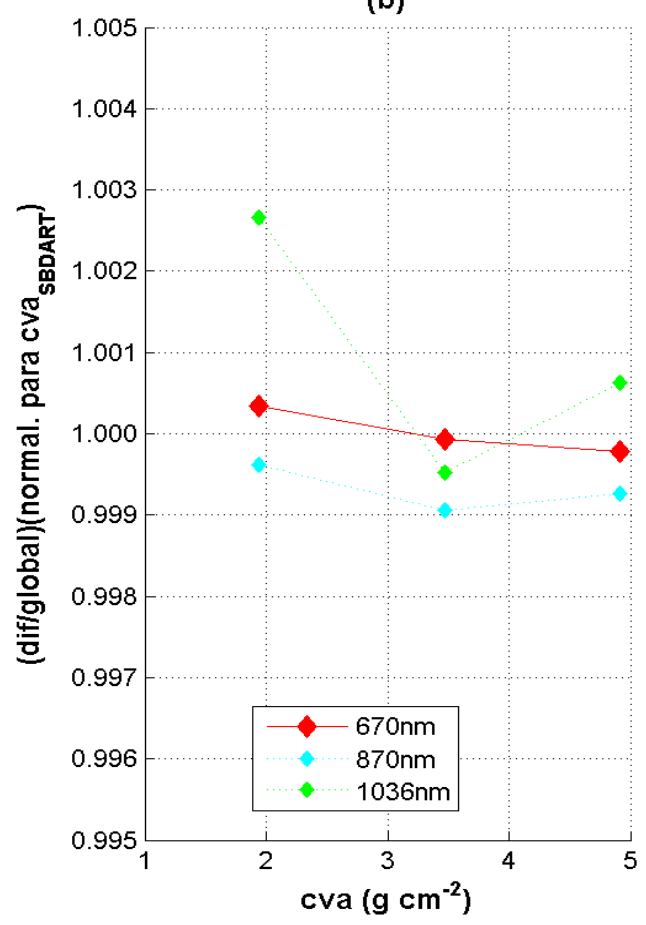

Figura 4.11 - Razão entre irradiância global e difusa dos canais de 670, 870 e 1036nm à superfície para diferentes valores de conteúdo de vapor d'água (cva, em g.cm²). (a) Para o disco solar localizado no zênite. (b) Para a distância zenital solar igual a $60^{\circ}$. 
(a)

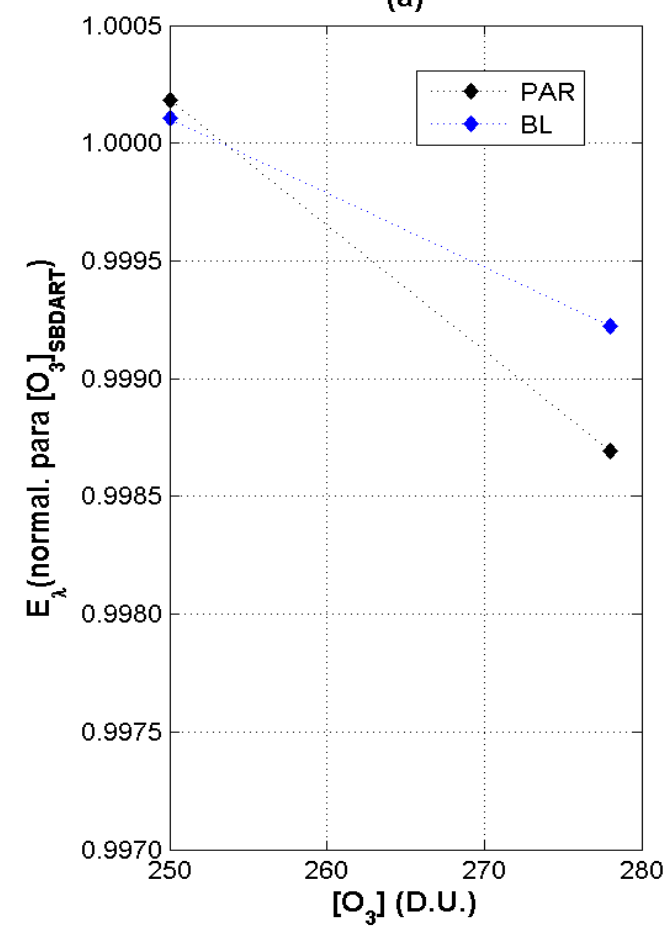

(b)

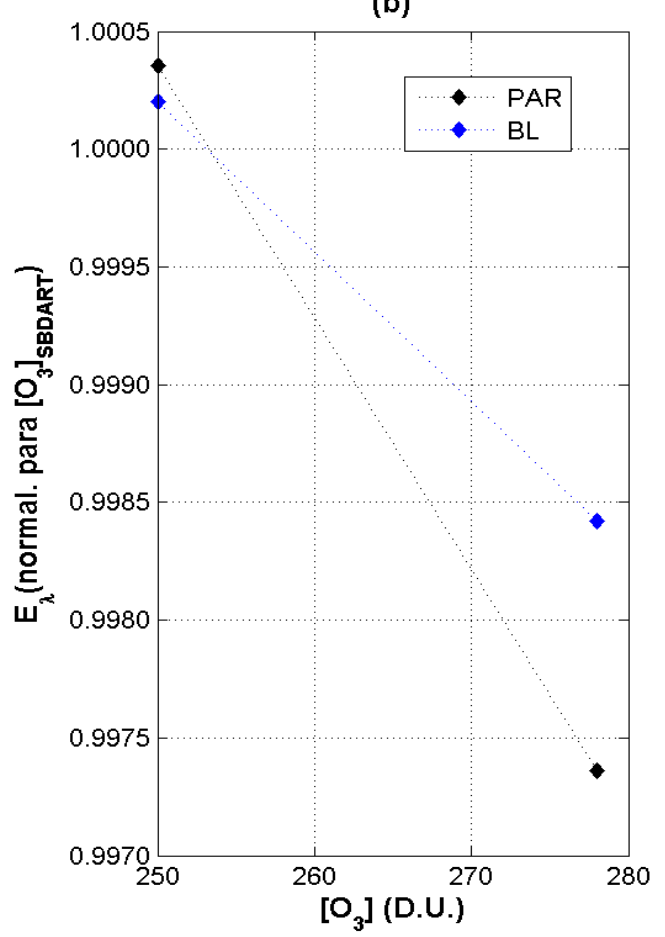

Figura 4.12- Irradiância PAR e solar total global à superfície para diferentes valores de concentração de ozônio ([ $\left.\mathrm{O}_{3}\right]$, D.U.). (a) Para o disco solar localizado no zênite. (b) Para a distância zenital solar igual a $60^{\circ}$.

(a)

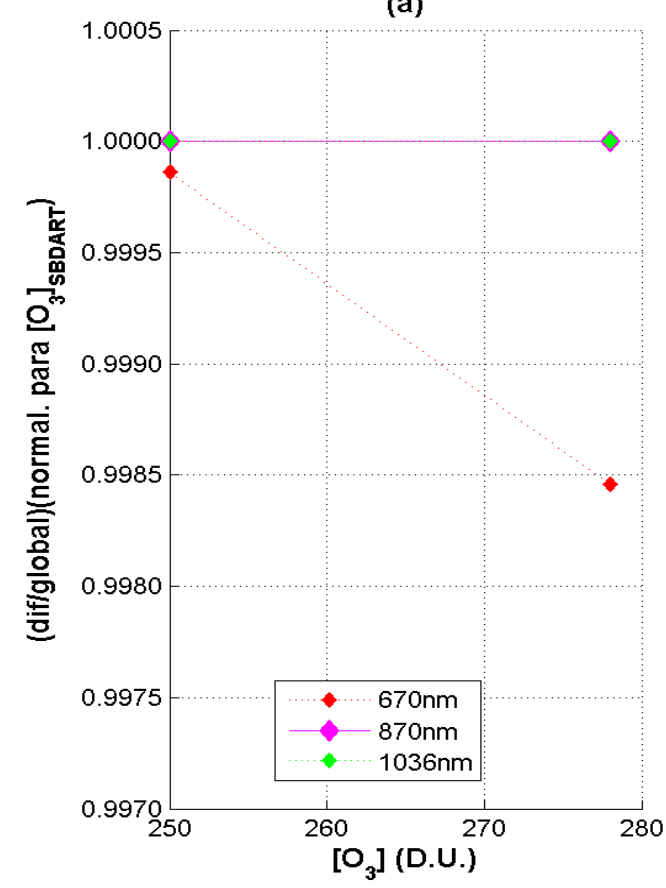

(b)

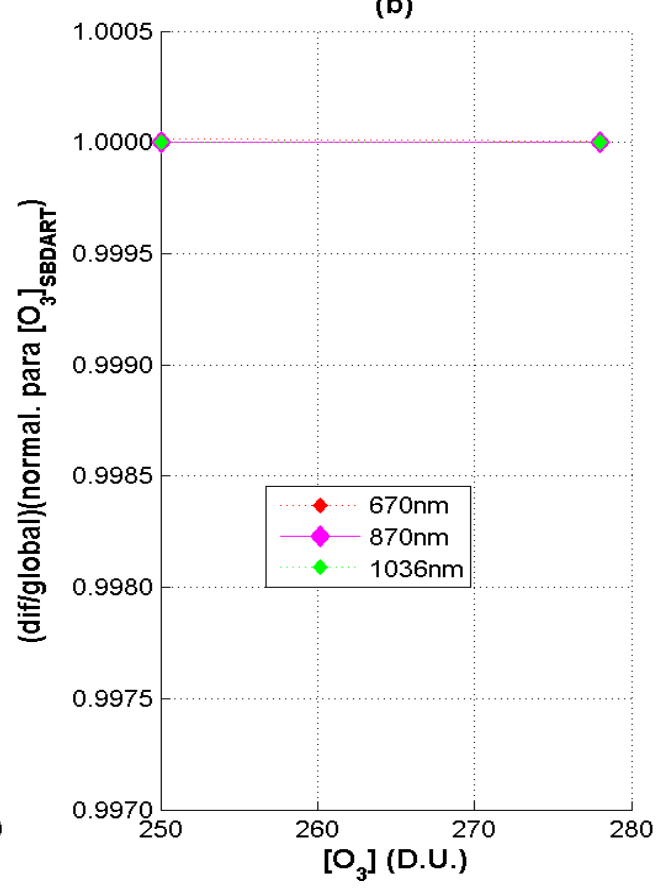

Figura 4.13- Razão entre irradiância global e difusa dos canais de 670, 870 e 1036nm à superfície para diferentes valores de concentração de ozônio ([ $\left.\mathrm{O}_{3}\right]$, D.U.). (a) Para o disco solar localizado no zênite. (b) Para a distância zenital solar igual a $60^{\circ}$. 


\subsection{Irradiância Modelada versus Observada}

A partir da utilização dos modelos ópticos para o aerossol de queimadas desenvolvido por Rosário (2011) como parâmetros, valores de irradiância PAR, solar total global e para os canais de 670, 870 e 1036nm foram calculados para o período de agosto a outubro de 2007 no sítio da Reserva Biológica do Jaru. Os valores calculados foram confrontados com medidas in situ para avaliar qual dos modelos é o mais adequado para diferentes situações. A seguir serão apresentados alguns estudos de caso feitos para a avaliação dos modelos ópticos propostos.

\subsubsection{Estudos de Caso para Avaliação do Modelo Óptico}

\subsubsection{Sensor PAR e Bandas Estreitas}

Alguns dias do período analisado foram escolhidos para avaliar o comportamento dos modelos ópticos para o aerossol de queimadas propostos. Como o sensor PAR estava a aproximadamente $6 \mathrm{~km}$ de distância do MFRSR, foi feito um filtro para evitar a contaminação de nuvens. O filtro consistia em fazer uma média móvel, com os quatro dados anteriores e os quatro dados seguintes àquele analisado. Se o valor em questão apresentasse um valor com diferença superior a três incertezas (para mais ou para menos) da média, ele era automaticamente descartado. O dia 269 foi escolhido por apresentar valores moderados de profundidade óptica em $550 \mathrm{~nm}$, que variou entre 1,0 e 1,3. O coeficiente de Ångström ficou entre 1,6 e 1,8. 
(a)

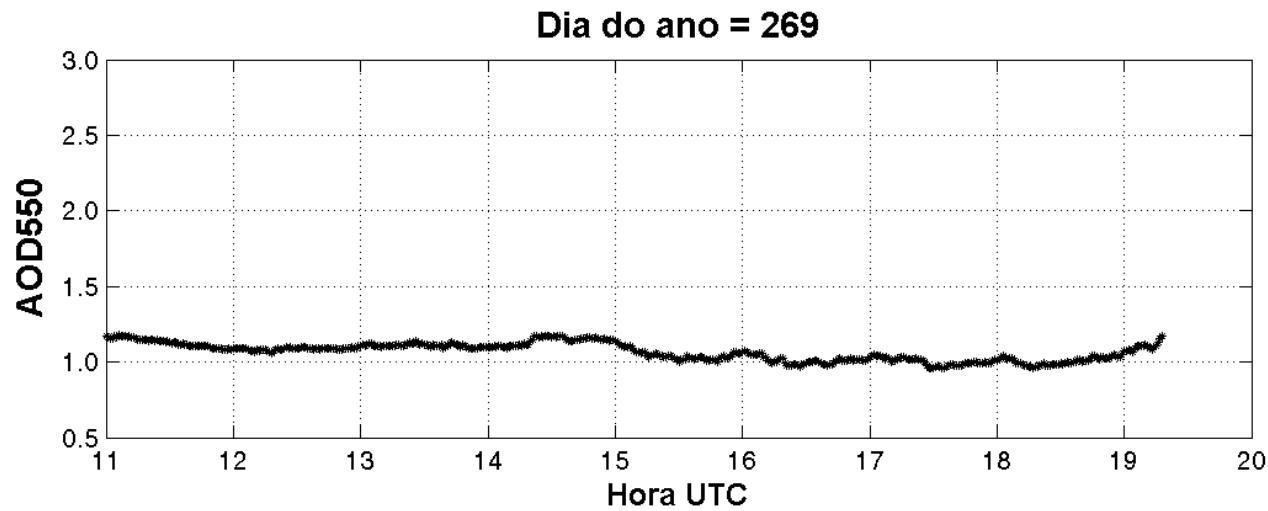

(b)

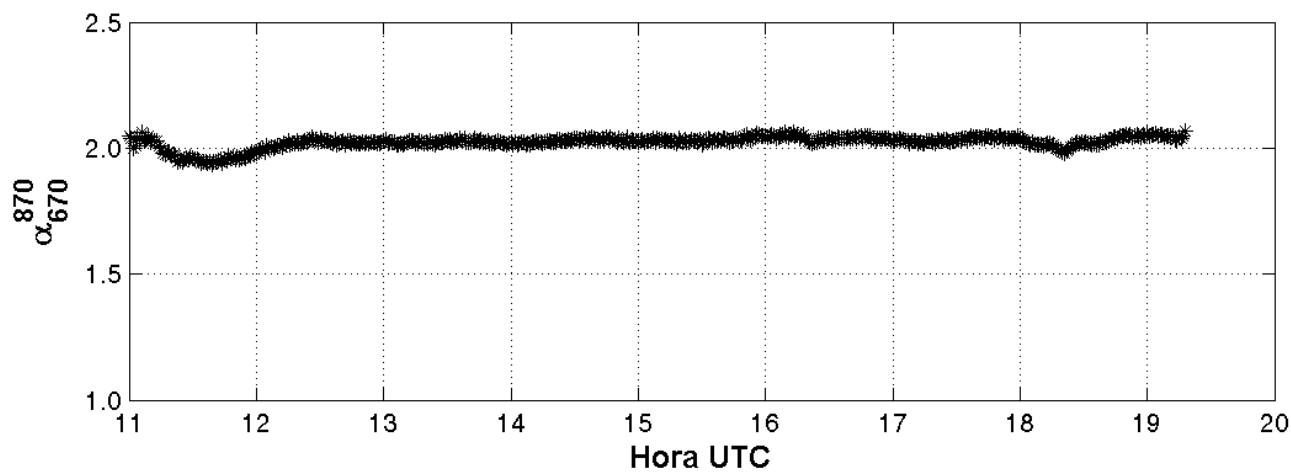

Figura 4.14 - Valores da profundidade óptica em 550nm (a) e do coeficiente de Ångström (b), $\propto_{670}^{870}$, para o dia do ano 269.

Na figura 4.15 é apresentado o gráfico da irradiância PAR observada e a simulada com os modelos ópticos para o aerossol de queimadas da Amazônia para o dia analisado. Pode-se observar que neste caso os modelos RR e R2 foram os que mais se aproximaram do valor observado, com diferenças menores do que $5 \%$. 


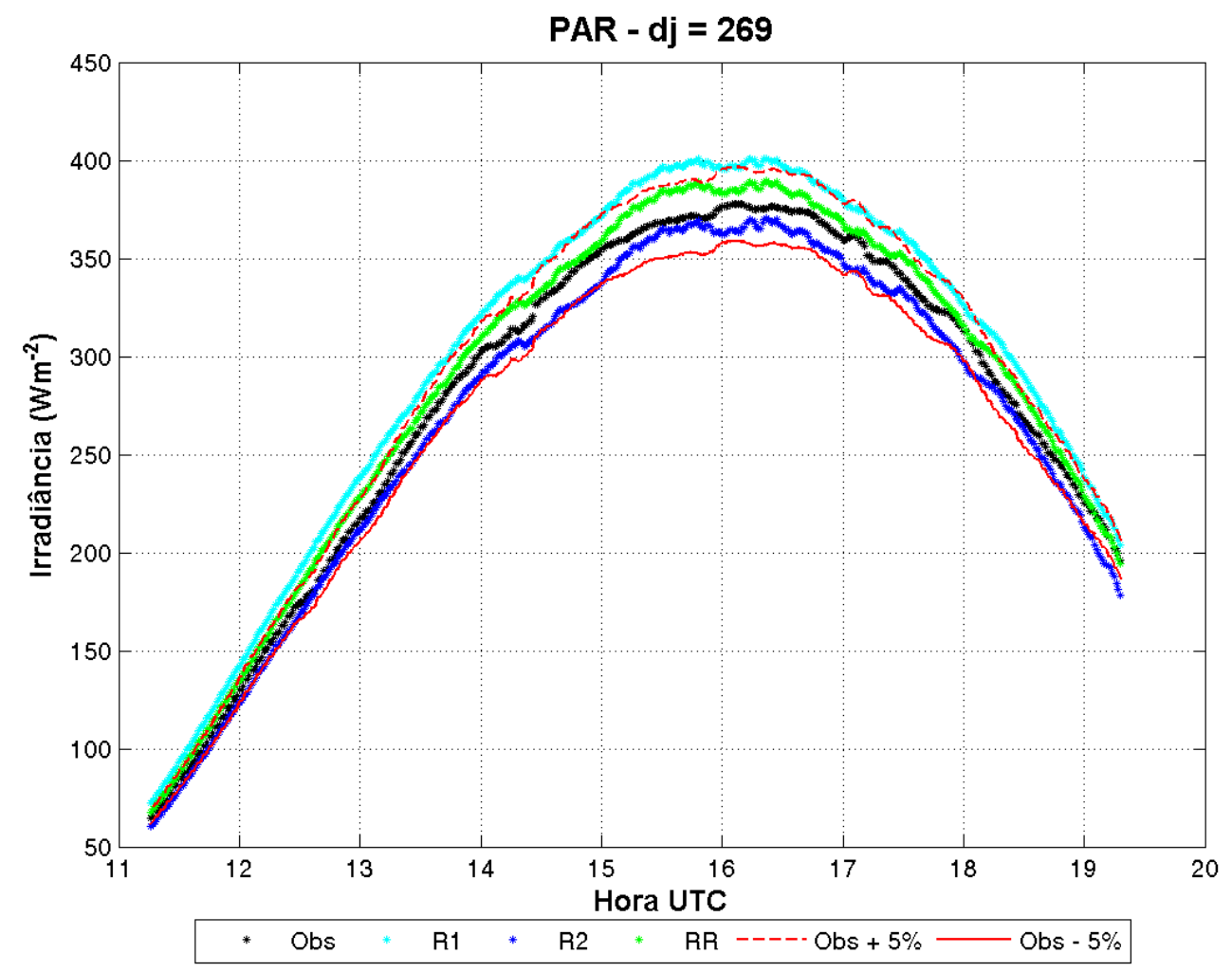

Figura 4.15 - Irradiância PAR observada e simulada à superfície para o dia 269. A linha vermelha representa o valor observado menos $5 \%$ e a linha vermelha tracejada representa o observado mais $5 \%$.

Para as bandas estreitas do MFRSR, optou-se por comparar a razão entre as irradiâncias difusa e global observadas e as simuladas, para tentar contornar o problema de degradação do instrumento, que reduz a intensidade da irradiância medida. No canal de 670nm, o modelo R2 é o que se aproxima mais do observado, mas os valores simulados com o modelo RR também estão dentro da incerteza instrumental. Esse comportamento parecido com a irradiância PAR era de se esperar já que o canal de $670 \mathrm{~nm}$ faz parte do intervalo espectral da PAR.

Para os canais de 870 e 1036 nm, o modelo R2 é o que apresenta os valores mais próximos daqueles medidos pelo MFRSR, porém grande parte dos valores simulados fica no limite da incerteza instrumental e parte deles está fora desse limite. 
(a)

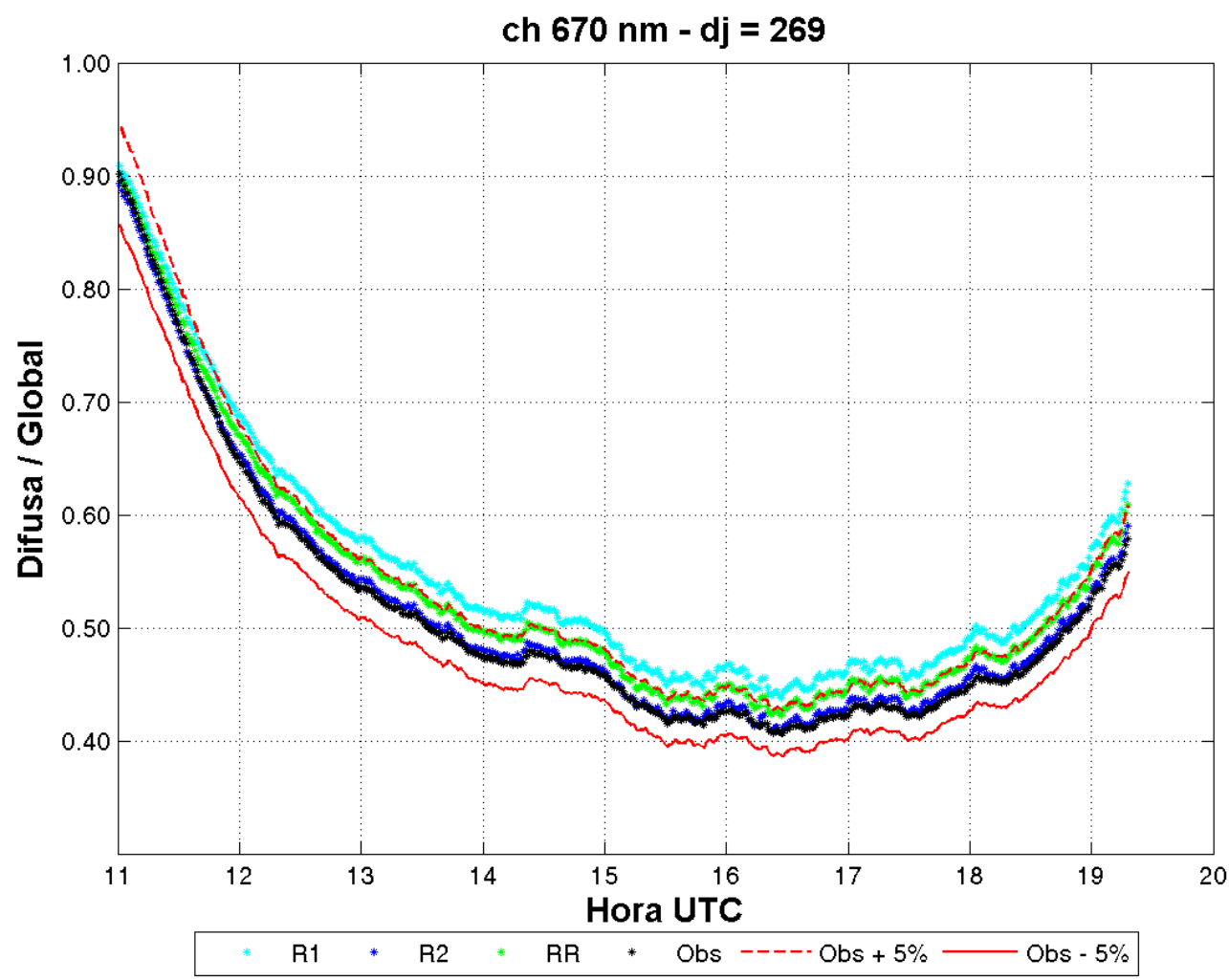

(b)

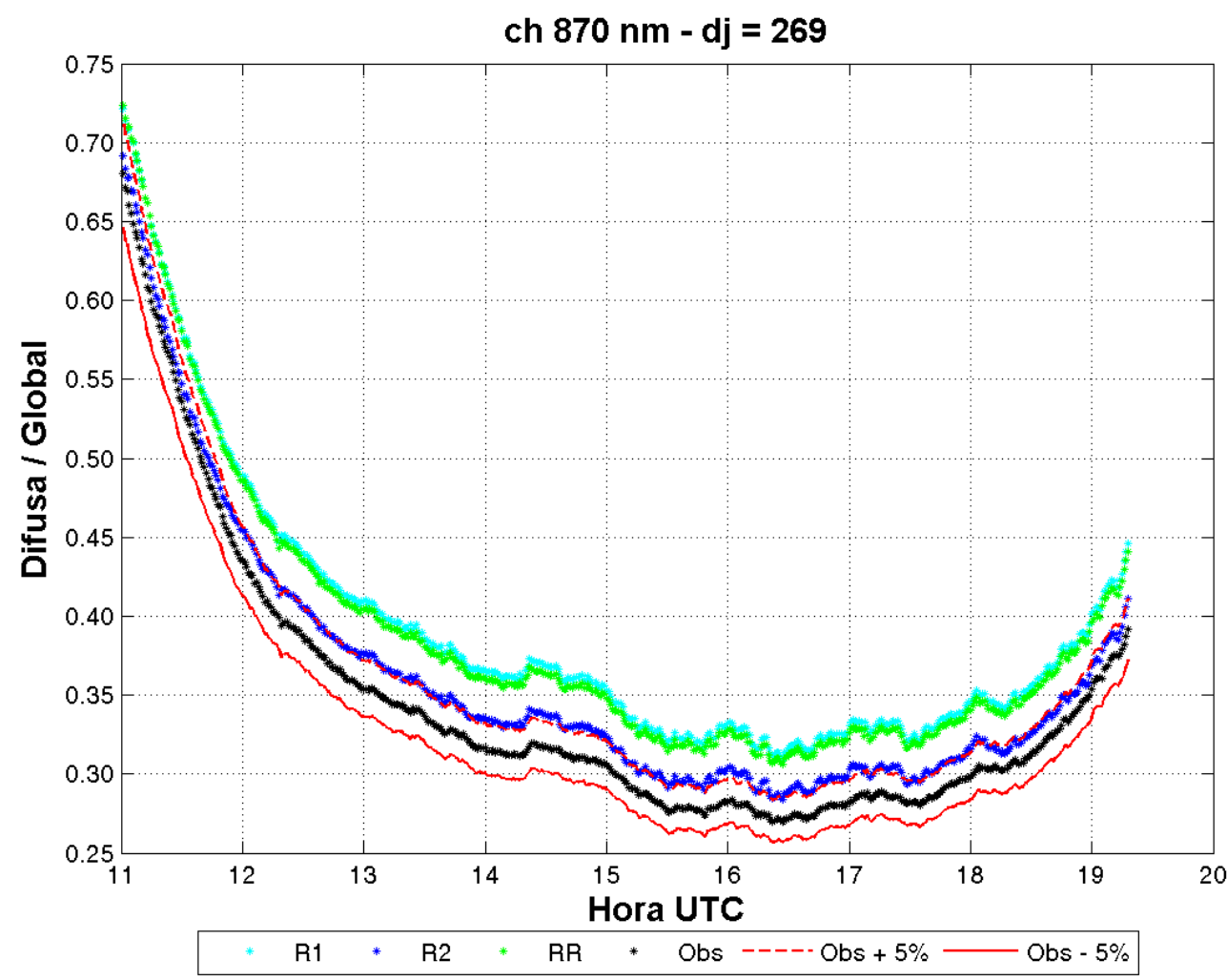


(c)

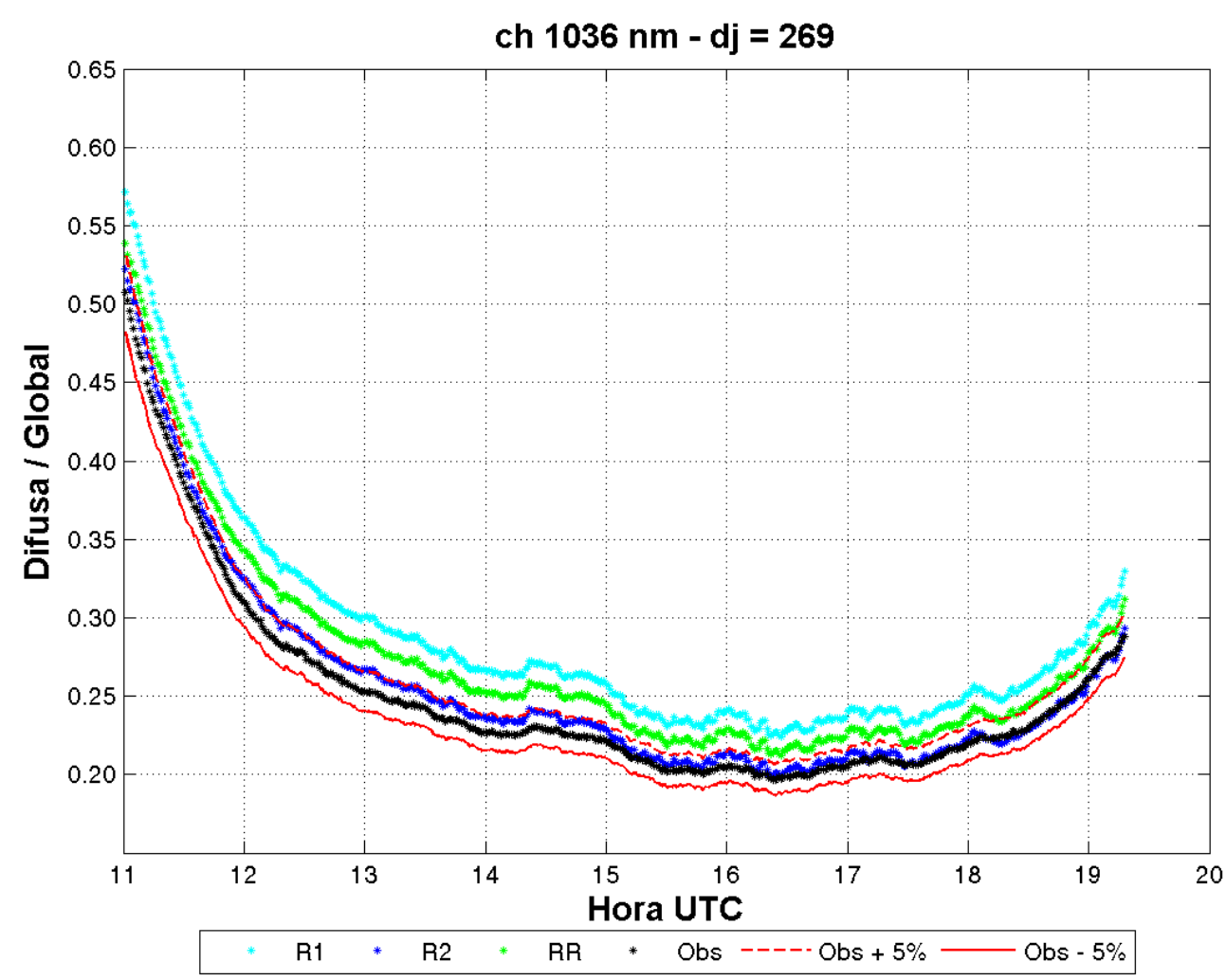

Figura 4.16 - Razão entre a irradiância difusa e global observada e simulada à superfície para os canais de $670 \mathrm{~nm}$ (a), $870 \mathrm{~nm}$ (b) e $1036 \mathrm{~nm}$ (c) para o dia 269. A linha vermelha representa a razão dos valores observados menos $5 \%$ e a linha vermelha tracejada representa o observado mais $5 \%$.

Para avaliar se a divergência observada entre a PAR e as bandas espectrais foi causada pela dependência espectral do modelo óptico, optou-se por avaliar o coeficiente de Ångström e as profundidades ópticas calculadas e observadas. Sayão (2008) comparou as profundidades ópticas obtidas pelo MFRSR e pelo fotômetro solar da AERONET (que passa por um rígido controle de qualidade e calibração) entre os anos de 2004 e 2006. Os resultados obtidos por ele indicaram que os dados são bem correlacionados, apresentando diferenças não muito significativas. Dessa forma os resultados de profundidade óptica obtida pelo MFRSR podem ser considerados confiáveis.

Pelo gráfico da figura 4.17 (a), pode-se notar que a profundidade óptica do aerossol para o canal de $670 \mathrm{~nm}$ obtida com o modelo médio (RR) foi o que apresentou a menor diferença com relação à observada (diferença entre 3 e 5\%). Para os canais e 870 e $1036 \mathrm{~nm}$ é observado o mesmo comportamento, porém a diferença entre os 
valores de profundidade óptica calculados e observados aumenta, chegando a valores acima de $40 \%$ para o canal de $1036 \mathrm{~nm}$ obtidos com o modelo mais espalhador (R1).

Pelos gráficos das figuras 4.17(b), 4.18(b) e 4.19(b), vê-se que existe uma diferença na dependência espectral da AOD observada e a dos modelos ópticos, o que poderia provocar um impacto maior nas bandas espectrais estreitas do que na irradiância PAR. No entanto, a profundidade óptica do aerossol obtida com o modelo médio é a que mais se aproxima dos valores observados, mas esse modelo não é o que apresenta o melhor resultado quando analisada a razão entre as irradiâncias difusa e global. O melhor ajuste é apresentado pelo modelo mais absorvedor (R2) para os três canais de banda estreita analisados.

(a)

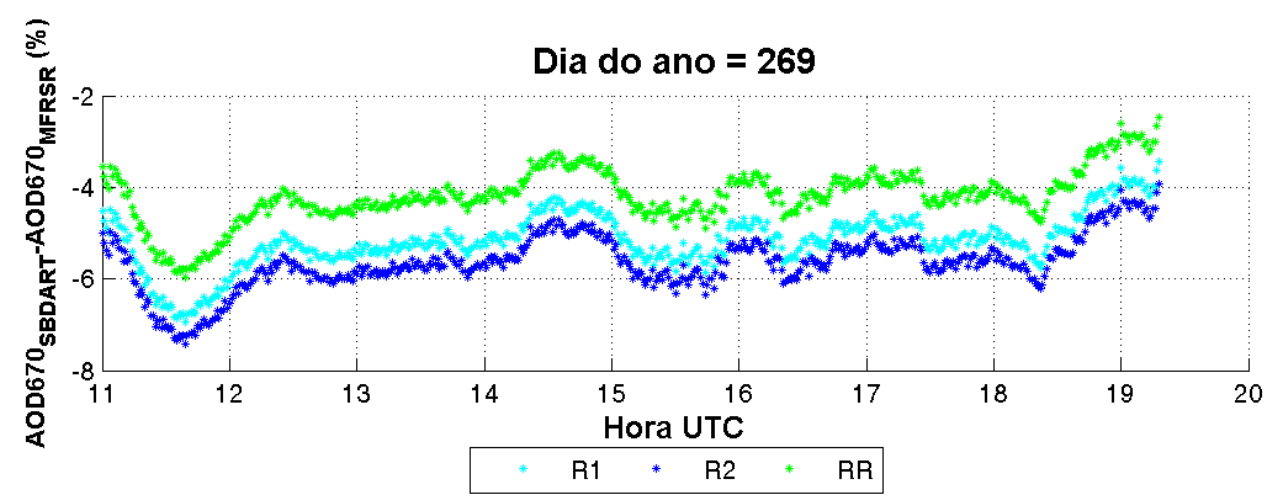

(b)

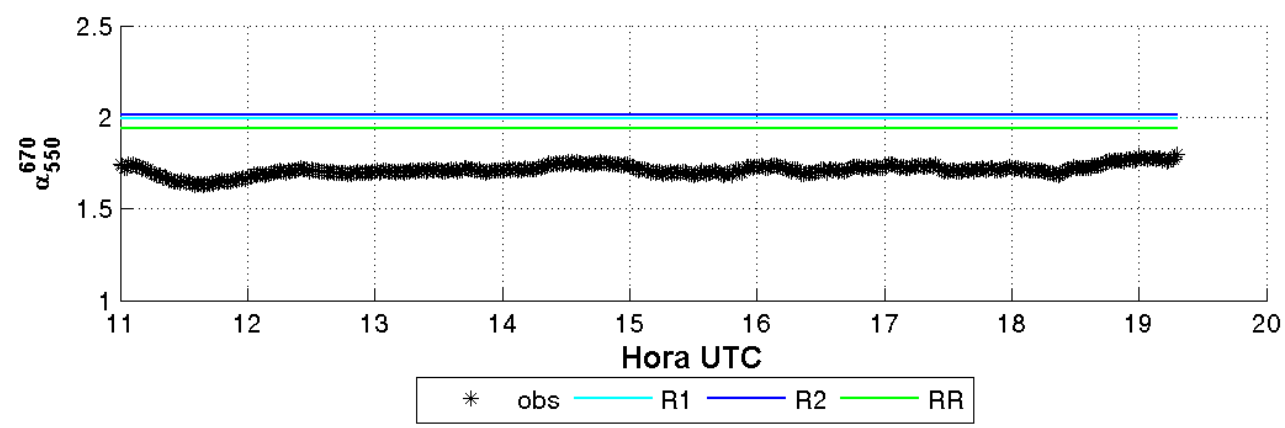

Figura 4.17 - (a) Diferença relativa entre a profundidade óptica de 670nm calculada e observada e (b) coeficiente de Ångström calculado com a profundidade óptica de 670nm obtida pelo MFRSR (em preto) e com o fator de eficiência de extinção dos três modelos ópticos para o dia 269. 
(a)

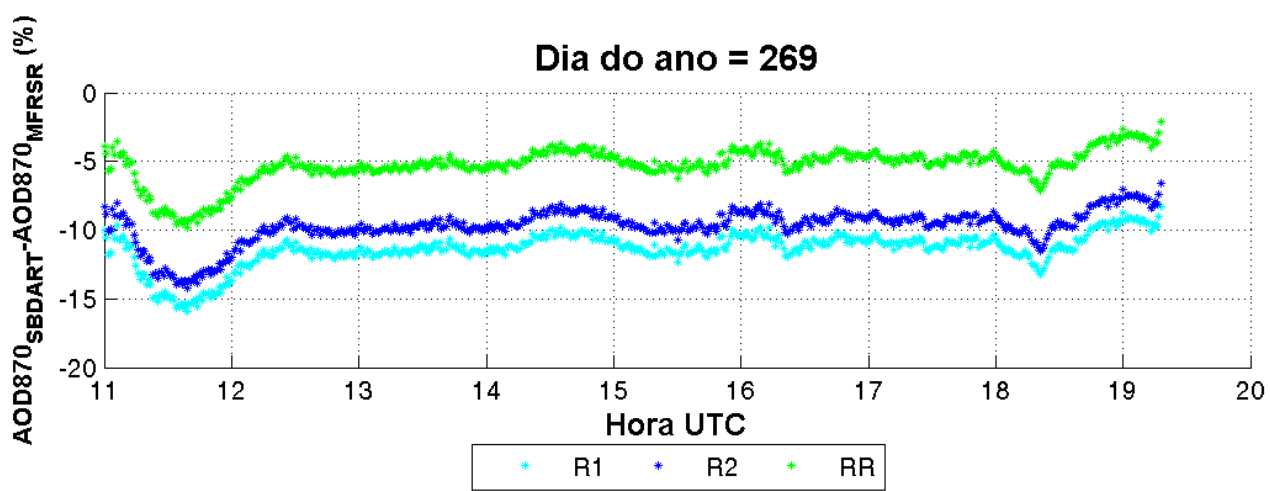

(b)

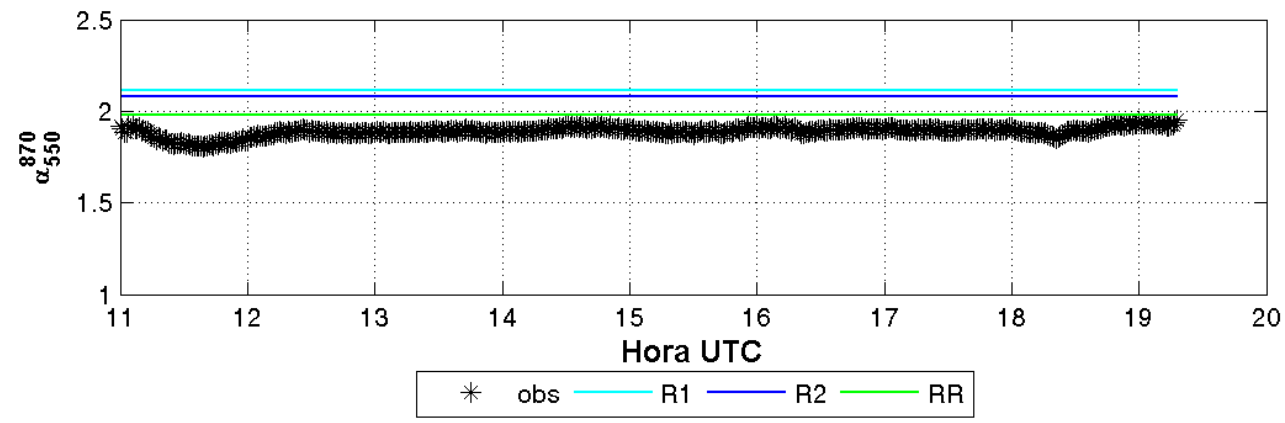

Figura 4.18 - (a) Diferença relativa entre a profundidade óptica de 870nm calculada e observada e (b) coeficiente de Ångström calculado com a profundidade óptica de $870 \mathrm{~nm}$ obtida pelo MFRSR (em preto) e com o fator de eficiência de extinção dos três modelos ópticos para o dia 269. 
(a)

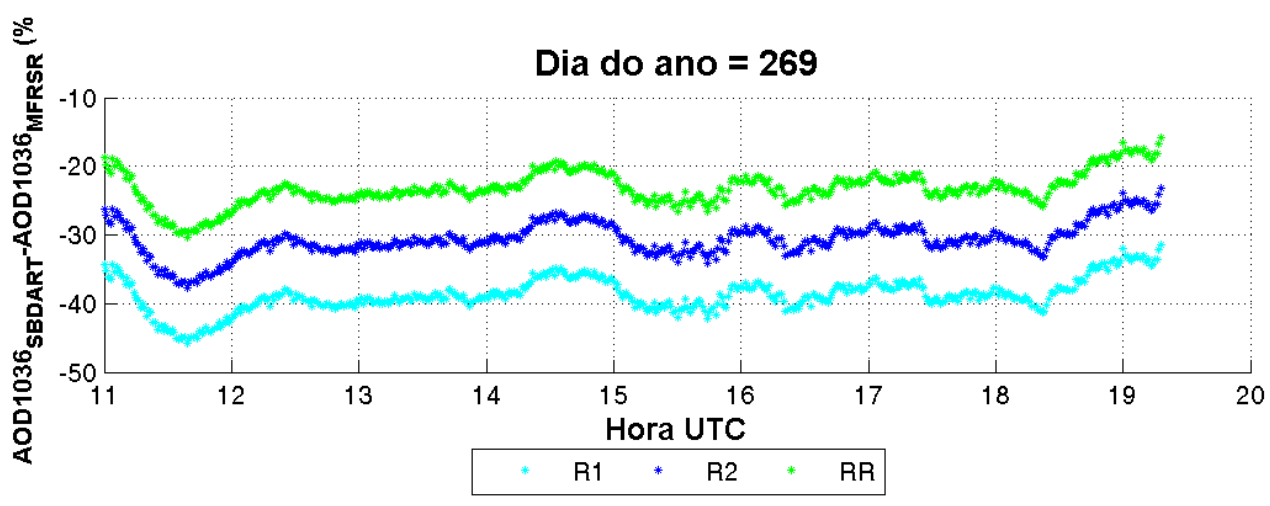

(b)

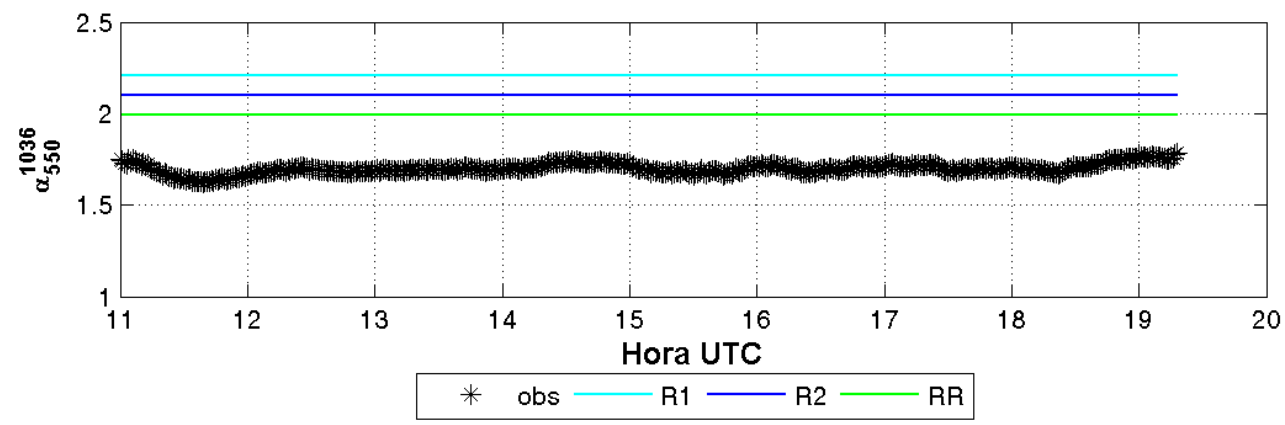

Figura 4.19 - (a) Diferença relativa entre a profundidade óptica de $1036 \mathrm{~nm}$ calculada e observada e (b) coeficiente de Ångström calculado com a profundidade óptica de 1036nm obtida pelo MFRSR (em preto) e com o fator de eficiência de extinção dos três modelos ópticos para o dia 269. 
O dia 250 era um dia bastante poluído, com valores de AOD550 entre 2,5 e 3,0 na maior parte do período (figura 4.20). O coeficiente de Ångström variou pouco, com valores próximos de 2,0 na maior parte do dia. Neste caso, o modelo óptico que apresentou a melhor aproximação em relação à irradiância PAR observada foi o modelo R1.

(a)

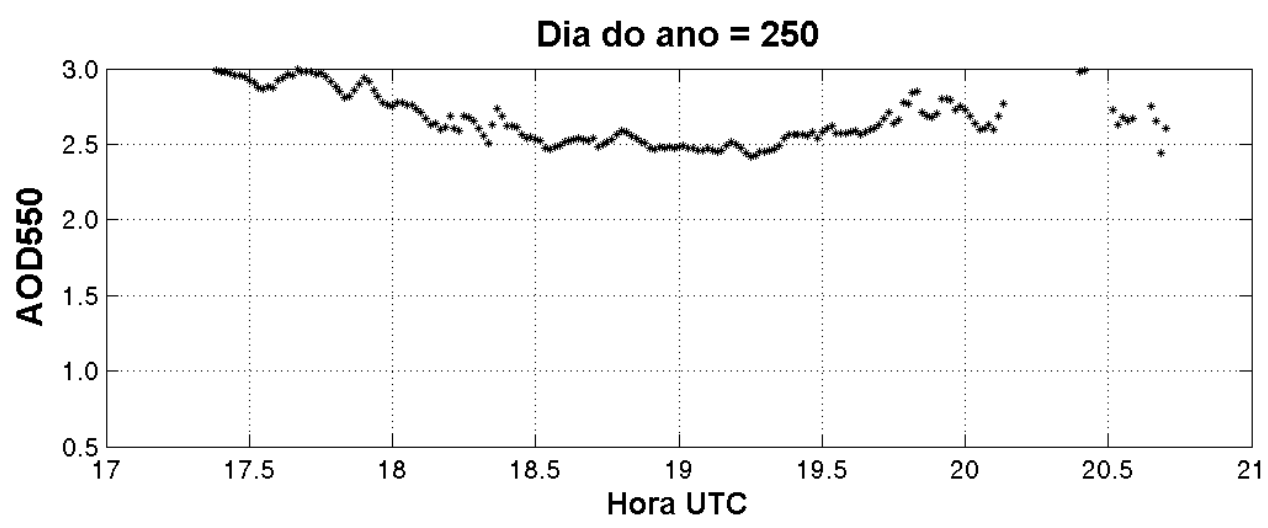

(b)

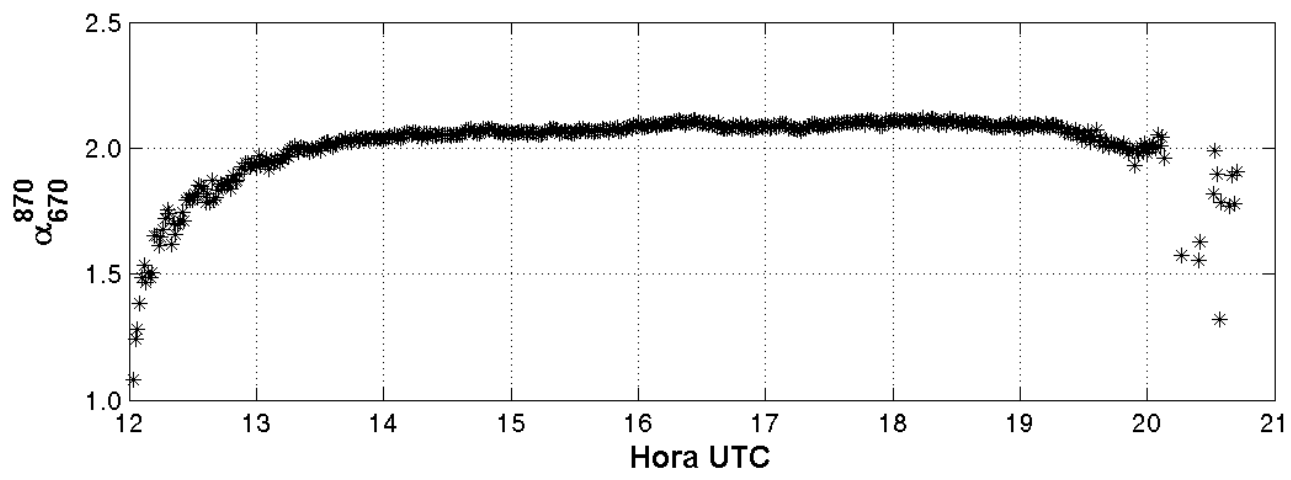

Figura 4.20 - Valores da profundidade óptica em 550nm (a) e do coeficiente de Ångström (b) para o dia do ano 250 . 


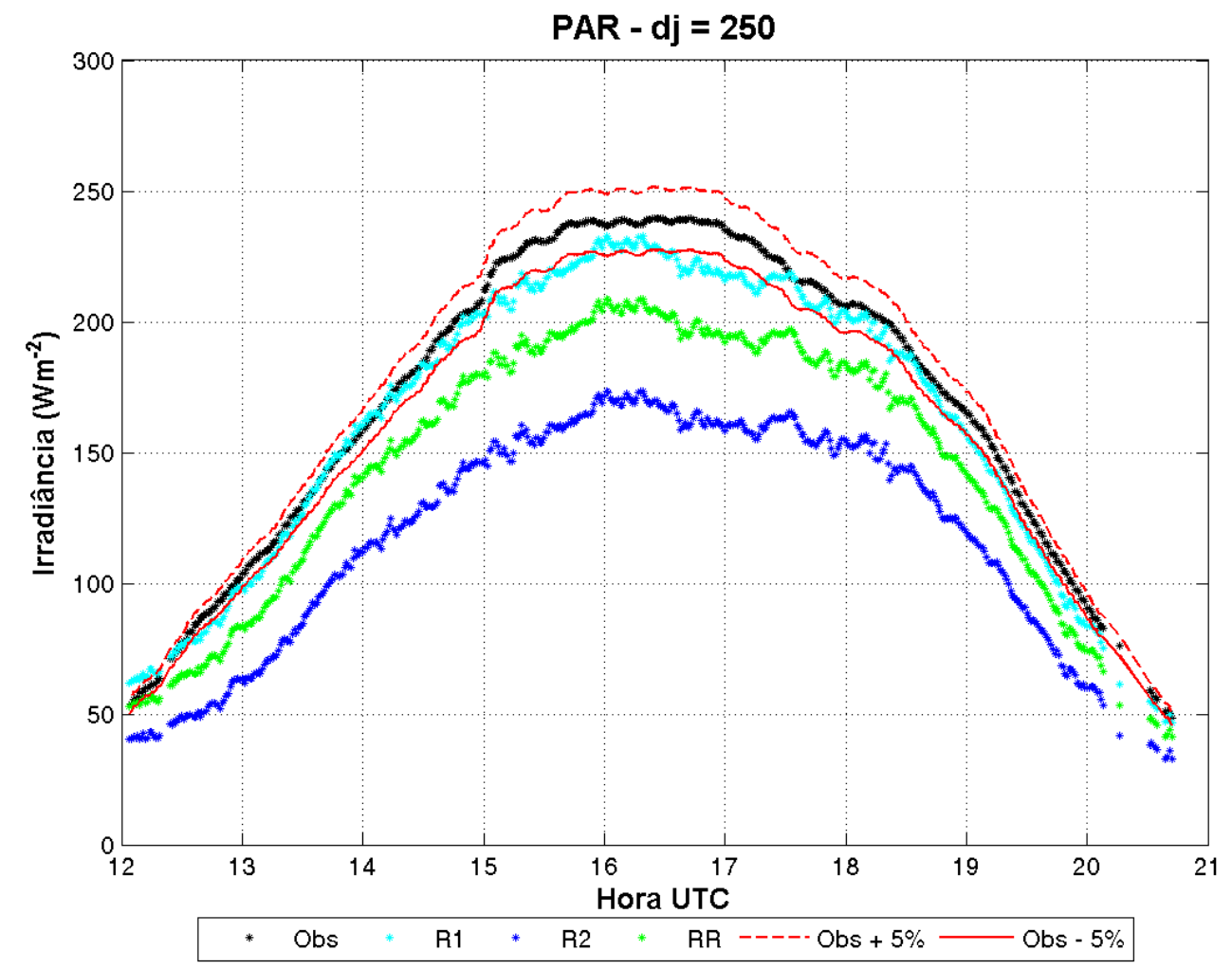

Figura 4.21 - Irradiância PAR observada e simulada à superfície para o dia 250. A linha vermelha representa o valor observado menos $5 \%$ e a linha vermelha tracejada representa o observado mais $5 \%$.

Nos canais de $670 \mathrm{~nm}$ e $870 \mathrm{~nm}$, os resultados obtidos com os três modelos se encontraram dentro dos limites de 5\% de incerteza. No canal de $1036 \mathrm{~nm}$ os resultados obtidos com os modelos RR e R2 são os que mais se aproximaram dos valores observados. As diferenças neste caso não foram tão grandes como as observadas para o dia 269, porém pode-se notar a mesma tendência dos canais de banda estreita em se ajustar melhor com as simulações efetuadas com um modelo mais absorvedor do que o da irradiância PAR. As diferenças entre as profundidades ópticas observadas e as calculadas, assim como no dia 269, também aumentaram com o comprimento de onda analisado. O coeficiente de Ångström calculado com os modelos ópticos não apresentou, na maior parte do período, diferenças superiores a 0,2 daquele calculado com o valor de profundidade óptica observado. 
(a)

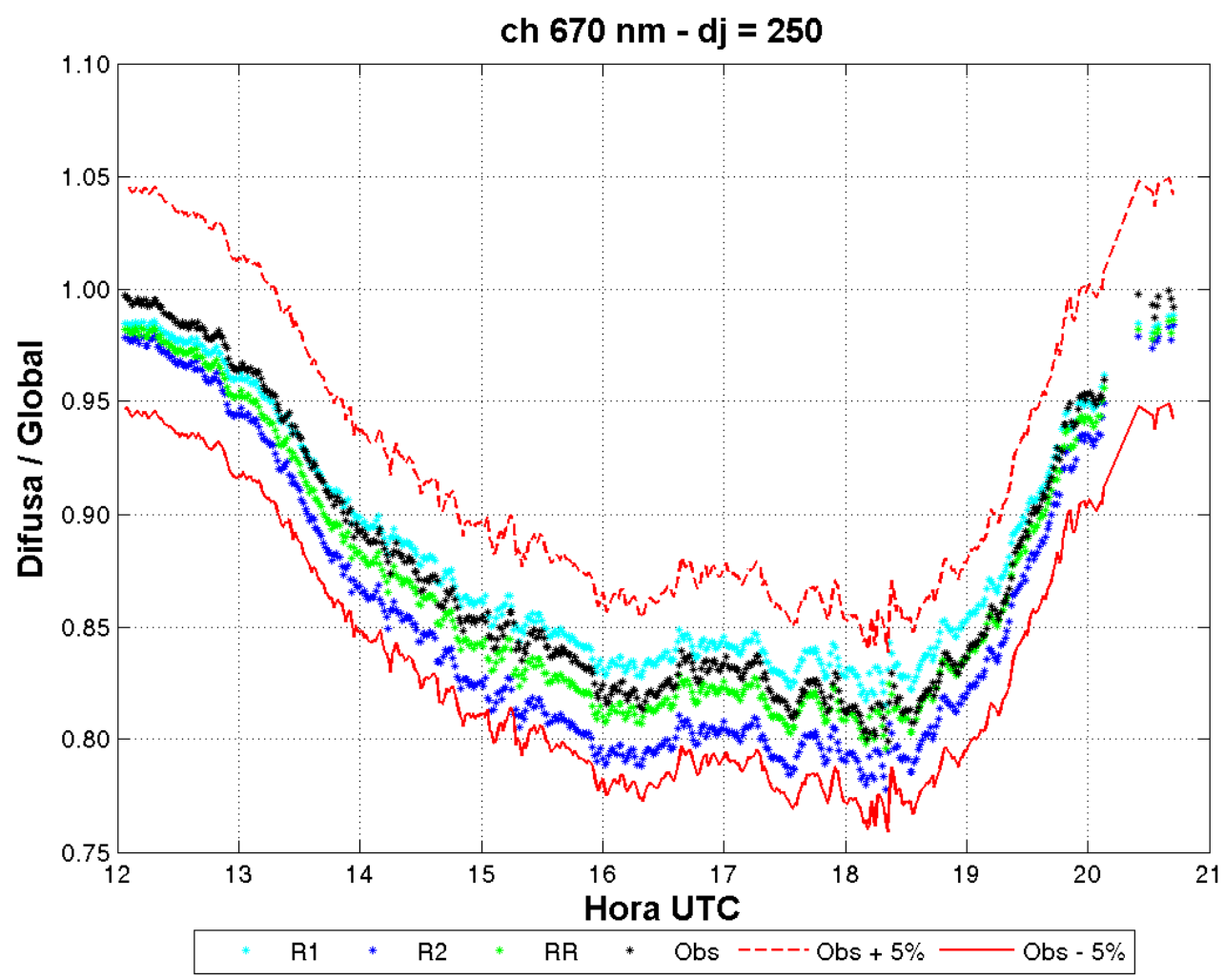

(b)

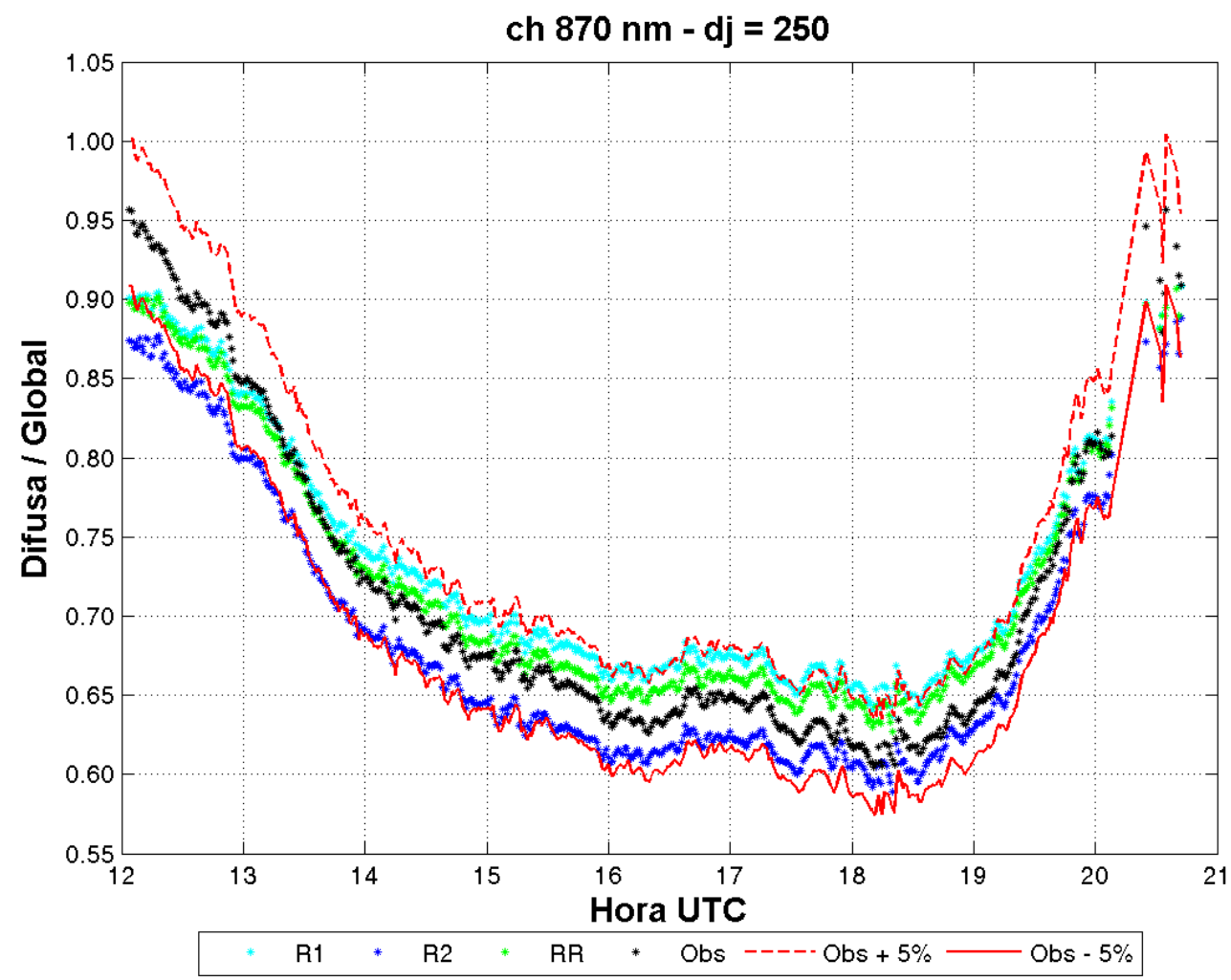


(c)

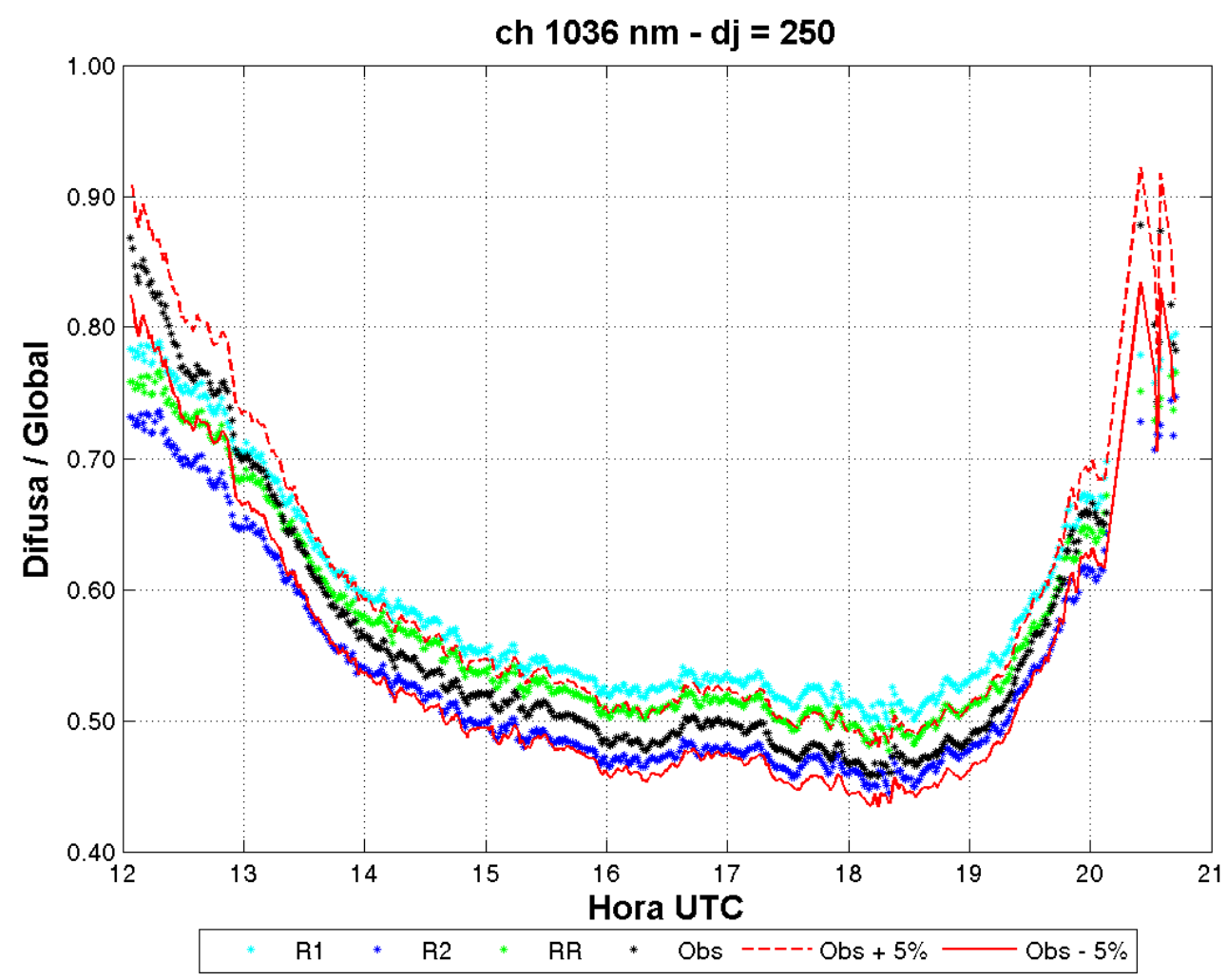

Figura 4.22 - Razão entre a irradiância difusa e global observada e simulada à superfície para os canais de $670 \mathrm{~nm}$ (a), $870 \mathrm{~nm}$ (b) e $1036 \mathrm{~nm}$ (c) para o dia 250. A linha vermelha representa a razão dos valores observados menos $5 \%$ e a linha vermelha tracejada representa o observado mais $5 \%$. 
(a)

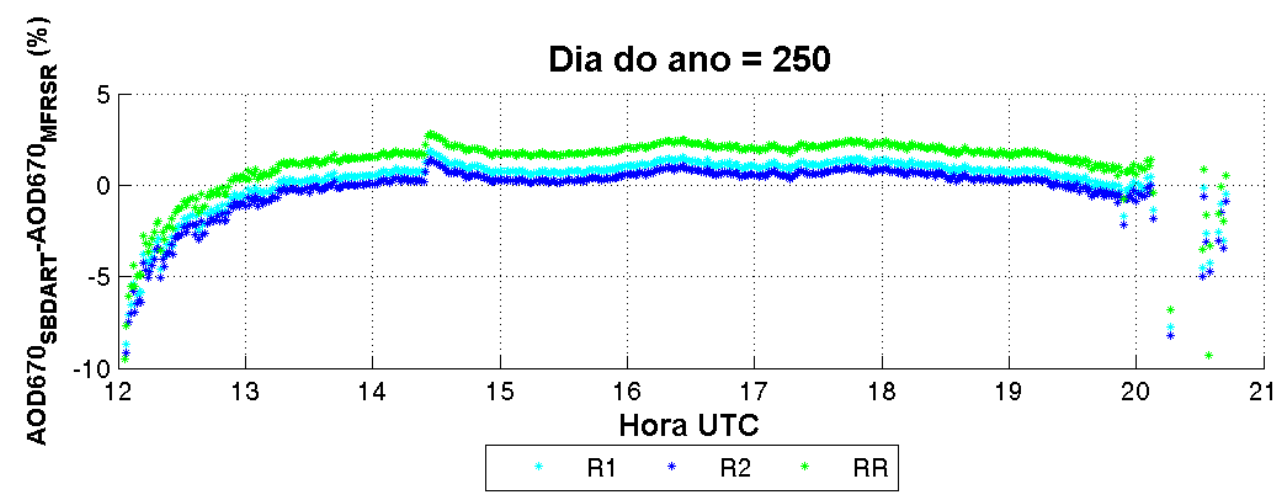

(b)

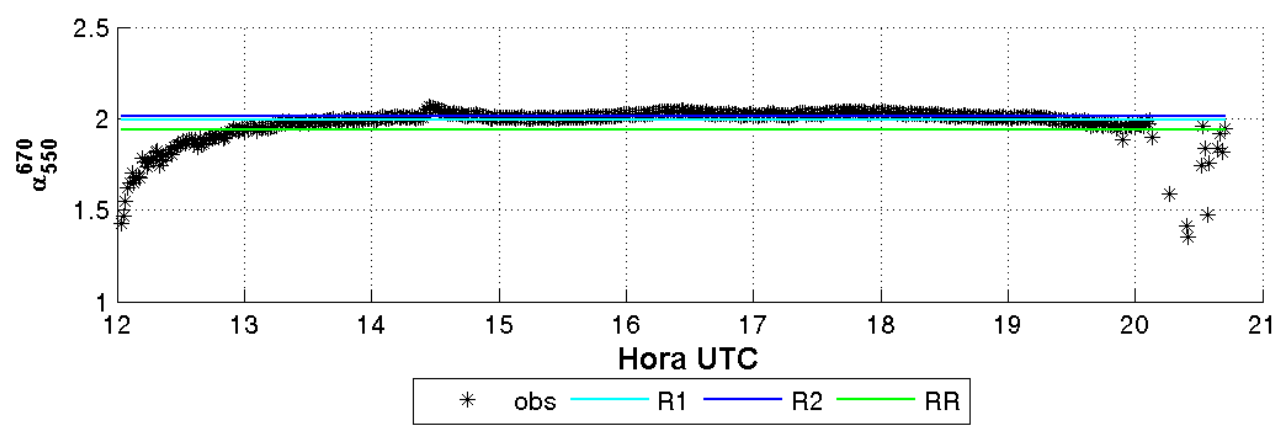

Figura 4.23 - (a) Diferença relativa entre a profundidade óptica de $670 \mathrm{~nm}$ calculada e observada e (b) coeficiente de Ångström calculado com a profundidade óptica de $670 \mathrm{~nm}$ obtida pelo MFRSR (em preto) e com o fator de eficiência de extinção dos três modelos ópticos para o dia 250. 
(a)

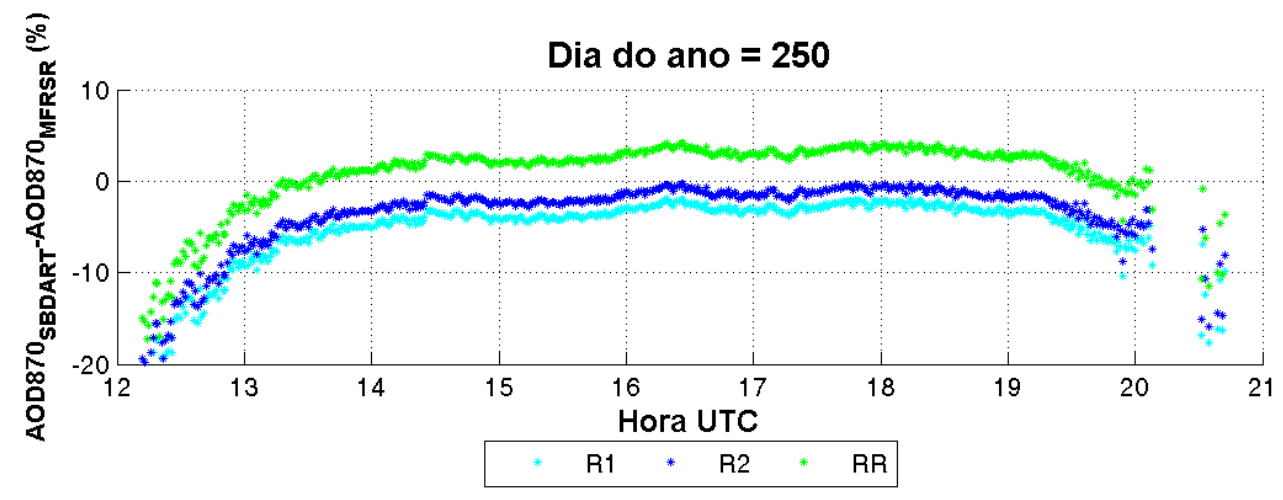

(b)

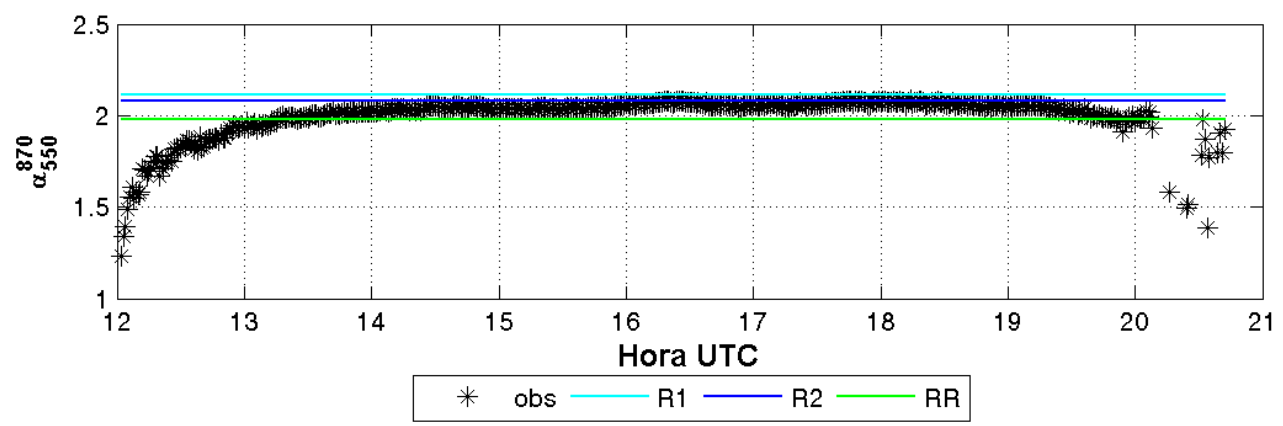

Figura 4.24 - (a) Diferença relativa entre a profundidade óptica de 870nm calculada e observada e (b) coeficiente de Ångström calculado com a profundidade óptica de $870 \mathrm{~nm}$ obtida pelo MFRSR (em preto) e com o fator de eficiência de extinção dos três modelos ópticos para o dia 250. 
(a)

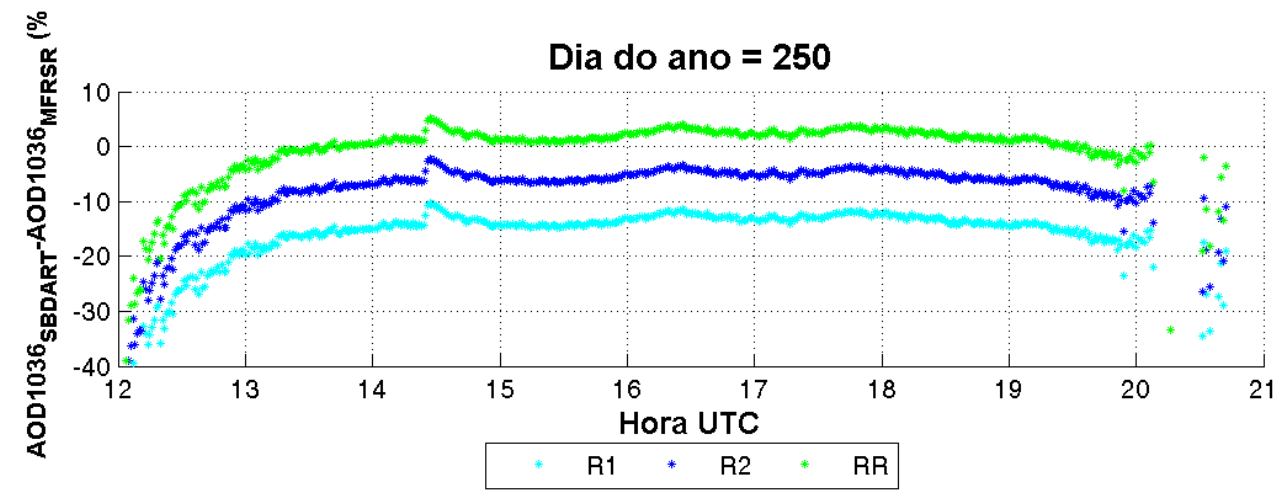

(b)

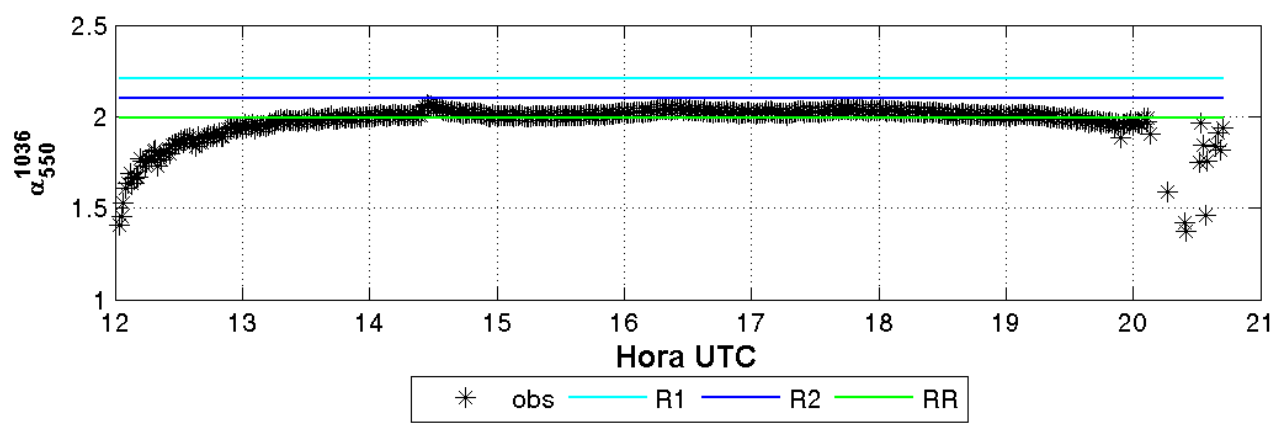

Figura 4.25 - (a) Diferença relativa entre a profundidade óptica de $1036 \mathrm{~nm}$ calculada e observada e (b) coeficiente de Ångström calculado com a profundidade óptica de $1036 \mathrm{~nm}$ obtida pelo MFRSR (em preto) e com o fator de eficiência de extinção dos três modelos ópticos para o dia 250. 
Na figura 4.26 são apresentados os valores de AOD550 e do coeficiente de Ångström para o dia 236. O coeficiente de Ångström não variou muito, ficando entre 1,8 e 2,0; a AOD550 na maior parte do período ficou entre 1,3 e 1,5, porém no final do dia os valores ficaram próximos de 1,0. A figura 4.27 apresenta a comparação entre a irradiância PAR medida e os valores calculados pelo SBDART com os modelos ópticos para o aerossol de queimadas para o mesmo dia. É possível observar que os valores obtidos pelo modelo R1 são os que mais se aproximaram dos valores observados. Os outros modelos, na maior parte do período, subestimaram os valores observados.

(a)

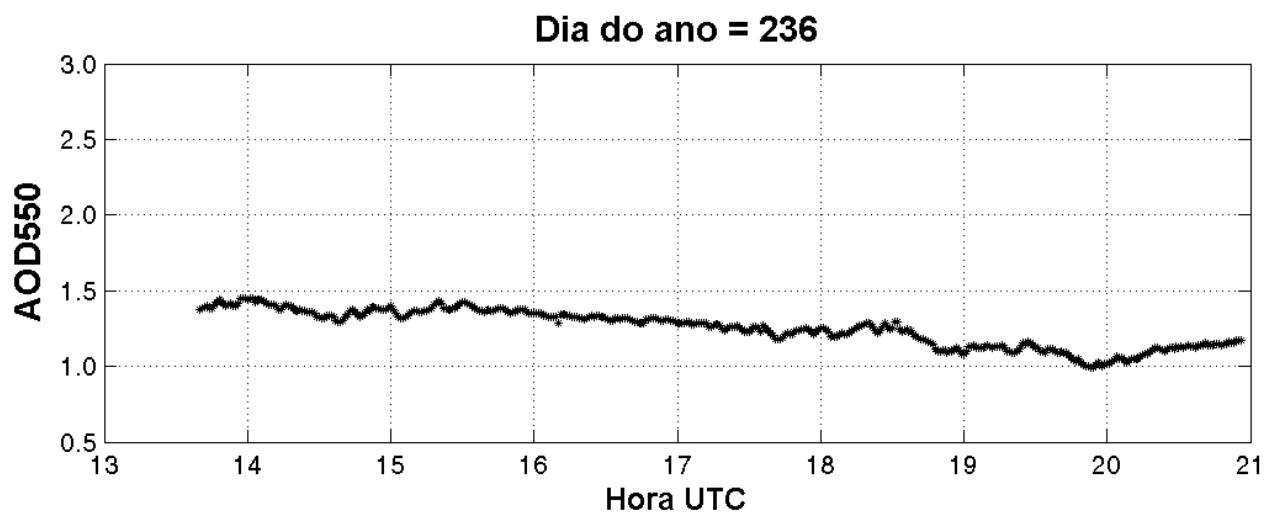

(b)

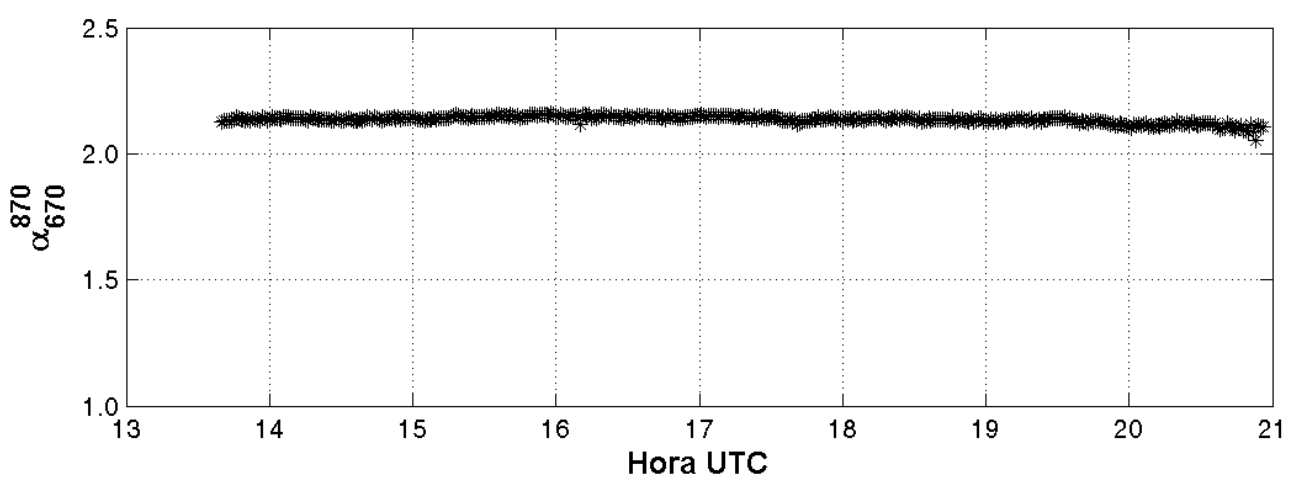

Figura 4.26 - Valores da profundidade óptica em 550nm (a) e do coeficiente de Ångström (b) para o dia do ano 236. 


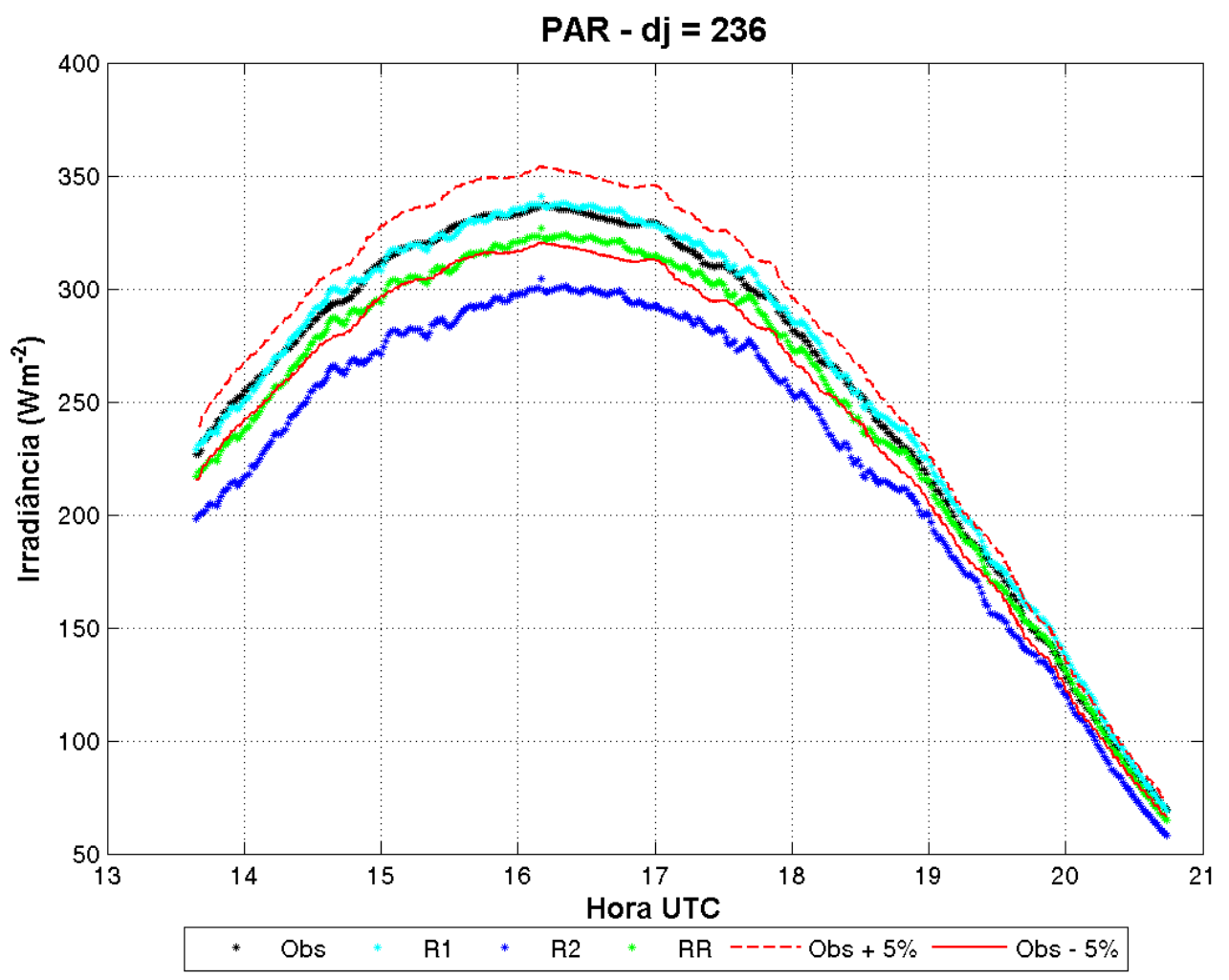

Figura 4.27 - Irradiância PAR observada e simulada à superfície para o dia 236. A linha vermelha representa o valor observado menos $5 \%$ e a linha vermelha tracejada representa o observado mais $5 \%$.

Pelo gráfico da figura 4.28, observa-se que para o canal de $670 \mathrm{~nm}$, os valores calculados com o modelo mais absorvedor é o que mais se aproximaram dos valores obtidos com o MFRSR. O modelo médio (RR) ficou na maior parte do período dentro do intervalo de diferença de 5\%. Nesse canal, ao contrário do que ocorreu para os dias 269 e 250, o modelo óptico que melhor ajustou os valores observados não foi o mesmo que resultou em melhor concordância com a região espectral da irradiância PAR. Na maior parte do período, nenhum dos modelos apresentou diferenças menores do que 5\% dos valores observados nos canais de 870 e $1036 \mathrm{~nm}$.

Note-se que a profundidade óptica do aerossol calculada com os três modelos ópticos apresentou uma diferença do valor observado de aproximadamente $2 \%$, ou menor, para o canal de $670 \mathrm{~nm}$. Por esse motivo, as diferenças observadas para as irradiâncias não são devidas à estimativa incorreta da AOD no código de transferência radiativa. Diferenças da ordem de 5\% foram observadas para o canal de $870 \mathrm{~nm}$ e de até $30 \%$ para o canal de $1036 \mathrm{~nm}$. O coeficiente de Ångström por sua vez apresentou 
resultados bastante similares aos três modelos para os canais de 670 e $870 \mathrm{~nm}$. No canal de 1036 nm, o coeficiente de Ångström obtido com o RR foi o que se aproximou mais do valor calculado com a profundidade óptica de $1036 \mathrm{~nm}$ observada. Para os três canais de banda estreita, o modelo que apresentou os resultados mais próximos dos observados foi o modelo mais absorvedor,o que reforça a hipótese de que a degradação instrumental seja a responsável pelas diferenças observadas entre a irradiância PAR e os canais analisados.

(a)

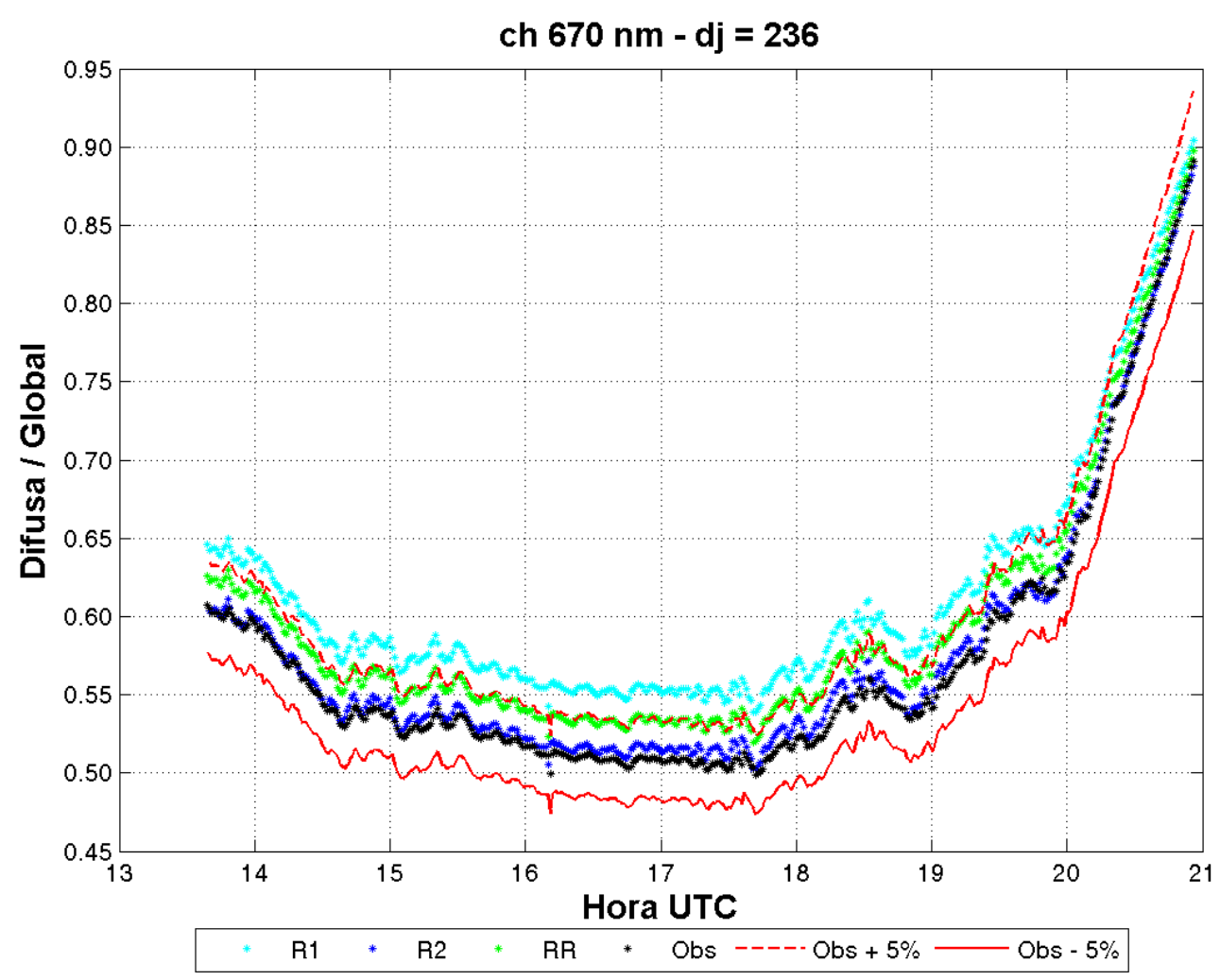


(b)

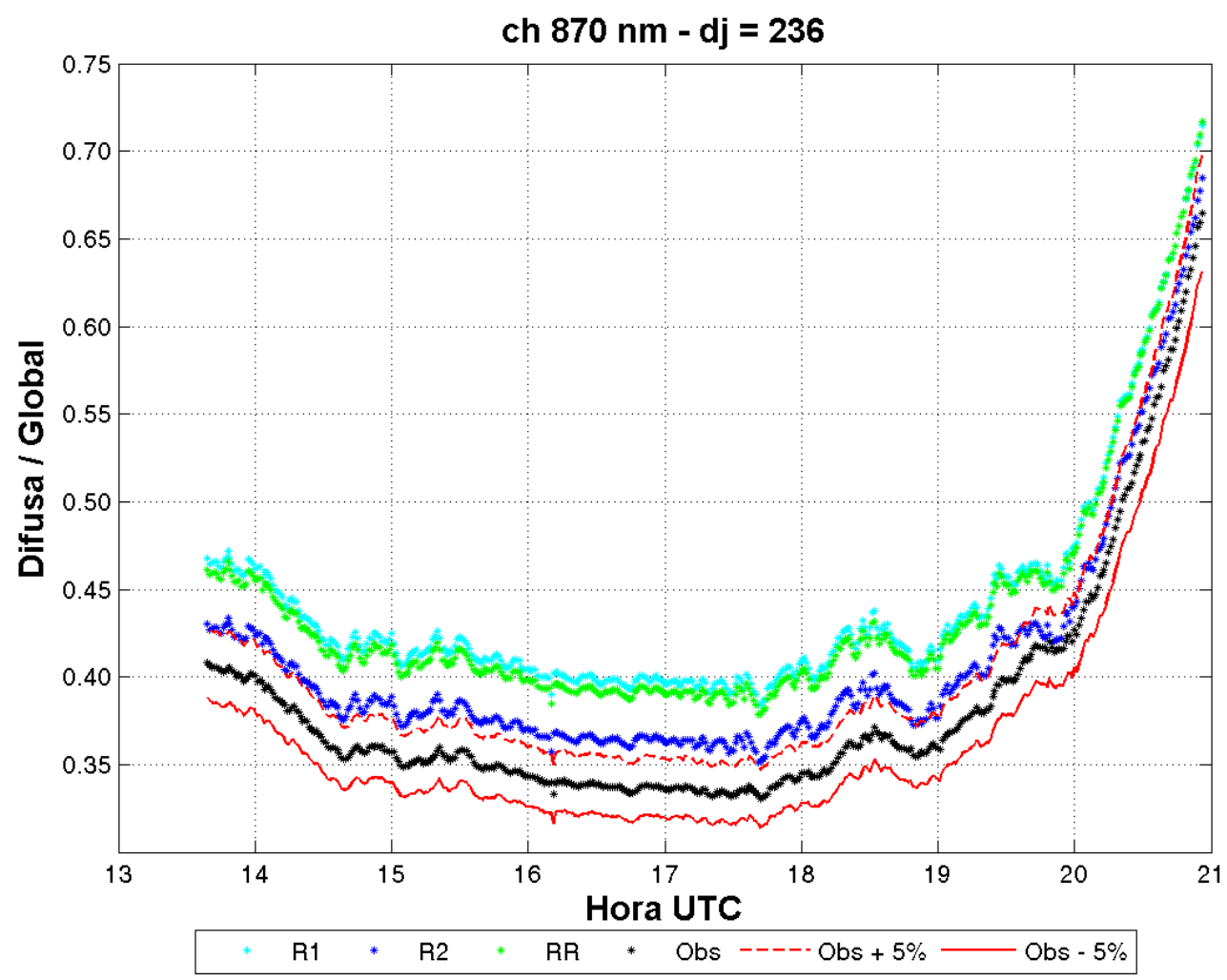

(c)

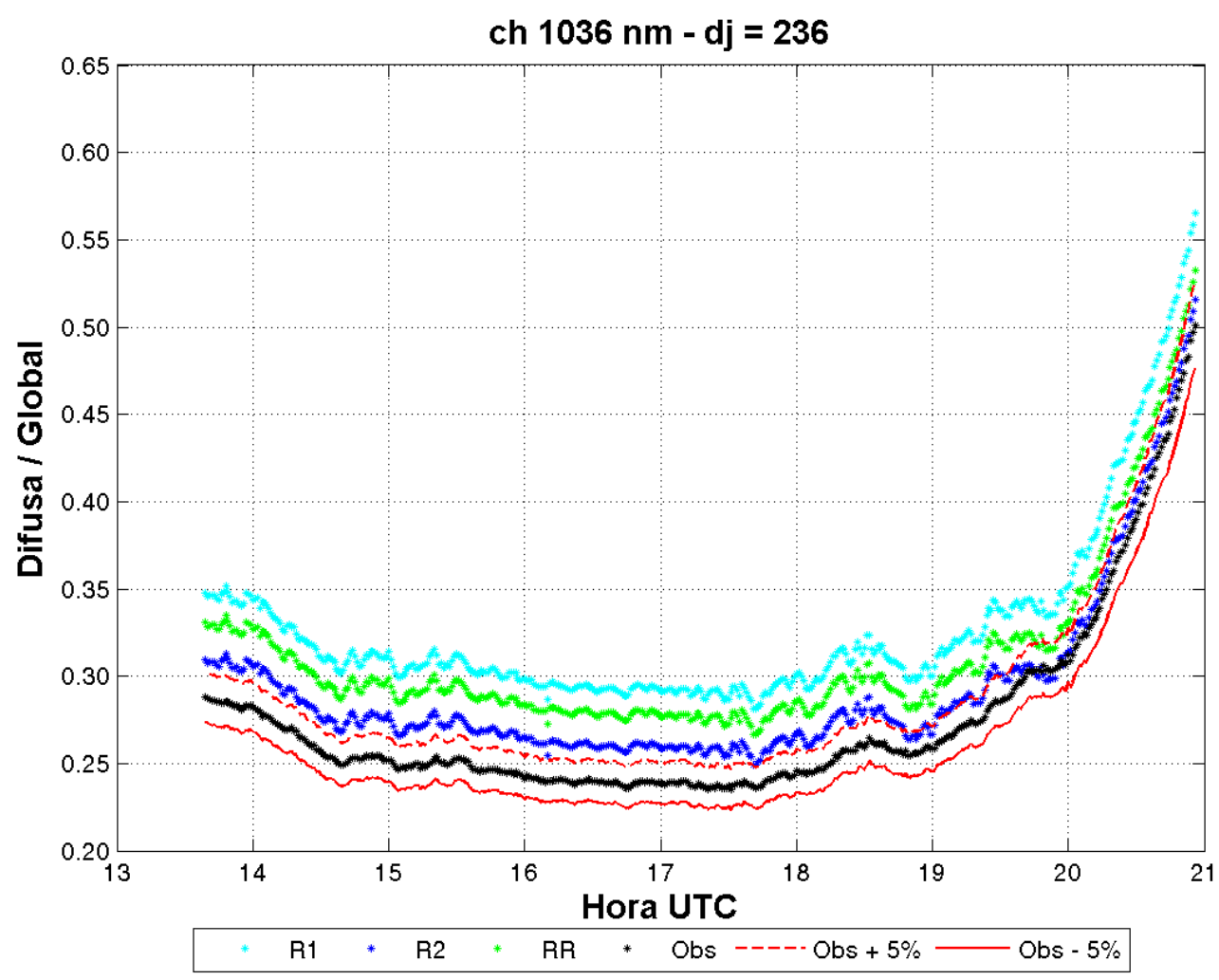

Figura 4.28 - Razão entre a irradiância difusa e global observada e simulada à superfície para os canais de $670 \mathrm{~nm}$ (a), $870 \mathrm{~nm}$ (b) e $1036 \mathrm{~nm}$ (c) para o dia 236. A linha vermelha representa a razão dos valores observados menos $5 \%$ e a linha vermelha tracejada representa o observado mais $5 \%$. 
(a)

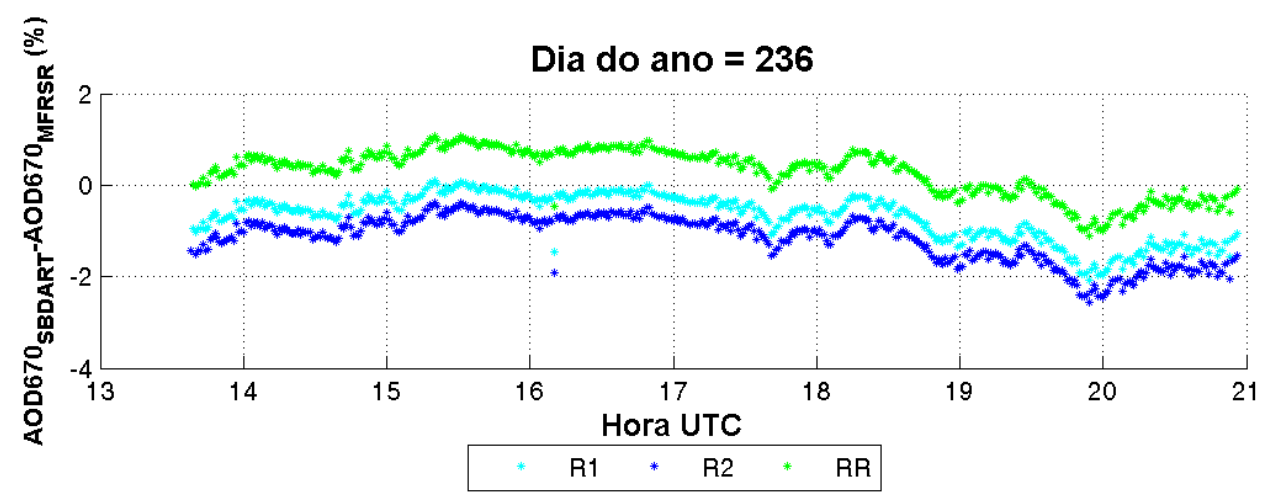

(b)

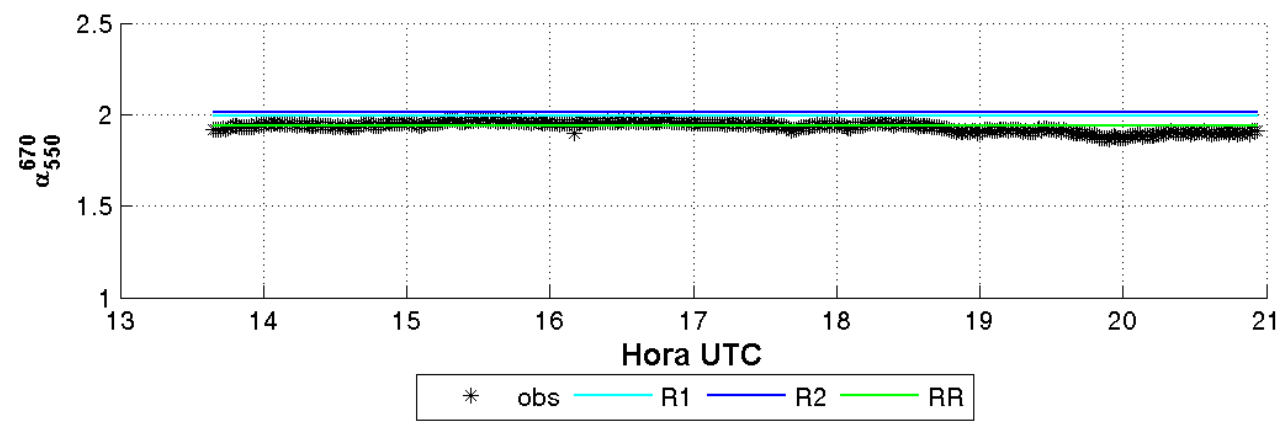

Figura 4.29 - (a) Diferença relativa entre a profundidade óptica de 670nm calculada e observada e (b) coeficiente de Ångström calculado com a profundidade óptica de 670nm obtida pelo MFRSR (em preto) e com o fator de eficiência de extinção dos três modelos ópticos para o dia 236. 
(a)

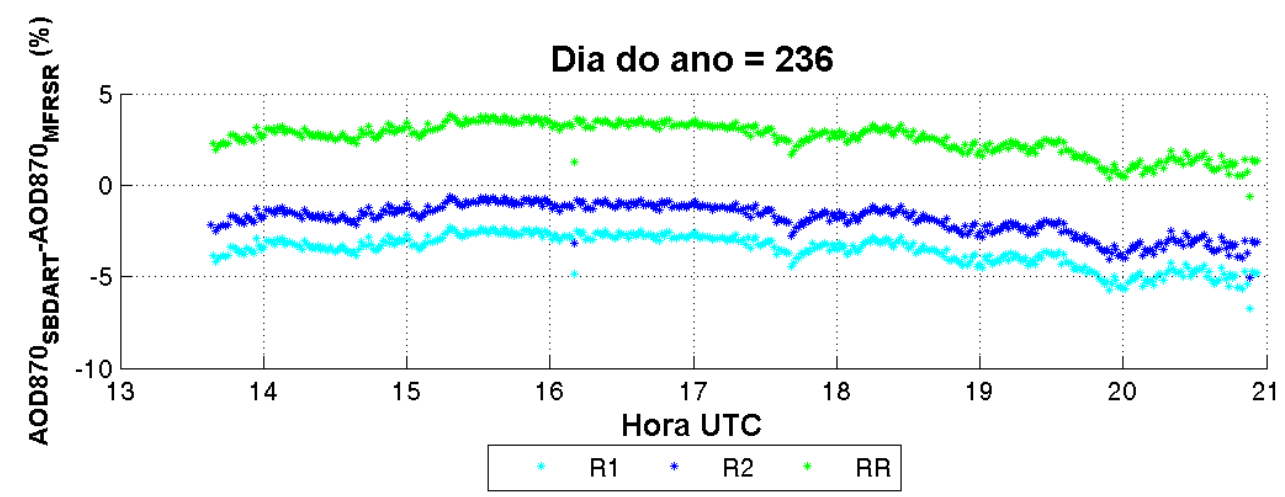

(b)

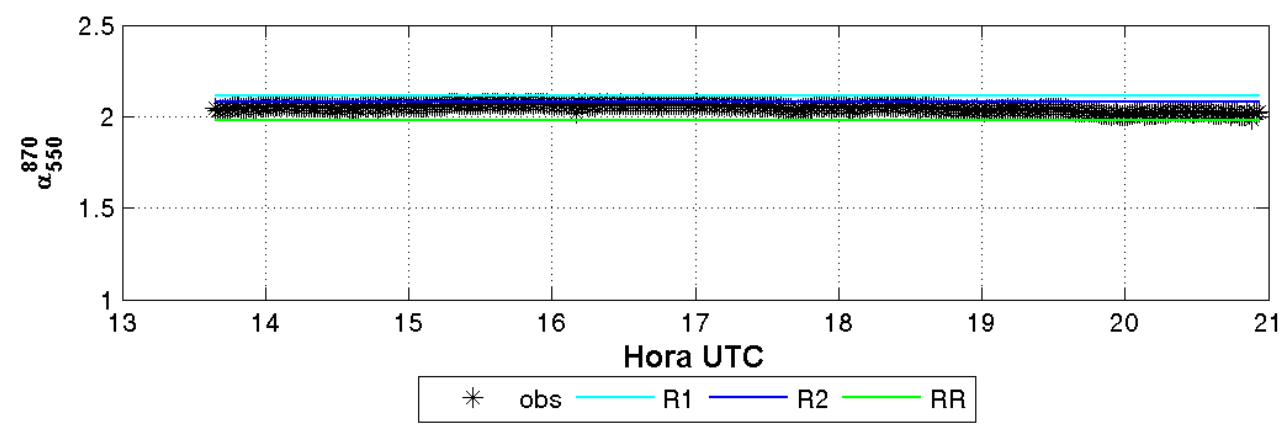

Figura 4.30 - (a) Diferença relativa entre a profundidade óptica de $870 \mathrm{~nm}$ calculada e observada e (b) coeficiente de Ångström calculado com a profundidade óptica de $870 \mathrm{~nm}$ obtida pelo MFRSR (em preto) e com o fator de eficiência de extinção dos três modelos ópticos para o dia 236. 
(a)

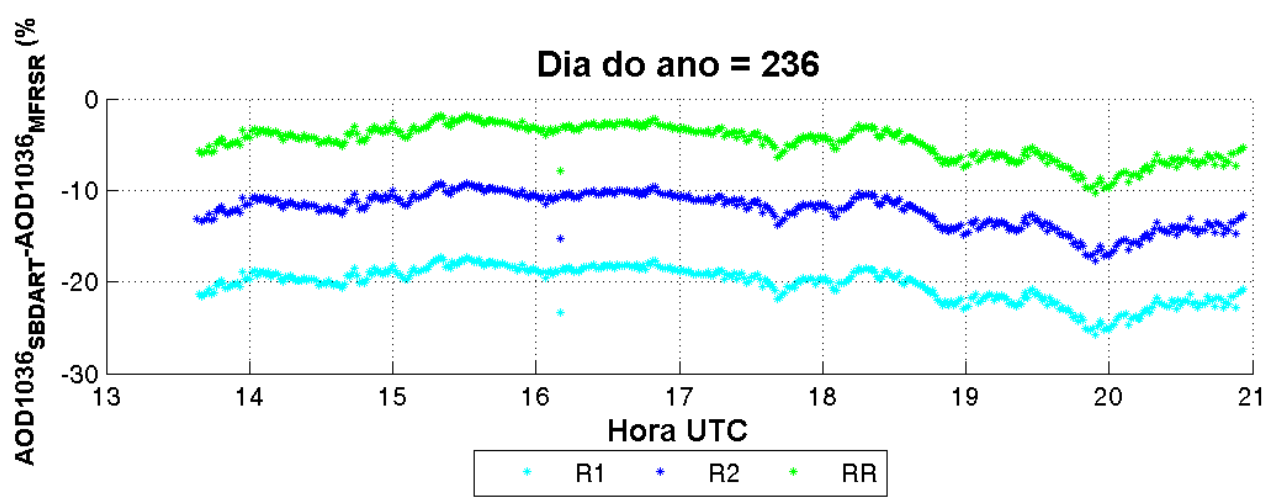

(b)

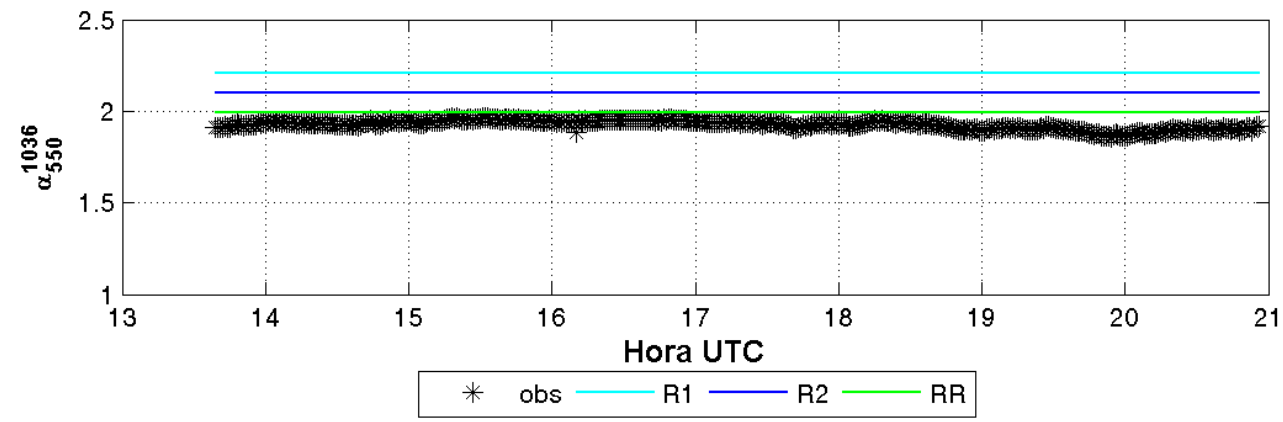

Figura 4.31 - (a) Diferença relativa entre a profundidade óptica de $1036 \mathrm{~nm}$ calculada e observada e (b) coeficiente de Ångström calculado com a profundidade óptica de $1036 \mathrm{~nm}$ obtida pelo MFRSR (em preto) e com o fator de eficiência de extinção dos três modelos ópticos para o dia 236.

O dia 237 apresentou valores de AOD550 moderados, variando entre 1,0 e 1,4. O coeficiente de Ångström variou pouco, mantendo valores entre 2,0 e 2,3. Assim como no dia 236, o modelo mais espalhador é o que apresentou o melhor ajuste com os dados de irradiância PAR obtidos em superfície. Para os canais de 670, 870 e 1036 o modelo mais absorvedor é o mais próximo do observado.

Assim como o observado no dia 236, o coeficiente de Ångström calculado com os canais de 670 e $870 \mathrm{~nm}$ apresentou valores próximos dos coeficientes obtidos com os modelos ópticos. Já para o canal de 1036 nm, o modelo médio é o que apresentou valores mais próximos. A profundidade óptica do aerossol em $670 \mathrm{~nm}$ calculada com o modelo absorvedor apresentou valores mais próximos dos observados até aproximadamente 13 e 14 UTC e após esse período, o modelo mais espalhador 
apresentou o melhor ajuste. No canal de $870 \mathrm{~nm}$, a profundidade óptica calculada com o modelo absorvedor se ajustou melhor. Os valores mais próximos de profundidade óptica para o canal de $1036 \mathrm{~nm}$ foram apresentados pelo modelo médio.

(a)

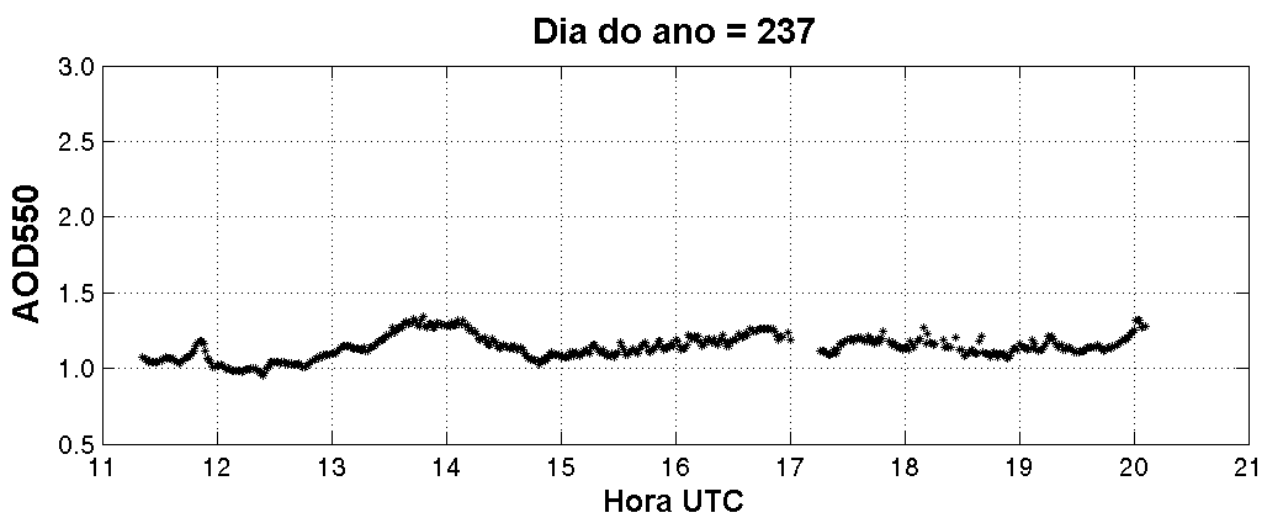

(b)

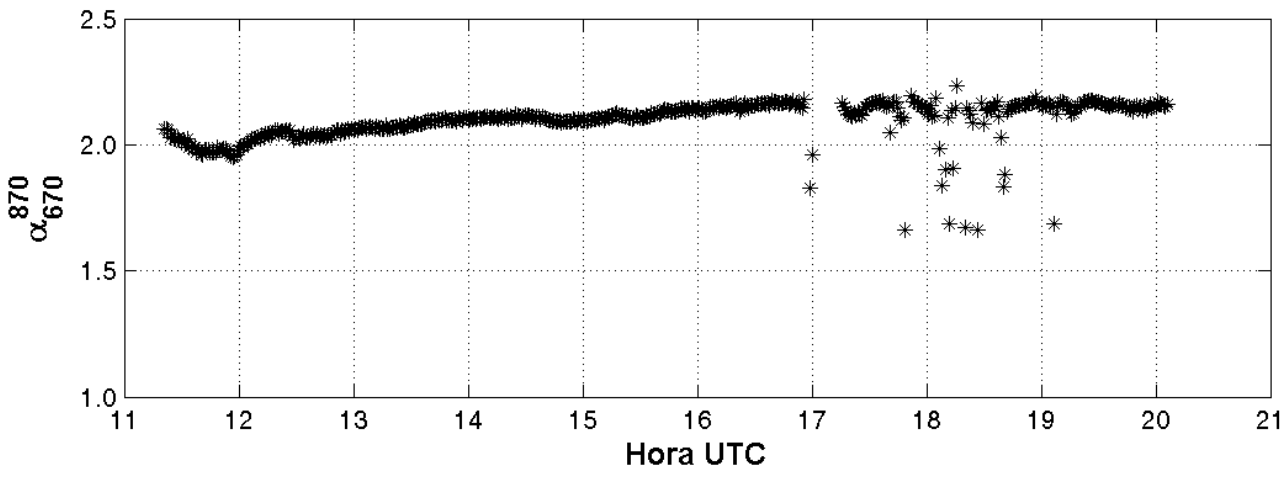

Figura 4.32 - Valores da profundidade óptica em 550nm (a) e do coeficiente de Ångström (b) para o dia do ano 237. 


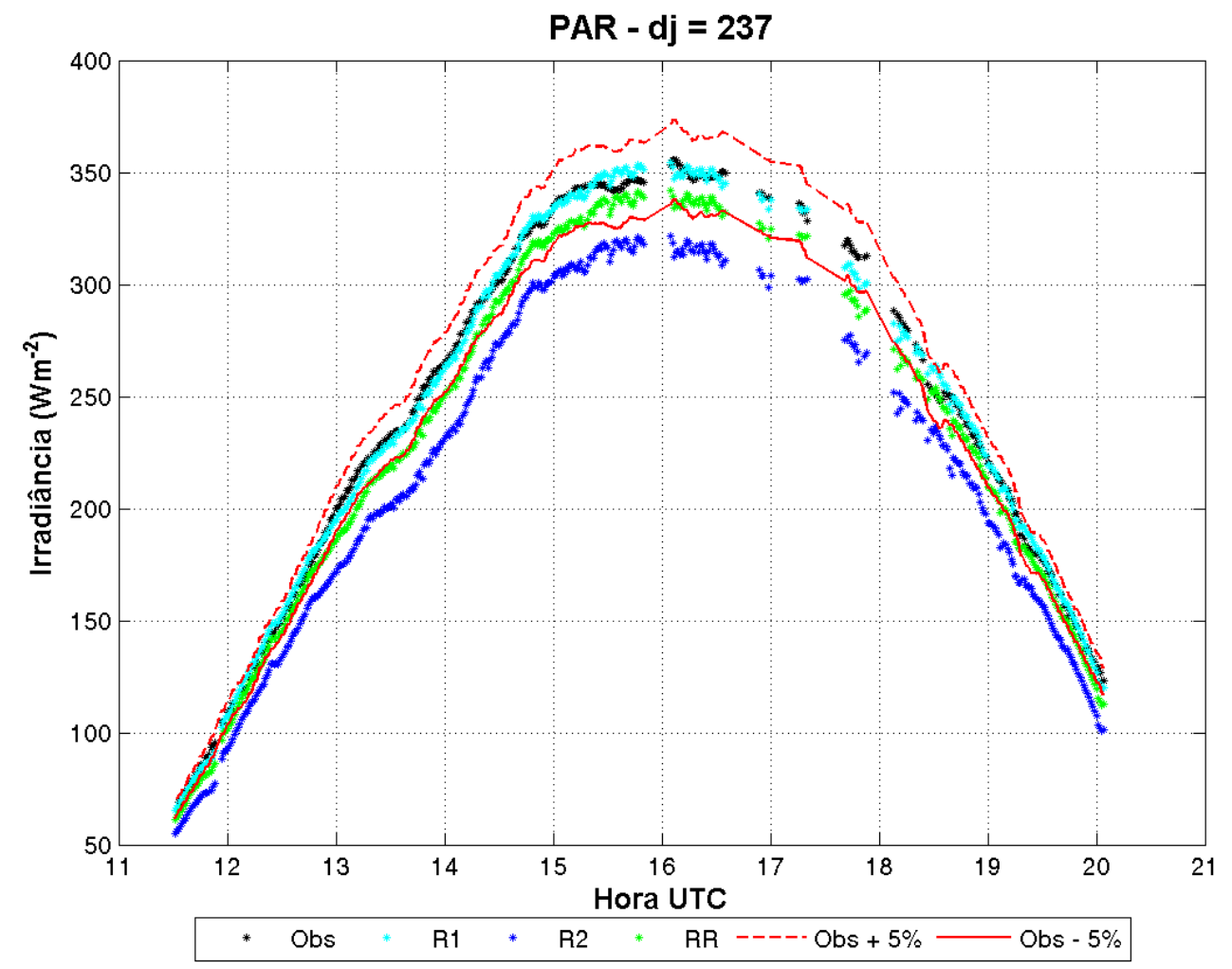

Figura 4.33 - Irradiância PAR observada e simulada à superfície para o dia 237. A linha vermelha representa o valor observado menos $5 \%$ e a linha vermelha tracejada representa o observado mais $5 \%$.

(a)

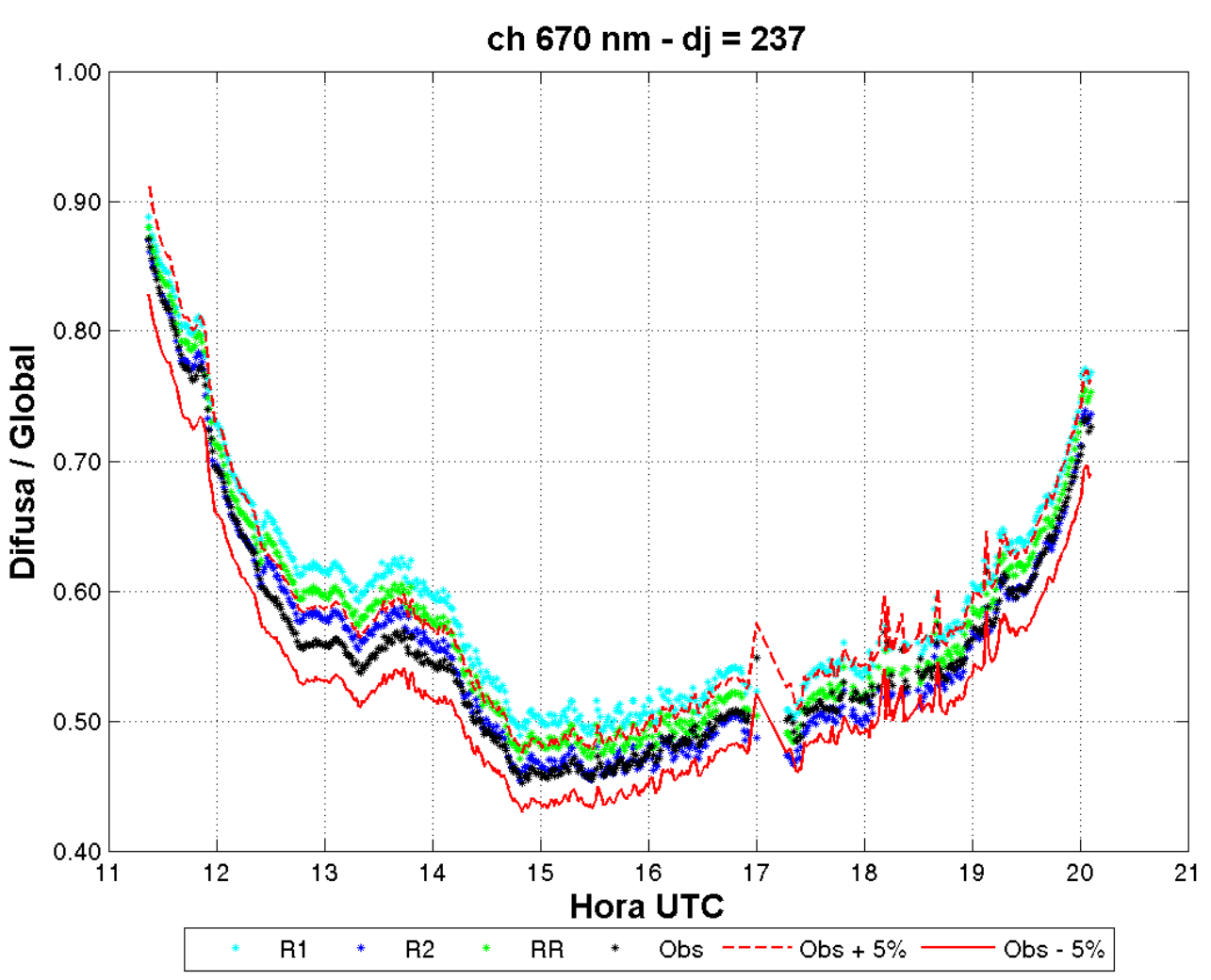


(b)

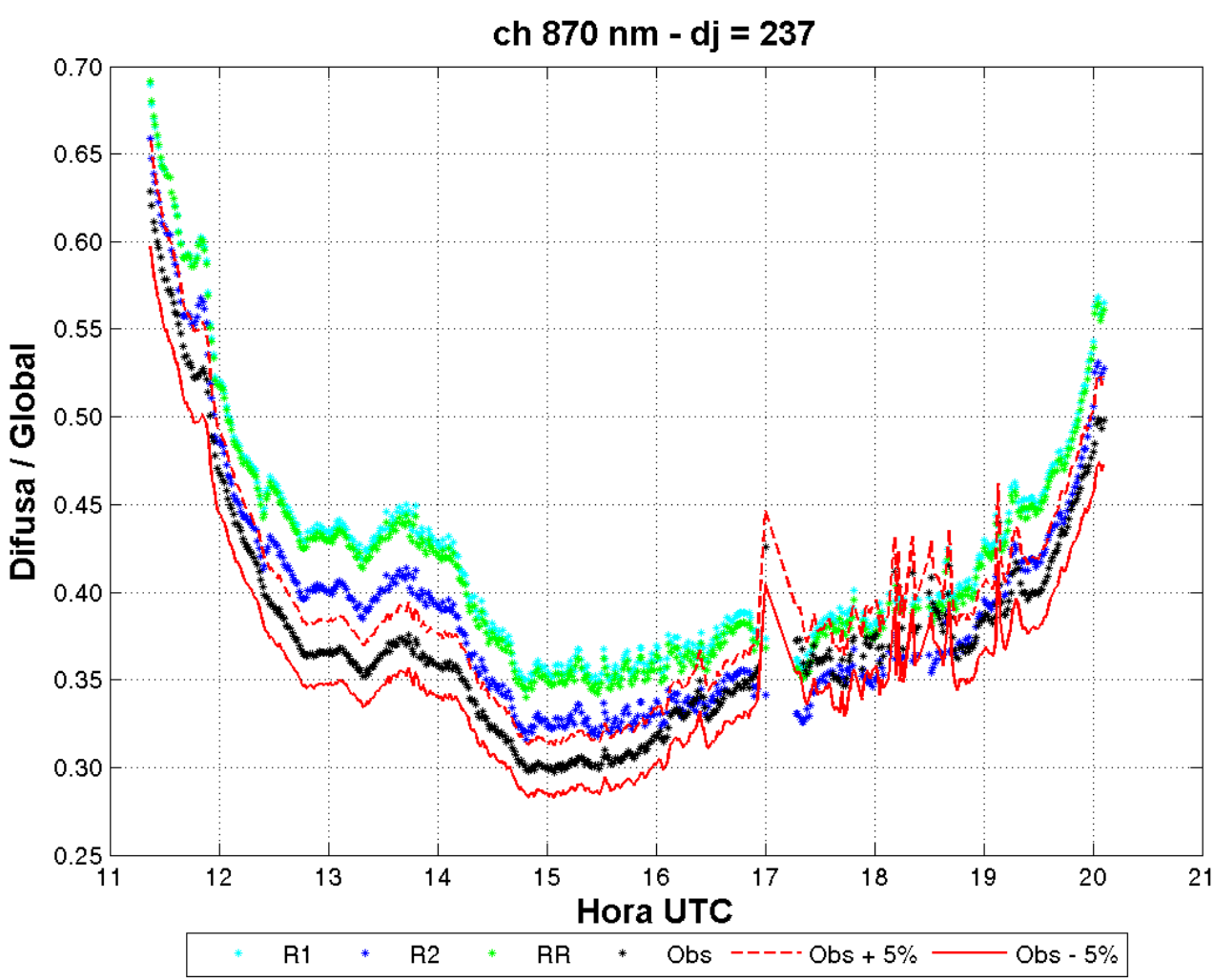

(c)

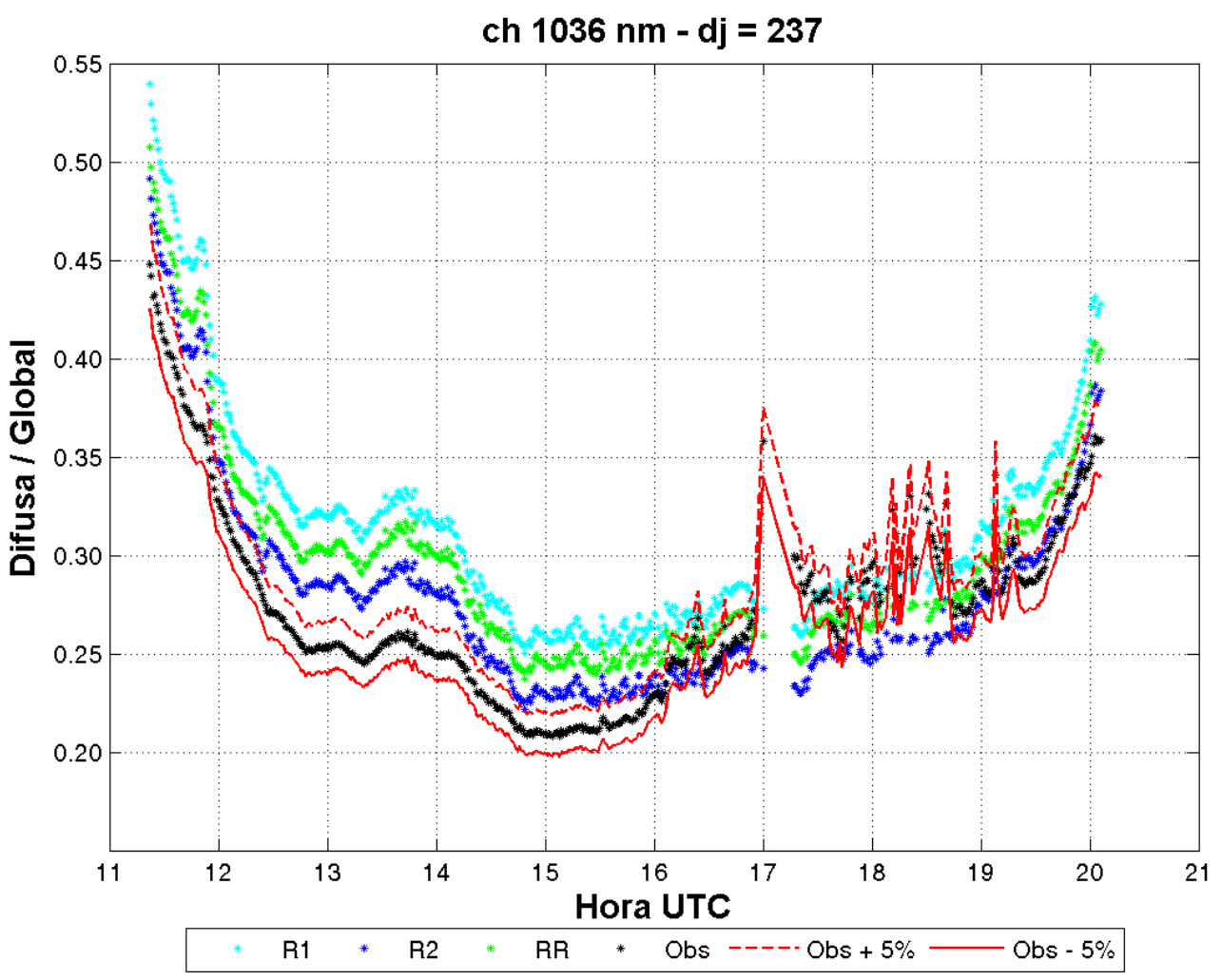

Figura 4.34 - Razão entre a irradiância difusa e global observada e simulada à superfície para os canais de $670 \mathrm{~nm}$ (a), $870 \mathrm{~nm}$ (b) e $1036 \mathrm{~nm}$ (c) para o dia 237. A linha vermelha representa a razão dos valores observados menos $5 \%$ e a linha vermelha tracejada representa o observado mais $5 \%$. 
(a)

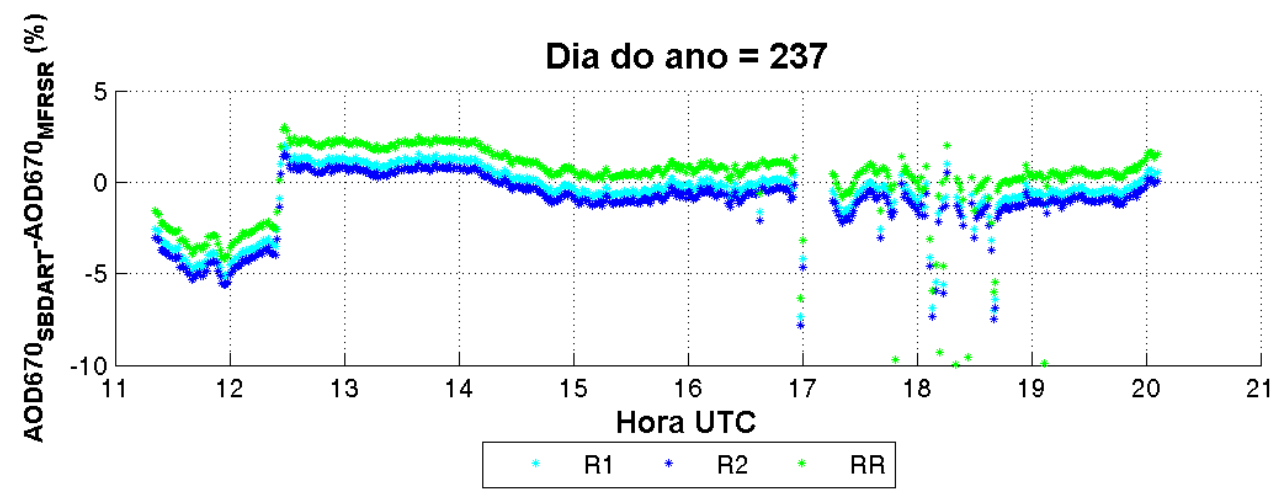

(b)

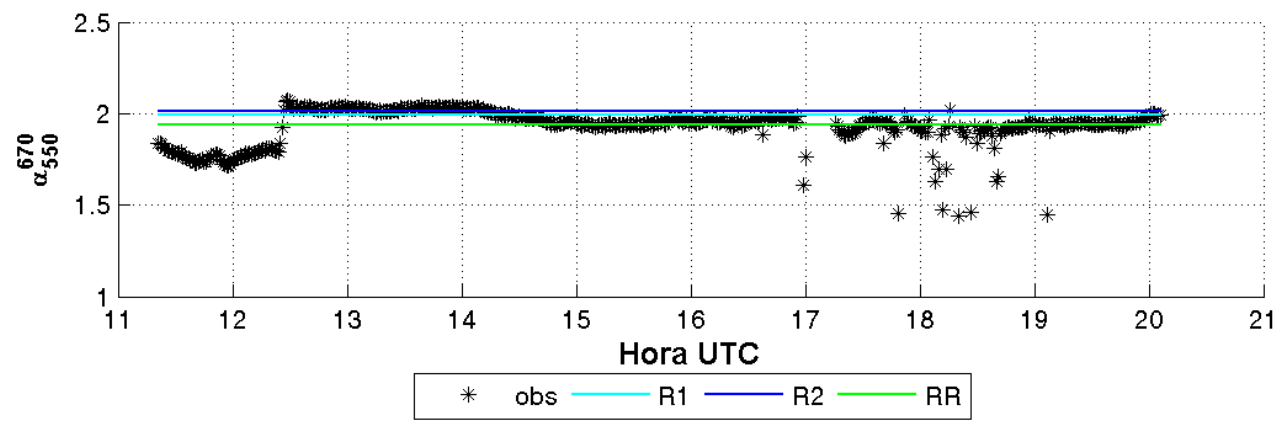

Figura 4.35 - (a) Diferença relativa entre a profundidade óptica de $670 \mathrm{~nm}$ calculada e observada e (b) coeficiente de Ångström calculado com a profundidade óptica de 670nm obtida pelo MFRSR (em preto) e com o fator de eficiência de extinção dos três modelos ópticos para o dia 237. 
(a)

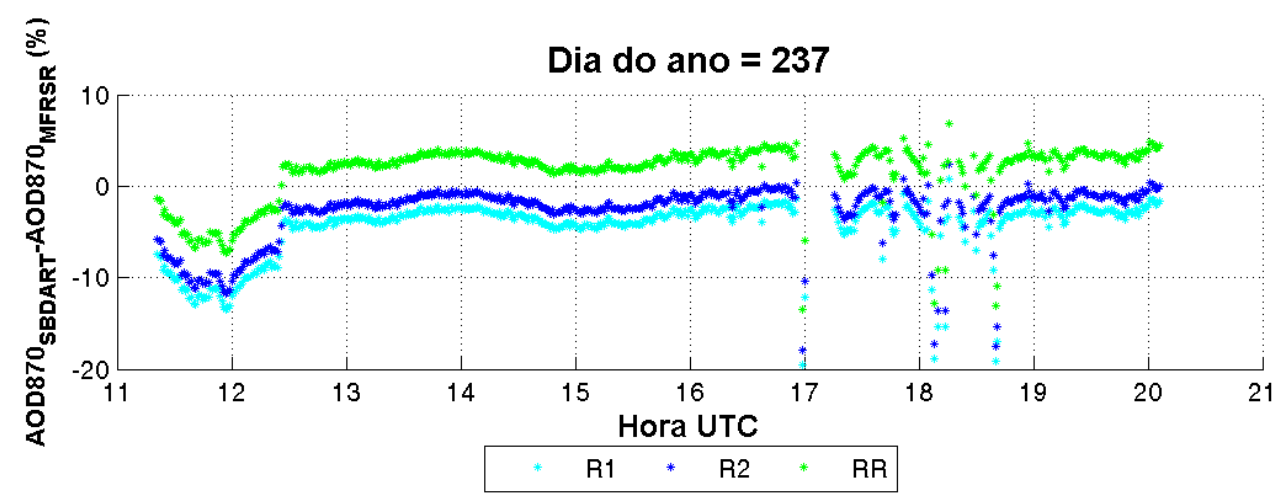

(b)

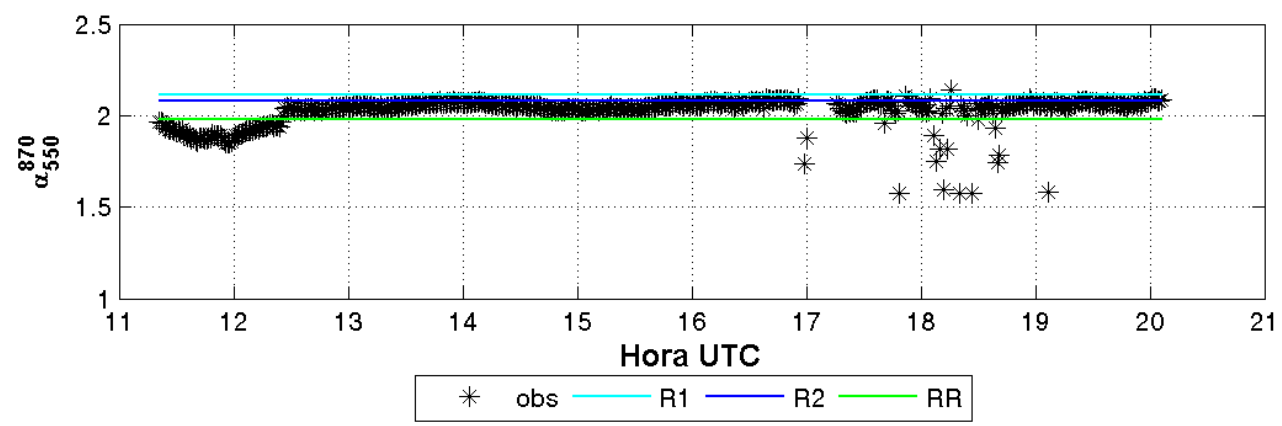

Figura 4.36 - (a) Diferença relativa entre a profundidade óptica de 870nm calculada e observada e (b) coeficiente de Ångström calculado com a profundidade óptica de $870 \mathrm{~nm}$ obtida pelo MFRSR (em preto) e com o fator de eficiência de extinção dos três modelos ópticos para o dia 237. 
(a)

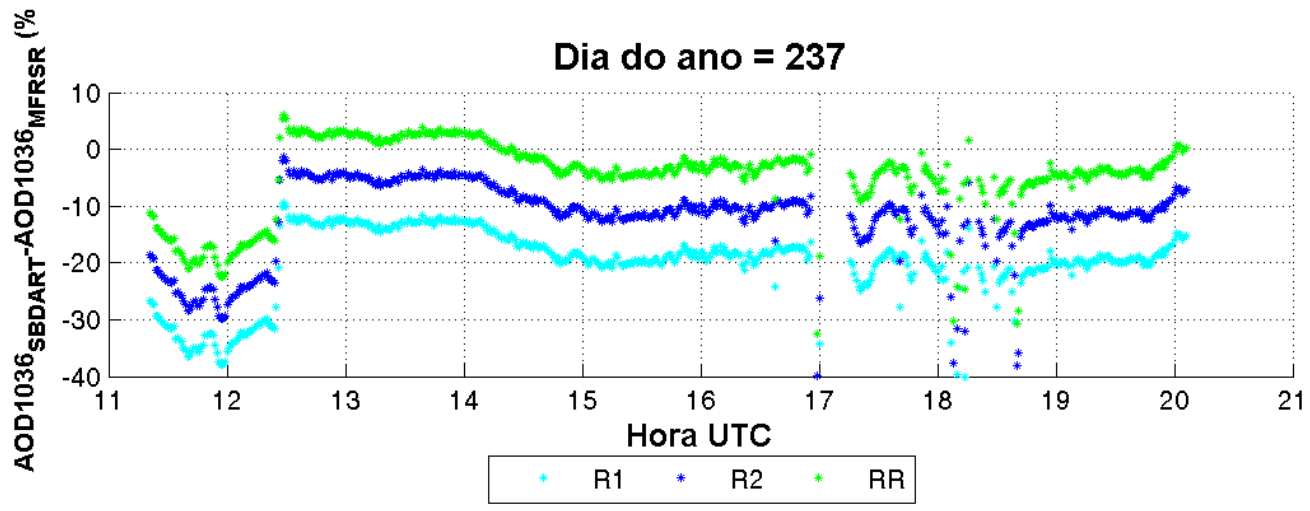

(b)

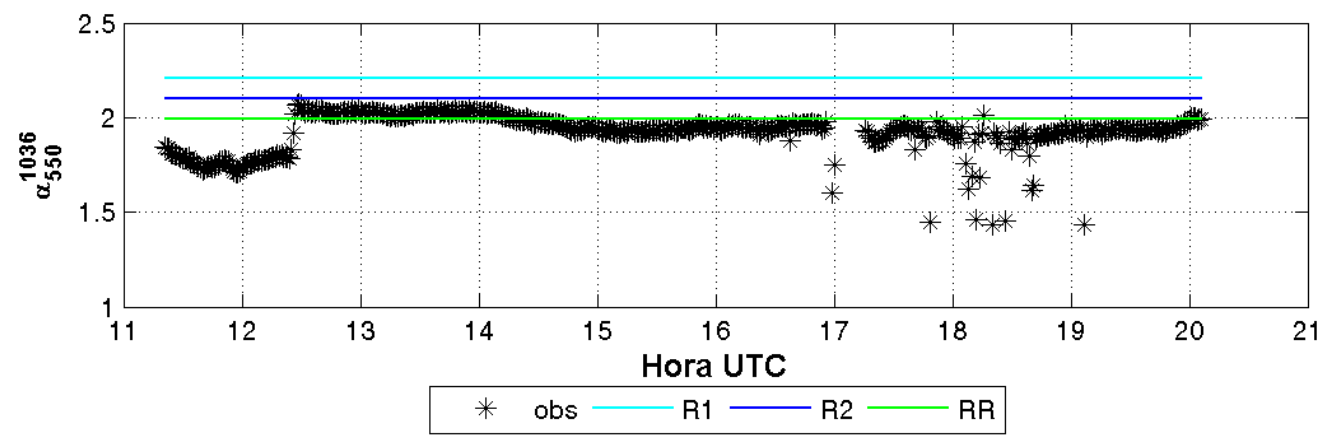

Figura 4.37 - (a) Diferença relativa entre a profundidade óptica de $1036 \mathrm{~nm}$ calculada e observada e (b) coeficiente de Ångström calculado com a profundidade óptica de $1036 \mathrm{~nm}$ obtida pelo MFRSR (em preto) e com o fator de eficiência de extinção dos três modelos ópticos para o dia 237. 
No dia 253, o coeficiente de Ångström também variou pouco, ficando entre 1,9 e 2,1. A AOD550 diminuiu no decorrer do dia, com valor máximo próximo de 2,5 no começo do dia, passando ao seu valor mínimo de 1,4 no final do período. Pelo gráfico da figura 4.39 nota-se que o modelo mais espalhador é o que apresentou o melhor ajuste para a irradiância PAR.

Para o canal de $670 \mathrm{~nm}$, novamente os três modelos resultaram em valores dentro do intervalo de incerteza. No canal de 870nm o modelo mais absorvedor apresentou a melhor aproximação. Em 1036nm, o modelo mais absorvedor se ajustou melhor até aproximadamente a hora 15,5. Após esse período, o modelo médio é o que apresentou o melhor ajuste.

(a)

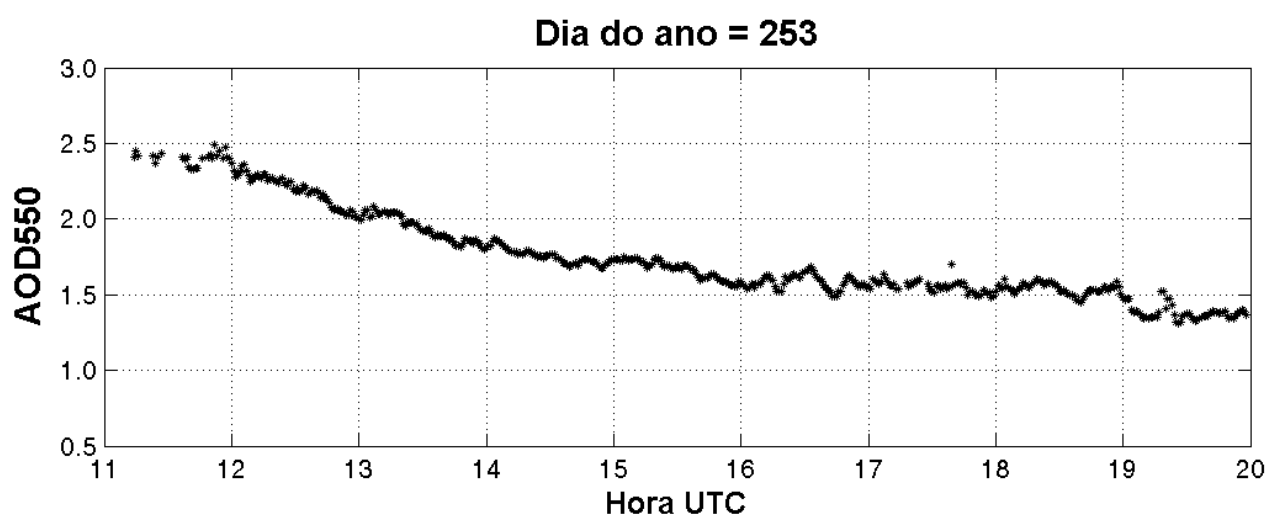

(b)

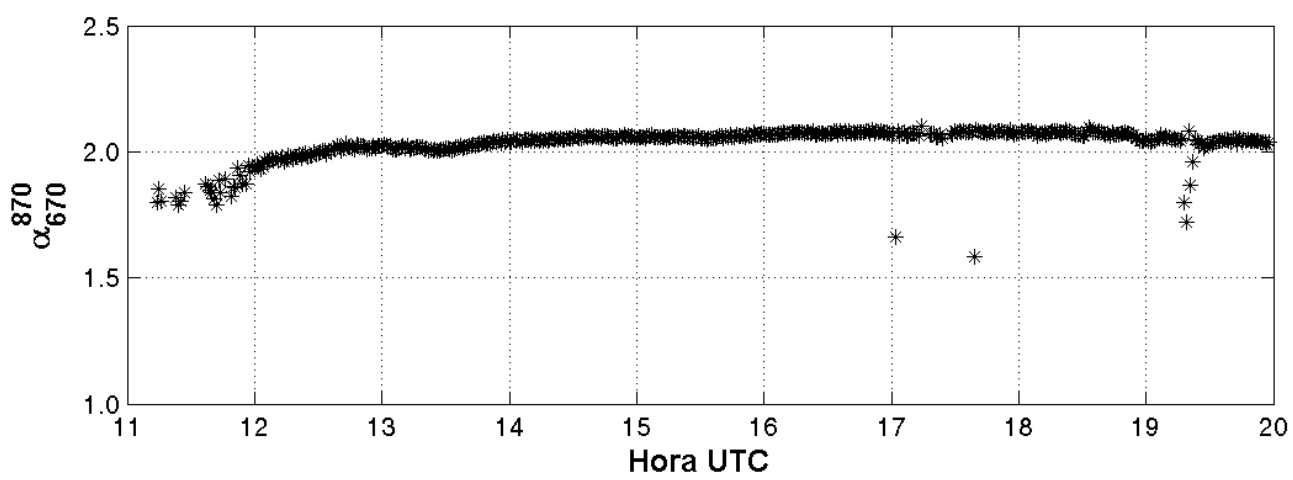

Figura 4.38 - Valores da profundidade óptica em 550nm (a) e do coeficiente de Ångström (b) para o dia do ano 253. 


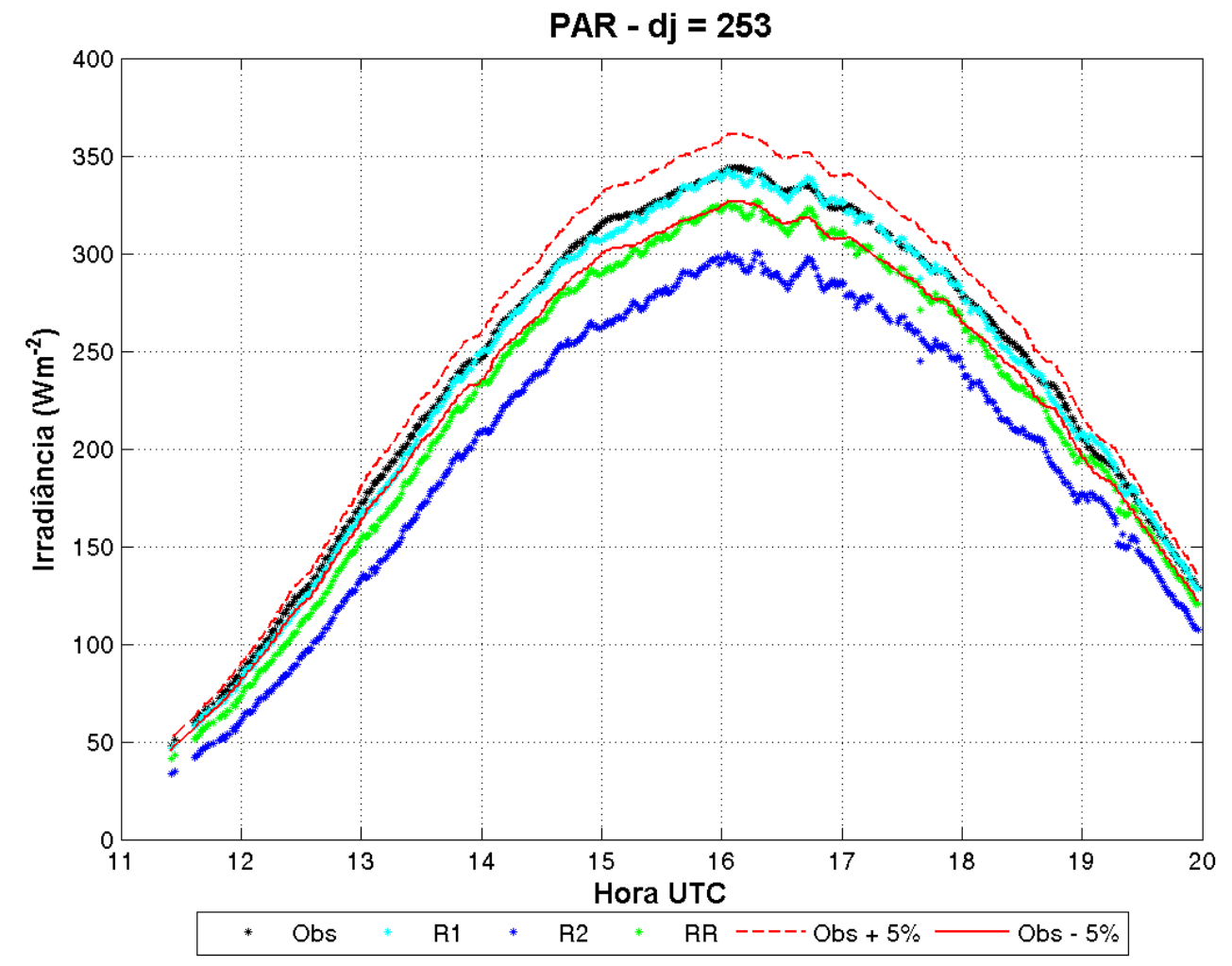

Figura 4.39 - Irradiância PAR observada e simulada à superfície para o dia 253. A linha vermelha representa o valor observado menos $5 \%$ e a linha vermelha tracejada representa o observado mais $5 \%$.

(a)

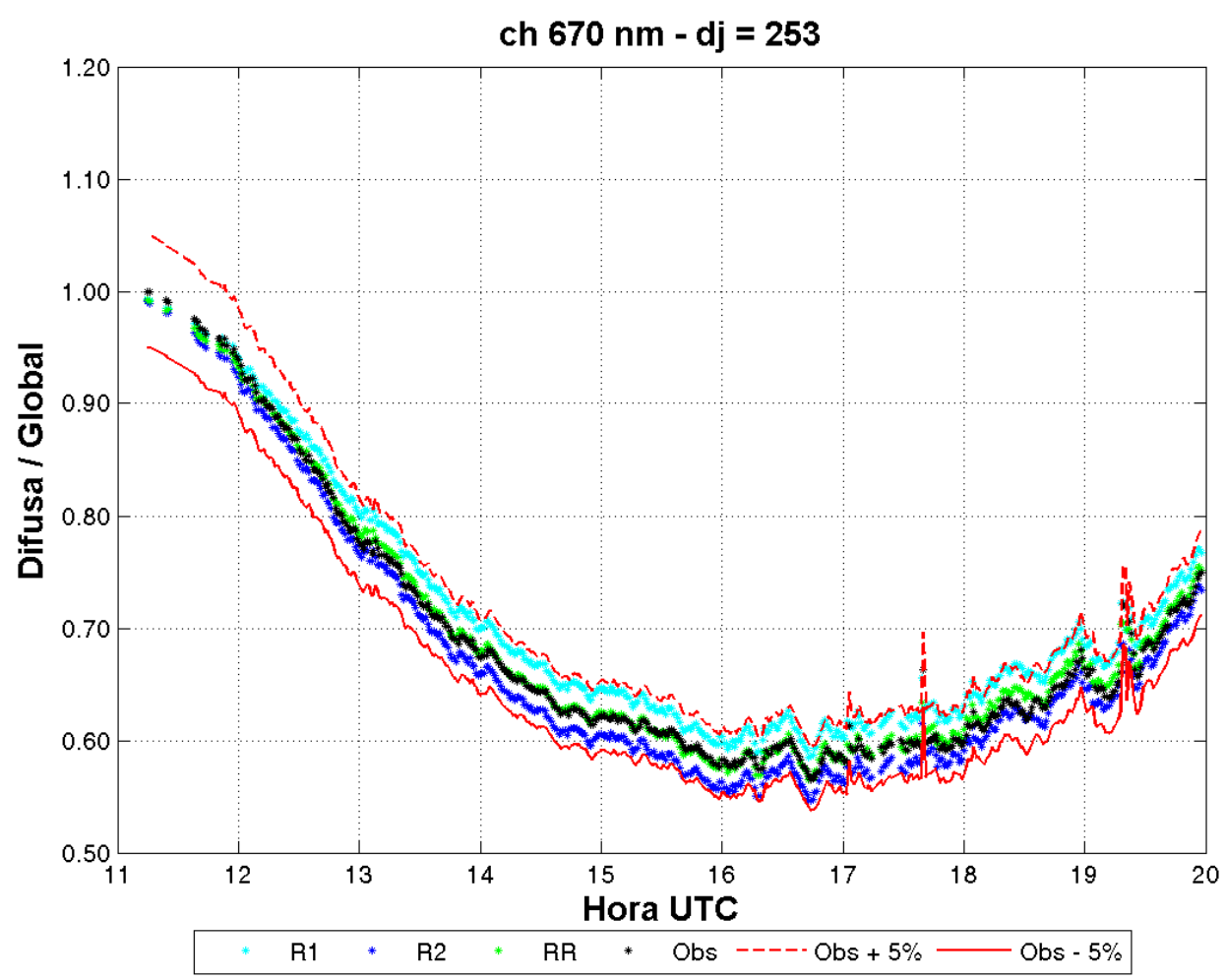


(b)

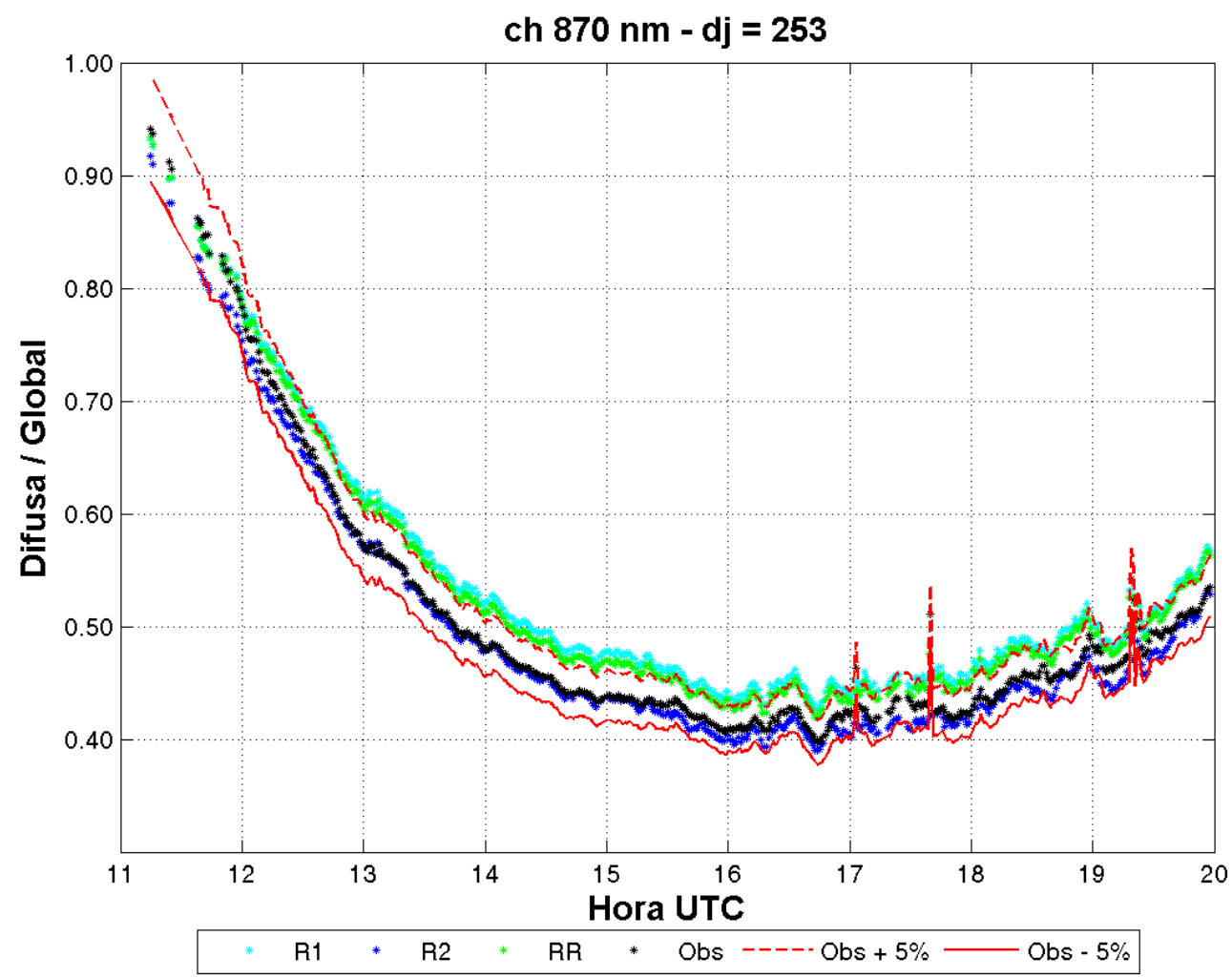

(c)

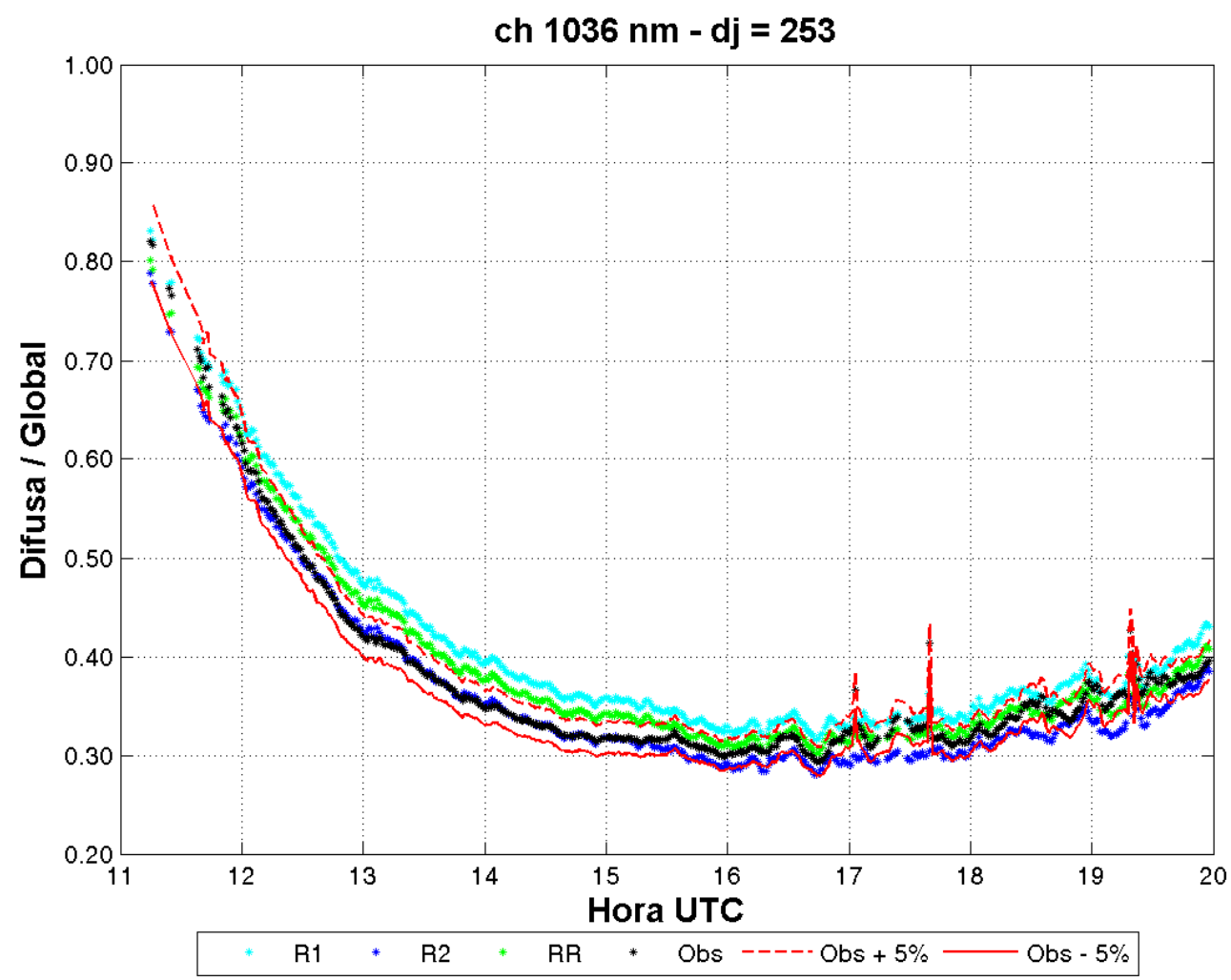

Figura 4.40 - Razão entre a irradiância difusa e global observada e simulada à superfície para os canais de $670 \mathrm{~nm}$ (a), $870 \mathrm{~nm}$ (b) e $1036 \mathrm{~nm}$ (c) para o dia 253. A linha vermelha representa a razão dos valores observados menos $5 \%$ e a linha vermelha tracejada representa o observado mais $5 \%$. 
(a)

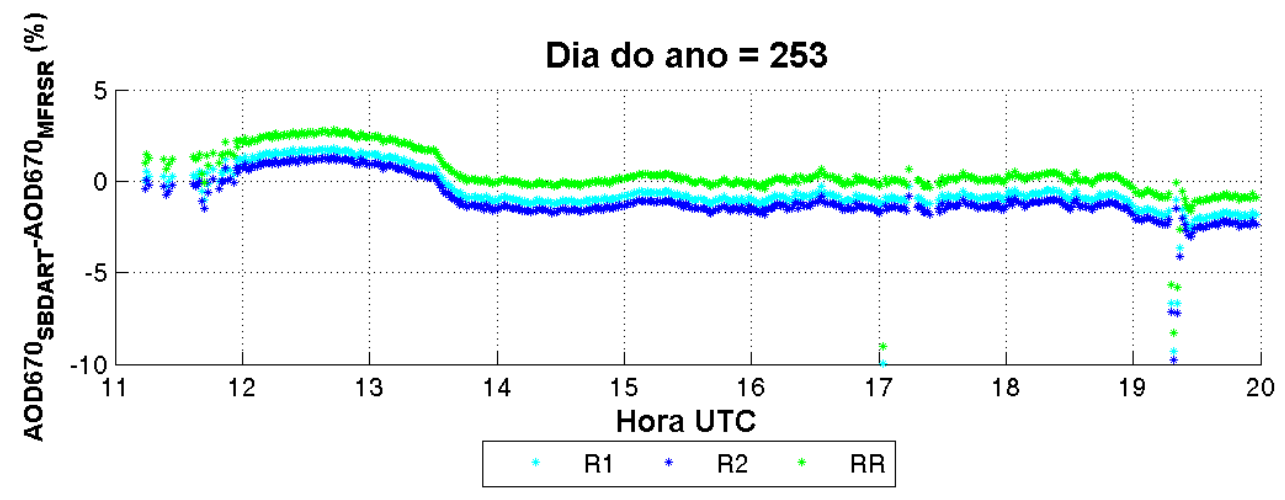

(b)

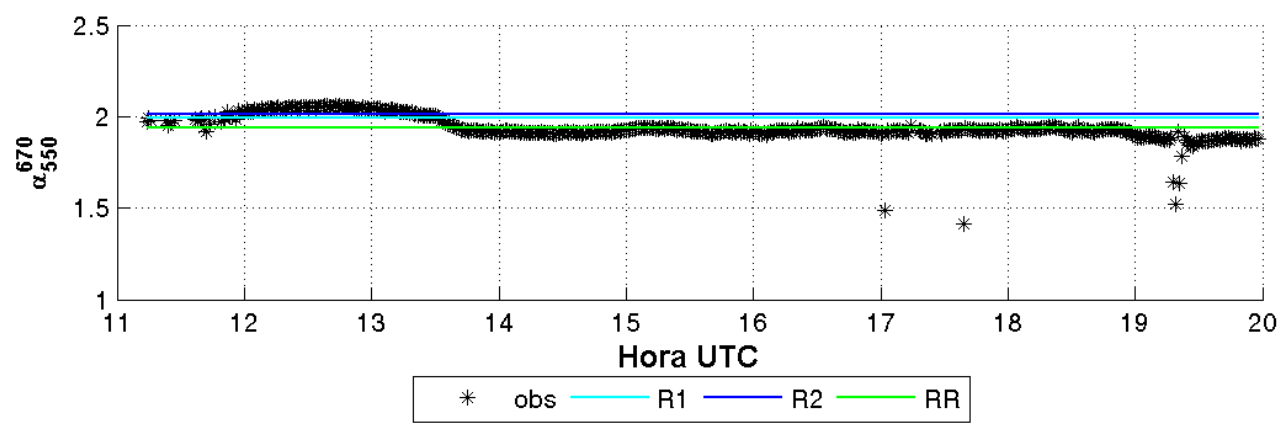

Figura 4.41 - (a) Diferença relativa entre a profundidade óptica de 670nm calculada e observada e (b) coeficiente de Ångström calculado com a profundidade óptica de $670 \mathrm{~nm}$ obtida pelo MFRSR (em preto) e com o fator de eficiência de extinção dos três modelos ópticos para o dia 253. 
(a)

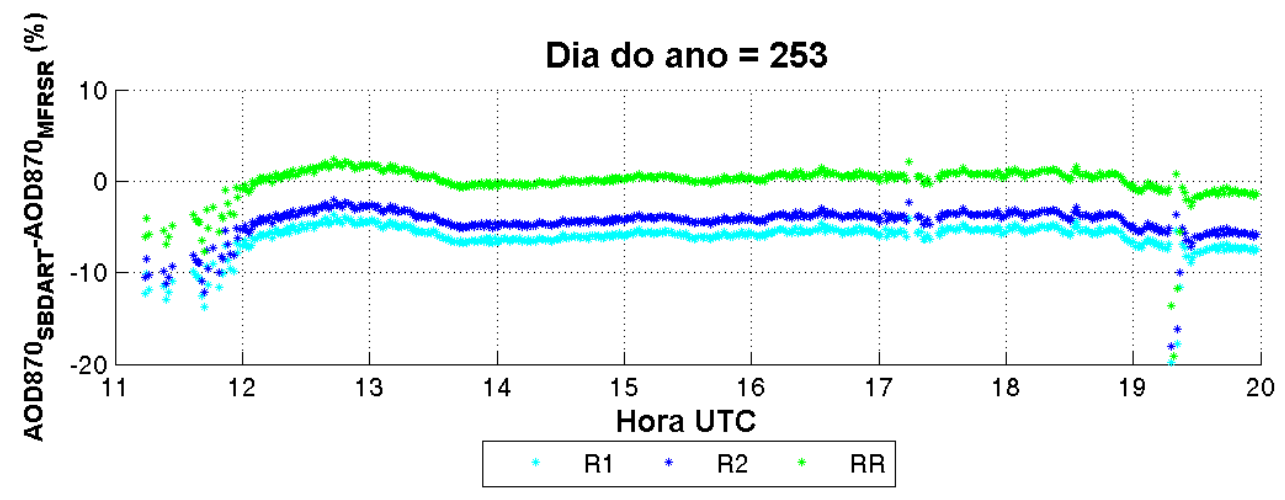

(b)

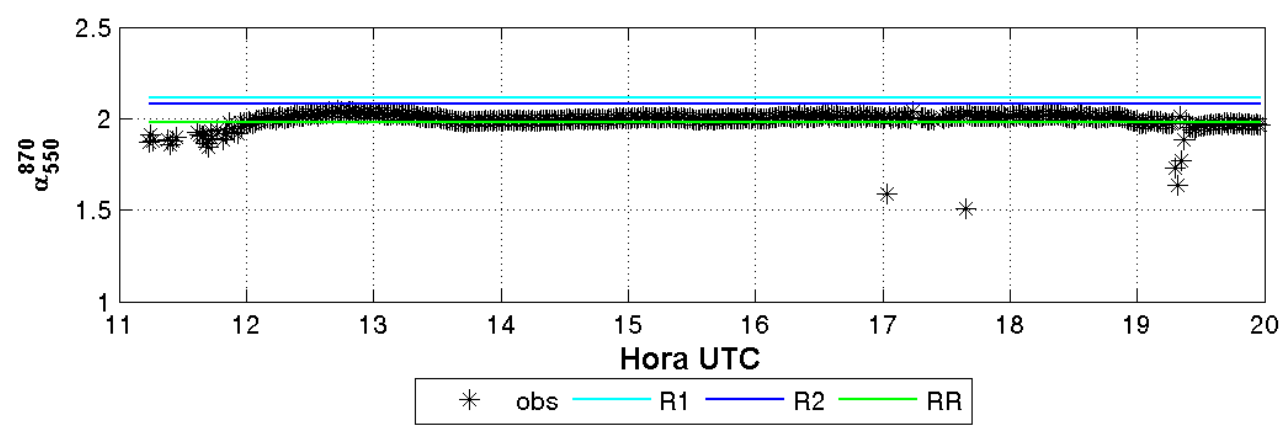

Figura 4.42 - (a) Diferença relativa entre a profundidade óptica de 870nm calculada e observada e (b) coeficiente de Ångström calculado com a profundidade óptica de $870 \mathrm{~nm}$ obtida pelo MFRSR (em preto) e com o fator de eficiência de extinção dos três modelos ópticos para o dia 253. 
(a)

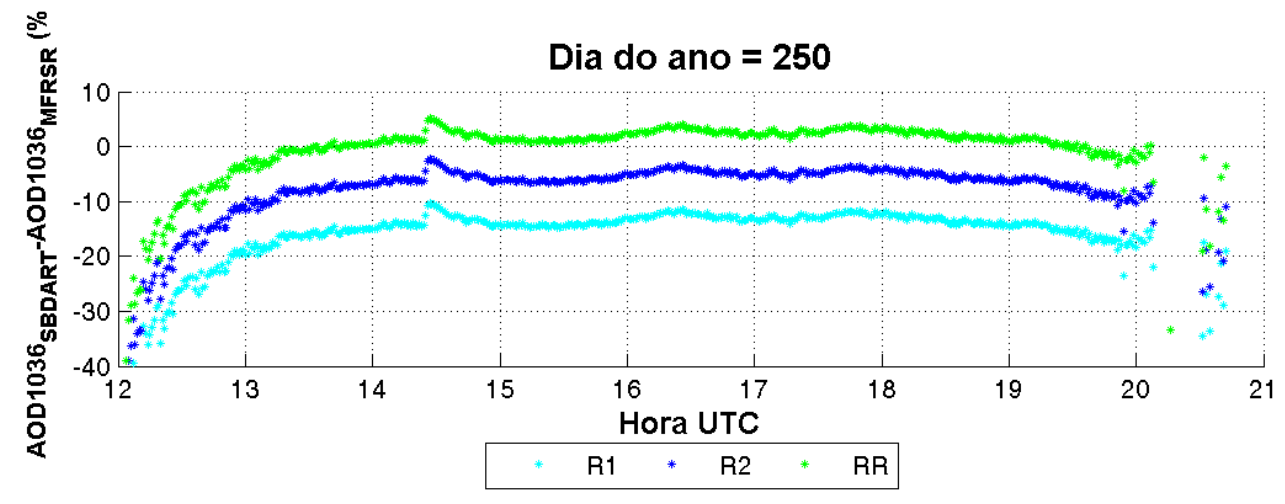

(b)

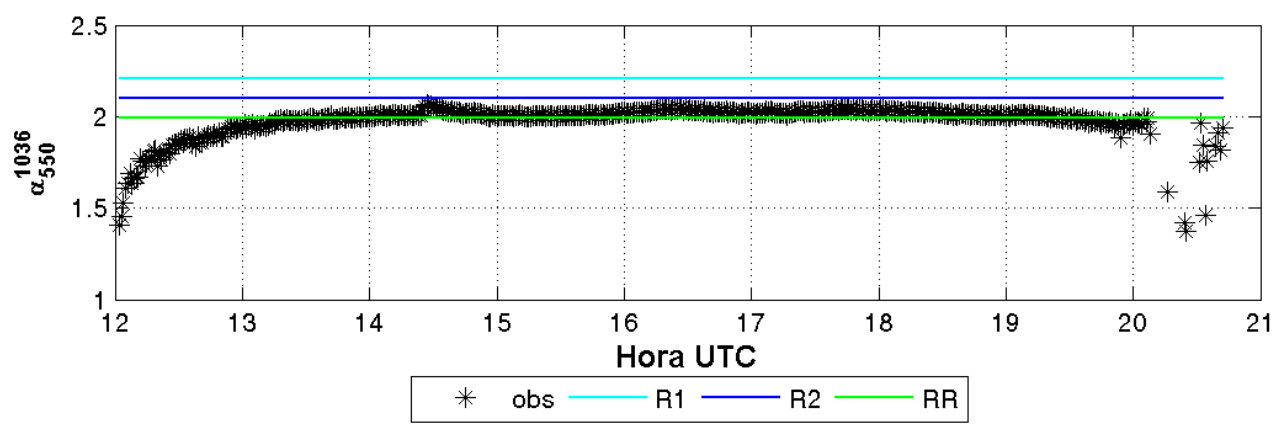

Figura 4.43 - (a) Diferença relativa entre a profundidade óptica de $1036 \mathrm{~nm}$ calculada e observada e (b) coeficiente de Ångström calculado com a profundidade óptica de $1036 \mathrm{~nm}$ obtida pelo MFRSR (em preto) e com o fator de eficiência de extinção dos três modelos ópticos para o dia 253. 
O dia 254 foi caracterizado por uma forte queda no valor da AOD550 (figura 4.44). No começo do dia, o valor era de aproximadamente 1,8 e no fim do dia o valor chegou a 1,0. O coeficiente de Ångström não variou muito no decorrer do período, apresentando valores próximos de 1,8.

(a)

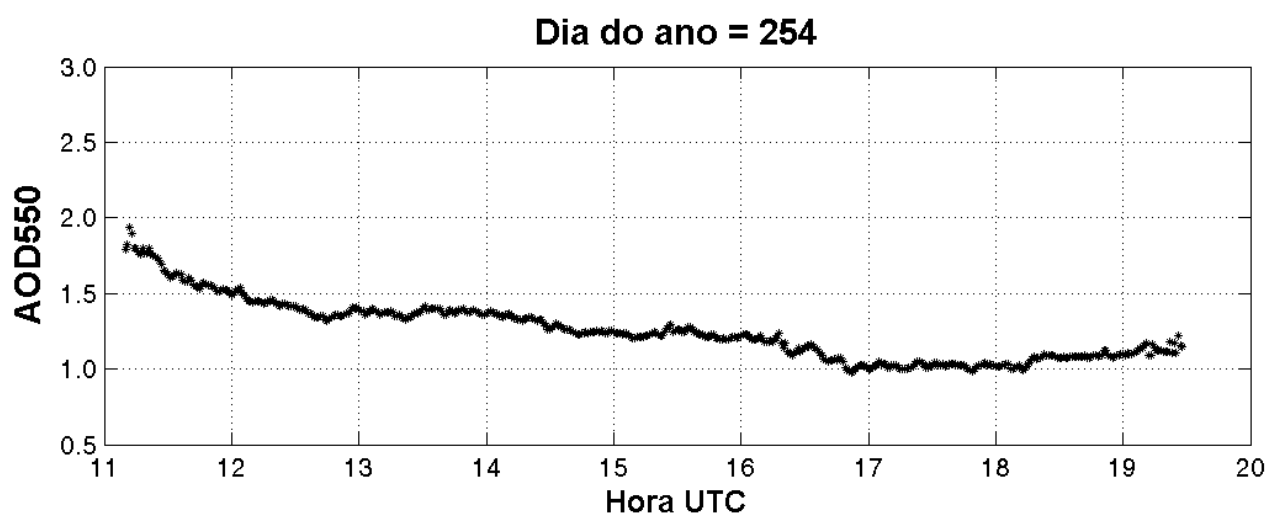

(b)

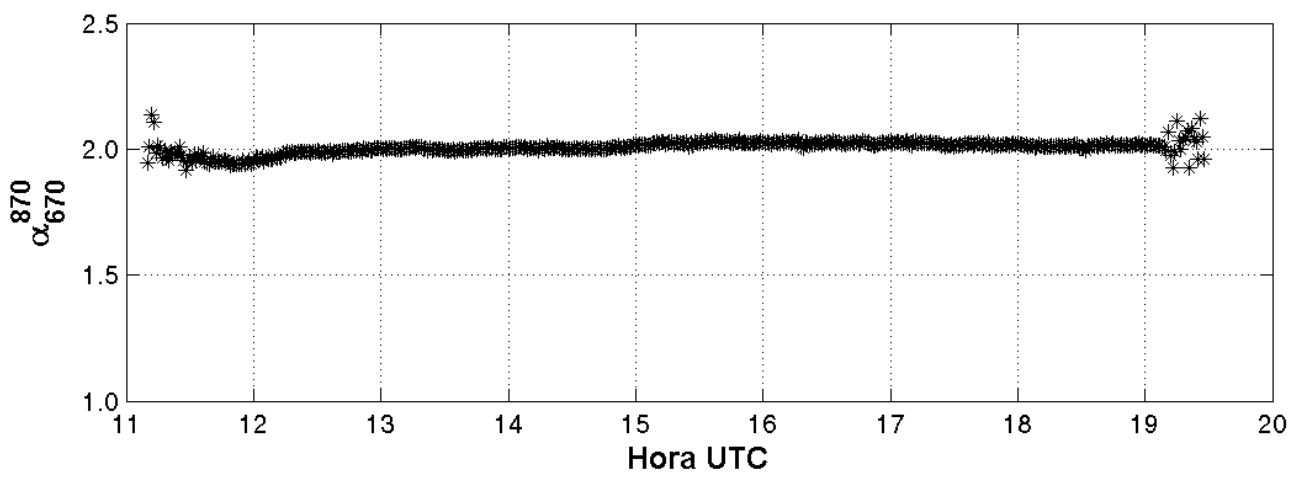

Figura 4.44 - Valores da profundidade óptica em 550nm (a) e do coeficiente de Ångström (b) para o dia do ano 254. 


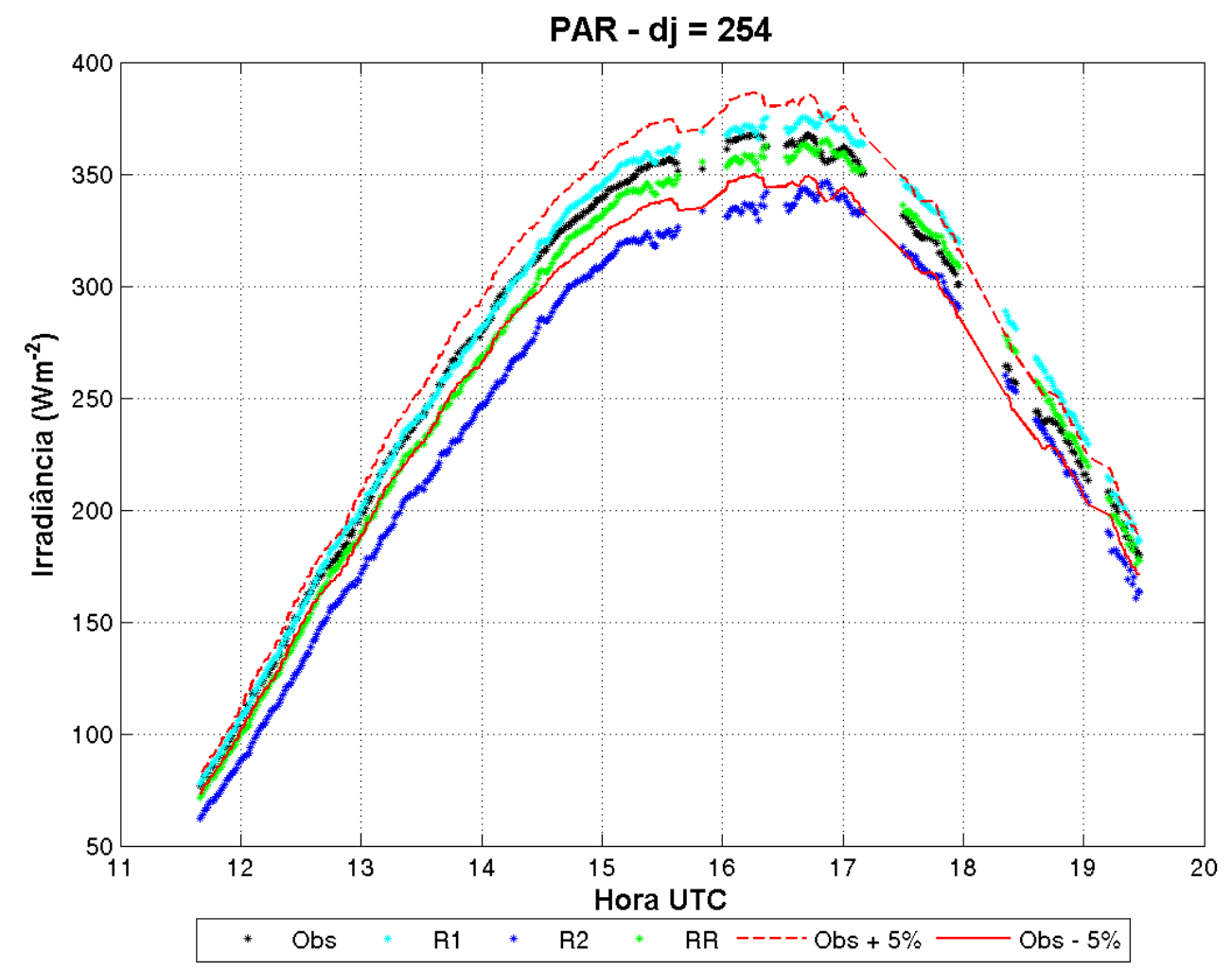

Figura 4.45 - Irradiância PAR observada e simulada à superfície para o dia 254. A linha vermelha representa o valor observado menos $5 \%$ e a linha vermelha tracejada representa o observado mais 5\%.

Pelo gráfico da figura 4.45 vemos que os resultados do modelo mais espalhador, $\mathrm{R} 1$, foram os que se aproximaram mais dos valores observados até aproximadamente as 16 UTC. Após esse horário, o modelo médio, RR, é o que apresentou os resultados mais próximos do medido pelo sensor PAR. Nos canais de 670, 870 e 1036nm, o modelo mais absorvedor, R2, é o que apresentou valores mais próximos daqueles obtidos pelo MFRSR.

Analisando a profundidade óptica, vemos que os valores obtidos com o modelo médio é o que apresentou os resultados mais próximos dos observados. Porém, como discutido acima, o modelo mais absorvedor foi o que apresentou a razão entre irradiância difusa e global mais próxima da observada. Note-se particularmente para o canal de $1036 \mathrm{~nm}$ que, mesmo a AOD sendo da ordem de $20 \%$ menor que a observada para o modelo absorvedor (Figura 4.49a), os resultados para a irradiância se mostraram em melhor concordância com as observações utilizando-se esse modelo óptico. 
(a)

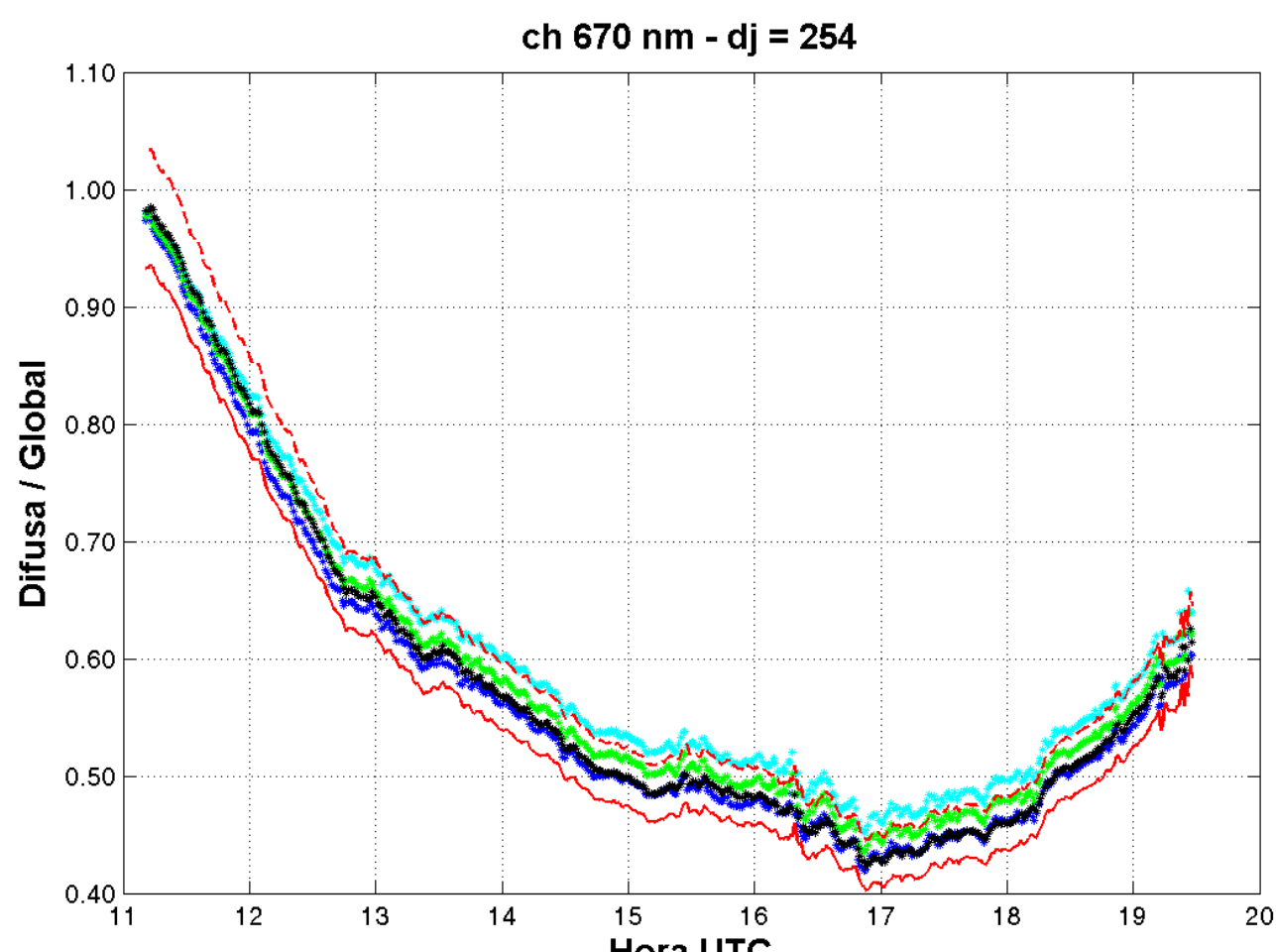

Hora UTC

* R1 * R2 * RR * Obs ---- Obs $+5 \%-$ Obs $-5 \%$

(b)

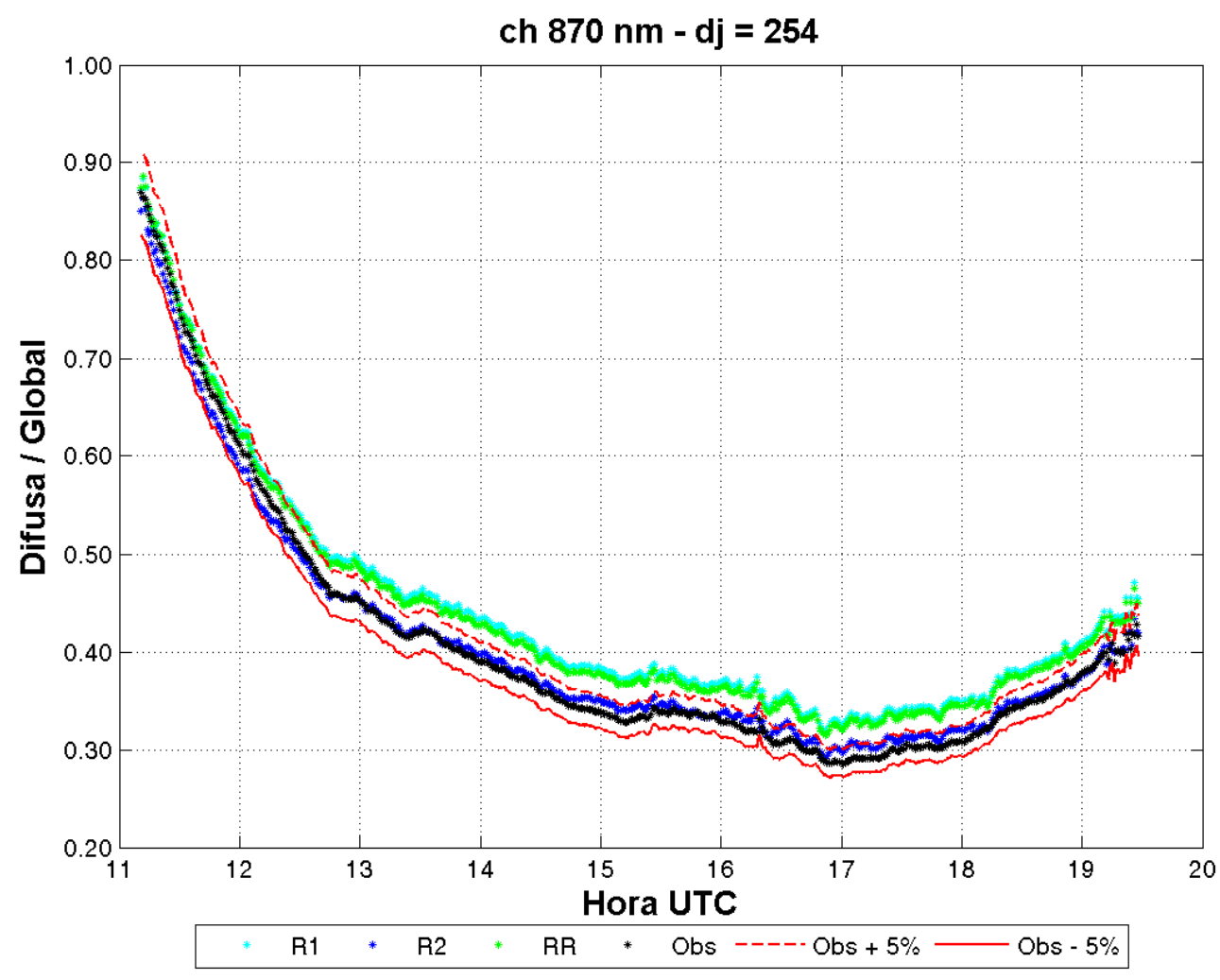


(c)

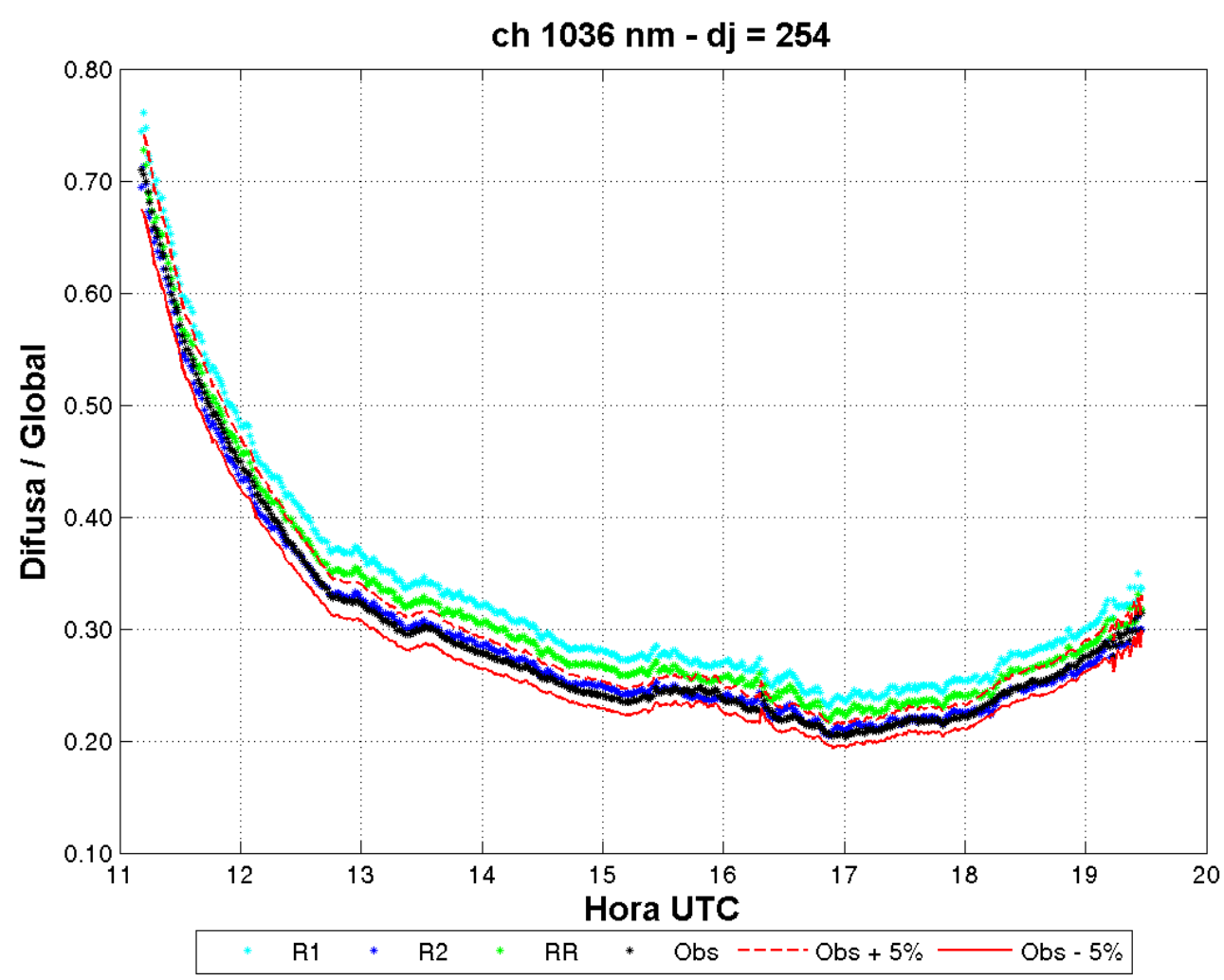

Figura 4.46 - Razão entre a irradiância difusa e global observada e simulada à superfície para os canais de $670 \mathrm{~nm}$ (a), $870 \mathrm{~nm}$ (b) e $1036 \mathrm{~nm}$ (c) para o dia 254. A linha vermelha representa a razão dos valores observados menos $5 \%$ e a linha vermelha tracejada representa o observado mais $5 \%$. 
(a)

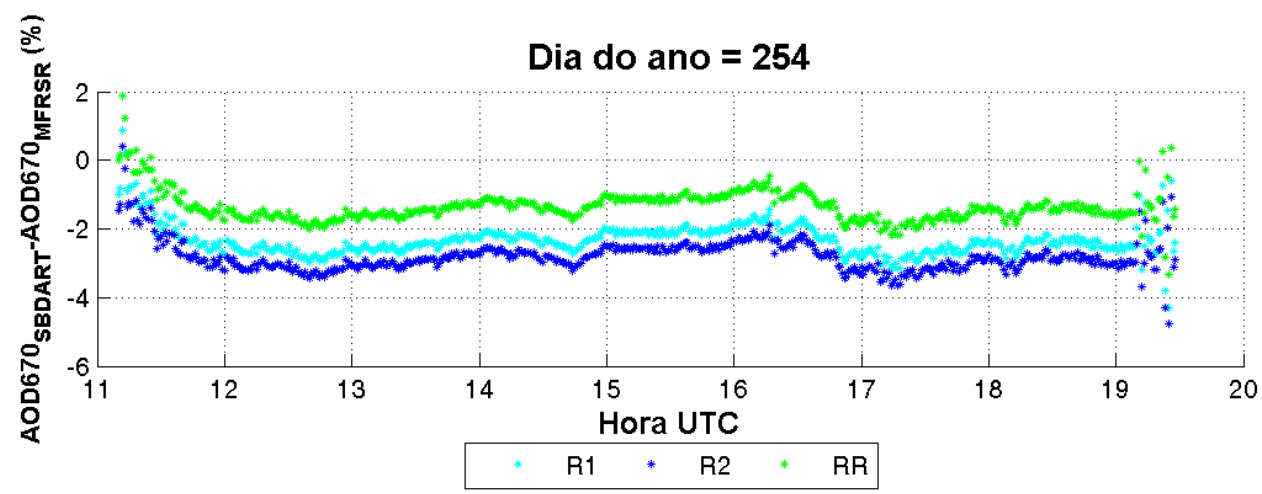

(b)

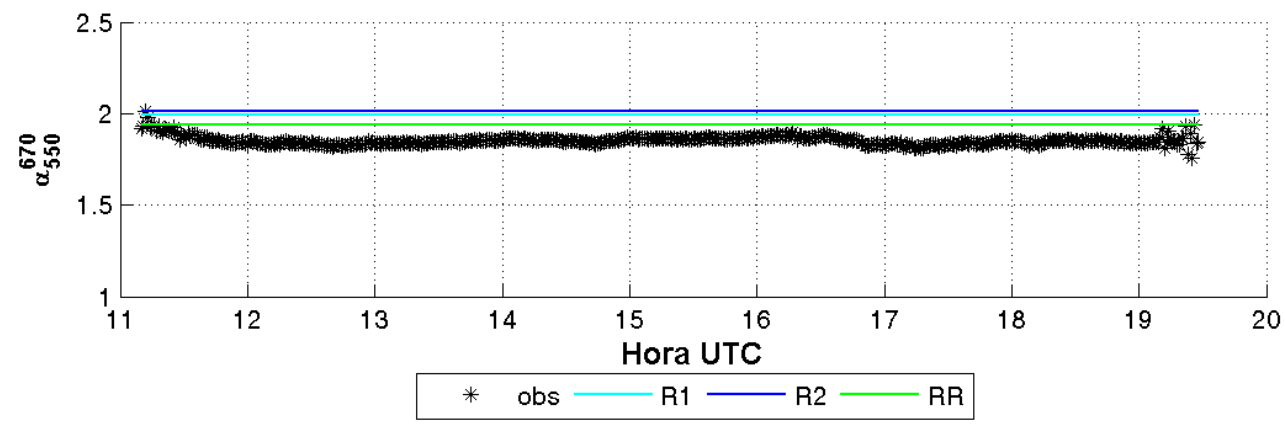

Figura 4.47 - (a) Diferença relativa entre a profundidade óptica de 670nm calculada e observada e (b) coeficiente de Ångström calculado com a profundidade óptica de 670nm obtida pelo MFRSR (em preto) e com o fator de eficiência de extinção dos três modelos ópticos para o dia 254. 
(a)

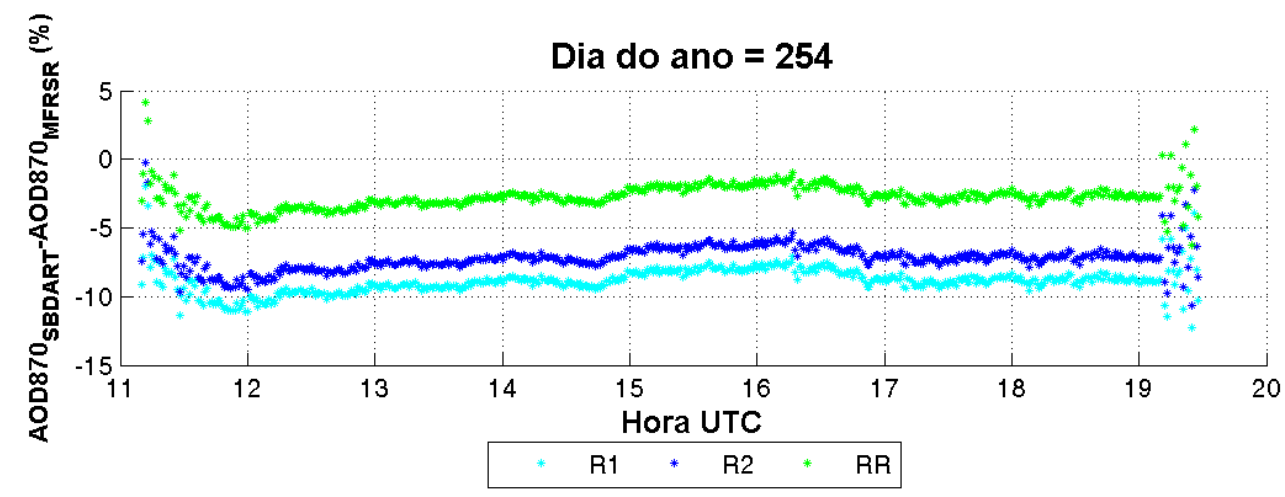

(b)

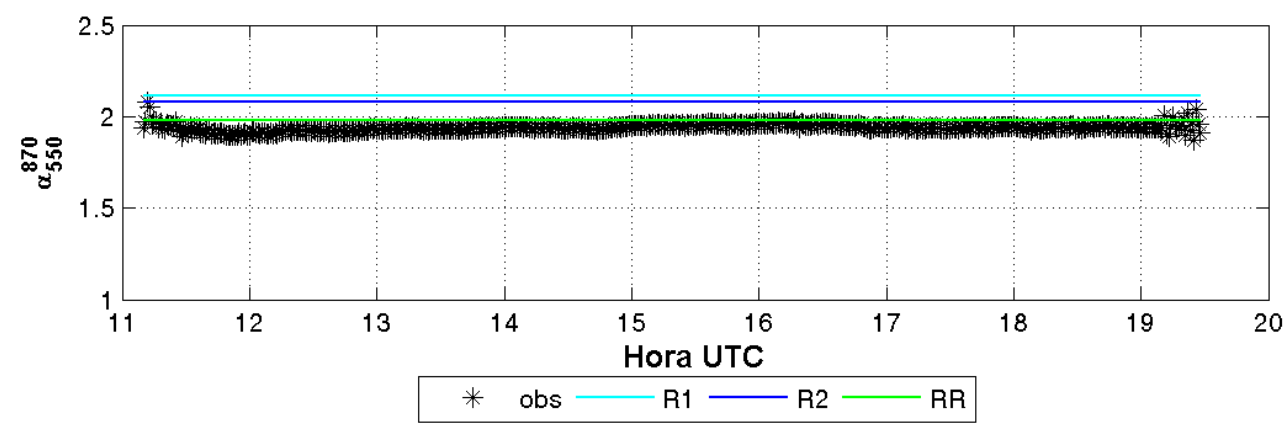

Figura 4.48 - (a) Diferença relativa entre a profundidade óptica de 870nm calculada e observada e (b) coeficiente de Ångström calculado com a profundidade óptica de $870 \mathrm{~nm}$ obtida pelo MFRSR (em preto) e com o fator de eficiência de extinção dos três modelos ópticos para o dia 254. 
(a)

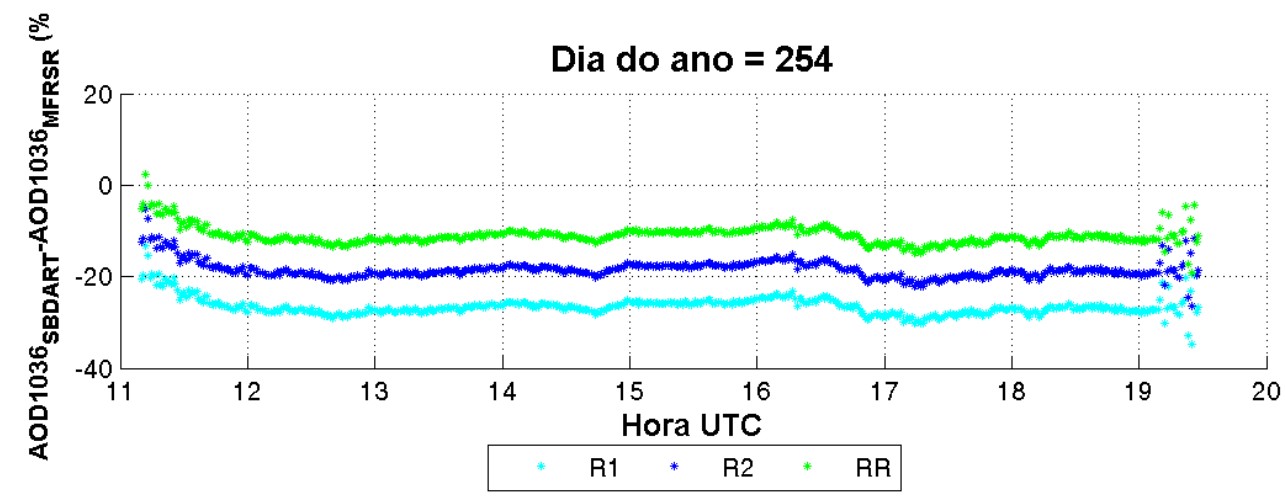

(b)

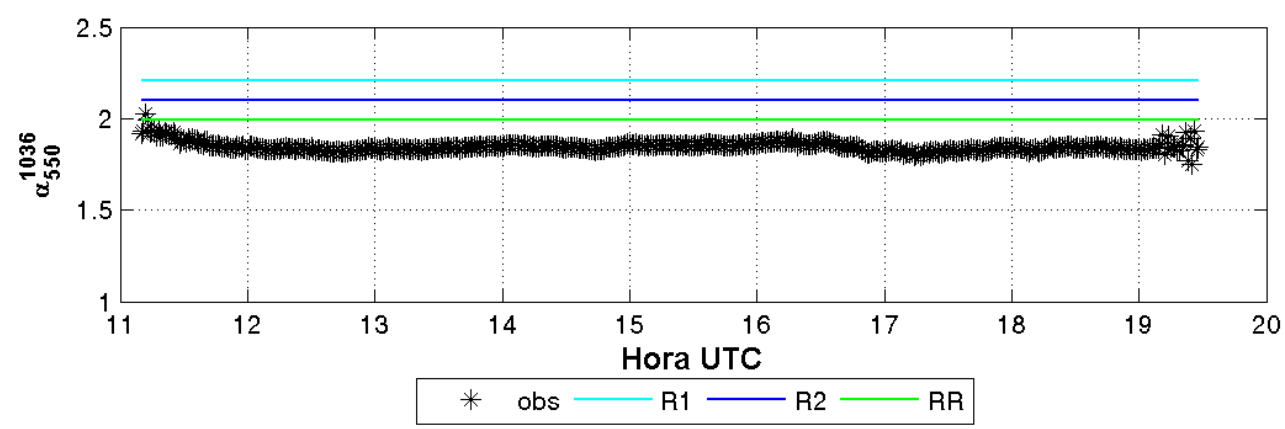

Figura 4.49 - (a) Diferença relativa entre a profundidade óptica de 1036nm calculada e observada e (b) coeficiente de Ångström calculado com a profundidade óptica de $1036 \mathrm{~nm}$ obtida pelo MFRSR (em preto) e com o fator de eficiência de extinção dos três modelos ópticos para o dia 254. 
O esperado era que o mesmo modelo óptico fosse o mais adequado para todas as bandas espectrais analisadas. Entretanto, viu-se que em grande parte dos casos analisados, os canais de banda estreita tendem a se ajustar a um modelo mais absorvedor do que a irradiância PAR, mesmo quando a profundidade óptica obtida por modelos mais espalhadores são as que se aproximou mais dos valores observados.

Portanto, a explicação para as diferenças entre a irradiância PAR e os canais de banda estreita é a degradação sofrida pelos sensores do MFRSR ao longo dos anos. Nas simulações, é utilizada a função filtro fornecida pelo fabricante do MFRSR, que foi adquirido pelo grupo no ano de 1999. O instrumento nunca foi enviado ao fabricante para troca de filtros, avaliação da resposta espectral, correções angulares ou recalibração. Já o sensor PAR passa por constante re-calibração no LIM - CPTEC/INPE.

\subsubsection{Irradiância Solar Total Global}

Nesta etapa compararam-se os dados simulados pelo SBDART e os dados medidos pelo sensor de Banda Larga do MFRSR (BL) e o Piranômetro (PIR) nos dias 236 e 269. Não há dados do piranômetro para o dia 250, por isso ele não é apresentado neste item. O dia 254 não é apresentado neste item por apresentar comportamento similar ao dia 236, e não iria contribuir mais para a análise. Os dados do PIR são fornecidos em um intervalo de 30 minutos e para tornar possível a comparação, foram tiradas as médias a cada meia hora dos dados simulados com o SBDART. Para a BL, nos dois dias, os resultados obtidos pelos três modelos ópticos superestimaram o valor observado, ficando fora do limite de 5\%. Neste caso, a degradação do instrumento também pode ser o motivo da diferença entre o simulado e o observado.

No caso do PIR para o dia 236, os resultados obticos com o modelo mais espalhador, R1, foram os que se aproximaram mais dos valores observados, assim como o que ocorreu com os dados do sensor PAR. No dia 269 o sensor do PIR obteve medidas apenas entre as 11,5 e 15 UTC. Nesse período os três modelos ficaram dentro da incerteza, indicando que para, o piranômetro, nas condições de AOD observadas, tanto faz o modelo óptico a ser utilizado. 
(a)

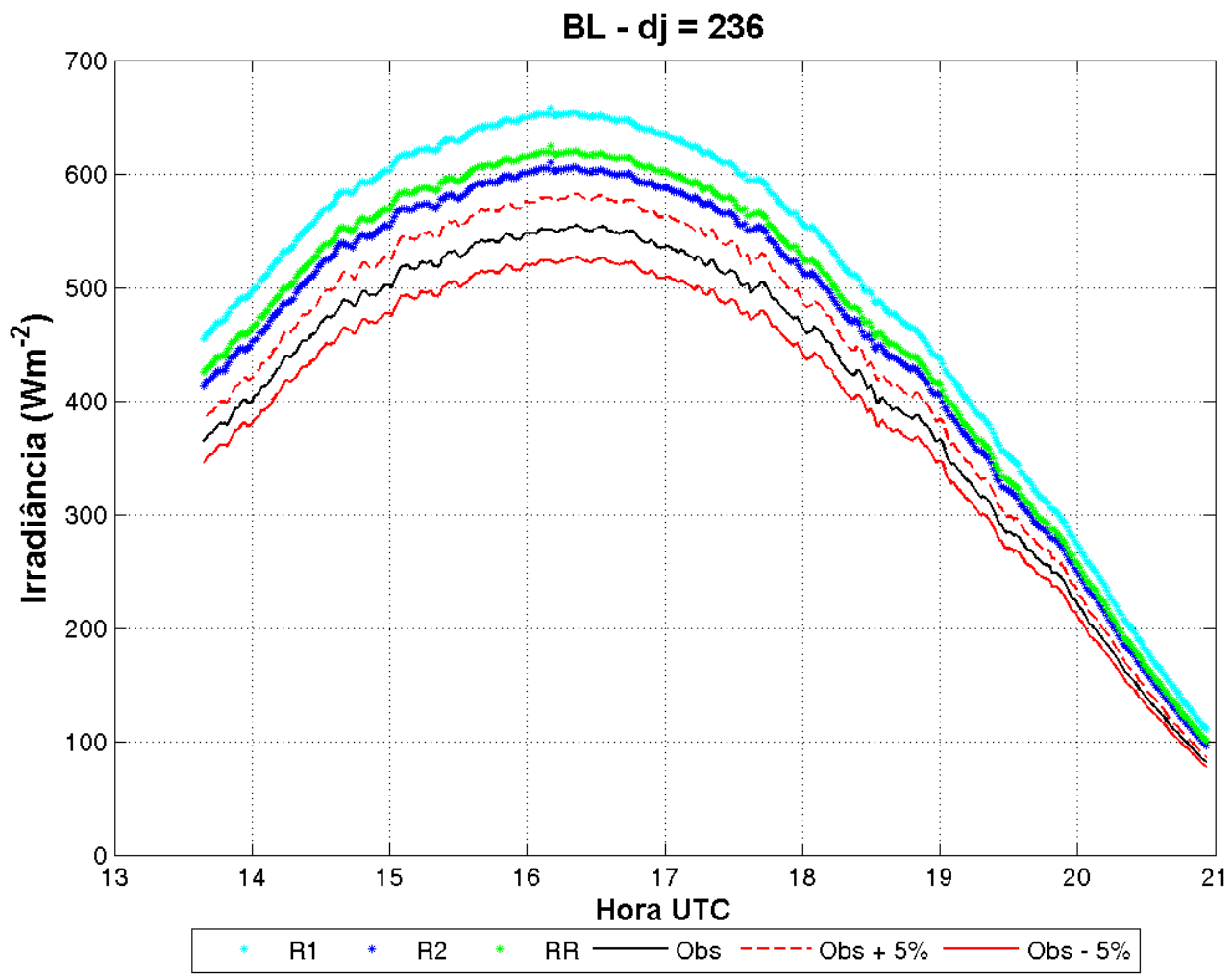

(b)

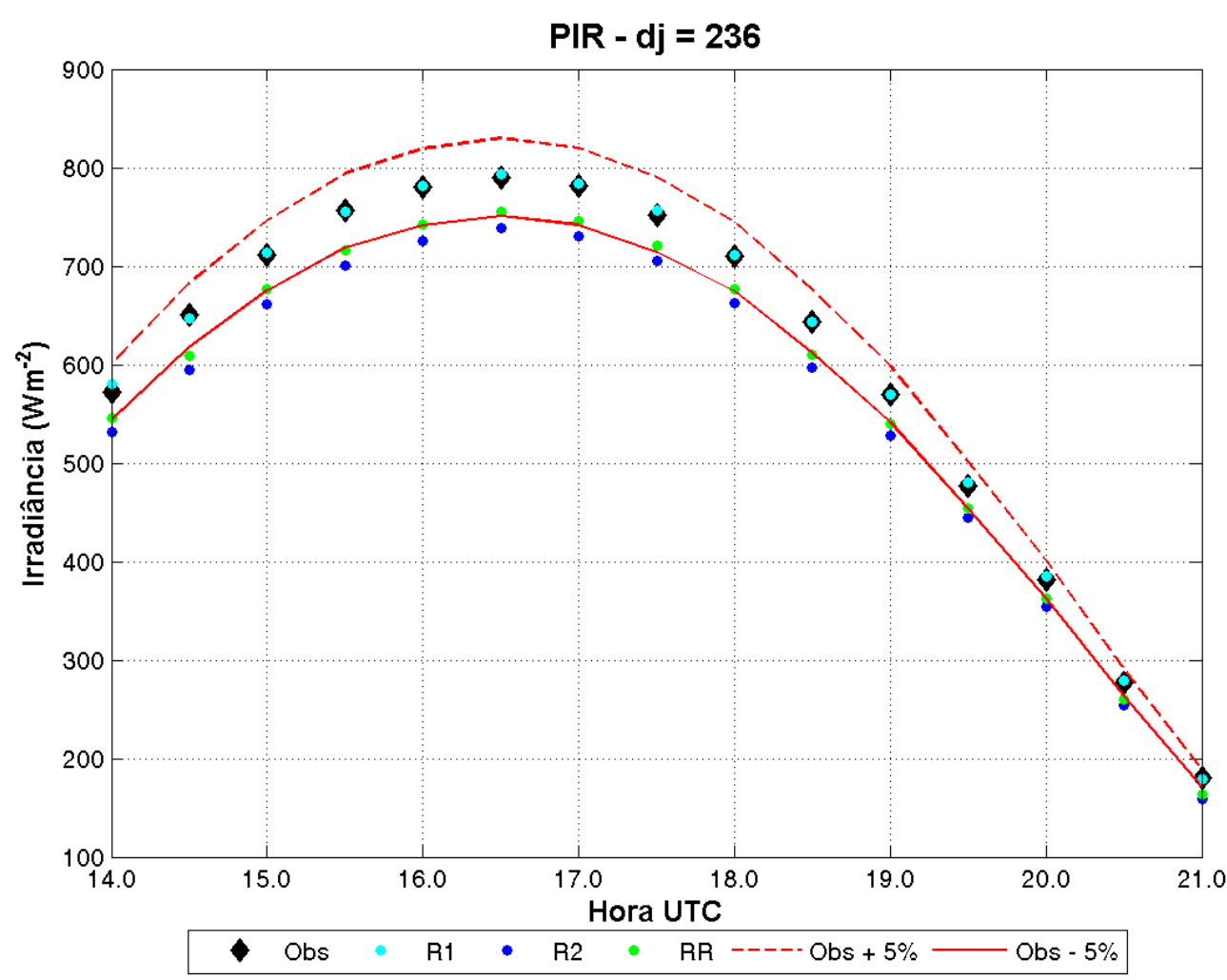

Figura 4.50 - Irradiância solar total global observada pelo MFRSR (a) e pelo Piranômetro (b) e simulada à superfície para o dia 236. A linha vermelha representa o valor observado menos $5 \%$ e a linha vermelha tracejada representa o observado mais $5 \%$. 
(a)

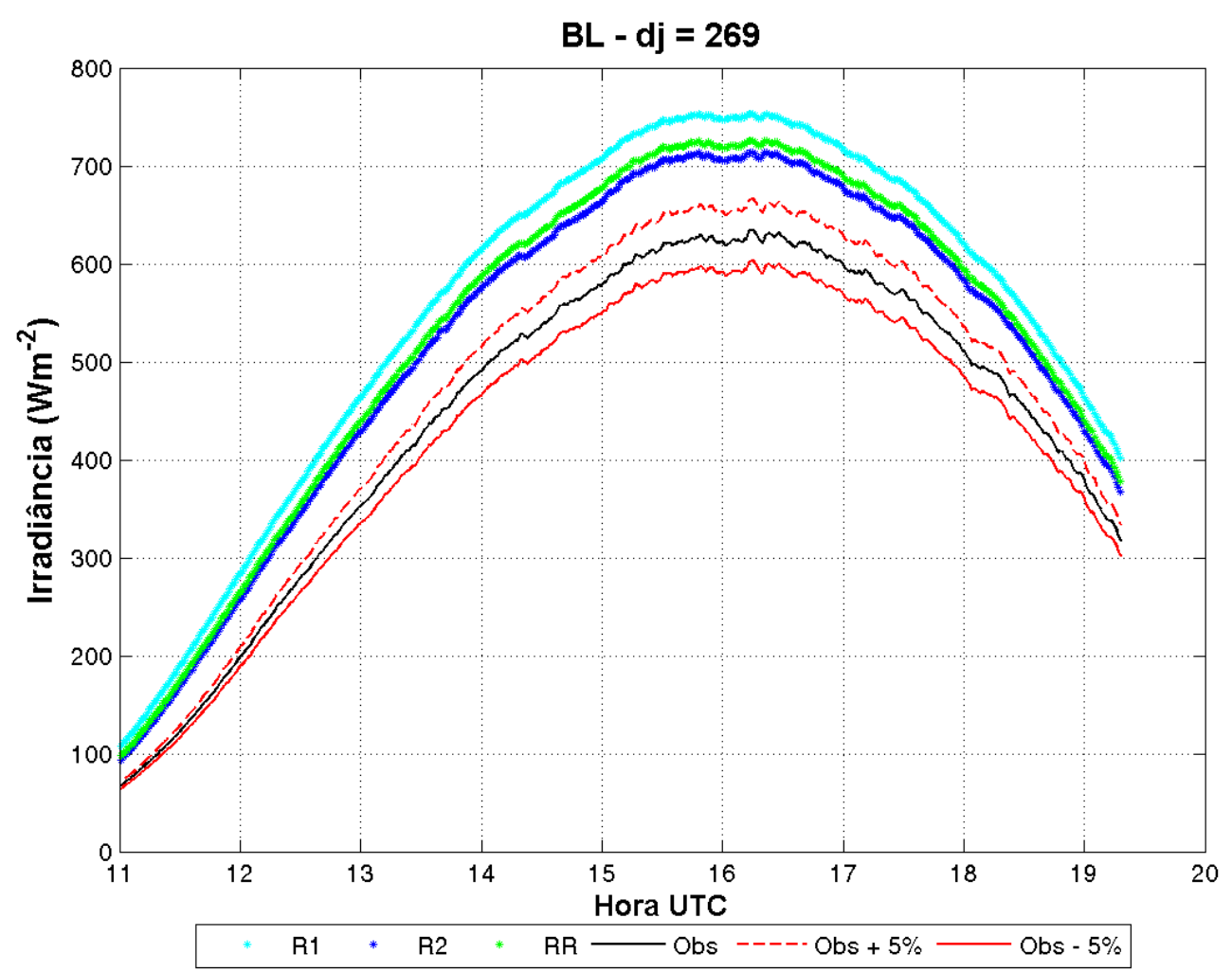

(b)

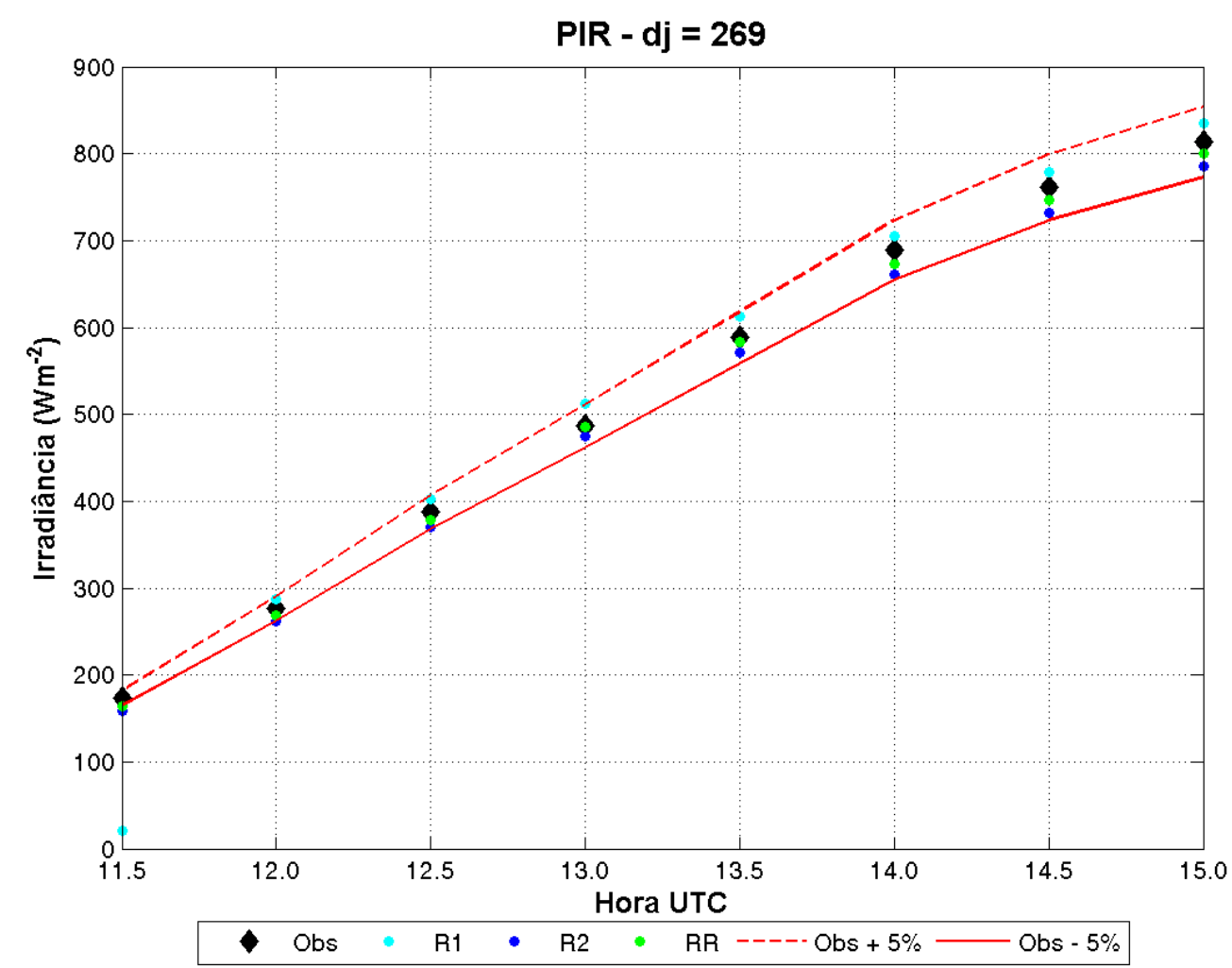

Figura 4.51 - Irradiância solar total global observada pelo MFRSR (a) e pelo Piranômetro (b) e simulada à superfície para o dia 269. A linha vermelha representa o valor observado menos $5 \%$ e a linha vermelha tracejada representa o observado mais $5 \%$. 


\subsubsection{Avaliação do Melhor Modelo Óptico para todo o Período Analisado}

A irradiância PAR foi escolhida para avaliar qual o modelo que se ajusta a um maior número de dados durante o período estudado, por ser a grandeza com o maior número de observações e devido ao sensor ter sua calibração periodicamente aferida. A figura 4.52 mostra a frequência de ocorrência da diferença relativa entre os dados observados e os calculados com os três modelos ópticos (modelo médio RR, modelo espalhador R1 e modelo absorvedor R2). É possível observar que cerca de 64\% dos dados obtidos com o modelo espalhador estão dentro da incerteza instrumental (entre $5 \%$ e $5 \%$ ), para o modelo médio, $49 \%$ se encontram dentro desse intervalo e para o modelo absorvedor, menos de $20 \%$ da diferença relativa se encontram dentro do intervalo da incerteza instrumental.

(a)

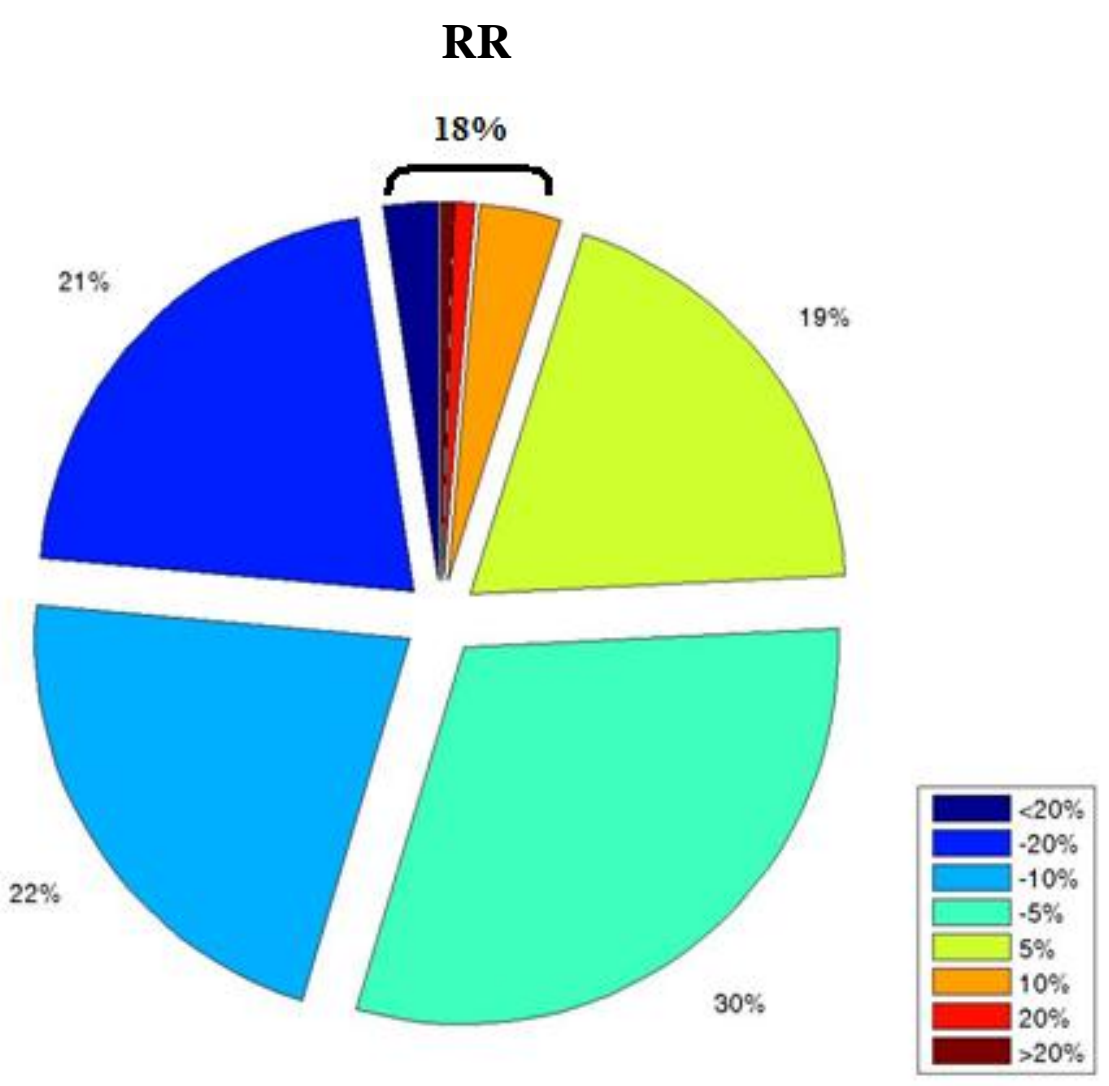


(b)

R1

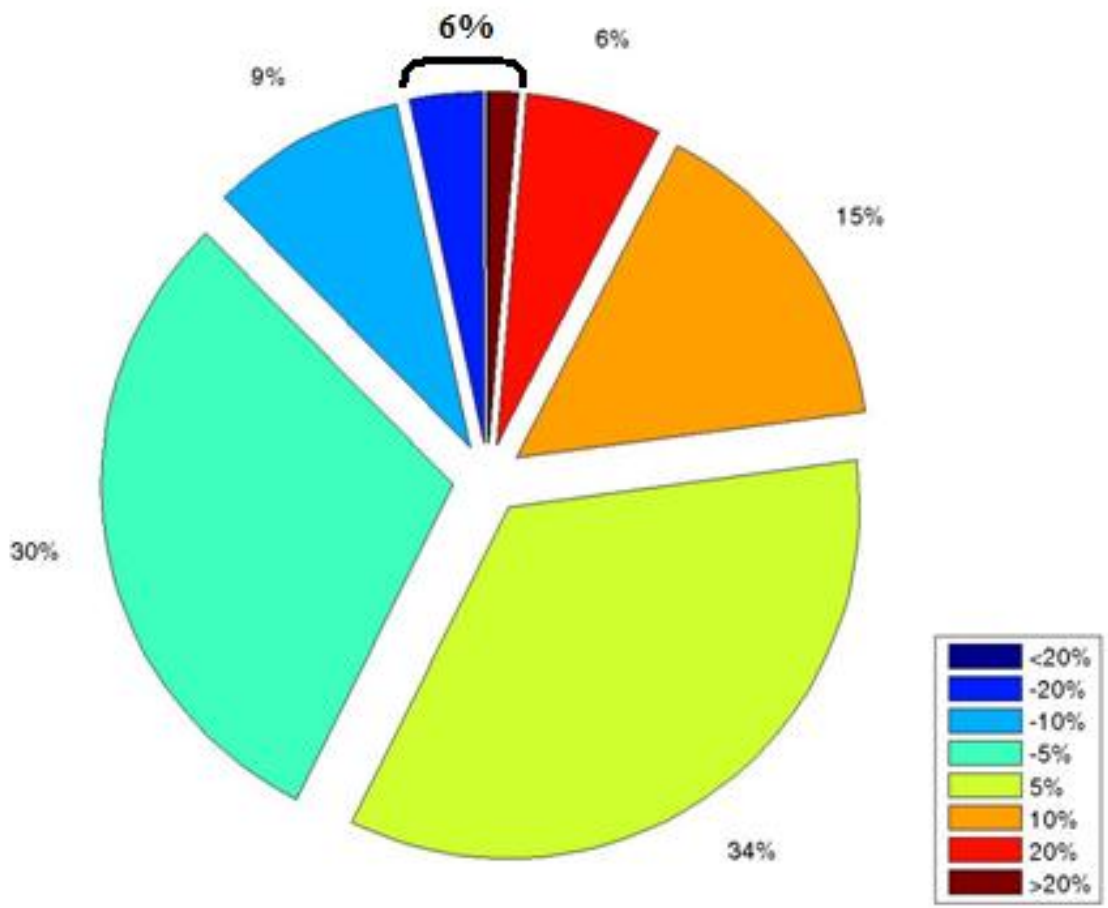

(c)

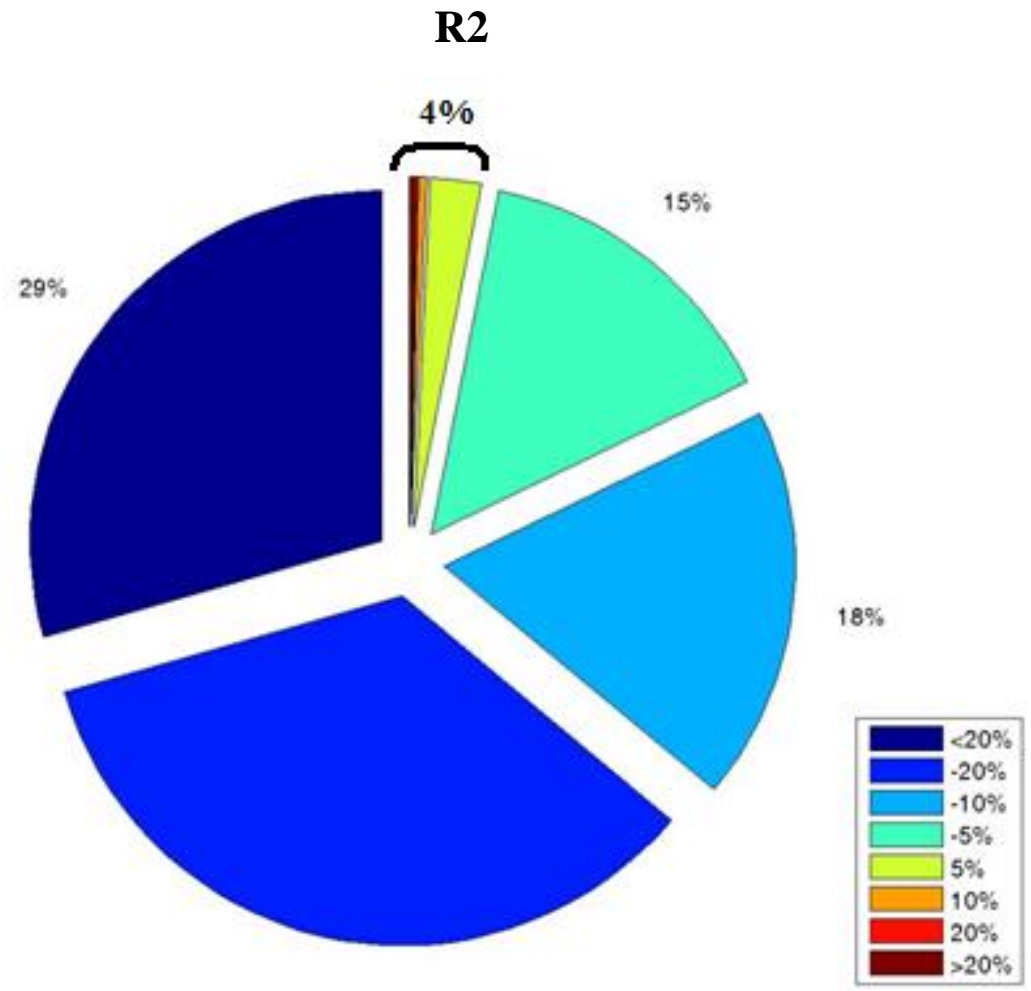

$34 \%$

Figura 4.52 - Frequência de ocorrência da diferença relativa entre os dados de irradiância PAR observados e os calculados com os três modelos ópticos para o aerossol de queimadas: (a) modelo médio, (b) modelo espalhador e (c) modelo absorvedor. 
A figura 4.53 mostra a diferença relativa entre os valores observados e os simulados com cada modelo óptico em função do dia e da profundidade óptica (AOD550). É possível observar também que o modelo com o melhor ajuste não apresenta dependência com a AOD550. Rosário (2011) em um estudo de caso para a região de Alta Floresta (MT), mostrou que a escolha do melhor modelo óptico apresenta uma dependência não só com a profundidade óptica do aerossol, mas também com o conteúdo de vapor d'água integrado na coluna atmosférica. Segundo o autor, em condições poluídas e mais úmidas, a diferença entre a irradiância solar total em superfície e a simulada é preferencialmente positiva; em condições menos úmidas, diferenças negativas são mais frequentes.

(a)

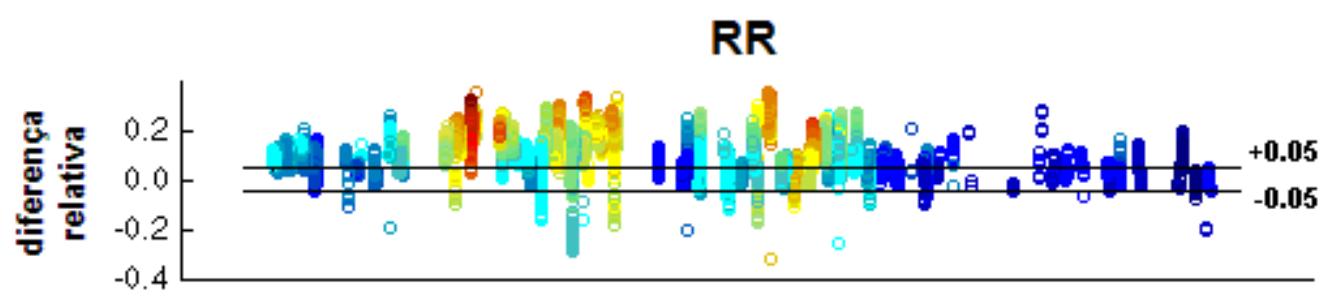

(b)
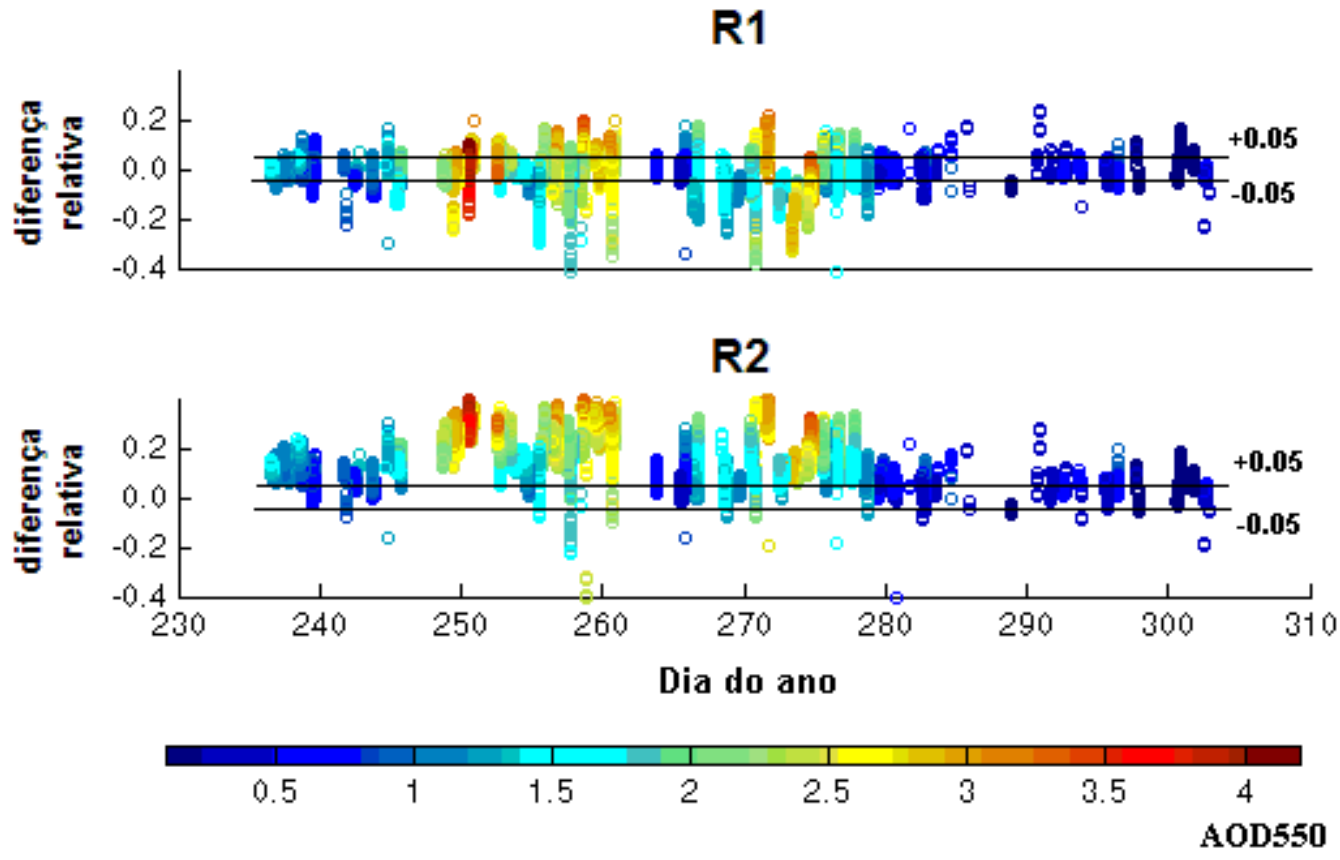

Figura 4.53 - Diferença relativa entre a irradiância PAR observada e a simulada, utilizando os três modelos ópticos propostos para o aerossol de queimadas da Amazônia, em função do dia e da profundidade óptica em $550 \mathrm{~nm}$ (AOD550). Modelo médio (a), modelo espalhador (b) e modelo absrovedor (c). 
Existem muitos processos associados à umidade que podem afetar as propriedades radiativas dos aerossóis. Entre eles estão o teor de umidade do material queimado, processamento dentro de nuvens (Reid et al., 2005), depósito de água sobre a partícula e a razão de material de pastagem e floresta queimado (Eck et al., 2009). No início da temporada de queimadas, quando ocorre a queima de um material mais seco e preferencialmente de pastagem, a eficiência de combustão é maior, ocorrendo dessa forma uma porcentagem maior de combustão na fase flaming (Eck et al., 2009), levando à produção de um material mais absorvedor. Já a queima de um material mais úmido leva a índices maiores de combustão na fase smoldering (Schafer et al., 2008, Reid et al., 1998), que produz um material mais espalhador. Na fase de transição entre a estação seca e úmida, ocorre o aumento de processamento de aerossóis por nuvens (Reid et al., 2005), que alteraria as propriedades radiativas das partículas através de suas propriedades microfísicas. Os dados analisados para a Rebio não apresentaram tais tendências, possivelmente associado ao fato de que o aerossol já se encontrar mais envelhecido ao chegar lá. Dessa forma, um estudo mais detalhado ainda é necessário para definir um método eficaz para a escolha do melhor modelo óptico para o aerossol nos arredores da Rebio Jaru. Com os resultados obtidos neste trabalho, sugere-se a utilização do modelo mais espalhador, embora deve-se ter em mente que apenas uma estação de queimadas foi analisada. 
Capítulo 5: Conclusões e Perspectivas 
O objetivo geral deste trabalho era avaliar o desempenho dos modelos ópticos para o aerossol de queimadas propostos por Rosário (2011) para a Reserva Biológica do Jaru, RO, (Rebio Jaru) durante a estação de queimadas de 2007. Para isso foram comparadas medidas in situ da irradiância fotossinteticamente ativa (PAR), obtida pelo sensor PAR da SKYE, da irradiância solar total global e para os canais de 670, 870 e 1036nm medidas por um Multifilter Rotating Shadowband Radiometer (MFRSR) e da irradiância solar total global aferida por um pirânometro (PIR) com dados simulados utilizando o código de transferência radiativa Santa Barbara Disort Radiative Transfer SBDART.

Durante o período analisado a profundidade óptica do aerossol em 550nm (AOD550) apresentou valores diários médios entre 0,5 e aproximadamente 3,2 (ocorrendo nos dias 265 e 250, respectivamente). Estudos de caso para analisar o desempenho dos modelos ópticos propostos em diferentes situações: com valores baixos e altos de AOD550 e também para dias com uma grande variação dessa grandeza.

Para a avaliação da relação entre a irradiância simulada e a observada nos canais de banda estreita, optou-se por comparar a razão entre as irradiâncias difusa e global a fim de contornar diferenças de calibração. Era esperado encontrar um modelo que se ajustasse melhor a todos os intervalos espectrais, porém com relação ao resultado obtido para a irradiância PAR, os resultados para os canais de 870 e 1036 nm não concordaram em nenhum dos casos estudados. Nos dias que apresentaram uma mesma tendência de valores de AOD550, tanto baixos como altos, o canal de 670nm foi compatível, já nos dias com grande variação dessa propriedade, não ocorreu o mesmo, isto é, enquanto na maioria dos casos analisados o modelo espalhador foi o que possibilitou estimativas numéricas de irradiância PAR compatíveis com os valores observados, para o canal de 670nm, o uso do modelo mais absorvedor é que forneceu resultados dentro da incerteza instrumental. Quando analisada a irradiância solar total medida pelo MFRSR e pelo PIR para um dia com variação e um com baixo valor de AOD550, notou-se que os dados obtidos com o SBDART superestimam os valores observados pelo MFRSR; em contrapartida, o resultado obtido com a comparação com os dados do PIR foram similares àqueles encontrados quando analisada a irradiância PAR.

As profundidades ópticas do aerossol calculadas a partir dos modelos ópticos foram comparadas com as profundidades ópticas do aerossol observadas. O objetivo era analisar se a diferença observada entre os canais estudados poderia estar associada à diferença na dependência espectral real e a dos modelos. Apesar das diferenças 
observadas na dependência espectral, nota-se que a influência da degradação instrumental tem um papel mais importante. O fato do MFRSR nunca ter sido enviado ao fabricante para troca de filtros, avaliação da resposta espectral, correções angulares ou re-calibração, pode justificar as diferenças observadas, provavelmente devido a degradação sofrida por esse instrumento ao longo destes oito anos de operação. $O$ sensor PAR é enviado a cada um ou dois anos para calibração com instrumento de referência no LIM - CPTEC/INPE.

Através da análise da irradiância PAR simulada e observada ao longo do período estudado, foi possível concluir que o modelo mais espalhador é o que apresenta o maior número de dados dentro do intervalo da incerteza instrumental, logo esse é o modelo mais adequado para a Rebio Jaru para o ano de 2007. Analisando o comportamento dos modelos aliados com a AOD550 notou-se que somente com a profundidade óptica não é possível definir o modelo óptico mais adequado. Como observado por Rosário (2011), o conteúdo de vapor d'água na coluna atmosférica em Alta Floresta, para condições poluídas, também deve ser levado em consideração quando se pondera a escolha do modelo mais adequado, porém essa relação não foi avaliada no presente estudo. Dessa forma, em trabalhos futuros, a análise dessa influência deve ser analisada para verificar se essa hipótese também é válida para a região da Reserva Biológica do Jaru. Também deve-se analisar se existe influência do erro na prescrição do albedo de superfície que possa justificar a diferença sistemática dos canais de comprimentos de onda maiores, cujos resultados foram melhor explicados com um modelo mais absorvedor. O desempenho dos modelos ópticos associado a outras propriedades e variáveis atmosféricas também poderiam ser avaliadas para determinar quais são os fatores dominantes na determinação do tipo de aerossol e, dessa forma, criar um método eficiente para a seleção do modelo mais representativo não só para a Rebio Jaru, mas como para qualquer região ao sul da Bacia Amazônica. 


\section{Bibliografia}

Alexandrov, M.D., A.A.L. Carlson, B.E. Carlson e B. Cairns. Remoting sensing of atmospheric aerossols and trace gases by means of multifilter rotating shadowband radiometer. Part I: retrieval algorithms. Journal of the Atmospheric Sciences, v. 59, n. 31, p. 524-543, 2002.

Andreae, M. O., P. Artaxo, C. Brandão, F.E. Carswell, P. Ciccioli, A.L. da Costa, A.D. Culf, J.L. Esteves., J.H.C. Gash, J. Grace, P. Kabat, J. Lelieveld, Y. Malhi, A.O. Manzi,, F. X. Meixner, A.D. Nobre, C. Nobre, M.d.L.P. Ruivo., M.A. Silva-Dias, P. Stefani, R. Valentini, J. von Jouanne, e M.J. Waterloo. Biogeochemical cycling of carbon, water, energy, trace gases, and aerosols in Amazonia: The LBA-Eustach experiments, J. Geophys. Res, 107 (D20), 8066, 2002.

Andreae, M. O. Correlation between cloud condensation nuclei concentration and aerosol optical thickness in remote and polluted regions, Atmos. Chem. Phys., 9, 543$556,2009$.

Ångström, A. On the atmospheric transmission of sun radiation and on dust in the air, Geografiska Annaler, 11, 156-166, 1929.

Ångström, A. On the atmospheric transmission of sun radiation II, Geografiska Annaler, 12, 130-159, 1930.

Artaxo, P., J. V. Martins, M. A. Yamasoe, A. S. Procopio, T. M. Pauliquevis, M. O. Andreae, P. Guyon, L. V. Gatti, e A. M. C. Leal. Physical and chemical properties of aerosols in the wet and dry seasons in Rondônia, Amazonia, J. Geophys. Res., 107(D20), 8081, 2002.

Artaxo, P., M. A. F. Silva-Dias, e M. O. Andreae. O mecanismo da floresta para fazer chover. Scientifc American Brasil , 40-45, Abril, 2003.

Braham, R.R. Cloud Physics of Urban Weather Modification - A Preliminary Report. Bulletin American Meteorological Society, vol. 55, No. 2, 1974.

Bucholtz, A. Rayleigh-scattering calculations for the terrestrial atmosphere. Applied Optics, v. 34, p. 2765-2773, 1995.

Chandrasekhar, S. Radiative Transfer. Oxford University press, Oxford, 1950.

Charlson, R.J., S.E. Schwartz, J.M. Hales, R.D. Cess, J.A. Coakley, J.E. Hansen,. e D.J. Hofmann. Climate Forcing by Anthropogenic Aerosols. Science, vol. 255, 423- 430, 1992.

Eck, T. F., B. N. Holben, J. S. Reid, A. Sinyuk, E.J. Hyer, N.T. O’Neill, G.E.Shaw, J.R. Vande Castle, F.S. Chapin, O. Dubovik, A. Smirnov, E. Vermote, J.S. Schafer, D. Giles, I. Slutsker, M. Sorokine, e W.W. Newcomb. Optical properties of boreal region 
biomass burning aerosols in central Alaska and seasonal variation of aerosol optical depth at an Arctic coastal site. J. Geophys. Res., 114, D11201, 2009.

Fröhlich, C. e Shaw, G.E. New determination of Rayleigh scattering in the terrestrial atmosphere, Applied Optics, 19, 1773 - 1775, 1980.

Hansell, R. A., SC. Tsay, Q. Ji, K.N. Liou, SC. Ou. Surface aerosol radiative forcing derived from collocated ground-based radiometric observations during PRIDE, SAFARI and ACE-Asia. Applied Optics.V. 42, n. 27, p. 5533-5544, 2003.

Hansen, J., M. Sato, e R. Ruedy. Radiative forcing and climate response. Journal of Geophysical Research, vol. 102, no.d6, pages 6831-6864, 1997.

Hansen, J.E., e Travis, L.D. Light scattering in planetary atmospheres. Space Sci. Rev., 16:257-610, 1974.

Harrison, L., J. Michalsky, e J. Berndt. Automated multifilter rotating shadow-band radiometer: an instrument for optical depth and radiation measurements. Applied Optics, 33(22): 5118 - 5125, 1994.

Horvath, H. Aerosols - an introduction. Journal of Environment Radioactivity, 51, 5-25, 2000.

Horvath, H.: Atmospheric Light Absorption - A Review. Atmospheric Environment, vol. 27A, No. 3, pp. $293-317,1993$.

Haywood, J. e O. Boucher. Estimates of the direct and indirect radiative forcing due to tropospheric aerosols: a review. Reviews of Geophysics, v. 38, p. 513-543, 2000.

Iqbal, M. An Introduction to Solar Radiation. Academic Press, San Diego, Califórnia. 1983.

Johnson, F.S. The solar constant. Journal of Meteorology, 11, 431 - 439, 1954.

Kasten F. e A.T. Young. Revised optical air mass tables and approximation formula. Applied Optics, v. 28, p. 4735-4738, 1989.

Kaufman, L., e P.J. Rousseeuw. Finding Groups in Data: An Introduction to Cluster Analysis. John Wiley \& Sons, Inc., New York, 1990.

Kokhanovsky, A.A. Aerosol Optics - Light Absorption and Scattering by Particles in the Atmosphere. Praxis Publishing Ltd, Chichester, UK, 2008.

Koren, I., Y.J. Kaufman, L.A. Remer, e J.V. Martins. Measurement of the Effect of Amazon Smoke on Inhibition of Cloud Formation. Science, vol. 303, 1342 - 1345, 2004.

Kotchenruther, R. A., e P.V. Hobbs. Humidification factors of aerosols from biomass burning in Brazil. J. Geophys. Res. Atmos., 103, 32081-32089, 1998. 
Liou, K. N. A numerical experiment on Chandrasekhar's discrete-ordinates method for radiative transfer: application to cloudy and hazy atmospheres. Journal of the Atmospheric Sciences, 30, 1303 - 1326, 1973.

Liou, K.N. An Introduction to Atmospheric Radiation. Second Edition, Academic Press, USA, 2002.

Martin, S. T, M.O. Andreae, P. Artaxo, D. Baumgardner, A.H. Goldstein, A. Guenther, C.L. Heald, O.L. Mayol-Bracero, P.H. McMurry, T. Pauliquevis, U. Pöschl, K.A. Prather, G.C. Roberts, S.R. Saleska, M.A. Silva-Dias, D.V. Spracklen, E. Swietlicki, e I. Trebs, Sources and Properties of Amazonian Aerosol Particles. Rev. of Geophys., 48, RG2002, 2010.

Michalsky, J. J., E. Duttton, M. Rubes, D. Nelson, T. Stoffel, M. Wesley, M. Splitt, e J. DeLuisi. Optimal measurement of surface shortwave irradiance using current instrumentation. J. Atmos. Oceanic Technol.,16, 55-69, 1999.

Moosmüller, H., R. K. Chakrabarty, e W. P. Arnott. Aerosol light absorption and its measurement: A review. Journal of Quantitative Spectroscopy and Radiative Transfer, volume 110, issue 11, pages 844-878, 2009.

Plana-Fattori, A., P. Dubuisson, B.A. Fomin, e M. de P. Corrêa. Estimating the atmospheric water vapor content from multi-filter rotating shadow-band radiometry at São Paulo, Brazil. Atmospheric Research, 71, 171 - 192, 2004.

Procópio, A. S., e P. Artaxo: Queimadas esfriam a Amazônia. Pesquisa Fapesp, pág 33, Abril, 2003.

Ramanathan, V., P.J. Crutzen, J. Lelieveld, A.P. Mitra, D. Althausen, J. Anderson, M.O. Andreae, W. Cantrell, G.R. Cass, C.E. Chung, A.D. Clarke, J.A. Coakley, W.D. Collins, W.C. Conant, F. Dulac, J. Heintzenberg, A.J. Heymsfield, B. Holben, S. Howell, J. Hudson, A. Jayaraman, J.T. Kiehl, T.N. Krishnamurti, D. Lubin, G. McFarquhar, T. Novakov, P.K. Ogren, I.A. Podgorny, K. Prather, K. Priestley, J.M. Prospero, P.K. Quinn, K. Rajeev, P. Rasch, S. Rupert, R. Sadourny, S.K. Satheesh, G.E. Shaw, P. Sheridan, e F.P.J. Valero. Indian Ocean Experiment: an integrated analysis of the climate forcing and effects of the great Indo-Asian haze. Journal of Geophysical Research, vol. 106, d22, $28.371-28.398,2001$.

Reid, J. S., R. J. Ferek, D. R. Blake, J. V. Martins, M.R. Dunlap, e C. Liousse. Physical, chemical,and optical properties of regional hazes dominated by smoke in Brazil. J. Geophys. Res., 103 32059-32080, 1998.

Reid, J. S., T. F. Eck, S. A. Christopher, R. Koppmann, O. Dubovik, D.P. Eleuterio, B.N. Holben, E.A. Reid, e J. Zhang. A review of biomass burning emissions part III: intensive optical properties of biomass burning particles. Atmos. Chem. Phys., 5, 827849, 2005. 
Ricchiazzi. P. SBDART: A research and teaching software tool for plane - parallel radiative transfer in the Earth's Atmosphere. Bulletin of the American Meteorological Society, v. 79, p. $2101-2114,1998$.

Rosário, N. E. Comparação de profundidades ópticas espectrais do aerossol obtidas para São Paulo a partir de um Multi Filter Rotating Shadowband Radiometer e do fotômetro solar da AERONET. Dissertação de Mestrado, Instituto de Astronomia, Geofísica e Ciências Atmosféricas, Universidade de São Paulo, 2006.

Rosário, N.E., M.A. Yamasoe, e K.M. Longo. Aerosol Optical Depth and Ångström Coefficient retrievals over the Amazon Forest during 2007 biomass burning season. AIP Conf. Proc. 1100, 494, 2009.

Rosário, N. E. Estudo da Variabilidade das Propriedades Ópticas dos Aerossóis sobre a América do Sul e dos Impactos do Efeito Radiativo Direto das Partículas de Queimadas. 225p, Tese (Doutorado) - Instituto de Astronomia, Geofísica e Ciências Atmosféricas, Universidade de São Paulo, São Paulo, 2011.

Sayão, A.C. Estudo da Variabilidade Sazonal da Profundidade Óptica do Aerossol em São Paulo a partir de Radiômetros MFRSR. Tese (Doutorado) Instituto de Astronomia, Geofísica e Ciências Atmosféricas, Universidade de São Paulo, São Paulo, 2008.

Schafer, J. S., T. F. Eck, B. N. Holben, P. Artaxo, e A. F. Duarte. Characterization of the optical properties of atmospheric aerosols in Amazonia from long-term AERONET monitoring (1993-1995 and 1999-2006). J. Geophys. Res., 113, D04204, 2008.

Schmid, B. e C. Wehrli. Comparison of Sun Photometer Calibration by Langley Technique and Standard Lamp. Applied Optics, v. 34, p. 4500-4512, 1995.

Seinfeld, J.H. e S.N. Pandis. Atmospheric Chemistry and Physics - From Air Pollution to Climate Change. John Wiley \& Sons, New York, 1998.

Shaw, G.E. Sun Photometry. Bulletin of the American Meteorological Society, v. 64, p. $4-10,1983$.

Staehelin, J., H. Schill, B. Hoegger, P. Viatte, G. Levrat, e A. Gamma. Total ozone observation by sun photometry at Arosa, Switzerland. Opt. Engin., v. 34, p. 1977-1986, 1995.

Stammes, K., SC. Tsay, W. Wiscombe, e K. Jayaweera. Numerically stable algorithm for discrete-ordinate-method radiative transfer in multiple scattering and emitting layered media. Applied. Optics, v. 27, p. 2502 - 2509, 1988.

Twomey, S.A., e T.L. Wolfe. An assessment of the impact of pollution on global cloud albedo. Tellus, 36B, 356 - 366, 1984.

Wallace, J.H., e P.V. Hobbs. Atmospheric Science - An Introduction Survey. Academic Press, USA, 1977. 
Whitby, K.T. The Physycal Characteristics of Sulfur Aerosols. Atmospheric Environment, vol. 12, pp 135-159, 1978

Yokelson, R.J., T. J. Christian, T. G. Karl, e A. Guenther. The tropical forest and fire emissions experiment: Laboratory fire measurements and synthesis of campaign data, Atmos. Chem. Phys., 8, 3509-3527, 2008.

Yamasoe, M. A. Estudo de propriedades ópticas de partículas de aerossóis a partir deuma rede de radiômetros. 1999. 213f. Tese (Doutorado), Instituto de Física da Universidade de São Paulo, São Paulo, 1999. 